For z 





\section{VOYAGE}

A U B R É S L. 


\section{Ouvrages nouveaux chez le méme Libraire.}

HISTOIRE COMPLÈTE DES VOYAGES ET DÉCOU-

VERTES EN AFRIQUE, depuis les sic̀cles les plus reculés jusqu'à nos jours; accompagnée d'un Précis géographique sur ce continent et les lles qui l'environnent; de Notices sur l'état physique, moral et politique des divers peuples qui l'habitent, et d'un Tableau de son Histoire naturelle; par le docteur LEYDEN et M. HUGH MURRAY; traduite de l'anglais et augmentée de toutes les découvertes faites jusqu'à ce jour; par M. A.C., S. du S., de F., 3 vol. in-80, avec un atlas in- $4^{\circ}$, composé de la carte générale de l'Afrique et de six autres cartes. Prix. $25 \mathrm{fr}$.

Nota. Le tome $4^{\mathrm{e}}$ et dernier est sous presse.

Le même Libraire fait traduire, de l'anglais l'Hrstorne des Voyages et Découvertes en Asie, etc.; cet ouvrage sera enrichi de notes par M. Langlès, de la bibliothèque du roi; 3 vol. in $-\delta^{\bullet}$, avec cartes et figures.

\section{Ouvrages de M.de Lantier, chevalier de Saint.Louis.}

Voyages d'Antenor en Grìce et en Asie, avec des notions sur l'Egypte ; manuscrit trouvé à Herculanum ; 5 vol. in-18, quatorzième édition, 5 figures, I820.

Nota. Sous presse, la quinzième édition, 3 vol. in $-8^{\circ}$, imprimée sur beau papier, ornée de très-belles figures, $d^{\prime}$ 'après les dessins de $\mathrm{M}$. Chasselat. Il ne sera tiré qu'un très-petit nombre d'exemplaires sur papier vélin.

Les voyageurs en Suisse, 3 vol. in-8o avec portrait. Deuxième édition, $18_{2} 0$.

$18 \mathrm{f}$.

Voyage en Espagne, du chevalier Saint-Gervais, officier francais, et les divers événemens de son voyage; 2 forts volumes in- $8^{\circ}$, figures; deuxième édition, 1820 . $12 \mathrm{f}$.

Contes en vers et en prose, 3 vol. in $-8^{\circ}$, fig. II $f$.

Nota. Le tome $3^{\mathrm{e}}$ se vend séparément. $\quad 3 \mathrm{f}$.

Correspondance de Suzette Césarine d'A

- la même, 3 vol. in-r 2 .

7 f. $50 \mathrm{c}$.

IMPRIMERIE DE COSSON, RUE GARENCIÈRE, $N^{\circ} 5$. 


\section{VOYAGE}

\section{AU BRÉSIL,}

DANS LES ANNÉES I815, 18 I6 et 1817,

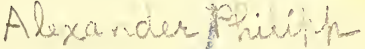

\section{PAR S. A. S. MAXIMILIEN,} PRINCE DE WIED-NEUWIED;

TRADUIT DE L'ALLEMAND

\section{PAR J. B. B. EYRIÈS. TO574}

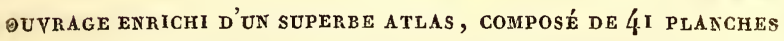
GRAVÉEs EN TAILLE-DOUCE, ET DE Trois cartes.

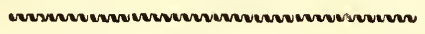

\section{TOME PREMIER.}

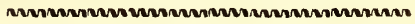

\section{PARIS,}

ARTHUS BERTRAND, LIBRAIRE,

RUE HAUTEFEUILLE, $\mathrm{N}^{\bullet} 23$.

1821. 


$$
\begin{aligned}
& R B \\
& \text { Fos } \\
& \text {, w } 64 \\
& \text { IR I I E v } \\
& a^{2} x^{2}
\end{aligned}
$$

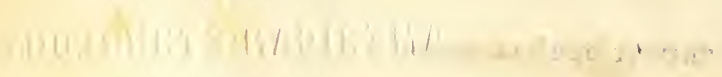

Arcor 


\section{INTRODUCTION.}

Des événemens extraordinaires, des guerres qui se renouvelaiěnt sans cesse, ont, pendant une longue suite d'années, mis des obstacles insurmontables aux désirs des hommes qui voulaient parcourir les parties du monde lointaines, pour agrandir le domaine de l'histoire naturelle et de la géographie; l'Angletẹrre, moins gênée par ces obstacles, a presque seule, durant cette période, contribué à enrichir ces sciences. Parmi les nombreux bienfaits que le rétablissement de la paix donne lieu d'espérer, on doit compter pour les hommes animés de la passion de faire des découvertes dans le règne de la nature, l'avantage de pouvoir entreprendre avec succès des voyages importans, et communiquer les richesses qu'ils auront

I. 
trouvées à ceux de leurs compatriotes que leur penchant, leurs affaires, leurs liaisons enchaînent au sol paternel. Puisse une paix solide nous assurer, pour de longues années, ces bienfaits inappréciables!

Les regards des naturalistes ont pendant long-temps été principalement fixés sur le Brésil, dont la situation heureuse permettait une riche récolte aux recherches, mais qui précédemment était si rigoureusement fermé à quiconque voulait le parcourir et l'examiner.

Quelques relations de voyageurs anciens, les récits des navigateurs espagnols et portugais, les renseignemens plus détaillés fournis par les jésuites, enfin les observations de Marcgraf'et de Pison, composaient tous les ouvrages que nous possédions sur ce pays découvert depuis trois siècles et si intéressant. Cependant l'état des choses qui rendait si difficiles les recherches sur le Brésil a subi un heureux changement. Des événemens 
trop connus pour qu'il soit besoin de les rapporter engagèrent le monarque à se transporter dans cette belle partie de ses états, qu'il n'avait pas encore vue, et où était la principale source de ses richesses ; changement de résidence qui dèvait avoir une influence extraordinaire sur ce pays. En effet le système oppressif des entraves mystérieuses fut aboli ; la confiance remplaça l'inquiétude, et les voyageurs étrangers obtinrent de pénétrer dans ce champ de découvertes. Les intentions libérales d'un roi sage, soutcnues par un ministère éclairé, non-seulement accordèrent l'entrée du pays aux étrangers, mais encouragèrent aussi leurs recherches de la manière la plus généreuse. C'est ainsi que M. Mawe füt gratifié de la permission de visiter les mines de diamant, dontl'approche même avait précédemment été interdite aux étrangers, et parcourut en minéralogiste une partie du gouvernement de Minas-Geraës. 
Depuis quelques voyageurs allemands ont visité cette province. M. d'Eschwége, lieutenant-colonel dans le corps royal du génie à Villa-Rica, favorisé par un séjour de plusieurs années au Brésil, a déjà donné au public des mémoires intéressans, et c'est avec raison que nous devons attendre des découvertes importantes d'un homme aussi profondément instruit. Il a mesuré la haute chaîne de montagnes de Minas-Geraës, dessiné leurs profils, et a cherché dans ses voyages minéralogiques les différens produits de ces monts élevés, où il a entre autres découvert depuis peu des sources d'eau sulfureuses. Il accueille les voyageurs étrangers avec une bonté prévenante, les encourage de ses conseils et les aide. D'autres Allemands, animés du mêmè zèle, sont allés au Brésil, et sûrement ils ne manqueront pas de riches matériaux pour leurs observations. Recommandés au roi par le comte de Barca, ministre 
protecteur des sciences, on leur a accordé la permission non-seulement de voyager sans obstacles dans les différentes capitaineries de la monarchie, mais on leur a généreusement fixé une somme annuelle pour leur entretien; on leur a donné dés passe-ports concus en termes flatteurs, et des lettres de recommandation les plus pressantes pour les capitaines généraux des différentes provinces. Combien, par ces mesures éclairées et libérales, le gouvernement actuel s'écarte honorablement de l'ancien système, où le voyageur, à son arrivée dans le Brésil, était soigneusement entouré de soldats et surveillé! Au nom de mes compatriotes et de tous les voyageurs européens, que ce témoignage solennel exprime le sentiment de reconnaissance dont je me sens pénétré pour le monarque qui a pris ces mesures libérales. Quelle satisfaction inexprimable pour le voyageur éloigné de ses foyers de trouver un 
accueil si rempli de bienveillance et d'éprouver un traitement si amical! il en résulte aussi pour les sciences un avantage incalculable, auquel participe tout le monde civilisé et instruit.

Quiconqúe veut parcourir avec utilité les parties intérieures de cette vaste région doit y destiner plusieurs années, et diriger son plan d'après cette détermination. Par exemple, pour pénétrer jusqu'à Goyaz et Cuiaba, deux ans ne suffisent pas; et il faut cependant consacrer cet intervalle de temps pour traverser le Brésil jusqu'aux frontières du Paraguay, jusqu'aux rives de l'Uruguay, jusqu'aux confins les plus éloignés de Mato-Grosso, où une pyramide de marbre taillée à Lisbonne marque les limites du royaume à l'embouchure du Jauru. Le gouvernement de Minas-Geraës a déjà été parcouru par MM. Mawe et d'Eschwége; et quoique le sujet ne soit pas épuisé, il est au moins connu en 
grande partie. Par conséquent, à mon arrivée au Brésil, je trouvai qu'il valait mieux diriger mes courses vers les côtes orientales du pays, qui sont encore entièrement inconnues, ou qui plutôt n'ont pas du tout été décrites. Plusicurs tribus des habitans primitifs de cette contrée y vivent encore dans leur état naturel et n'ont pas été troublées par les Européens, qui se répandent graduellement partout. La haute chaîne de montagnes nues du moyen Brésil, des provinces de Minas-Geraës, de Groyaz et de Pernambouc, est séparée de la côte orientale par une large ceinture de forêts primitives qui s'étènd depuis Rio-de-Janeiro jusqu'aux environs de Bahia de Todos-osSantos, c'est-à-dire sur une longueur de 11 degrés de latitude ou 198 legoas portugaises ( 165 milles géographiques), et qui n'a pas été encore oscupée par les colons portugais. On s'est jusqu'à présent borné à ouvrir avec beaucoup de 
peine un petit nombre de chemins le long des fleuves qui les traversent. C'est dans ces forêts; où les habitans originaires du pays, inquiétés partout ailleurs, ont continué à trouver une retraite sûre, que l'on peut encore observer ces hommes dans leur état primitif. Comment une telle région n'aurait-elle pas attiré, par préférence, un voyageur qui n'avait pas le projet de passer plusieurs années dans cette portion de la zone torride?

Le nom même des tribus indigènés qui habitent ces déserts est inconnu en Europe, à l'exception peut-être du Portugal. Les jésuites, et entre autres Vasconcellos dans ses noticias curiosas do Brazil, partageaient toutes les tribus de sauvages, tant ceux qui vivaient le long de la côte maritime que ceux qui demeuraient dans ces forêts antiques, en deux classes, savoir: ceux des côtes, qui, un peu civilisés par les Portugais, surtout par les jésuites, étaient appelés Indios 
Mansos, et ceux des forêts et des déserts de l'intérieur, qui, encore barbares et en partic inconnus, étaient nommés Tapuyas; ce sont ces derniers qui, s'étant maintenus jusqu'à présent dans l'état de nature brut, méritent d'être mieux connus. Les jésuites et plusieurs anciens voyageurs nous ont à la vérité donné quelques notices sur ces cantons couverts de forêts continues; mais elles sont bien imparfaites, et mêlées de circonstances fabuleuses; d'ailleurs elles ne donnent aucuns détails sur l'histoire naturelle. Ainsi nous ne savions que peu de chose, et même rien, sur les habitans primitifs de ce pays qui vivent encore danš l'état de nature, non plus que sur ses productions naturelles tant animées qu'inanimées; etcependant que de choses nouvelles et intéressantes dans ces pays, surtout pour le botaniste et l'entomologiste! Mais quand on veut parcourir ces régions, il faut s'être résigné d'avance 
à supporter une infinité de désagrémens et d'obstacles, tels que le manque de vivres pour soi et les gens de sa suite, et de pâturage pour les bêtes de somme; les difficultés pour transporter les objets d'histoire naturelle; les pluies de longue durée, l'humidité, et une infinité d'autres inconvéniens. Mais la privation la plus pénible est celle de bonnes cartes des pays que l'on parcourt; celle d'Arrowsmith fourmille d'erreurs; il y manque des rivières considérables sur la côte orientale, et au contraire il en place dans des endroits où il n'en existe aucune; ainsi la meilleure cartc du Brésil connue jusqu'à présent est à peu près inutile pour les voyageurs. Pour remédier à ce défaut, le gouvernement a ordonné récemment de faire un relèvement exact des côtes, afin d'indiquer avec précision les dangers qui menacent les navigateurs; cette opération salutaire, est déjà commencée, et d'habiles officiers de marine, M. José. 
da Triniład, capitaine lieutenant, et M. Antonio Sylveira de Arajo ont relevé les côtes depuis Macari, San-Mateo, Viçoza et Caravellas jusqu’à PortoSeguro.

J'ai aussi à, remercier le gouvernement portugais de ce que sa façon de penser éclairée et libérale m'a mis à même de présenter à mes compatriotes cette relation d'un voyage le long de la côte orientale depuis le $23^{\text {me }}$ jusqu'au $13^{\text {me }}$ degré de latitude méridionale. Dux Allemands, MM. Freyreiss et Sellow, qui ont le projet de parcourir le Brésil pendant plusieurs années, ont trouvé un généreux appui dans le roi de Portugal et de Brésil. Il ne sera pas facile à un étranger de pénétrer dans le pays avec plus d'avantages que ces deux voyageurs, car ils en connaissent la langue et les mœurs, et les excursions qu'ils font depuis plusieurs années les y ont convenablement préparés. J'ai fait 
avec eux une partie de mon voyage, et M. Freyreiss m'a communiqué plusieurs notices intéressantès dont jé lui témoigne hautement ma reconnaissance.

Je sens combien il est téméraire de présenter au public ces observations sur mon voyage dans une partie de l'Amérique méridionale, après la publication de celles de mon illustre compatriote M. Alexandre de Humboldt, qui parcourt avec un succès si brillant le vaste domaine des connaissances humaines; mais la bonne volonté peut suppléer à la faiblesse des moyens, et quoique je n'aie pas la prétention de donner quelque chose de parfait, j'ose cependant espérer que les amis de l'histoire naturelle et de la géographie trouveront dans mon livre plusieurs faits assez importans pour contribuer aux progrès de ces sciences. 


\title{
TABLE DES CHAPITRES
}

\author{
DU TOME PREMIER.
}

Pages.

\section{CHAPITRE PREMIER.}

Traversée d'Angleterre à Rio-de - Janeiro.

\section{CHAPITRE II.}

Séjour à Rio-de-Janeiro. - La ville et ses environs. - Les Indiens de San-Lourenzo. - Préparatifs pour un voyage dans l'intérieur.

\section{CHAPITRE III.}

Voyage de Rio-de-Janerro au cap Frio.-Praya-Grande. - -San-Gonsalvez. - Le Guajintibo. - La Serra-deInua. - Lac et Freguesia-de-Marica. - Gurapina. Ponta-Negra. - Sagoarema. - Lagune de Ararouama. -San-Pedro dos Indios. - Le cap Frio.

CHAPITRE IV.

Voyage du cap Frio à Villa deSan-Salvador dos Campos dos Goaytacasés. - Campos Novos. - Rivière et Villa de San-Joao. - Rio das Ostras. - Fazenda de Tapebuçu. - Rivière et Villa de Macahé. - Paulista. - Coral de Battuba. - Barra do Furado. - Rio Barganza. - Abbaye de San-Bento. - Villa de SanSalyador sur le Paraiba. 


\section{CHAPITRE V.}

Séjour à Villa de San-Salvador. - Villa de SanSalvador. - Excursion à San-Fidelis. - Les Indiens Coroados. - Les Pourys.

\section{CHAPITRE VI.}

Muribecca. - Hostilités des Pourys. - Quartel das Barreiras. - L'Itapemirim. - Villa-Nova de Benevente sur I'Iritiba. - Goaraparim.

\section{CHAPITRE VII.}

Séjour à Espirito-Santo et voyage au Rio-Doçe. - Villa Velha do Espirito-Santo. - Cidade de Victoria. - Barra de Juçù. - Araçatiba. - Coroaba. - Villa nova de Almeïda. - Quartel do Riacho. - Rio-Doçe. - Linharès. - Les Boutocoudys, ennemis invétérés des Portugais.

\section{CHAPITRE VIII.}

Voyage du Rio-Doçe à Caravellas, ou Rio d'Alcobaça, et retour au Morro d'Áraba sur le Mucuri. -Quartel de Juparanan da Praya. - Rivière et barra de SanMateo. - Le Mucuri. - Villa Viçoza. - Caravellas. - Ponte de Gentio sur l'Alcobaça. - Séjour en cet endroit.

FLN DE LA TABLE DU TOME PREMIER. 


\section{VOYAGE}

\section{AU BRÉSIL.}

\section{CHAPITRE PREMIER.}

Traversée d'Angleterre à Rio-de-Janeiro.

LE Brésil, vers lequel depuis quelques années un grand nombre de voyageurs ont dirigé leurs regards, offre l'avantage d'être séparé del'Europe par une de mers les plus tranquilles. Quoique les tempêtes soient fréquentes sur lïmmense Océan, durant certains mois, surtout vers le temps des équinoxes, toutefois elles sont généralement moins dangereuses dans ces parages que dans ceux qui avoisinent le caj de Bonne-Espérance, le cap Hōrn, etc.

Je quittai Londres le 15 mai 1815 ; c'est l'époque à laquelle les tempêtes ont ordinairement:

I. 
perdu leur plus grande violence; et je me flattai en conséquence de l'espoir d'une traversée tranquille et agréable. Notre navire le Janus, de trois cent vingt tonneaux, sortit de la Tamise par un très-beau temps; et nous eûmes d'autant plus confiance au proverbe des matelots anglais, evening red and morning grey, sign of a very fine day (soirée rouge et matinée grise, signes d'un beau jour), que le soir du jour de notre départ, le ciel était d'un rouge magnifique. Un vent frais et favorable nous fit promptement arriver à l'embouchure de la Tamise; mais dans la nuit il changea, il fallut mouiller.

Les premiers jours d'une traversée sont ordinairement employés à s'arranger dans le navire et à considérer les objets nouveaux dont on est entouré; ils passèrent promptement. Le second jour commençait à peine que tout nous donnait lieu d'espérer un voyage heurenx. Nous faisions route en compagnie d'un grand nombre de vaisseaux de toutes les grandeurs, qui, les voiles gonflées, glissaient rapidement sur la surface des eaux. Vers midi ces présages flatteurs s'évanouirent, le vent devint contraire, on fut obligé de louvoyer. On passa devant Margate, jolie petite ville, on doubla le cap North-

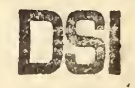


Foreland avec ses falaises blanches et escarpées, on entra dans la Manche, et le soir on mouilla aux Dunes en face de Deal. Cette partie de la côte d'Angleterre est entièrement ouverte; aucune anse, aucune hauteur ne mettent le navigateur ă l'abri des tempêtes. Beaucoup de navires étaient à l'ancre devant Deal; on $\mathrm{y}$ voyait des bâtimens de la compagnie des Indes et plusieurs vaisseaux de guerre. Le vent contraire nous retint plusieurs jours sur cette rade. Le capitaine profita de ce temps pour prendre une augmentation de provisions fraîches. Au bout de quelques jours, le vent paraissait un peu plus favorable, on leva l'ancre et l'on doubla le. cap South-Foreland; mais le vent devint de nouveau si contraire et le temps si mauvais, qu'il fallut songer à reprendre l'ancien mouillage à Deal. La furie du vent augmenta; le nombre des hommes de quart fut doublé pendant la nuit; le ciel se couvrit de plus en plus, l'on ne distinguait plus le cap South-Foreland, dont nous étions tout près. Enfin la tempête éclata dans toute sa furie; on amena les vergues pour donner moins de prise au vent. Ce mauvais temps continua pendant quelques jours, et ne donnapas aux passagers qui n'avaient pas encore 
navigué une idée avantageuse des agrémens de la vie des marins. Une après-midi que le vent sembla un peu plus favorable, un vaisseau de ligne donna le signal; toute la flotte leva l'ancre. Mais à l'approche de la nuit un nouveau danger nous menaça; les bâtimens naviguaient à si peu de distance les uns des autres, et se rapprochaient tellement à chaque instant, qu'il fallait user des plus grandes précautions pour ne pas s'aborder. Vers minuit un gros navire arriva sur nous à pleines voiles, l'obscurité ne permit de l'apercevoir que lorsqu'il vint à passer près de nous en nous rasant. Le vent fraîchissait constamment

Au point du jour la scène avait singulièrement changé. L'atmosphère dégagée de nuages paraissait terne et comme voilée par des vapeurs. Pendant tout le jour la tempête augmenta sans cesse de violence. Notre navire, entièrement sur le côté, ne se soutenait contre le vent qu'avec un petit nombre de voiles; à dix heures du matin nous étions devant le fanal de Dungeness. Tous les passagers étaient malades. Un silence affreux régnait dans la chambre; il n'était interrompu que par le sifflement du vent dans les cordages, et par le bruit effrayant des 
vagues et leur choc contre le navire. Le capitaine fit de vains efforts pour poursuivre sa route, il fallut céder et retourner au mouillage. En rebroussant chemin le vent nous favorisait; nous parcourûmes en peu de temps et avec un petit nombre de voiles le même espace que nous avions employé la nuit entière à traverser. Ur brick qui faisait route avec nous était continuellement couvert par les lames; notre navire étant plus élevé sur l'eau nous préservait en partie de cet inconvénient. Nous arrivions sur la côte de Deal avec tant de vitesse que pour éviler d'y être jetés on laissa tomber l'ancre à la hâte, ce qui ne s'effectua pas sans peine, car le câble filait avec unesi grande rapidité, que la force du frottement faillit à enflammer le bois; il s'en élevait déjà une vapeur; on prévint l'accident par destorrens d'eau, et nous échappâmes au danger. Heureusement notre navire; qui était en général très-bon et très-solide, avait des câbles neufs et d'excel-

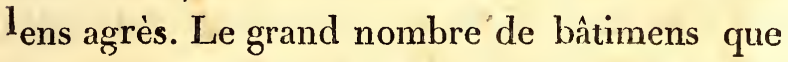
nous trouvâmes au mouillage nous consola en quelque sorte de la perte de temps que nous avions éprouvée. Tous les grands navires avaient amené leurs mâts de hune et de perroquet, ainsi que leurs vergues, pour être moins exposés à la 
fureur de la tempête; les vaisseaux de guerre étaient mouillés sur deux ancres.

Nous avions échappé au danger le plus imminent; mais toujours renfermés dans le navire, que les lames ballotaient encore d'une manière terrible, nous menions une triste vie; aussi nous nous sentîmes doublement heureux lorsqu'enfin l'agitation violente des vagues s'apaisa, et que nous pûmes faire route vers notre destination. Nous passâmes devant Dungeness, nous vîmes les deux rochers de Beachyhead, promontoire du Sussex, situé entre Hastings et Shoreham, et devant lequel une escadre française battit en 1690 les flottes combinées d'Angle${ }_{t}$ erre et de Hollande; nous aperçûmes à nidi la ville de Brighthelmstone, par abréviation Brighton, si renommée pour ses bains de mer, et nous nous trouvâmes en vue del'île de Wight. La mer était tranquille, la lune éclairait l'horizon; la gaîté avait reparu à bord ; les violons des matelots se firent de nouveau entendre; les jeunes gens dansèrent, et oublièrent l'inquiétude qui les avait tourmentés.

Le 20 mai dans la matinée nous quittâmes la pointe de Sainte-Catherine dans l'île de Wight; bientôt nous fûmes devant la pointe de Portland 
dansle Dorsetshire, d'où se tire la belle pierre à bâtir que l'on emploie à Londres. Mais dans la nuit il s'éleva encore une tempête si rude qu'il fallut louvoyer pour n'être pas jeté contre les rochers; une de nos voiles fut déchirée par le vent. Le lendemain la grosse mer et lc vent peu favorable nous forcèrent de relâcher à Torbay, rade sûre et vaste, entourée de hautes falaises, etfermée au nord par la pointe de Portland, au sud par le cap Start-Point; le soir nous doublâmes ce promontoire, qui consiste en hauts rochers dentelés; au-dessus s'étend, de même que tout le long de la côte du Devonshire, une belle plaine verdoyante, dont l'uniformité est interrompue par la couleur jaune des fleurs de l'ajonc (ulex europceus), arbrisseau très-commun des deux côtés de la Manche. On voyait à la surface de la mer des rochers contre lesquels les vagues venaient se briser, tableau qu'embellissait la lumière douce du soleil couchant. Cependant notre vaisseau continuait rapidement sa route. Dés le lendemain matin nous aperçûmes au loin le fort Pendennis, près de Falmouth, et nous quittâmes la Manche au cap Lézard qui se distingue par ses deux phares blancs. Les côtes du Cornouailles et $\mathrm{du}$ 
Devonshire n'ont pas la couleur blanche de celles de North et South Foreland; elles offrent une teinte rougeâìre.

Enfin nous nous trouvons dans l'immense Océan ; la terre avait entièrement disparu de nos yeux, et le cap Landsend, la pointe la plus méri dionale de l'Angleterre, se dérobe à nos regards le 22 mai à midi. De ce moment cesse toute distraction causée par la diversité des objets dont on est entouré ; le ciel et la mer sont les seuls que l'on aperçoive; on cherche à s'occuper en écrivant; heureux qui a fait une ample provision de bons livres !

Il ne nous arriva rien de remarquable jusqu'à Madère, que nous aperçûmes le dixième jour de notre navigation. On eut beau jeter des lignes et d'autres instrumens de pêche, on ne prit que des grondins (trigla gurnardus), poisson très-bon à manger. Des troupes de marsouins nous accompagnaient souvent de loin, surtout quand la mer était un peu agitée; on fit. feu sur eux, on n'en tua aucun. L'oiseau de tempête était aussi de nos fidèles compagnons; les Portugais le nomment alma de mestre. Les marins, qui regardent comme l'indice d'une tempête prochaine l'arrivée d'une troupe nombreuse 
de ces oiseaux autour d'un navire, ne le voient pas avec plaisir.

Un cutter de la marine royale d'Angleterre nous annonça que son pays avait déclaré la guerre à la France; aussitôton fit l'appel de nos matelots; cependant on n'en prit aucun pour le service de l'état. Cette nouvelle nous causa de vives inquiétudes, surtout lorsqu'en passant devant la côte d'Espagne nous vîmes un bâtiment se diriger vers le nôtre; mais nos alarmes furent bientôt dissipées, c'était un navire anglais; il se chargea de nos lettres pour l'Europe.

Le $1^{\text {er }}$ juin, vers midi, une terre haute et des montagnes se montrèrent confusément dans le lointain; c'était Madère. A six heures du soir, nous étions devant Ponta-Parga, sa pointe occidentale, que nous doublâmes avec bon vent; la mer était couverte d'oiseaux de tempête, de mouettes, et d'autres oiseaux aquatiques. L'aspect de Madère est imposant de tous côtés : cette île s'offrait à nos regards comme un immense rocher dont les flancs se perdaient dans les nuages; ses côtes escarpées et noires sont coupées par des ravines et des gorges profondes; partout cependant la vigne étale ses pampres verdoyans, entre lesquels s'élèvent les maisons blanches des habi * 
tans. Sur le dos des hauteurs que les nuages ne voilaient pas, on voyait des pâturages verts comme ceux des Alpes, et des groupes d'arbres hauts et touffus ombrageaient les maisonnettes. Cette belle île jouit du plus heureux climat; les végétaux de la zone töride y croissent à merveille; la grande chaleur y est mêlée à beaucoup d'humidité, et les pluies doivent y être fréquentes, car les torrens auxquels elles donnent naissance ont sillonné profondément les rochers escarpés de la côte. Quatre-vingt mille habitans tirent en grande partie leur subsistance de la culture des vignes, qui donnent un vin générale . ment recherché, ainsi que de celle des oranges, des citrons, des bananes et d'autres fruits exquis.

Comme nous n'avions pas le projet de visiter Funchal, capitale de l'île, nous continuâmes notre route à la faveur d'un vent frais, et nous perdîmes bientôt l'île de vue. Le vent alisé nous fit arriver avec rapidité au tropique. Des troupes de poissons volans s'élevaient des deux côtés du navire, au-dessus de la surface des eaux; plus on approche de l'équateur, plus ils deviennent nombreux; on les voit plus rarement avant de parvenir au tropique.

Le 6 juillet nous avons coupé le tropique du. 
Cancer. La diversité des mollusques qui se montraient à nos regards nous donnait de la distraction. Ce fut par les $22^{\circ} 17^{\prime}$. de latitude nord que nous vîmes la première physalie, mollusque très-singulier (1), qui depuis ce point se montre toujours en plus grande quantité à mesure qu'on s'avance vers la ligne, de sorte que plus au sud, on en voit chaque jour par centaines. Plusieurs voyageurs ayant dẹjà parlé de cette singulière production de la nature, je mis un intérêt particulier à l'observer avec attention. La partie la plus grosse de l'animal est une vésicule transparente et remplie d'air, qui nage au-dessus de l'eau, et qui parâit uniquement destinée à soutenir la portion supérieure dans cette position; la partie inférieure offre huit à neuf faisceaux de longs tentacules gélatineux qui tiennent à la racine par des tubercules gélatineux, courts et épais, formant une masse ì la base de la vésicule. La vie de l'animal réside dans cette parlie: les tentacules sont irritables, la vésicule ne l'est pas; ils s'allongent, se raccour-

(1) Voyez sur ce mollusque la notice de M. Tilesius, dans le troisième volume du voyage de Krusenstern autour du monde, en allemand, p. 1 à $10 \%$ 
cisssent, saisissent la proie, etsont couverts d'une infinité de suçoirs. La vésicule ne paraît sujette à aucun changement; je n'ai pu y découvrir l'orifice d'aucun vaisseau. A la mort de l'animal elle ne s'affaisse pas, et même plongée dans l'esprit de vin elle conserve sa forme. Sa faculté de se mouvoir est faible; elle se contracte en forme de croissant; elle courbe aussi ses deux extrémités, en haut et en bas : par ces mouvemens elle se relève lorsqu'une vague l'a renversée. On peut toucher la vessie sans éprouver une sensation douloureuse; mais les tentacules occasionnent une démangeaison violente. Les Portugais nomment ce singulier mollusque agoa viva ou caravela; les Anglais portuguese man of war, les Français galère. Plus près de l'équateur, le nombre de ces mollusques diminua; au contraire celui de la medusa pelagica augmenta. Des oiseaux de mer voltigeaient quelquefois autour de nous. Notre capitaine en second prit à la main, après un grain, une hirondelle de mer qui de fatigue étoit venue se reposer à bord; nous vîmes aussi des frégates qui avaient été emportées de dessus les rochers voisins.

Pendant que nous avions traversé la partie septentrionale de la zone torride, le temps avait 
été généralement beau; mais ensuite la chaleur qui augmentait continucllement nous était souvent très-incommode dans le vaisseau. Des nuages sombres, indices de pluie et d'orage, s'élevaient quelquefois isolément sur l'horizon; ils s'étendaient et arrivaient avec rapidité, apportant une bourrasque violente et une forte ondée de pluie, qui dans un instant inondait le navire; mais ordinairement le soleil brillait de nouveau une demi-heure après. Lorsque l'eau commença à se gâter, ces ondées furent reçues avec plaisir. Les navigateurs imprudens qui, à l'approche d'un semblable météore, ne serrent pas leurs voiles supérieures, ont souvent beaucoup à souffrir de ces raffales subites, et quelquefois en sont victimes. Notre capitaine nous raconta qu'un accident de ce genre était arrivé peu de temps auparavant à un navire qui avait péri. Le nôtre eut une voile déchirée; comme on prenait toujours les précautions requises, il n'éprouva pas d'autre dommage.

Le 22 juin le Janus passa la ligne. Les cérémonies usitées en pareille occasion ne furent pas oubliées. Au sud de l'équateur le temps fut plus mauvais. Des grains de peu de durée, ac-o compagnés de raffales violentes, étaient fréquens; 
la mer était assez souvent agitée. Les oiseaux de tempête, les marsouins, les cachalots, et de plus gros cétacées, se montraient communément.

Nous avions coupé l'équateur par les $28^{\circ}, 25$ de longitude à l'occident de Greenwich parce qu'étant auparavant dans des parages plus rapprochés des côtes d'Afrique, où nous avions essuyé beaucoup de pluie et d'ouragans, nous avions, pour nous en éloigner, gouverné à louest; cc qui nous porta dans les courans, qui nous firent avancer vers la côte d'Amérique.

Le 27 juin, pendant que nous déjeunions, on nous annonça que l'on voyait la terre. Tout le monde courut sur le pont pour contempler la côte du Brésil, qui s'élevait du sein de l'Océan. Bientôt parurent, sur la surface de la mer, deux espèces de goémons et de nombrenx indices de terre; enfin nous rencontrâmes un radeau de pêcheur qui portait trois hommes; on nomme ces radeaux jangadas; ils sont faits de cinq à six pièces d'un bois léger que l'on appelle au Brésil pao de jangada. Koster en a donné la figure dans son voyage au Brésil (1). Ces jangadas naviguent assez sûrement en mer; on s'en sert.

(1) Page 5. Traduction française, tome 1, page 4. 


\section{AU BRÉSIL.}

pour la pêche ou pour le transport de différens objets le long de la côte; ils vont très-vite, au moyen d'une grande voile latiue, attachée à un mât court. Nous aurions volontiers, après une longue traversée, profité de l'occasion de nous procurer du poisson frais, mais ce n'était pas la peine, pour satisfaire ce désir, de courir après les pêcheurs. Nous fîmes route vers la côte; nous nous en étions assez rapprochés à midi pour reconnaître que c'étaient les environs de Goïana ou Paraïba-do-Norte, dans la capitainerie de Pernambouc. Si près de la terre, la force du vent aurait pu pendant la nuit nous faire courir des dangers : heureusement nous pûmes à temps virer de bord, et retourner au large. Il tomba pendant la nuit des torrens de pluie accompagnée d'un gros temps, qui nous obligea de louvoyer pendant plusieurs jours, presque sans changer de place. Le vent soufflait avec furie; le navire roulait avec violence. La pluie ne discontinuait pas : nous n'étions guère en sûreté dans nos lits. Nos matelots souffraient le plus de l'humidité; le danger qui nous menaçait les obligeait d'être jour et nuit sur le pont; le rhum suffisait à peine à soutenir leur courage et leur bonne volonté. L'aspect de la 
mer, dans les nuits sombres, orageuses, pluvieuses, était effrayant ; les vagues bruyantes venaient en s'élevant frapper le navire; l'immense surface de l'eau semblait être en feu; des milliers de points lumineux, des bandes et même de larges traînées de lumières brillaient de tous côtés, changeant de forme et́ de place à chaque instant. Cette lumière ressemblait entièrement à celle que donne le bois pourri lorsqu'il est mouillë ; c'est un phénomène que l'on voit fréquemment dans les forêts. Durant ces nuits sombres et orageuses, on met son espérance dans le jour qui suivra; mais souvent le jour paraissait sans que notre position devînt meilleure. Il était aussi nébuleux, aussi sombre que la nuit qui l'avait précédé; les marins ne pouvaient cacher leurs craintes; ils appréhendaient une tempête plus violente. Chaque fois qu'elle semblait s'annoncer, on faisait les préparatifs nécessaires pour résister à sa violence, préparatifs qui causent des inquiétudes et des alarmes extrêmes aux passagers. Nous avions commis une grande fáute de nous tant approcher de la côte dans le voisinage de Pernambouc, parce quedurant l'hiver de la zone torride, les orages et les tempêtes 'règnent dans ces parages. Le 
capitaine dirigea sa route, autant que le vent le lui permit, pour gagner la haute mer, mais il fut constamment obligé de louvoyer, et par conséquent n'avạnça pas beaucoup. Enfin, huit jours après avoir aperçu la terre pour la première fois, le vent devint un peu meilleur et nous laissa la liberté de prendre une route plus directe. On mesurait quelquefois la force des courans, précaution nécessaire quand on navigue si près de la côte. De grands oiseaux de mer, des goélands ou des petrels nous entouraient sans que nous pussions en tirer un seul; les physalies nageaient autour de nous, les poissons volans fendaient l'air en avant du navire, et de gros cétacées lançaient l'eau par leurs évents.

Le 8 juillet à midi nous vîmes de nouveau la côte du Brésil dans le voisinage de la Bahia-detodos-os-Santos. Elle se montrait sous l'aspect de montagnes de belles formes, au-dessus desquelles reposaient d'épais nuages. On voyait la pluie tomber sur la côte, et en mer nous éprouvions constamment des alternatives de gros temps, de pluie, et de vent contraire. Comme tous les soirs le vent soufflait de terre, nous nous rapprochions de la côte pendant le jour, et pendant la nuit nous regagnions le large:

I. 
de cette manière nous ne perdions guères la terre de vue.

Le 10, le temps fut beau et le vent favorable. Nous avions passé les écueils dangereux nommés Abrolhos (ouvre les yeux : adra os olhos); ainsi nous pûmes faire route directement pour le cap Frio. Par les $22^{\circ} 23^{\prime}$ de latitude sud j'observai une seconde espèce de physalie, qui est beaucoup plus petite que l'autre, et n'a pas du tout de teinte rouge (1). Ces mollusques se montraient en grand nombre. La chaleur à midi dans ces parages devenait chaque jour plus accablante: une seule tasse de thé causait une transpiration abondante. En revanche la température des nuits, pendant lesquelles la lune brillait et les étoiles resplendisaient d'un éclat singulier, était très-agréable. Les indices de l'approche de la terre augmentaient à chaque instant : on rencontrait des goémons, des plantes, $\mathrm{du}$ bois, toutes sortes d'objets semblables; enfin le 14 à midi nous revîmes la côte et nous reconnûmes distinctement devant nous le cap Frio, en avant duquel gît un îlot rocailleux. La

(1) C'est sans doute celle que M. Bosc a représentée dans la planche 19 de son Histoire Naturelle des Vers. 
joie se manifesta vivement de toutes parts; nous tenions la mer depuis soixante-dix jours, et nous n'avions plus qu'une bien courte traversée jusqu'à Rio-de-Janeiro.

Dans la matinée, le Junus doubla le cap Frio avec un vent frais et favorable; le 15 nous vîmes de près la côte méridionale du Brésil, car ce cap la sépare de la côte orientale. Le vent agitait fortement la mer, qui, de même que sur les côtes d'Europe, avait pris la teinte de vert clair qu'elle a près de terre. La vue des montagnes du Brésil, remarquables par la beauté et la variété de leurs formes, par la verdure de leurs superbes forêts éclairées dans ce moment de la manière la plus diversifiée, par leur étendue sans interruption le long de la côte, nous causait un plaisir, un ravissement extraordinaire : nous nous figurions dans notre imagination les scènes nouvelles que nous allions contempler, et nous attendions avec empressement l'instant de déba:quer. Les montagnes primitives vers lesquelles nous faisions voile out les formes les plus variées : elles sont souvent coniques ou pyramidales; les nnages couvraient leurs cimes, et une nuée ou vapeur légère leur donnait une teinte douce très- 
agréable. A midi, par un vent très-faible, le thermomètre à l'ombre se soutenait à $19^{\circ}$ de Réaumur; bientôt il descendit à $17^{\circ}$ par un calme qui dura jusqu'au soir : un peu plus tard, le vent s'éleva avec assez de force, le navire marcha avec rapidité, et le lendemain matin nous étions devant l'entrée de la baie de Riode-Janeiro.

Le calme qui survint de nouveau nous fit rester en place, pendant que l'agitation de lá mer nous secouait rudement. Nous étions près de l'ouverture qui mène à la ville royale de Rio-de-Janeiro ; une multitude de petites îles, dont quelques-unes frappent par leurs formes bizarres, s'y élèvent au-dessus de la surface de l'eau, et s'unissant à la masse des montagnes dans le lointain, présentent une perspective très-pittoresque.

Le vent s'étant élevé très-doucement vers onze heures, le bâtiment avançait à peine d'une manière visible, quoiqu'il eût toutes ses voiles dehors. Nous prîmes le parti de profiter de cette inactivité pour visiter les îlots les plus proches de nous, et faire ainsi connaissance avec le sol du Brésil. Le capitaine fit mettre un canot dehors, et prit avec lui quelques matelots ; trois 
passagers, du nombre desquels j'étais, l'accompagnèrent. Nous allions de l'avant, sans remarquer que l'eau entrait avec rapidité dans le canot; comme il était resté suspendu à l'arrière du navire, la chaleur du soleil en avait déjoint les coutures. Après avoir pendant une demiheure travaillé péniblement à vaincre la houle, nous nous vîmes contraints de vider l'eau qui remplissait le canot; mais nous manquions des. instrumens nécessaires, il fallut nous servir de nos souliers. La hauteur des lames nous avait dérobé la vue du navire; enfin, après avoir vidé deux fois le canot, nous arrivâmes heureusement à l'Ilha raza, l'île plate, ainsi nommée pour la distinguer de l'Ilha rotunda, qui est haute. Mais en approchant de cette île déserte, nous reconnûmes l'impossibilité d'y descendre. De tous côtés s'élevaient des rochers aigus, sur lesquels une multitude de mollusques étendaient un véritable réseau. La mer brisait avec tant de fracas et de furie sur ce récif, que, remplis de crainte, il fallut nous contenter d'admirer de loin les beaux arbustes touffus qui couvrent la surface de l'île, et d'écouter le ramage des oiseaux qui se faisait entendre au-dessus de nos têtes. L'aspect de cette île du. 
tropique était entièrement nouveau, et très-intéressant pour nous. Sur les pointes des rochers se tenaient, par couples, une múltitude de mouettes à dos noir, qui ressemblent en tout au larus marinus des mers d'Europe. Nous leur tirâmes plusieurs coups de fusil sans en tuer une seule, car au premier elles s'étaient toutes envolées, et nous entouraient en nous assourdissant de leurs cris. Après avoir resté environ une heure près de cette île, nous songeâmes à retourner à notre bâtirient que nous n'apercevions plus. Notre position devenait critique, car il règne dans cette entrée des courans qui détournent insensiblement les vaisseaux de leur route, et les jettent à la côte. On en a vu plusieurs exempies (1). Nos matelots furent obligés de travailler vigoureusement contre la force

(1) Les courans de l'entrée de la baie de Pio sont souvent dangereux pour les bàtimens quand il survient du calme. Un événement remarquable de ce genre avait eu lieu peu de temps avant mon arrivée. Un navire américain entra tut bientôt suivi d'un corsaire anglais. L'Américain hésita long-temps à ressortir, enfin il s'y décida ; l'Anglais voulut appareiller aussitôt pour le prendre. D’après les réglemens du port de Rio, il est accordé un délai de trois beures à un 
de la mer, sans savoir de quel côté se trouvait le Janus. Nous les aidions de tout notre pouvoir, nous vidâmes encore deux fois le canot avec nos souliers; enfin nous eûmes le bonheur d'apercevoir au-dessus des lames la pointe des mâts de notre navire. Après bien des peines et des fatigues nous y arrivâmes : on y était inquiet de nous.

Nous ne faisions que peu de route à cause de la faiblesse du vent, toutefois nous jetâmes l'ancre le soir dans le goulet de l'entrée de la baie. Cette entrée est imposante et très-pittoresque. De chaque côté s'élèvent des rochers âpres et gigantesques, semblables à ceux de la Suisse, et terminés par des cimes arrondies ou en pointe, qui la plupart ont un nom particulier; deux pointes réunies portent celui de Daos

navire avant qu'un bâtiment ennemi puisse le suivre. L'Anglais fut donc obligé d'attendre trois heures, alors il mit toutes voiles dehors, et poursuivit l'Américain. Mais à peine était-il arrivé dans le voisinage de l'Ilha rotunda , qu'il survint un calme plat; le courant poussa violemment le corsaire contre les rochers; le bâtiment échoua et périt avec tout l'équipage, tandis que l'Américaín était depuis long-temps au large. 
Irmaos (les deux frères); une autre a reçu des Anglais celui de Parrot Beak (bec de perroquet). Plus loin on voit le Corcovado, que gravissent les habitans de Rio pour jouir du superbe coup d'œil des environs. Quand nous eûmes mouillé à peu près à un mille anglais du fort, nos regards se portèrent sur la nature grande et nouvelle qui nous entourait. Lés montagnes à cime dentelée sont en partie couvertes de forêts d'un vert sombre, du sein desquelles s'élancent fièrement les cocotiers à la tige svelte. Le matin et le soir les nuages s'abaissaient sur ces énormes montagnes primitives, et voilaient leur sommet; la mer venait battre leur pied en écumant, et produisait un bruit que nous entendions de tous côtés pendant toute la nuit. A la lueur du soleil couchant, nous apercevions à la surface de la mer des troupes de poissons de couleurs brillantes, et dont le rouge vif produisait un coup d'œil singulier. Les goémons et les mollusques que nous pêchions nous occupèrent jusqu'aux approches de la nuit; alors la rosée, extrêmement abondante dans cette zone, nous chassa de dessus le pont du vaisseau. Nous allions nous abandonner au repos, lorsqu'un coup de canon tiré au loin nous 
rappela sur le pont. Dans le fond de la baie, précisément à l'endroit où la quantité de grandis navires nous avait fait supposer qu'était situé Rio - de - Janeiro, un coup d'œil vraiment magnifique nous surprit au milieu de la nuit, c'était celui d'un beau feu d'artifice.

Nous attendions le lendemain avec un redoublement d'impatience; dès le point du jour, on leva l'ancre, et, à la faveur d'un vent modéré, on s'avança vers le port. La joie animait tout le monde, on était réuni sur le pont. $\mathrm{U}_{\mathbf{n}}$. canot arrivé de terre et conduit par huit Indiens nous amena deux pilotes qui dirigèrent le Janus à son mouillage devant la ville. Ces matelots nous apportèrent de fort belles oranges qui nous semblèrent d'autant meilleures que, depuis soixante-douze jours que nous étions en mer, nous n'avions pas goûté un fruit frais.

Nous voguions d'un côté à l'autre de l'entrée resserrée, et nous nous approchions de la ville; les montagnes diminuaient de hauteur sur chà que rive, nous apercevions de jolies maisons avec des toits rouges, au milieu des ravines ombragées par des arbres touffus, et dominées par les cocotiers; des bâtimens naviguaient en tous sens sur la rade. Nous laissâmes derrière nous 
plusicurs îles, entre autres celle sur laquelle Villegagnon bâtit le fort Coligni, et qui porte encore son nom. De ce point on aperçoit une grande partie de la baie de Rio qui est entourée de hautes montagnes, parmi lesquelles $l a$ Serra dos Orgàos (la montagne des orgues) se distingue par ses pics, semblables à ceux des Alpes de Suisse. Beaucoup de jolies îles sont éparses dans ce port, le plus bean et le plus sûr du Nouveau-Monde, et dont l'entrée est défendue de chaque côté par de fortes batteries. On est en ce lieu vis-à-vis de la ville de Rio-de-Janeiro, bâtic sur plusieurs collines au bord de la mer. Elle présente une belle perspective avec ses églises et ses couvens situés sur les hauteurs. Le fond du tableau derrière la ville est formé par des montagnes de forme conique, arrondies au sommet et couvertes de forêts : elles embellissent infiniment le paysage, dont le devant est animé pąr une multitude de navires de toutes les nations. C'est là que règnent l'activité et la vie; des canots, des chaloupes y sont sans cesse en mouvement; les petits navires des ports voisins remplissent les intervalles entre les grands vaisseaux des nations de l'Europe.

A peine nous eûmes laissé tomber l'ancre, 
que nous fûmes entourés de bateaux; l'un portait des soldats qui couvrirent aussitôt le pont du navire. Les employés de l'alfandega ou de la douane s'établirent à bord; la commission de santé arriva aussi; il vint des officiers qui examinèrent nos passeports; enfin le bâtiment fut rempli d'une quantité d'Anglais qui demandèrent des nouvelles de leur pays. La dernière soirée que nous passâmes à bord, après un emprisonnement de soixante-douze jours, se passa rapidement; il faisait un beau clair de lune, le temps étoit d'une chaleur douce et agréable: nous restâmes à causer sur le pont jusque bien avant dans la nuit; cependant nous ne pouvions nous cacher les uns aux autres une certaine impatience de voir arriver le lendemain. Notre imagination s'occupait vivement de l'avenir. Au milieu de ces pensées mes yeux se portèrent sur les mâts du navire qui nous avait amenés heureusement de régions éloignées; échappé à des dangers nombreux, il étoit mouillé tranquillement dans le port : je le considérai avec un vif intérêt. Le voyageur qui a, pendant quelques mois, fait sa demeure sur l'Océan, dans une de ces grandes machines mobiles, éprouve envers elle un mouvement de reconnaissance quand il 
est sur le point de la quitter; il dit un adieu cordial au matelot grossier, mais franc, qui lui a si long-temps prêté son secours, et lui souhaite pour l'avenir une heureuse chance dans ses voyages sur l'élément mobile et trompeur auquel il a consacré son existence. 


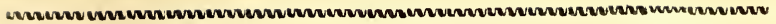

\section{CHAPITRE II.}

Séjour à Rio-de-Janeiro. - La ville et ses environs. - Les Indiens de San-Lourenzo. - Préparatifs pour un voyage dans l'intérieur.

LE lieu où est bâti Rio-de-Janeiro, ou San Sebastiam de Eneré, portait chez les sauvages habitans primitifs de ces contrées le nom de Ganabara. Cette ville, qui dans la dernière moitié du dix-septième siècle ne comptait que 2500 habitans avec une garnison de 600 hommes (1), s'est élevée aujourd'hui au rang des premières cités du nouveau monde. Comme il existe beaucoup de descriptions de cette capitale, ce serait entrer dans des répétitions inutiles que de vouloir en entreprendre une détaillée. M. Barrow en a donné une idée assez exacte (2); mais depuis qu'il a écrit,

(1) Voyez History of Brazil by Southey, tome 2, p. 667.

(2) Voyage à la Cochinchine, etc., tome 1, p. $9^{2}$ à 150 de la traduction française, qui contient des additions importantes de MI. Malte-Brun aux observations de l'écrivain anglais (E). 
l'ensemble des choses a bien changé. Près de vingt mille Européens venus de Portugal avec le roi se sont établis dans cette ville, il en est résulté la conséquence naturelle que les usages du Brésil ont été modifiés par ceux d'Europe. Des améliorations de tous les genres ont été entreprises dans la capitale. Elle a beaucoup perdu de son caractère d'originalité : aujourd'hui elle est devenue plus ressemblante aux cités européennes. Cependant les étrangers qui arrivent sont frappés du très-grand nombre de nègres et de mulâtres qu'ils rencontrent dans les rues au milieu de la foule dont elles sont remplies; car la population de Rio-de-Janeiro compte plus de nègres et de gens de couleur que de blancs.

Plusieurs nationssont rassemb́lées en ce lieu parle commerce, et de leur réunion sont sortis de nouveaux et nombreux mélanges. La classe qui a le pas sur les autres dans toute l'étendue du Brésil est celle des Portugais d Europe (Portuguezes ou Filhos do reino); viennent ensuite les Brésiliens ou Portugais créoles, d'origine plus ou moins pure (Brasilë̈ros); les mulâtres, provenant du mélange de blancs et de nègres (mulatos); les manselus ou métis sortant de blancs et d'Indiens (mamaluccos); 
les nègres d'Afrique (negros ou maleccos); les nègres créoles, nés au Brésil (creolos); les aribocos, nés d'un nègre et d'un Indien; les Indiens purs, ou habitans primitifs du Brésil (Indios); on appelle caboclos ceux qui sont civilisés; et gentios, tapuyès ou bugrrès ceux qui vivent encore dans leur état naturel.

Toutes ces variétés de couleurs frappent dans Rio-de-Janeiro, les tapuyes n'y paraissent qu'isolément comme des objets curieux. Dès qu'on met le pied dans les rues on voit ce singulier mélange d'hommes diversement occupés, et auprès d'eux une réunion de toutes les nations de l'Europe. Les Anglais, les Espagnols, les Italiens, sont ici très-nombreux; il y arrive actuellement une quantité de Français; on y rencontre beaucoup moins d'Allemands, de Hollandais, de Suédois, de Danois, de Russes. Les nègres à moitié nus font tous les gros ouvrages; c'est cette classe utile d'hommes qui transportent toutes les marchandises du port à la ville; ils se réunissent à cet effet dix à douze, et avec de fortes barres de bois, emportent les fardeaux les plus pesans, maintenant l'ensemble dans leurs mouvemens par des chants ou plutôt des cris; car on ne se sert pas de charrettes pour ce travail. 
D'un autre côté on voit des carrosses et d'autres voitures, traînées par des mulets, rouler dans les rues en général mal pavées, mais garnies de trottoirs; la plupart se croisent à angles droits; les maisons n'ont ordinairement qu'un rez-de-chaussée, ou un étage au-dessus; cependant il y en a de fort grandes dans quelques parties de la ville, surtout dans le voisinage du port, dans la ruaDireita, et près du palais du roi, qui n'est pas magnifique, mais qui est très-bien situé, et d'où l'on jouit d'une belle vue sur la mer. Les principaux édifices sont les églises, dont l'intérieur est assez généralement orné avec magnificence; les fêtes religieuses, les processions et autres cérémonies semblables sont fréquentes; une coutume singulière dans toutes ces solemnités est de tirer dans les rues, devant les portes des églises, des feux d'artifice avec grand bruit et grand fracas.

Rio possède une salle d'opéra assez grande; on y joue des opéras italiens; les danseurs sont français. L'aquéduc est un ouvrage important; la promenade à la colline de laquelle il se rend à la ville, est très-agréable; on y jouit de la vue du port et de celle de la ville, qui s'étend dans une ravine d'où s'élèvent des cocotiers du Bré- 
sil (cocos butyracea). Du côté de terre, Pio est entouré de marais couverts de mangliers ( $R h i-$ zophora). Ce voisinage, et en général sa situation, ne doivent pas être favorables à la santé des habitans.

L'Européen transplanté pour la première fois dans cette contrée équatoriale, est ravi de la beauté des productions de la nature, et surtout de l'abondance et de la richesse de la végétation. Les plus beaux arbres croissent dans tous les jardins : on y voit le manguier colossal, qui donne un ombrage épais et un fruit excellent, le cocotier à la tige haute et svelte, le bananier en groupes serrés, le papayer, l'érythrina aux fleurs d'un rouge de corail, et un grand nombre d'autres, répandus dans tous les jardins qui touchent à la ville. Ces superbes végétaux rendent les promenades extrêmemeut agréables; les bo: cages qu'ils forment offrent à l'admiration des étrangers des oiseaux et des papillons qu'il n'a pas encore vus, parmi lesquels je ne citerai que les colibris au plumage doré, comme les plus connus. Les promenades sur les bords de la mer n'ont pas moins de charmes, par la vue des vaisseaux qui arrivent des régions du monde les plus éloignées. Je ne dois pas onblier non plus le 
Passeio publico, grande place plantée d'allées d'arbres, et terminée par une terrasse.

Jusqu'à présent la nature a plus fait que l'homme pour le Brésil: toutefois depuisl'arrivée du roi on a beaucoup effectué pour l'avantage du pays. On doit mettre de ce nombre plusieurs ordonnances rendues en faveur du commerce, qui est très-actif, et dans lequel, cependant, au détriment des sujets, l'Angleterre a une trop grande prépondérance; car les navires portugais paient des droits plus forts que ceux de la Grande-Bretagne. Toulefois la circulation de capitaux considérables a beaucoup enrichi la capitale; le séjour de la cour ne contribue pas peu à cette prospérité : elle nourrit un grand nombre de personnes, et les envoyés des cours d'Europe ainsi qne les étrangers attirés par divers motifs en ce pays, ont extrêmement répandu le goût du luxe parmi les différentes classes d'habitans. La mise, les modes, y ressemblent entièrement à celles des capitales d'Europe. On y trouve déjà une si grande quantité d'artistes et d'artisans de tous les pays et dans tous les genres, que dans peu d'années on y manquera de peu de ces choses qui tiennent $\grave{a}$ l'agrément de la vie. On y jouit d'ailleurs d'une 


\section{AU BRÉSIL.}

abondance de fruits et d'autres productions de la nature que l'on doit à la beauté du climat, et que l'homme ne sait apprécier et mettre à profit que lorsqu'il les obtient par le travail, la culture, et lorsqu'il parvient à les perfectionner. Les oranges, les mangues, les figues, les raisins, les goyaves, les ananas, acquièrent ici une qualité parfaite; on y a plusieurs variétés de bananes, notamment celle de San-Tome, et la banana da terra, que l'ou regarde comme plus saine encore : toutes deux sont très-nourrissantes et très-savoureuses. Parmi les fruits qui se vendent dans les rues, on remarque le coco, dont le lait est si rafraîchissant; le fruit du jaquier à feuilles entières (artocarpus integrifolia), dont le goût est d'une douceur désagréable; les melons d'eau (melancias); les amandes du quatelé (lecythis ollaria); celles du pin du Brésil (araucaria). On dit que la canne à sucre croît naturellement dans le pays, notamment aux environs de la capitale. Les marchés ne sont pas moins bien fournis de poissons de différente espèce, des formes les plus singulières et des couleurs les plus belles; enfin, la volaille et le gibier de toutes sortes viennent ajouter à l'abondance. On a ici une race 
de poules à bec et à pieds jaunes, qui, dit-on, vient d'Afrique.

La garnison, qui est très-nombreuse, répand aussi beaucoup d'argent dans la ville. La différence entre les soldats venus d'Europe après avoir servi en Espagne sous Wellington, et ceux qui rie sont pas sortis du Brésil, frappe au premier coup d'œil. Les premiers ont une tournure tout-à-fait militaire; les autres sont amollis par la chaleur du climat: l'exercice fini, ils font rapporter leurs armes chez eux par des nègres.

On ne peut pas atlendre un tableau complet de cette capitale et de ses habitans, de la part d'un voyageur qui n'y a fait qu'un court séjour. De combien de jugemens précipités et faux ne s'expose-t-on pas à se rendre coupable, quand on veut ainsi prononcer à la hâte, sans s'être mis à même de mûrir ses idées par de longues observations. On risque aussi de rendre sa véracité suspecte. Laissons donc le soin de peindre cette capitale aux Européens qui l'ont considérée plus à loisir, et qui, sans doute; ne feront pas trop long-temps attendre le fruit de leurs observations.

J'arrivai à Rio pendant l'hiver de la zone tor- 
ride; la température ressemblait ì celle de nos mois les plus chauds de l'été. Je m’attendais à voir tomber de la pluie durant cet hiver des tropiques, mais, à ma grande joie, j’étais dans l'erreur, il ne plut pas : ce qui prouve le peu de fondement de l'opinion vulgaire, que dans la saison froide de la zone torride en Amérique, il pleut constamment. Mes lettres de recommandation me procurèrent un accueil plein de bienveillance dans plusieurs maisons. Je dois citer avec une reconnaissance profonde $M$. Westin, consul de Suède, M. Langsdorff, consul de Russie, M. Chamberlain, chargé d'affaires d'Angleterre, et M. Svertskoff, chargé d'affaires de Russie. Ces messieurs s'efforcèrent à l'envi de me rendre mon séjour agréable, et mon compatriote M. Feldner, ingénieur-major, me combla de marques de bonté. Il me fit faire plusieurs parties de campagne très-gaies, qui me donnèrent occasion de connaître les beaux environs de Rio. La plus intéressante pour moi fut celle que nous fîmes au village de San-Lourenzo, le seul des environs de la capitale où il se trouve encore des habitans primitifs du pays, jadis si nombreux dans ces cantons. Pour mieux examiner ces hormmes, nous quittâmes 
la ville sous la conduite du capitaine Perreira, qui connaît très-bien les environs. On s'embarqua pour traverser une partie de la baie. Un très-beau temps nous favorisail; chaque instant m'offrait le coup d'oil ravissant de tableaux nouveaux pour moi qui se renouvelaient sans cesse, et dont le charme s'accroissait par la diversité et la vivacité des teintes de lumière qui animaient les jolis bosquets répandus le long du rivage.

On débarqua à peu de distance de San-Lourenzo, et l'ou se mit à gravir des collines d'une élévation médiocre par un sentier qu'ombrageaient des haies touffues de végétaux élégans; lcs lantana, avec leurs fleurs de couleur de feu, ronge foncé ou rose; les héliconia, et d'autres arbustes d'un aspect également gracieux, forment ici des taillis épais. Au sommet de la colline, les maisons des Indiens sont éparses au milieu des bosquets d'orangers, de bananiers, et d'autres arbres chargés de fruits exquis. C'est ici qu'un peintre de paysages aurait l'occasion de perfectionner son pinceau, par la vue de la riche végétation des tropiques et de tableaux champêtres d'une nature sublime. Les habitans étaient occupés dans leurs huttes à fabriquer de 
la poterie avec une argile d'un gris foncé, qui rougit quand elle a passé au feu : ils étaient assis à terre. Ils font de grands vaisseaux avec leurs mains seules, sans employer la roue, et unissent la surface au moyen d'une petite coquille qu'ils humectent avec la bouche. Les hommes travaillent au service du roi sur les vaisseaux. Le visage de la plupart de ces Indiens portait encore les traits distinctifs de leur race; d'autres, au contraire, semblaient offrir une origine déjà mélangée. Les caractères distinctifs de la race brésilienne, que j'observai dans ce lieu pour la première fois, et que j'ai ensuite constamment retrouvés, sont une taille moyenne, souvent médiocre; le corps bien proportionné, ramassé et musculeux chez les hommes; la peau rougeâtre ou d'un brun jaunâtre, les cheveux durs, longs, épais, lisses, d'un noir foncé; la face large, assez osseuse; les yeux souvent obliques, et cependant le visage bien fait; les traits forts, les lèvres généralement épaisses; les mains et les pieds petits et d'une forme délicate; la barbe généralement peu fournie et dure.

Le petit nombre d'Indiens qui demeurent en ce lieu est le reste de l'ancienne et nombreuse 
population de ce canton : ce n'était pourtant pas, à proprement parler, dans ce lieu qu'ils vivaient. Dans l'origine, Rio et les environs étaient habités par la tribu belliqueuse des $\mathrm{Ta}$ moyos. Ceux-ci, chassés en partie par les Toupinimbas, nommés Toupinambas par les Portugais, se réunirent ensuite avec ces Indiens contre les derniers, el firent conjointement alliance avec les Français; mais ces Européens ayant été expulsés en 1567 par les Portugais, les indigènes qui avaient pris leur parti furent en partie exlerminés, en partie repoussés dans les forêts. S'il faut en croire une tradition peu vraisemblable, ces Toupinambas furent forcés de reculer à travers les forêts jusque sur les bords du fleuve des Amazones, où ils se sont établis. Toutefois, il est certain que l'on trouve un reste de cette tribu dans une petite île située au confluent de ce grand fleuve et du Madeira, et où l'on voit la bourgade de Toupinambara, qui a ensuite donné naissance à celle de Topayos : on peut juger par là de l'extension immense de cette peuplade (1). Le Français Jean.

(1) Suivant le P. d'Acunha, cité par la Condamine, pag. 140 de son Voyage de la rivière des Amazones, les tri- 
de Lery et l'Allemand Hans Staden, nous ont donné dans leurs relations intéressantes un tableau extrêmement fidèle de l'état, des mœurs et des usages des Toupinambas; elles sont d'autant plusinstructives, qu'elles peignent en même temps toutes les tribus des Indiens civilisés qui vivent le long des côtes, et que les Portugais nomment Indios mansos, Indiens apprivoisés. M. Southey, dans son History of Brazil, livre rempli de bons renseignemens, et M. Beauchamp, dans son Histoire du Brésil, ouvrage romanesque, ont mis ces sources à contribution. Vasconcellos, dans ses Noticias curiosas da Brasil (1), divise en deux classes toutes les tribus indigènes du Brésil oriental, les civili-

bus des Toupinambas et des autres Indiens des côtes qui ont de l'affinité avec eux , s'étendaient dans tout le Brésil ; c'est ce que prouvent les noms tirés de leur langue, que l'on trouve sur toute la côte orientale, le long du fleuve des Amazones, et même dans le Paraguay, où Azara leur applique la dénomination de Guaranys. (Voyage dans l'Amérique méridionale, tom. II, pag. 52.)

Les mots de la langue guarany que cite ce voyageur, offrent plusieurs différences avec la lingoa geral, mais en même temps plusieurs points de ressemblance, de sorte que ces deux peuples paraissent avoir entre eux beaucoup d'affinité.

(1) Noticias antecedentes, curiosas, e necessarias, das. 
sées ou apprivoisées, Inclios mansos, et les hordes sauvages, Tapuyas. Les premiers, lorsque les Européens découvrirent ce pays, n'habitaient que les côtes maritimes; ils étaient partagés en tribus nombreuses, qui ne différaient pas beaucoup entre elles par la langue, les mours et les usages. Toutes nourrissaient leurs prisonniers de guerre, les tuaient un jour de fète, avec le tacapé ou ivera pemmé, massue ornée de plumes, et ensuite les mangeaient. On cite parmi ces tribus les Tamoyos, les Toupinambas, les Toupinaquins, les Tobayaras, les Toupis, les Toupigoaes, les Toumiminos, les Amoïgpyras, les Araboyares, les Rasiguaras, les Potygoarès, les Carisos, etc. Comme leur langue se parlait tout le long de la côte, on la nommait lingoa geral ou matriz. Les jésuites, et entre autres José de Anchieta, nous en ont donné une grammaire très-complète (1). Quoique tous ces Indiens soient aujourd'hui civilisés et parlent portugais, ils comprennent cependant quelques mots de cette langue, et plusieurs vieillards la

cousas do Brasil. Cet ourrage se trouve dans sa Chronica da companhia de Jcsu do Estado de Brasil, etc.

(1) Artè da Lingoa brasilica. Lisboa, etc. 
possèdent assez complètement, mais chaque jour elle se perd davantage.

C'est de cette langue que viennent tous les noms d'animaux, de plantes, de rivières, que l'on voit dans les relations de voyages au Brésil. Comme elle était parlée depuis Saint-Paul jusqu'à Para, on y trouve tous les noms, notamment ceux des animaux, dont les auteurs ont fait usage, surtout Marcgraf dans son Histoire naturelle du Brésil. Toutefois l'adoption de ces dénominations provinciales dans les ouvrages systématiques a causé assez souvent des erreurs fâcheuses; car, quoique ces noms soient en général compris dans une vasie étendue le long de la côte, il s'y rencontre cependant de grandes modifications, comme on le verra dans la suite de mon récit. Voici quelques exemples de mots et de noms de celte langue : Jauarété (Felis onca); Tamandua (Myrmecophaga); Pécari (Sus); Tapiirété( Tapirus americanus); Cuia (1) (Gourde); Tapyya (Peuple barbare ou ennemi): on en a fait ensuite Tapouyas, $\mathrm{Pa}-$

(1) Les cuias sont des portions de l'écorce d'une certaine espèce de gourde qui, lorsqu'elle est vidée et netloyée, fournit des assiettes et des écuelles très-légères pour manger et pour boire. Si la gourde creusée est entière et a la forme 
nacoum (Corbeille allongée); Tinga (Blanc); Miri (Petit); Uassu ou (Grand). Les Portugais ont adopté et conservé les noms indiens des végétaux comestibles du pays, et des mets que l'on en prépare. Par exemple ils mangent le $M$ ingant des anciennes tribus.

Les noms d'animaux cités par Azara dans son IIistoire naturelle du Paraguay, prouvent que cette langue était extrêmemeut étendue dans le Brésil et dans les pays voisins; ils sont tirés de la langue des Guaranys, et en partie les mêmes que ceux de la lingoa geral.

La première classe d'Indiens, d'après la division de Vasconcellos, ayant changé entièrement de manière de vivre, a nécessairement perdu son caractère original. Il en est autrement de la seconde, les Tapouyas : ceux-ci sont en-. core dans leur état primitif. Habitant l'intérieur des grandes forêts qui bordent les côtes, ce séjour dérobait ces sauvages aux regards et à l'influence des Européens qui arrivaient dans leur pays; ils vivaient plus sûrement et plus

d'une bouteille, on la nomme caboça. Cet usage et le mot de cuia dérivent, ainsi qu'or l'a dit plus haut, de la lingoa geral : l'un et l'autre ont été adoptés au Brésil. 
tranquillement que leurs frères qui demeuraient près de la mer, avec lesquels, de même qu'avec les Européens, ils étaient constamment en guerre. Ils sont partagés en plusieurs tribus, et ce qui est très-remarquable, toules ces petites hordes parlent des langues absolument différentes. Une seule tribu de Tapouyas, tribu très-farouche, les Ouetacas (1), ou Goaytacasès, comme les nomment les Portugais, habitait sur la côte orientale parmi les peuplades de la lingoa geral, mais elle parlait un idiome absolument différent du leur, vivait en état d'hostilité continuelle avec elles, et en était redoutée de même que des Européens. Enfin les jésuites, qui s'entendaient si bien à civiliser ces hordes sauvages, parvinrent, par la patience, la douceur et la persévérance, à dompter aussi le caractère intraitable de cette tribu.

Quand Mendo de Sa fonda San-Sebastiam ( Rio-de-Jaueiro ), en 1567 , il établit le village de San-Lourenzo pour les Indiens qui s'étaient distingués par leur bravoure dans les combats contre les Français et leurs alliés les Toupinambas, et avaient contribué à les chasser; il

(1) Lery, pag. 50 . 
les plaça sous la direction de Martim Afonzo. Les jésuites y ont ensuite introduit des Goaytacasés nouvellement convertis, pour peupler de nouveau ce lieu. Ainsi, les Indiens qui l'habitent aujourd'hui descendent de cette tribu.

Pietournons aux demeures paisibles de SanLourenzo. Un treillage fait avec des perches, et dont les intervalles sont remplis d'argile, forme les murs des huttes, dont le toit est couvert de feuilles de cocotiers. Les meubles sont trèssimples. Des nattes de roseaux (esteiras), posées sur des morceaux de bois, tiennent la place de lits; quelquefois on voit des hamacs (rédé) faits avec des cordes de coton entrelacées, qui autrefois étaient en usage chez ces peuples. Ces deux manières de se coucher ont aussi été adoptées dans tout le Brésil par les Portugais de la classe inférieure. Les talha, grands vases de terre où l'eau se conserve fraîche, se trouvent chez ces Indiens comme dans tout le pays; ils sont faits d'une argile à travers laquelle l'eau filtre lentement, de sorte qu'elle s'évapore à la surface intérieure du vase, et se rafraîchit dans l'intérieur. Une écale de coco, pourvue d'un manche en bois, sert à puiser l'eau dans le vase. Quelques pots de terre pour la cuisine (panellas), des 
cuias ou des gourdes, dont on se sert comme d'assiettes, différentes bagatelles pour l'habillement ou la parure, quelquefois le fusil ou l'arc et les flèches p our la chasse, composent le reste de l'ameublement.

Ces Indiens viventen partie du manioc (mandioca) et du maïs (milho) qu'ils cultivent. Je ne décrirai pas la préparation de ces deux substances alimentaires, parce que Koster et Mawe (1) ont donné à ce sujet des détails suf-

(1) Travels in Brazil. - Lond on, 1816, I vol. in-4ㅁ avec figures.

Voyages dans la partie septentrionale du Brésil, depuis $\mathbf{1} 809$ jusqu'en 1815 , comprenant les provinces de Pernambuco (Fernambouc), Seara, Paraïba, Firaragnan; par Henri Koster, traduit de l'anglais par M. Jay. - Paris. Delaunay, $1818 ; 2$ vol. in $-8^{\circ}$ avec figures.

Travels in the interior of Brazil, particularly in the gold and diamond districts of the country. -London, 1812, I vol. in $-\dot{4}^{\circ}$ avec figures.

Voyages dans l'intérieur du Brésil, particulièrement dans les districts de l'or et du diamant, faits en 1809 et 1810 ; par Jean Mawe; traduits de l'anglais par J. B. B. Eyries. - Paris, Gide fils, 1816; 2 vol. in- $8^{\circ}$ avec figures.

Ces deux ouvrages se trouvent aussi chez Arthus Bertrand, rue Hantefeuille, $n^{\circ} 25$. 
fisans (1). Indépendamment de ces deux végétaux, qui font proprement la base de la nourriture de tous les peuples du Brésil, on cultive, dans les pimenteiras qui entourent les maisons, diverses plantes qui servent à l'assaisonnement des mets : ce sont différentes sortes de piment, entre autres la malaguéta, dont le fruit est rouge et a longé, et le pimenta di cheiro, qui est rond et de couleur rouge ou jaune. On y voit aussi des touffes de ricin ( baga) (2), aux feuilles anguleuses, et des graines duquel on exprime de l'huile pour les besoins du ménage. M. Sellow, notre botaniste, trouva près des habitations des Indiens une espèce de lepidium sauvage, dont le goût ressemble à celui du cresson alénois d'Europe: les Indiens disent que c'est un remède assuré contre les maux de poitrine. Pendant que M. Sellow moissonnait dans son champ, j'achetai des Indiens de jolis oiseaux qu'ils tenaient dans des cages de bois, entre autres le tangara violet et orange ( tanagra vio-

(1) Koster, pag. 369 ( tom. II, pag. 265 de la traduction). - Mawe, pag. 73 (tom. I, pag. 124 de la Traduction).

(2) Nommé carrapato à Peruambouc, suivant Koster, pag. 376 ( tom. II, pag. $28_{7}$ ). 


\section{AU BRÉSIL.}

lacea), nommé gatturama dans cette partie du Brésil.

Après ce court, mais intéressant séjour à SanLourenzo, nous allàmes débarquer près de la maison de campagne de M. Chamberlain, située dans une petite anse entourée de rochers. Elle est au milieu de bosquets charmans d'orangers et de cacaoyers, dont le fruit croit immédiatement sur le tronc; des manguiers qui surpassent en hauteur nos plus grands chênes ombragent une source fraîche qui sort d'une gorge étroite, et en font un lieu de repos délicieux. Sur les bords de ce ruisseau, nous admirions la diversité de formes des fruits sauvages: parmi ces capsules, ces gousses, ces noix, le fruit du fromager (ceiba), qui a la grosseur et la figure des calebasses, est le plus commun. C'est sur cet arbre, dont le tronc est très-épineux et le branchage touffu, que vit, selon l'observation de M. Selluw, le brillant charanson impérial (curculio imperialis), un des plus beaux insectes du Brésil, et dont la métamorphose remarquable sera fidèlement décrite par ce voyageur iustruit. Sur les montagnes voisines s'élèvent, près de la côte, dés murailles de rochers extrêmement hautes, couvertes I. 
d'immenses cactus et d'agave fretida; à leurs pieds croissent des buissons dont la couleur sombre offre les effets les plus pittoresques. En revenant à hio, nous avons aussi visité l'armaçao das baleüas, ou le magasin de la pêche de la baleine. Ces cétacés sont très-nombreux le long de la côte du Brésil, mais actuellement on les poursuit avec trop d'ardeur. Jadis, comme on le voit par la relation de Lery, ils venaient jusque dans la baie de Rio-deJaneiro (1).

Quelque agréable qu'eût été pour moi un plus long séjour dans la capitale, il n'entrait cependant pas dans mon plan de m'y àrêter trop long-temps, puisque c'est dans les campagnes et les forêts, et non pas dans les villes, que la nature déploie ses richesses. Grâcés à l'appui du gouvernement, dont les intentions libérales se manifestent par la conduite bienveillante de $\mathbf{M}$. le comte de Barca, ministre qui encourage tout ce qui est bon et utile, je fus à même de pousser avec activité les prếparatifs de mon voyage. J'obtins un passeport et des lettres de recommandation adresséés aux

(r) Voyage. ...., pag. 42. 
capitaines-généraux des provinces, et conçues en termes si flatteurs pour moi, que je doute qu'on en ait donné de pareilles aux voyageurs qui m’ont précédé. Les autorités étaient invitées à nous porter aide et protection en toute occasion, à faire parvenir nos collections à Rio, et à nous procurer, quand nous le demanderions, des soldats, des guides, des porteurs, des bêtes de somme. Deux jeunes Allemands, MM. Sellow et Freyreiss, qui connaissaient les mœurs et la langue du pays, m'avaient promis de m'accompagner dans mon voyage le long de la côte orientale, jusqu'à Caravellas, et de m'aider dans mes recherches. Nous avions seize mulets, portant chacun deux coffres en bois couverts d'une peau crue de bœuf, qui les mettaient à l'abri de la pluie et de l'humidité. Nous avions pris à notre service dix hommes, les uns pour soigner-les mulets, les autres comme chasseurs; tous armés, et suffisamment pourvus de munitions et de tous les objets nécessaires pour recueillir les productions de la nature, objets dont $j$ 'avais inutilement apporté d'Europe vne partie; nous nous mîmes en route. 


\section{CHAPITRE III.}

Voyage de Rio-de-Janeiro au cap Frio.-Praya-Grande.-SanGonsalvez. - Lc Guajintibo. - La Serra-de-Inua. - Lac et Freguesia-de-Marica. - Gurapina. - Ponta-Negra. - Sagoarema. - Lagune de Ararama. - San Pedro dos Indios. - Le cap Frio.

Après avoir fait à Saint-Christophe, petit village dans le voisinage de Rio, les préparatifs nécessaires pour notre départ, nous embarquâmes nos mulets dans un grand bateau, ce qui ne fut pas une opération facile; car, indépendamment de l'entêtement de ces animaux, qui est connu, nous avions à vaincre les obstácles que nous présentait le peu de facilités que l'on trouve ici pour faire entrer les bêtes de somme dans les bateaux : il fallut finir par tenter de les y faire sauter, 'ce qui réussit. Ayant quitté Saint-Christophe le 4 août, je traversai la baie,' et je débarquai à minuit au village de Praya-Grande. Tout le monde y était plongé dans un profond sommeil. Des nègres dormaient en plein air, couchés sur le sable, autour d'un 
feu qui ne répandait qu'une faible chaleur; leurs corps n'étaient, couverts que d'une toile de coton mince, qui ne pouvait pas beaucoup les mettre à l'abri de la rosée très-abondante. A force de frapper, un aubergiste enveloppé dans son manteau et les yeux à moitié ouverts nous ouvrit sa porte. Il fallut passer toute la journée dans ce lieu, parce que notre tropa, nom que l'on donne à un certain nombre de bêtes de somme réunies, ne put, à cause du peu de profondeur de l'eau, être débarquée qu'à midi. Il fut encore nécessaire d'avoir recours aux coups, pour forcer ces animaux à sauter hors du bateau. Deux conducteurs expérimentés (tropeiros) Mariano et Félipe, tous deux natifs de San-Paulo, dont les habitans sont renommés pour leur habileté à manier les mulets, nous rendirent de grands services dans cette occasion.

Le 6, je quittai Praya-Grande, accompagné de plusieurs de mes amis qui voulaient être témoins de mon départ. J'espérais parcourir une distance considérable, mais je reconnus bientôt qu'il est plus embarrassant et plus pénible de voyager avec des mulets chargés, que de faire transporter comme en Europe son bagage 
sur une voiture. L'incommodité était d'autant plus grande pour nous, que ces animaux, achetés à la hâte, ne connaissaient pas encore leur selle et leur charge. Ici une courroie gênait; là, les coffres étaient mal arrangés. A peine étions-nous en route, qu'à notre grand chagrin et au divertissement inexprimable de tous les spectateurs, la plupart des mulets, en faisant les cabrioles les plus singulières, essayèrent de se débarrasser de leur fardeau. Dans ces voyages, on laisse marcher en liberté à la file les bêtes de somme, qui s'habituent bientôt les unes aux autres : les nôtres se mirent à courir de tous côtés dans les bois, et plusieurs réussirent à jeter leurs charges à terre. Nous fûmes obligés de courir à cheval de côté et d'autre, pour chercher nos coffres et nos paquets, et de les garder jusqu'à l'arrivée de nos tropeiros qui les replacèrent sur les mulets. Cette perte de temps nous empêcha d'avancer beaucoup.

Après deux heures de marche, nous atteignînes une jolie prairie unie, entourée de buissons de mimoses aux feuilles finement pennèes. Quoiqu'il y eût des maisons dans les environs, nous fîmes halte en ce lieu, pour nous accoutumer à coucher en plein air. Afin de pré- 
server notre bagage de l'humidité de la nuit, on le plaça en demi-cercle, et l'on étendit dans l'intélicur des peaux de bouf, qui nous servaient de lit. Au milieu de l'enceinte on alluma un grand feu. D'épaisses couvertures de laine nous défendirent de la forte rosée de ce climat : nos porte-manteaux nous tenaient lieu d'oreillers. Notre souper frugal, qui consistait en riz et en viande, fut bientôt prêt; nous portions avec nous des plats, des cuillers et tous les autres ustensiles nécessaires. Les étoiles brillaient de cet éclat remarquable qu'elles ont entre les tropiques : notre repas en plein air fut assaisonné par la gaîté. Les planteurs voisins, qui passaient près de nous en se relirant chez eux, faisaient leurs commentaires sur cette singulière troupe de bohémiens (1). Comme nous pouvions être volés dans ces cantons habités, nous nous étions partagés en plusieurs troupes pour faire tour à tour la garde pendant la nuit. Mes chiens de chasse allemands me furent très-utiles en cette occasion; car au moindre

(1) On dil qu'il y a au Brésil des bohémiens ou zingaris: Koster en parle, pag. 599 ( 10 m. 1I, pag. 527), mais je n'ew ai pas vu. Koster les nomme ciganos. 
bruit qu'ils entendaient, ils couraient tout de suite en aboyant du côté d'où il venait. La nuit était superbe. Souvent nous portions avec plaisir nos regards vers le magnifique spectacle que le ciel nous offrait : le cabouré, petit hibou de couleur brune ferrugineuse, faisait entendre sa voix du milieu des buissons; des insectes luisans brillaient dans les flaques d'eau qui nous entouraient, et les grenouilles coassaient doucement. La matinée, claire et sereine, me procura pour la première fois une partie de chasse que je ne connaissais encore que par le tableau intéressant que Vaillant en a fait dans la relation de son Voyage en Afrique. Nos couvertures et notre bagage étaient pénétrés par la rosée, comme ils l'auraient été par la pluie, mais le soleil, dont la chaleur devint bientôt brûlante, ne tarda pasà tout sécher. Le déjeûner fini, chacun prit son fusil, et l'on se mit à parcourir les environs. Tous les buissons d'alentour étaient animés par une multitude d'oiseaux qui, à leur réveil, nous divertissaient agréablement par leur chant. Si l'on avançait d'un côté pour entendre un gazouillement singulier, on était attiré ailleurs par la beauté du plumage d'un autre oiseau. Je tuai dans les broussailles d'un marais 
voisin une jolie poule d'eau, plusieurs espèces de tangara dont le plumage était également fort beau, et un petit colibri charmant. La chaleur du soleil, qui commençait à être trop forte, me força à revenir au camp. Chaque chasseur montra les trésors qu'il rapportait : M. Freyreiss apportait, entre autres beaux oiseaux, le nectarinia cyanea (1), remarquable par sa magnifique couleur bleue.

Ensuite on chargea la tropa. Les mulets n'étant pas encore bien accoutumés à porter, il y eut des paquets jetés à bas; cependant tout alla graduellement mieux. Nous marchions au milieu de montagnes où nous admirions la beauté de la végétation. Des plantations de manioc, de canne à sucre, d'orangers, qui forment de petits bois autour des habitations, se succèdent alternativement avec des marais peu étendus. Des touffes épaisses de bananiers, des papayers et des cocotiers élancés, ornent les maisons isolées. De belles fleurs de couleurs variées parent les arbustes les plus humbles, entre autres l'érythrina, avec ses longs rameaux de fleurs d'un

(1) Le guit-guit. 
rouge éclatant, une espèce de bignonia avec de grandes fleurs d'un jaune tendre, à laquelle M. Sellow donna le nom spécifique de coriacea. Du milieu de ces buissons s'élevaient des cactus, des agave foetida, et des touffes d'un roseau en éventail. Le long des chemins croît le balisier aux fleurs d'un rouge brillaut, qui a quelquefois dix à douze pieds de haut; mais le buginvillæa brasiliensis, arbre un peu épineux, touffu, et remarquable par le bel aspect des nombreuses bractées d'un rose tendre qui couvrent ses fleurs, est de tous ces végétaux celui qui charme le plus les yeux d'un étranger.

Les habitans des environs, en vestes courtes faites d'étoffes légères, de grands chapeaux ronds et plats sur la tête, couraient à cheval de côté et d'autre, et nous regardaient avec surprise. Les cheyaux du Brésil sont ordinairement très-bons et vifs, de taille moyenne, et même plutôt petits, comme tous ceux de race espagnole; ils ont généralement une belle croupe bien unie, et la jambe jolie. Les selles sont à l'antique, massives, pesantes, garnies de bourrelets, revêtues de velours, et souvent brodées avec délicatesse; on y attache une paire d'étriers lourds, à vieille mode, en bronze ou 


\section{AU BRÉSIL.}

en fer, qui sont travaillés à jour: on en voit cependant qui ont la forme de petites boîtes ou de souliers en bois, et qui enveloppent le pied. Les Portugais vont en général beaucoup à cheval; l'on rencontre parmi eux d'excellens cavaliers. Ils aiment à aller l'amble, et attachent des morceaux de bois aux pieds de leurs chevaux pour les accoutumer à cette allure. Nous avons traversé le village de San-Gonzalvez, qui a une petite église. L'après-midi, nous sommes arrivés sur les bords du Guajintibo, et nous avons établi notre camp près d'une venda isolée (1).

Le Guajintibo est une petite rivière qui serpente dans un enfoncement à pentes douces et sablonneuses, à travers des bois touffus. Les prairies promettaient de bons pâturages à nos mulets, et les forêts étaient remplies d'oiseaux : voilà pourquoi nous avions choisi cet endroit pour y camper. Le lendemain, au point du jour, les chasseurs se séparèrent; je courus au bord de la rivière, qui était ombragée par de très-

(I) On appelle venda les maisons situées sur les grands chemins, ou même dans les villages, où l'on vend diverses denrées, surtout des vivres et des boissons. 
grands mimoses, famille d'arbres très-communs dans les forêts du Brésil comme dans toutes. celles des régions équatoriales. Bientôt j’aperçus les plus jolis oiseaux : le tijè (tanagra brasilia) et le coucou rouge brun à longue queue (cuculus cayanus), ainsi que d'autres belles. espèces, étalaient leurs couleurs rouges ardentes sous l'ombre épaisse qui couvrait la rivière. Je ne tardai pas à tuer un certain nombre de ces habitans de l'air, et j'eus occasion de connaître les incommodités de la chasse de ce pays : tous les buissons, notamment ceux de mimoses, sont garnis de petites épines et d'aiguillons, et les plantes grimpantes ou lianes (cipos) sont si étroitement entrelacées ensemble et autour des arbres, que l'on ne peut pénétrer dans ces solitudes qu'au moyen d'une large et forte serpe ( faccio ). Des bottes épaisses ou des souliers de chasse ne sont pas moins indispensables que cette arme. La petile espèce de moustiques est très-incommode pour les chasseurs, à l'ombre sur les bords du ruisseau. On les appelle maroúi ou murui (marouim). Cet insecte, quoique extrêmement petit, occasionne par sa piqûre une démangeaison très-vive. Des Anglais m'ont assuré que c'est le même qui porte dans leurs 
Antilles le nom de sandfly (1). Mais la nouveauté des objets qui nous entouraient, et surtout la beauté des oiseaux, nous dédommagèrent amplement de la gêne que ces insectes nous causèrent. Nous avons aussi trouvé de belles plantes, entre autres, à l'ombre des arbres, une sauge à fleurs rouges éclatantes, que M. Sellow nomma salvia splendens, et une carmantine justicia à fleurs roses.

Comme, malgré la grande chaleur, l'humidité produite par la rosée était encore trèsforte à l'ombre des buissons touffus, je gagnai une prairie découverte et plus sèche, parsemée de touffes de différens arbustes, surtout de lantana et d'asclepias curassavica aux fleurs orangées. Une multitude de colibris voltigeaient à l'entour, en suçant comme les abeilles les fleurs de ces végétaux. En revenant, j’abáttis plusieürs de ces jolis oiseaux, par' exemple l'oiseau mouche à gorge bleue et au bec d'un rouge de corail (trochilus saphirinus), qui est trèscommun dans cet endroit; jobservai aussi le

(1) Oldendorp. Histoire de la mission des frères évangéliques aux îles Caraïbes. - Barby, 1777, 2 vol. in-8* ( en allemand), tom. I, pag. 123. 
charmant oiseau-mouche hupecol, avec son aigrette d'un rouge de rouille (trochilus ornatus ). Nous ne vîmes de quadrupède nouveau, dans cette chasse, qu'un petit tapiti (lepus bresilicanus ), qui fut tué par Francisco, jeune Indien coropo attaché à M. Freyress. Cette espèce de lièvre est répandue dans toute l'Amérique méridionale; elle ressemble à nos lapins sauvages : sa chair est de bon goût. Ce Francisco était notre plus habile chasseur, il tirait avec une adresse égale le fusil et l'arc; il possédait de plus une dextérité merveilleuse pour pénétrer dans les buissons les plus épineux et les plus impraticables. On le récompensait en lui donnant le corps des oiseaux dépouillés; il les faisait rôtir à une petite broche de bois, et les mangeait de bon appétit.

En quittant les bords du Guajintibo, nous sommes entrés dans une forêt épaisse, entremêlée de touffes de rhexia hauts de dix à douze pieds, de très-grands arbres et de savanes : ce canton bas était entouré de tous côtés de montagnes bleuâtres, couvertes de forêts antiques et de cocotiers. On voyait voler et sautiller dans ces pâturages, au milieu des bestiaux,' des troupes d'anis (crotophaga ani), et des ben- 


\section{AU BRÉSIL.}

tavi (lanius pitangua), qui doivent leur nom à ce mot, qu'ils répètent sans cesse, ainsi que celui de tictivi. Dans le voisinage d'une fazenda (1), M. Sellow trouva une nouvelle espèce de balisier à fleurs jaunes. Unpeu plus loin, nous sommes arrivés à un endroit environné de collines boisées, et couvert de touffes d'arbrisseaux qui ombrageaient des mares limpides : une foule d'oiseaux animaient cet endroit. Le moteux, au plumage d'un roux clair et à la queue pointue (2), construisait son nid au milieu des roseaux. Plus loin, nous fûmes ravis de l'aspect d'une antique forêt. Des mimoses, des coulequins (cecropia), des cocos, et d'autres arbres à la tige blanche et svelte, qui s'élançaient vers le ciel, étaient entrelacés d'une si grande quantité de lianes, que l'ensemble semblait for-: mer un tissu impénétrable. Autour de la cime sombre des grands arbres brillaient de l'éclat de la flamme les touffes de fleurs du Bignonia bellas, plante grimpante, nommée ainsi par M. Sellow en honneur de la marquise de Bel-

(1) Les Portugais nomment ainsi un bien rural entouré de bâtimens d'exploitation et de plantations.

(2) L'inondé. Azara, Voyages, tom. III, pag. 460. 
las, qui a découvert ce beau végétal; d'autres fleurs non moins belles accompagnaient celle-là; au-dessous voltigeaient une multitude de colibris et de papillons. Cette forêt n'offrait cependant qu'une faible image des antiques solitudes que j'aie vues plus tard dans la Serra-de-Inua.

Nous avons rencontré des espaces où l'on avait brûlé les arbres pour cultiver le terrain, ou, comme on dit ici, pour établir un roçado ou un roça. Les troncs immenses, à demi-brûlés, étaient debouts comme les colonnes d'un portique, et encore entremêlés de cordons desséchés de plantes grimpantes. Tout à coup nos oreilles furent frappées du bruit insupportable que font, en roulant, les charrettes dont on se sert dans les fazendas. L'industrie est encore si arriérée dans ce pays, que ces voitures n'ont pas de roues comme celles d'Europe : les roues consistent en deux lourds et massifs disques de bois, percés de deux petites ouvertures par lesquelles passe l'essieu. Le frottement violent qu'elles produisent en tournant autour de cet axe occasionne un bruit extrêmement désagréable, et qui s'entend au loin. On serait tenté de croire que cette singulière musique est devenue pour les planteurs une espèce de besoin, 
tant la force de l'habitude est grande. En Portugal même, cette voiture détestable est encore en usage. Les boufs qui traînaient les charrettes dont nons avions entendu l'approche, étaient de stature colossale et d'une très-belle race : ils ont les cornes très-longues et très-fortes. Un nègre, un long bâton à la main, les conduisait.

Nous approchions de la chaîne de montagnes nommée la Serra-de-Inua. Cette solitude surpassa toutes les idées que mon'imagination s'était faites des scènes de la nature les plus grandes, les plus ravissantes. Nous sommes entrés dans un terrain bas où l'eau coulait en abondance sur un sol rocailleux, ou bien formait des mares tranquilles. Un peu plus loin s'élevait une forêt d'une beauté sans pareille. Les palmiers et tous les magnifiques végétaux arborescens de ce beau pays étaient si entrelacés de plantes grimpantes, que l'on ne pouvait pénétrer à travers l'épaisseur de ce mur de verdure. Partout, même sur les tiges les plus minces, croissent une quantité de plantes grasses: des vanilles, des cactus, des bromelias, etc., la plupart ornés de fleurs si remarquables, que quiconque les voit pour la première fois ne peut revenir de son enchantement. Je me contenterai

I. 
de citer une espèce de bromelia dont le calice est d'un rouge de corail, avec la pointe des folioles d'un beau bleu violet, et l'héliconia, plante musacée qui ressemble à la strelitzia, avec des spathes d'un rouge foncé et des fleurs blanches. Sous ces ombrages épais, près de ces sources fraîches, le voyageur échauffé ressent un froid subit. Cette température piquante nous plaisait à nous autres habitans du nord; elle ajoutait au ravissement dans lequel nous plongeait la sublimité des tableaux que nous présentait sans cesse la nature dans ce désert affreux. $\mathbf{A}$ tout instant chacun de nous trouvait quelque chose de nouveau qui fixait son attention; il l'annonçait par des cris de joie à ses compagnons. Les rochers mêmes sont ici couverts de plantes grasses et de cryptogames, dont les formes varient à l'infini. On voit entre autres de magnifiques fougères, qui, semblables à des guirlandes de plumes, sont suspendues aux arbres de la manière la plus pittoresque. Un champignon d'un rouge foncé orne les troncs desséchés; un lichen d'un rouge de carmin couvre de ses belles taches rondes l'écorce des arbres vigoureux (1).

(1) M. Mawe a apporté ce beau lichen en Angleterre, où 
Les arbres des forêts gigantesques du Brésil sont si hauts, que nos fusils ne portaient pas jusqu'à leurs cimes; aussi nous arriva-t-il plus d'une fois de tirer sur de très-beaux oiseaux que nous ne pûmes pas ramasser. En revanche nous pouvions cueillir de superbes fleurs de plantes grasses; mais, par malheur, il fallait bientôt les jeter, parce qu'elles se flétrissent aisément et ne se conservent pas du tout dans les herbiers. Quelle ample récolte un Redouté eût faite ici pour enrichir un magnifique recueil de plantes rares! L'abondance et la force de la végétation de l'Amérique méridionale est une conséquence de la grande humidité répandue partout daus ces forêts. L'Amérique a sous ce rapport un avantage immense sur les autres régions équatoriales. M. de Humbold en a déjà fait la remarque : « Le peu de largeur de ce ) continent, découpé de mille manières, dit ce ) savant voyageur, sa prolongation vers les " pôles glacés; l'Océan, dont la surface est ba) layée par les vents alisés, l'aplatissement de

l'on a déjà fait des expériences pour tirer parti de sa substance colorante. Voyage de IMawe, pag. 271, tom. II, pag. 132. 
) la côte orientale, des courans d'eau très-froide

) qui se portent depuis le détroit de Magellan

») jusqu'au Pérou, de nombreuses chaînes de ) montagnes remplies de sources, et dont les ») sommets, couverts de neige, s'élèvent bien ) au-dessus de la région des nuages; l'abon) dance des fleuves immenses, qui, après des ») détours multipliés, vont toujours chercher ») les côtes les plus lointaines; des déser's non 》) sablonneux, et par conséquent moins suscep》) tibles de s'imprégner de chaleur; des forêts » impénétrables qui couvrent les plaines de ) l'équateur remplies de rivières, et qui, dans ») les parties du pays les plus éloignées de ) l'Océan et des montagnes, donnent nais》) sance à des masses énormes d'eau qu'elles ont 》) aspirées, ou qui se forment par l'acte de la 》) végétation : toutes ces causes produisent, ») dans les parties basses de l'Amérique, un ») climat qui contraste singulièrement par sa ) fraîcheur et son humidité avec celui de „) l'Afrique. C'est à elles seules qu'il faut attri) buer cette végétation si forte, si abondante, ») si riche en sucs, et ce feuillage si épais, qui 
) forment les caractères particuliers du nou) veau continent (1). 》

Quand nous eûmes atteint les hauteurs de la Serra-de-Inua, nous aperçûmes des perroquets voler par couples au-dessus de la forêt, en poussant de grands cris : c'était le perroquet à front rouge, nommé camutanga dans ce canton, et chauc dans d'autres, à cause de son cri(2). Dans la suite il a souvent servi à nos repas. Nous sommes ensuite arrivés dans un pays agréable et uni, et nous avons passéla nuit à la Fazendade-Inua. Le propriétaire était un capitaine qui ne fut pas peu surpris de notre visite. Il élevait dans sa ferme beaucoup de bétail et de volaille. Ses boufs étaient d'une beauté et d'une grosseur étonnantes, et ses cochons très gras; on en a ici une race petite, noire, à dos abaissé , à boutoir allongé, à oreilles pendantes. La basse-

(1) Alexander von Humboldt; Ansichten der Natur, pag. 14, Tableaux de la Nature, traduits de l'allemand par J. B. B. Eyries. - Paris, 1808,2 vol. in-12 (tom. I , page 22 ).

(2) Perroquet du fiêne, de le Vaillant. 
cour renfermait encore des poules, des dindons, des pintades, dont quelques-unes à plumes blanches, des oies d'Europe, des canards musqués, qui quelquefois s'envolent, puis reviennent. On sait que cette espèce est indigène du Brésil.

La Serra-de-Inua est un bras de la grande chaîne de montagnes qui courent parallèlement à la côłe; il s'en détache pour se diriger vers la mer. Ce chaînon est couvert de forêts antiques où croissent différens arbres utiles, et où le chasseur trouve un riche butin. Nous avons passé un jour dans cet endroit, uniquement à chasser. Nous eûmes une quantité de jolis oiseaux, mais M. Freyreisset tira inutilement sur le marikina (simia rosalia, $L$.), petit singe à pelage roux doré. On l'appelle ici sahui rouge (sahui vermelho). Il vit dans les forêts les plusépaisses, et ne se trouve que dans le voisinage de Rio-deJaneiro et du cap Frio; du moins je ne l'ai pas rencontré plus au nord. Les perroquets sont extrêmement nombreux dans ces montagnes boisées, surtout quelques espèces à queue longue et cunéiforme, que l'on appelle ici maracana, et qui comprennent entre autres la psittanus macavuanna, et le P.guianensis; ils 
fondent par troupes sur les champs de maïs voisins des bois.

En quittant Inua nous sommes entrés dans une forêt d'arbres gigantesques entortillés de lianes, où des objets que nous n'avions pas encore vus se sont présentés à nos regards. Nous avons d'abord aperçu à terre la grande araignée velue, aranha carangucjeira (aranea avicularia, L.), dont la morsure occasionne, dit-on, une enflure douloureuse. Ainsi que M. Langsdorfl'a dit, elle vit principalement dans la terre. Indépendamment de ce singulier insecte, je trouvai une qnantité de gros et larges crapauds; ils n'étaient cependant pas si nombreux que dans la Serra, dont nous sortions, et où, aux approches de la soirée, la terre était absolument couverte de ces hideux reptiles, parmi lesquels j'observai une espèce qui probablement n'a pas encore été décrite, le bufo bimaculatus, reconnaissable à deux grandes plaques de couleur foncée sur le dos. Du haut des trones des mimosas pendaient des tiges de tillandsia d'une longueur prodigieuse. A la clarté du soleil on distinguait, à la pointe d'une plante desséchée, le procnias nudicollis, oiseau d'une blancheur de lait, et connu par'sa voix 
retentissante, qui ressemble parfaitement an bruit d'un marteau sur une enclume, ou au son d'une cloche félée. Cet oiseau, qui appartient au genre nommé procnias par Illiger, porte tout le long de la côte orientale le nom d'araponga; il ressemble beaucoup par son plumage au cotinga guirapanga ( ampelis caruncula$t a, L$.$) , mais il en diffère par des caractères$ essentiels; sa gorge nue et verte, le manque de caroncule charnue sur le front, l'en distinguent suffisamment.

La forêt ombragée dans laquelle nous voyagions était extrêmement agréable à parcourir ; des troupes de perroquets volaient de côté et d'autre en criant; on remarquait parmi les plus nombreux la jolie petite perruche à queue cunéiforme, que l'on nomme ici tiriba. Je tuai un écureuil (sciurus aestuans), le seul de cette espèce que j’aie rencontré dans mon voyage : il se distingue par son pelage mêlé de gris brunâtre et de jaune. Des trains de bêtes de somme. passèrent près de nous; leurs conducteurs n'étaient pas peu surpris des coups de fusil qu'ils entendaient tirer de chaque côté de la route, par nos chasseurs répandus dans toutes les directions. 
Après avoir traversé des plantations, dès forêts brûlées, des plaines marécageuses, et des prairies entourées de montagnes rocailleuses, couvertes de bois et très-pittoresques, nous sommes arrivés dans des prairies où les aigrettesblanches, le vanneau d'Amérique (vanellus cayennensis), les jacanas, nommés ici piasocca, et les pluviers, se promenaient par troupes. Les bestiaux paissaient dans ces pâturages, le loriot violet (oriolus violaceus) courait de tous côtés. Nos mulets de selle étaient déjà si bien dressés, que je pus tirer sur ces oiseaux sans descendre. Je tuai plusieurs loriots d'un coup. L'ani (crotophaga ani, L.)n'était pas moins commun que ce loriot brillant, dans les haies des fazendas et dans les prairies, à peu près comme les étourneaux dans plusieurs pays d'Europe; ils étaient en outre si peu farouches, que je pouvais m'en approcher de très-près sur ma monture.

Le soir, nous sommes entrés dans le village de Marica, sur le lac du même nom. Cette paroisse, (Freguesia) renferme à peu près huit cents âmes. Les habitans d'une maison un peu écartée, à laquelle nous fìmes halte, fermèrent soigneusement leur porte. Tous les voisins se rassemblèrent aussitôt pour nous regarder; 
mais à peine eûmes-nous commencé à dépouiller et à préparer les animaux que nous avions tués dans la journée, que jeunes et vieux se mirent à secouer la tête et à rire tout haut de la folie des étrangers. Nos fusils à deux coups, objets absolument nouveaux pour eux, les intéressaient beaucoup plus que nos personnes. Le lac Marica, sur les bords duquel nous nous sommes arrêtés un jour pour connaître ses environs sablonneux, a six heures de marche de circuit; ses rives sont basses et marécageuses; il est très-poissonneux. On y prit en ma présence une grande quantité de silures d'une petite espèce : ce genre paraît être riche en espèces dans les eaux intérieures de la côte orientale du Brésil. Je trouvai, sur les bords de ce lac, quelques moules qui étaient toutes d'une espèce trèsconnue, et dans les marais voisins, une bécasse dont je parlerai plus amplement ailleurs. On voyait sur les bords du lac une mouette qui ressemblait beaucoup à la mouette rieuse : elle avait la tête d'un gris cendré, le bec et les pieds rouges; une belle espèce d'hirondelle de mer; un pluvier, etc. Les ouroubous planaient en l'air au-dessus des buissons et des marais. Je tuai pour la première fois un acabiray (vultur 
aura, L. ), que, jusqu’à présent, Azara seul a distingué avec exactitude (1). Au premier coup d'oeil, il ressemble beaucoup à l'ouroubou à tête grise, mais en l'observant avec attention, même lorsqu'il vole très-haut, on s'aperçoit qu'il en diffère. Ces vautours sont un bienfait de la nature dans les pays chauds, car ils nettoient la terre de tous les débris d'animaux qui rempliraient l'atmosphère d'émanations fétides. Leur odorat est si fin, que dans un champ où l'on n'en apercevait aucun, pas même dans le lointain, on les voit arriver en troupes aussitôt qu'un animal est mort; c'est pourquoi on ne leur fait jamais la chasse, et ils sont également. nombreux dans les cantons ouverts et dans les forêts.

Les terres voisines du lac étant marécageuses et sablonneuses, ne paraissent pas très-fertiles.

(I) Les meilleures figures de ces deux vautours, quoiqu'elles offrent quelques inexactitudes, se trouvent dans l'Histoire naturelle des Oiseaux de l'Amérique septentrionale, par Vieillot ( Tom. I, pl. 2 et 2 bis). Celle-ci est la plus correcte, quoique la couleur de la tête ne soit pas fidèlement rendue. Le vultur uruba de l'auteur n'a pas, du moins au Brésil, la tête et le cou rouges : ces deux parties sont gris cendré. 
Tous les endroits secs sont des pelouses dont l'herbe est courte et où le bétail pâture, ou bien des montagnes couvertes de forêts et de rochers. Il m'a semblé que, dans ce lieu, l'on élevait beaucoup de chevaux, mais ils sont mauvais, et en général de peu de valeur. Nous avons aussi vu des chèvres : il y en avait dans le village de Marica, qui avaient le poil trèscourt, brillant, d'un rouge doré, et mélangé de taches noires. A peu de distance du lac, on arrive, par une route sablonneuse et à travers des buissons, ̀̀ Villa-de-Santa-Maria-de-Marica, chef-lieu de la Freguesia. C'est une petite ville qui consiste en maisons à un seul étage, bâties le long de rues régulières, mais non pavées. Les fenêtres ne sont fermées, comme dans tout le Brésil, que par des volets de bois. Dans le voisinage de cette petite ville on voit des plantations de manioc, de haricots et de maiis, quelques cafeyers, et beaucoup de cannes à sucre qui s'élèvent très-haut dans les terrains fertiles, mais qui, dans les terres sablonneuses, ne s'élèvent pas à plus de six palmes.

De jolis buissons qui changeaient à chaque instant jetaient de la variété sur notre route; les bignonias avec leurs belles fleurs s'entor- 
tillaient autour des bois; des fruits d'une forme singulière frappaient nos regards. Le botaniste remarque dans ces contrées que les plantes de la famille des légumineuses sont les plus nombreuses au Brésil. Malgré la quantité de fazendas qui se trouvent dans cette partie, le pays est pourtant désert; il forme une vallée large, renfermée entre des montagnes hautes et pittoresques, et qui est parsemée de monticules sur lesquels croissent de très-beaux arbres entourés de buissons; on observe sur les branches de leurs cimes de grosses masses d'un brun noirâtre : ce sont les nids d'un petit termite jaune nommé cupi ou cupim. Les fourmis et les autres insectes semblables sont extrêmement nuisibles aux plantations du Brésil. Ces animaux, généralement très-voraces, se trou. vent partout en si grand nombre, et offrent tant d'espèces diverses, qu'ils fourniraient seuls à un entomologiste une matière suffisante pour un ouvrage considérable. Ils diffèrent de grandeur : une des espèces les plus grosses a presque un pouce de longueur, et le corps d'une épaisseur disproportionnée; on la mange grillée dans plusieurs provinces, par exemple, dans celle de Minas-Geraës, où on la nomme Tand 
chara. Une autre espèce très-petite et de couleur rouge est extrêmement incommode et' malfaisante. Ces fourmis font aussi beaucoup de tort aux collections d'histoire naturelle; elles nous dévorèrent en peu de temps une quantité d'insẻctes, surtout de papillons. Souvent elles pénètrent en troupes nombreuses dans les maisons, où elles dévastent rapidement toutes les provisions, notamment les choses sucrées. Lion n'a d'autre moyen de les en écarter, que d'isoler les pieds de la table qui les portent en les plaçant dans des vases pleins d'eau, ou de les enduire de goudron; mais ces insectes surmontent fréquemment ce genre d'obstacles. Quelques espèces construisent en terre, sur des parois d'une chambre, de longues galeries couvertes avec de nombreux embranchemens qui leur servent à monter et à descendre. Dans les chemins au milieu des forêts, on aperçoit des troupes de grosses fourmis qui portent à leurs retraites des morceaux de feuilles vertes.

Une forêt dans laquelle nous entrâmes nous offrit de nouveau des scènes intéressantes. Le toucan (ramphastos dicolorus, L.), au bec colossal et à la gorge de couleur orange, qui forme un si beau contraste avec son plumage noir, 
excita pour la première fois l'impatience de nos chasseurs; mais leurs coups ne furent pas heureux, car ces oiseaux se tenaient si haut sur la cime des arbres, qu'il fut impossible de les atteindre. Bientôt nous marchâmes sur un fond de tourbe noirâtre, puis de nouveau sur de l'argile rouge. La forêt devenoit de plus en plus belle et majestueuse; elle formoit une solitude sombre, d'une verdure noirâtre, composée d'arbres superbes, tous vigoureux, et offrant des feuilles des contours les plus variés. L'Européen qui arrive des régions septentrionales n'a aucune idée de ces forêts; leur aspect le frappe d'étonnement. Il est impossible d'en donner une description qui réponde aux impressions que leur vue produit. Le cocotier nommé aïri assú dans la Lingoa gèral et brejeúba dans la province de Minas, est commun dans cette forêt; il croît à la hauteur de trente pieds; les sauvages en font des arcs. Son tronc est brun foncé, et couvert de longs piquans très-serrés, qui sont disposés en anneaux horizontaux. Ses feuilles sont longues et élégamment pinnées, comme dans toutes les espèces de cocotiers. Du point où elles sortent naît le pedoncule pendant, qui porte des fleurs jaunâtres, auxquelles succèdent des 
noix d'un brun noirâtre et luisant, très-dures, et de la grosseur d'un ouf de pigeon. On trouve aussi dans toutes ces forêts l'aïri mirim (1), autre palmier épineux qui ne s'élève jamais bien haut. Ces deux espèces ne sont pas encore citées dans les systèmes de botanique; cependant Arruda en parle (2). Autour de tous les troncs d'arbres s'entortillent des plantes grimpantes à tige ligneuse ou tendre, telles que des cactus, des agavés, des épidendrums, qui parent de leurs fleurs, diversement et richement colorées, les rameaux entrelacés. Partout où un tronc offre un trou ou une fente, on en voit sortir de grosses touffes d'arum, de caladium, de dracontium et d'autres plantes semblables, à grandes feuilles succulentes, cordiformes ou sagittées et d'un vert foncé, de sorte qu'il semble que plusieurs plantes croissent les unes au-dessus des autres, ou les unes à travers les autres. Parmi celles que je viens de citer on distinguait le plus fréquemment le dracontium pertusum, avec ses feuilles percées de la manière la plus singulière,

(1) Dans ce mot portugais et dans une infinité d'autres, l'm finale ne se fait pas sentir.

(2) Voyez l'appendice au Voyage de Koster. 


\section{AU BRÉSIL.}

un maranta à belles fleurs bleues attira aussi l'attention de nos botanistes.

Notre jeune Indien Francisco nous donna aujourd'hui une scène singulière. Quelqu'un de la compagnie crut voir un oiseau perché sur un grand arbre desséché et tira dessus : alors il s'apercut que ce qu'il avait pris pour un oiseau n'était qu'une excroissance de la branche. Francisco, doué comme tous ses compatriotes d'une vue perçante, avait du premier coup d'œil reconnu la méprise, mais il attendit tranquillement que l'autre eût tiré son coup de fusil, et alors il partit d'un éclat de rire si immodéré, qu'il resta un certain temps sans pouvoir se remettre. Les sens des Indiens sont si perfectionnés par l'exercice, qu'une bévue semblable à celle qui venait d'avoir lieu leur paraît extrêmement ridicule et pitoyable. Francisco nous divertissait souvent; il avait de la douceur et de la fidélité, mais aussi beaucoup d'amour propre et de vanité; il prétendait tonjours avoir tué le plus grand nombre d'oiseaux et les plus beaux. On ne pouvait pas le guérir de certaines singularités propres aux Indiens. Il n'allait jamais à la chasse a jeun comme les autres; il ne partait pas qu'il n'eût déjeuné, quand même ce repas se serait

I. 
fait attendre très-long-temps, et il aurait su très-mauvais gré à son maître, si celui-ci avait voulu le forcer à faire comme les autres chasseurs.

Nous avions le dessein d'arriver aujourd'hui à Ponta - Negra, mais nous nous égarâmes au milieu des chemins qui se croisaient dans l'épaisseur de la forêt. Cependant nous atteignîmes Gurapina, grande fazenda dont le propriétaire, M. l'Alferès da Cunha-Vieira, nous reçut de la manière la plus hospitalière. Cette fazenda contient une sucrerie. Koster et plusieurs autres voyageurs ont décrit suffisamment cette espéce d'usine et en ont donné des figures; je me bornerai donc à dire que la canne est placée entre trois rouleaux de bois posés verticalement et munis de dents qui s'engrènent les unes dans les autres; elle reparaît de l'autre côté aplatie comme une paille; le jus exprimé tombe dans une auge de bois placée au-dessous. Les rouleaux sont mis en mouvement au moyen d'un long levier, par des boufs, des mulets ou des chevaux. Après qu'on a fait bouillir le jus dans des chaudières, qu'il est purgé et qu’il s'est cristallisé, il est mis dans des formes semblables à celles que l'on emploie dans les raffineries d'Europe, 
le reste des procédés pour le rafiner est trop connu pour en parler.

M. da Cunha-Vieira nous a assuré qu'avec vingt nègres il fabrique anuuellement six cents arobes de sucre, chacune de trente-deux livres, par conséquent cent quatre-vingt-douze quintaux. Sil employait un plus grand nombre d'ouvriers, il pourrait préparer neuf cents à mille quintaux. On a d'abord cultivé dans ce canton la canne de Cayenne, mais quand on a connu celle de Taïti, on lui a donné la préférence, parce qu'elle est beaucoup plus productive. Notre hôte bierıveillant nous avait fait entrer dans un grand hangar, où toute notre troupe et notre bagage furent à couvert, et ò̀ nous pûmes commodément allumer plusieurs feux et faire notre cuisine. 11 nous rendit de fréquentes visites avec les autres habitans de la fazenda, et ne put, ainsi qu'eux, s'empècher de nous témoigner' son éionuement de uos occupations relatives à l'histoire naturelle. La pluie ayant commencé à tomber avec force, nous fìmes un long séjour dans ce lieu, et lorsque le temps s'éclaircit, les montagnes boisées qui environnaient la vallée plantée de cannes à sucre, nous offrirent une chasse abondante. Un jeune Portugais qui se 
nommait Francisco, de même que notre jeune Indien, se mit à notre service comme chasseur, et montra des talens rares pour ce métier. II était mince et leste, endurci à la fatigue, tirait très-bien, et joignait à ces qualités un bon caractère. Connaissant le pays et les animaux qui s'y trouvaient, il nous fournit une quantité d'objets intéressans, entre autres un marikina ( simia rosalia, L.) que nous n'avions pas encore pu nous procurer. L'araponga (procnicus nudicollis), dont j’ai parlé plus haut, était extrêmement commun dans toutes ces montagnes boisées; sa voix sonore l'annonçait partout. Francisco fut le premier qui tua ce bel oiseau pour notre collection. Les bons chasseurs brésiliens sont doués d'un haut degré d'adresse pour aller à la découverte dans les grandes forêts ; leur corps endurci et l'habitude de marcher toujours pieds nus leur rend cette besogne extraordinairement facile. Leur vêtement consiste en une chemise légère et des pantalons de toile de coton; ils portent souvent sur l'épaule une veste de drap, pour la mettre quand il pleut ou quand la fraîcheur de la nuit se fait sentir; ils se couvrent la tête d'un chàpeau de feutre ou de paille. Leur poire à poudre et leur gibecière 
sont suspendues à une courroie de cuir passée en bandoulière; la batterie de leur long fusil est ordinairement préservée de l'humidité par une peau d'animal.

La température de Gurapina était très-variable. Il fit si froid pendant quelques jours, que le thermomètre, à midi, tomba jusqu'à $13^{\circ}$ de Réaumur : dans l'intervalle, nous eûmes un temps assez chaud et agréable. Je m'enfonçais fréquemment dans cette solitùde montueuse, charmé du profond repos et du silence qui y régnaient, et qui n'étaient interrompus que par les cris de quelques troupes de perroquets : j’y aurais passé des journées entières. C'était dans des dispositions d'esprit semblables que nous passions le temps dans les environs de Gurapina, très-dispos et très-gais, et d'autant plus contens que nous avions des vivres frais en abondance. Ceux que le voyageur brésilien a la possibilité de porter avec lui sont la farine de manioc, que souvent on nomme simplement farinha; des haricots noirs (feijaio), du maïs (milho), de la viande salée sèche (carne seca ou do sertam ). (1). Au lieu de cette viande sèche, nous

(1) A Pernambouc, on la nomme carne de seara. Voyage. de Koster, pag. 123 et 130 , tom. I, pag. 210. 
nous procurions à la fazenda de bonne viande fraîche; en outre, le propriétaire nous approvisionnait d'une grande quantité d'oranges excellentes, d'eau-de-vie de sucre (agoa ardente de canna), de riz, de sucre, de farinha, de maïs, de coton, et il poussa le désintéressement au point de refuser toute espèce de paiement pour tant d'objets. Sa générosité nous obligea de partir de ce lieu plutôt que nous ne l'avions projeté, car ce canton, indépendamment de beaucoup d'autres avantages, nous offrait des jouissances aussi nombreuses qu'agréables, et une matière abondante à notre curiosité. Nous prînes donc congé de notre hôte, et nous nous mîmes en route pour Ponta-Negra.

Les chemins étaient souvent défoncés à un tel point, que nos bêtes de somme couraient le risque de s'y enfoncer avec leurs charges. Nous traversâmes à cheval des broussailles touffues, composées de haules graminées de la consistance des roseaux, de balisiers, de thexias et de palmiers nains. Sur quelques hauteurs nous vîmes des nègres qui, pour défricher le terrain, arrachaient les petits buissons avec, un fer en forme de faux attaché à une longue perche. En passant devant quelques fazendas, nous admi- 
râmes les haies épaisses d'orangers qui les environnaient. Nos gibecières et nos poches bien remplies d'oiseaux et de plusieurs sortes de graines mûres, nous arrivâmes enfin à la Lagoada-Ponta-Negra. Cette jolie lagune nourrit sur ses rives marécageuses couvertes de roseaux des troupes nombreuses de jacanas et de hérons blancs dont nos chasseurs tuèrent quelques-uns. Le plumage de ces oiseaux conserve toujours une propreté éclatante, même dans les endroits les plus bourbeux, grâce à leurs longs pieds. A peu de distance nous atteignîmes une venda isolée où les voyageurs ont coutume, dans la grande chaleur, de se rafraîchir avec de la limonade, ou, ce qui vaut mieux, avec du punch froid. Nous apprîmes en ce lieu que la nouvelle de notre venue prochaine nous avait précédés, et nous fîmes la désagréable expérience que l'hôte avait d'avance spéculé sur notre bourse. Sur une hauteur près de cette maison, nous fümes surpris du coup d'œil magnifique de la mer, de la lagune et du pays voisin de Rio-de-Janeiro qui s'étendait derrière nous. En avançant ensuite au milieu de halliers épais, nous trouvâmes un oiseau nouveau pour nous, le grand ani (crotophaga 
major, L. ), qui était fort commun. Son plumage est noir, à reflets verdâtres et violets. Nous entendions le bruit de la mer, et bientôt nous gravîmes des dunes d'où nous vîmes les vagues blanchissantes d'écume briser contre les montagnes de la côte couvertes de forêts. Au delà des monticules de sable blanc qui bordent la plage (praya) croissent des buissons touffus composés de toutes sortes d'arbres que les vents de mer et les tempêtes tiennent très-bas, et qui, par conséquent, ne s'élèvent graduellement qu'à mesure qu'ils s'éloignent du rivage.

Dans ces halliers hauts de vingt à trente pieds, au milieu desquels nous poursuivions notre route le long de la mer, croissaient de grands cactus : les bromélias, parés souvent de fleurs ma-' gnifiques, y sont très-nombreux. De petits lézards couraient sur les fevilles sèches au-dessous des arbres, tandis que le grand ani et le tijé (tanagra brasilia) an plumage rouge de sang animaient ces broussailles. Ce bel oiseau est très-commun dans le Brésil, surtout sur les côtes de la mer et sur les bords des rivières.

Vers le soir, nous nous trouvâmes entre la côte de la mer et un grand marais couvert de reseaux dans lequel des troupes d'oiseaux se 
reposaient. Les tijés yéétaient surtout nombreux; la grive à ventre roux (turdus rufiventris du musée de Berlin), que l'on nomme ici sabiah, se tenait sur le sommet des buissons, et faisait entendre sa voix agréable êt flûtée. Au crépuscule, les engoulevens vinrent voler autour de nos chevaux, de même qu'un grand papillon couleur bleu d'ardvise (papilio Idomenaeus, Fab.), dont nous aurions pu prendre plusieurs, si, dans ce moment, le filet qui nous était nécessaire ne nous avait pas manqué. Je trouvai une chauve-souris morte suspendue à une branche, elle avait sûrement expiré dans cette position : elle appartenait au genre phyllostoma, et ressemblait beaucoup à la chauve-souris première ou obscure et rayée d'Azara (1); je ne l'ai pas retrouvée durant tout le reste de mon voyage. Ayant voulu examiner la fleur d'un. petit palmier, nous trouvâmes fixé aux branches le nid de l'oiseau-mouche à tête bleue (trochilus pileatus ) (2), qui ressemble beaucoup

(1) Essai sur l'Histoire naturelle des quadrupèdes de la province du Paraguay, tom. II, pag 269 .

(2) Longueur : 4 pouces 8 lignes (mesure de France), 
au saphir-émeraude de Buffon (trochilus bicolor). Ce nid était aussi proprement revêtu de mousse que le sont ceux des chardonnerets et de plusieurs autres petits oiseaux d'Europe. On trouve dans tous les nids d'oiseaux-mouches deux œufs blancs de forme allongée, qui, chez quelques espèces, sont extraordinairement petits. A la nuit tombante, nous avançâmes entre quelques lagunes auprès desquelles brillaient des insectes luisans; des grenouilles faisaient entendre leur voix faible. Enfin, après une longue journée de marche, nous arrivâmes à une venda située sur la lagune de Sagroaréma, où nous trouvâmes nos gens et nos bêtes de somme, qui étaient venus plus vite par un autre chemin. Nous n'attendions que le moment de voir pendre la marmite, mais ce lieu était entièrement dépourvu de provisions. Nous envoyâmes nos gens en chercher; leur absence dura si longtemps que nous commençâmes à craindre qu'ils ne se fussent enfuis; il fallut en expédier d'autres à cheval après eux. Ils revinrent tous

corps d'un vert éclatant; le sommet de la tête, la queue tronquée, les plumes de l'aile d'un bleu foncé, le dos blanc, le bec droit. 
ensemble, ne nous rapportant que quelques sacs de petits poissons frais. Cependant la nuit était passée, et notre souper fut réellement un déjeûner.

La lagune de Sagoaréma communique avec la mer : elle a six legoas de long et trois quarts de legoas de large. Son eau est salée, et quoiqu'en certains endroits il s'en exhale une odeur désagréable, elle est très-poissonneuse. Des pêcheurs habitent de petites cabanes de terre éparses sur ses bords; chacune a un fossé qui lui sert de citerne pour l'eau de pluie. Ces pêcheurs, comme tous les Brésiliens, sont légèrement vêtus; ils portent de grands chapeaux de paille, de larges pantalons, et des chemises très-minces, ont le cou découvert, et marchent pieds nus : tous ont à la ceinture un stilet aigu, monté en laiton ou en argent. L'uságe de porter cette arme est, au reste, général chez les Portugais, usage fort dangereux, car il donne lieu à beaucoup d'assassinats, surtout parmi les hommes grossiers comme le sont les pêcheurs de Sagoaréma. Ils tiennent en commun la venda située sur les bords du lac, et en partagent le produit : il est par conséquent superflu de remarquer que les voyageurs y sont plus chère- 
ment que partout ailleurs. A peu près à une lieue d'ici se trouve la paroisse ou freguésia de Sagoaréma, grand village ou plutôt petite ville. Comme nous étions obligés de traverser la lagune avec notre tropa, nous nous logeâmes dans une maison vide, et nous employâmes le temps à examiner les environs.

Près de la freguésia s'éléve, le long du bord de la mer, une colline sur laquelle sont situés l'église, le cimetière et un télégraphe. Nous gravîmes cette hauteur au coucher du soleil. Quelle perspective grande et majestueuse! Devant nous l'immensité de la mer, dont les vagues venaient se briser contre le pied de la colline; à droite se montraient dans le lointain les montagnes de Rio; plus près de nous la côte, découpée par des baies innombrables, et plus près encore, Ponta-Négra : derrière nous de hautes montagnes boisées, devant elles un terrain plus bas, de même couvert de bois, et la lagune; à nos pieds la freguésia de Sagoaréma, et à gauche la côte baignée par la mer. Ce vaste tableau, éclairé par les derniers rayons du soleil couchant, puis enveloppé par le brouillard du crépuscule, réveilla dans notre esprit le souvenir de notre patrie dont nous étions éloignés. 
Nous gardions le silence; nous sentions vivement à combien de privations un voyageur doit s'attendre lorsque poussé par un désir irrésistible d'augmenter ses connaissances, il se trouve seul dans un monde étranger. Notre oeil s'efforça vainement de percer le voile mystérieux de l'avenir, il n'apercevait avec inquiétude que les peines qui nous restaient encore à surmonter avant que nous pussions espérer de parcourir de nouveau la plaine liquide de l'Océan pour retourner dans nos foyers. La nuit mit fin à nos réflexions.

Nous revînmes à Sagoaréma, qui est principalement peuplé de pêcheurs; quelques-uns ont aussi des plantations. On y récoltait autrefois beaucoup de cochenille, mais cette culture a cessé. Le roi payait la livre 6400 reis ou un demi-doblé ( 31 francs ). Les planteurs ont euxmêmes détruit cette branche avantageuse de commerce : ils mêlaient de la farinha à la cochenille, et la falsifiaient tellement, que cette marchandise perdit toute sa valeur. Le lendemain, qui était un dimanche, mes compagnons de voyage entendirent la messe à l'église de Sagoaréma : cependant je fis traverser la lagune à notre tropa; le bagage fut embarqué sur des 
pirogues, et les bêtes de somme passèrent à gué l'eau peu profonde. En quittant ce canton, nous entrâmes dans des forêts remplies des plus belles fleurs. Un des principaux ornemens de ce pays consiste dans les lagunes, qui s'étendent depuis Marica jusqu'au cap Frio. Leurs bords sont fréquentés par une multitude d'oiseaux aquatiques, surtout des lirondelles de mer, des mouettes, des hérons, etc. : en peu de temps nous er tuâmes une grande quantité. L'ornithologiste remarque au premier coup d'œil que la plupart des oiseaux aquatiques ou des marais que l'on rencontre dans ce pays, ont leurs analogues en Europe : ainsi nous vîmes une espièce de mouette, le larus marinus, qui ressemble beaucoup à la mouette rieuse, le sterna caspia, le sterna hirundo; et une troisième qui se rapproche infiniment du sterna minutı. Les différences entre ces oiseaux, dans les deux continens d'Europe et d'Amérique, nous parurent insignifiantes. La plus petite hirondelle de mer (1) était très-commune sur les dunes du

(1) J'ai nommé cet oiseau sterna argentea. On peut aisément le confondre avec notre sterna minuta, mais il en diffère: il est plus gros; car il a neuf pouces une ligne de 
bord de la mer : elles voltigeaient de côté et d'autre comme les hirondelles de rivage, et leur blancheur éclatante était rehaussée par le fond noirâtre du ciel qui présageait une tempête. Derrière les dunes se prolongeait une ligne de marais, et, dans l'mtervalle, le sol sablonneux était couvert de buissons touffus de palmiers nains qui ne s'élevaient pas à plus de trois pieds. Ce végétal est dépourvu de tige; il a les feuilles pinnées, roulées en dedans ou courbées en dehors, et ses pédoncules, de même que ceux de la massette (typha), sont portés sur une hampe droite, et couverts de petits fruits de la grosseur des noisettes, qui sont rangés comme les grains du maïs, et ont à leur racine une chair d'un jaune rougeâtre, douce et bonne à manger. Cette plante porte ici le nom de cocos de guriri ou de pissando.

Ayant décidé de passer la nuit à la fazenda de Pitanga qui se présentait devant nous juchée comme un vieux château sur une montagne, et

long; il a le bec et les pieds jaunes, la pointe du bec est noire; le front et tontes les parties inférieures du corps sont blanches, le sommet de la tête et le cou noirs, le dos, les ailes et la queue d'un beau gris argenté. 
éclairée par la lune, nous nous hâtâmes d'y arriver. La porte s'ouvrit à nos coups redoublés, et le feytor ou économe eut la complaisance de nous faire entrer dans un vaste bâtiment où l'on prépare la farine de manioc. Ayant trouvé ce gîte très-commode pour nos gens et notre bagage, nous y restâmes plusieurs jours pour parcourir le pays voisin.

Cette fabrique de farinha était une des plus complètes que l'on pût voir. Voici comme on prépare la farinha : on racle d'abord les racines du manioc pour les dépouiller de leur écorce, ensuite on les soumet à l'action d'une grande roue qui les réduit en une espèce de bouillie; on met cette pâte dans une longue et large poche faite de roseaux ou de morceaux d'écorce tressés, que l'on suspend par le haut à un pieu, et que l'on tire par le bas: la poche en s'étendant se rétrécit et exprime le suc qui se trouve dans la pâte (1); puis on porte celle-ci dans de

(1) Gilii. Saggio di storia americana (tom. II, p. 304, pl. 5.)

Mawe, pl. 74 ( tom. II , p. 123 et 124.$)$

Koster, pl. $36_{9}$ ( tom. II , pag. 275 .)

La poche à presser le manioc porte dans les colonies françaises le nom de couleuvre. 


\section{AU BRÉSIL.}

grandes chaudières de cuivre ou d'argile cuite, enchấsșées dans des massifs de maçonneric: la chaleur lui enlève son humidité, et pendant cette opération on la remue constamment avec une longue perche garnie à son extrêmité d'une petite planche, afin qu'elle ne brûle pas. Cette pâte desséchée est ce que l'on appelle au Brésil le mandioca (1). Nous nous servîmes des chaudières à mandioca pour faire sécher nos objets d'histoire naturelle quand le temps devint humide; mais, quoique l'on passât la nuit à surveiller l'opération, quelques animaux rares furent brûlés.

Le temps était froid, un vent violent soufflait le long de la côte. A midi le thermomètre s'élevait à $15^{\circ}$. Les environs de Pitanga, remplis de marais, de pâturages, de buissons et de forêts,

Labat, Nouveau voyage aux îles de l'Amérique, tom. 2, p. 101 , édition de 1742 .

Du Tertre, Histoire générale des Antilles, tom. II, pag. 112 et pl. p. 419.

Nicolson, Essai sur l'histoire naturelle de Saint-Domingue, pag. 269 (E).

(1) Koster, dit L. C. , que la farine préparée porte le nom de farinha do pao (farine de bois). C'est la cassave des colouies frauçạises (E).

I. 
nous fournirent plasieurs animaux intéressans. Nos chasseurs nous apportèrent pour la première fois le jacupemba(penelope marail,L.)(1), oiseau très-bon à manger, et des toucans verts, aracaris ou arassaris (ramphastos aracari, L.), bel oisean dont le cri bref articule deux syllabes. Pitanga était autrefois un couvent, c'est ce que l'on reconnaît facilement à son église. Sa vue est fort belle et très-étendue. Un télégraphe correspondait avec celui de Sagoaréma que nous apercevions dans le lointain. Vers midi notre tropa fut chargée. L'économe de la fazenda eut la complaissance de nous accompagner à cheval pour nous montrer le chemin, ce qui nous fut d'un grand secours; avec nos mulets indociles nous eussions sans doute perdu une partie de notre bagage pendant l'obscurité de la nuit qui nous surprit, et dans les mauvais chemins remplis d'eau; car ces animaux ne pouvaient avancer avec leur charge dans les sentiers étroits des forêts, se heurtaient contrẹ les arbres, s'effarouchaient et jetaient leur fardeau, puis s'enfuyaient. Nous perdîmes beaucoup de temps

(1) Yacou, dans le Nouveau dectionnaire d"histoire naturelle. 
à les attraper et à les recharger. Il fallut marcher avec plus de prudence et abattre les arbres qui gênaient notre marche. Enfin nous atteignîmes des prairies découvertes, remplies de grands marais, de halliers et de larges flaques d'eau que nous fủmes obligés de traverser à gué, circonstance désagréable pour nos piétons, surtout pourles Européens', qui chassaient dans les buissons, et qui n'étaient pas accoutumés à ces voyages à pied à travers des terrains noyés. 'Toutes ces contrariétés furent cause que nous n'arrivâmes que tard dans la nuit à la fazenda de Tiririca, où nous avions envoyé à l'avance un homme à cheval pour demander à y loger. Le capitaine Mor, propriétaire de cette fazenda, nous indiqua d'abord son moulin à sucre pour y passer la nuit; mais quand nous lui eûmes montré notre portaria (passeport du ministre), il nous combla de politesses et nous invita à entrer dans sa maison; nous ne pûmes profiter de son honnêteté, parce que nous voulions rester auprès de nos gens.

Tirica est une grande plantation, située dans une position agréable au pied d'une colline verdoyante, sur laquelle est placée la maison 
du propriétaire, entourée de vingt cases pour ses domestiques et ses nègres. Les champs de cannes environnent la fazenda; au-delà, les hauteurs sont couvertes de forêts épaisses; près du moulin à sucre, une prairie remplie de marais et de flaques d'eau était animée par des oiseaux que l'on pouvait aisément tuer des fenêtres $d u$ jâtiment. Le lendemain, après avoir déjمûné avec notre hôte, nous nous partageâmes en plusieurs troupes dans les forêts. Accompagné de M. Sellow, je traversai les champs de cannes, et d'autres petites fazendas entourées de jolis bocages d'orangers, puis je m'enfoncai dans l'épaisseur des forêts qui, pendant mon séjour au Brésil, m’ont toujours procuré les plus douces jouissances. Des troncs de grands arbres morts, placés sur la lisière de ces bois épais, portaient encore des traces du feu que l'on avait employé pour défricher ce canton. La forêt était un désert sombre où croissaient dans toute leur vigueur des arbres gigantesques, des mimosa, des jacaranda, des bignonia, des fromagers, le pao Brazil ou bois de Brésil (cuesalpinia brasiliensis), et une infinité d'autres chargés d'une quantité de cactus, de bromelia, d'epidendrum, de 
grenadilles, de bauhinia, de banisteria et de semblables plantes parasites ou grimpantes; celles-ci cnt leurs racines en terre, montent en serpentant autour des arbres, et après être parvenues jusqu'à leurs cimes les plus élevées, y déploient leurs fleurs. On ne peut les examiner qu'en abattant les arbres; mais souvent la dureté du bois brise le fer des meilleures haches. Ces plantes grimpantes portées par le vent d'un arbre à l'autre, les unissent quelquefois de la manière la plus extraordinaire. On distingue entr'autres un bauhinia dont les tiges sarmenteuses et ligneuses croissent en arcs qui alternent, et dont la courbure est si régulière qu'on les croirait creusés par l'art; le côté convexe est armé d'une épine courte et obtuse. Cette plante singulière, que l'on pourrait prendre aisément pour un ouvrage des hommes, s'élève jusqu'au sommet des arbres les plus hauts; sa feuille est petite et bilobée; je n’ai pas vu sa fleur, quoique ce soit une plante très-commune. D'autres espèces de végétaux sarmenteux se font remarquer par une odeur très-forte, tantôt suave, tantôt désagréable. Le cipo cravo a à peu près l'odeur du clou de girofle; un autre au contraire 
que la Condamine (1) a vue à la rivière des Amazones, sent l'ail. Plusieurs de ces plantes bizarres jetent de longs filamens qui pendent jusqu'à terre, où ils prennent racine et s'élèvent de nouveau, montent et descendent alternativement, et forment ainsi des réseaux épais et solides qui interceptent le chemin des voyageurs; on est obligé de les couper avec la serpe pour pouvoir avancer; ces filamens ligneux qui, lorsque le vent ou toute autre cause les met en mouvement, viennent frapper la tête des voyageurs, sont fort ordinaires dans toutes les forêts du Brésil et de la zone torride. La végétation est en général si abondante dans cette zone, que chaque grand arbre est une image d'un petil monde, une espèce de jardin botanique rempli de plantes souvent difficiles à obtenir, et la plupart inconnues.

.Nous avons tué dans cette forêt beaucoul, de beaux oiseaux. Le souroucoua on couroucou à ventre jaune (trogon viridis) y était très-commun; partout on entend retentir sa voix qui est un sifflement répété depuis le ton le plus haut jusqu'au plus bas; nous apprîmes bientôt à l'imi-

(1) Toyage à la rivière des Amazones, p. 77 . 
ter, et nous pûmes aisément le piper. On le voit s'avancer d'un vol rapide, mais doux, et se placer sur une branche peu éloignée, où on peut le tirer sans beaucoup de peine. Les dendrocalaptés d'Illiger, qui en compagnie du beau pic jaune rayé de noir (picus flavescens), du pic charpentier à huppe et cou rouges d'Azara, et du pic ouantou (picus lineatus), frappent sans cesse de leur bec le tronc des arbres, ne sont pas moins communs, ainsi que le petit perroquet à queue cunéiforme, que l'on nomme ici tiribas (1); nous en avons souvent tué de grandes quantités. Le soir j’obtins le pavô (pie ¿ gorge ensanglantée d’Azara), bel oiseau noir, de la grosseur d'une corneille, dont la gorge est du rouge le plus vif.

(1) Le perroquet connu sur la plus grande partie de la côte orientale, sous le nom de tiriba, me paraît être une espèce non décrite. Je l'ai nommé psittacus cruentatus. Il est de la grosseur d'une grive, sa queue est en forme de coin allongé; il a huit pouces onze lignes de long; le plumage vert, le sommet et le derrière de la tête gris-brun, le dos et le dessous du bec vert; l'espace entre l'œil et l'oreille rouge grisâtre; une tache orange derrière l'oreille sur le côté du cou; le devant du cou bleu céleste; une tache rouge de sang sur le ventre et le croupion ( $p$ sitacus erythrogaster, du muséum de Berlin). 
M. Sellow ne déćouvrit pas beaucoup de nouvelles plantes, mais il trouva en abondance la belle alstroeméria ligtu, L. ), fleur agréablement rayée de rouge et de blanc. Il rencontra aussi un serpent assez commun, mais qui fait l'ornement de ce genre; il est connu daus ce pays sous le nom de cobra coral ou coraës, cependant il ne faut pas le confondre avec le coraës décrit dans les ouvrages de M. de Lacepède, de Daudin et d'autres auteurs. Celui que nous avons pris ici mérite avec raison le nom de serpent corail. Le rouge le plus éclatant alterne sur son corps lisse, avec des anneaux noirs et d'un blanc verdâtre; de sorte que ce reptile, aussi innocent qu'il est joli, peut être comparé à un cordon de corail bariolé. Je l'ai souvent mis dans l'esprit de vin, et je n'ai jamais réussi à lui conserver sa magnifique couleur écarlate. Le nom de coluber fulvius, qu'il porte dans le système de la nature de Linné, lui a sans doute été donné d'après des individus qui avaient perdu leurs couleurs dans l'esprit de vin.

Le soir notre hôte nous irivita à souper. Conformément à la coutume da Brésil, les femmes ne parurent pas, mais les fentes des portes et 


\section{AU BRÉSIL.}

des volets des fenêtres leur fournirént les moyens de regarder les étranges convives qui étaient à tables. Nous fümes servis par des nègres et des négresses esclaves. Mawe et Koster ayant donné d'amples détails sur cet usage des Brésiliens et sur plusieurs autres, je ne m'y arrêterai pas. Pendant le repas nous cherchâmes à faire tomber la conversation sur ce qui con-cernait l'état et les productions du pays; mais notre hôte, d'ailleurs très-complaisant, eut l'air de ne vouloir ou de ne pouvoir nous donner aucun renseignement sur ces objets.

Le lendemain était un dimanche; l'on alla de bonne heure à la messe; après l'office nous partîmes. Il faisait très-chaud; nous nous rafraîchîmes en chemin avec du punch froid et des oranges que dans plusieurs endroits on obtient pour rien. On peut même, quand on est extrêmement échauffé, manger de ce beau fruit en quantité sans craindre de nuire à sa santé; cependant on dit qne le soir il fait du mal. On doit être beaucoup plus prudent dans l'usage des cocos et des autres fruits dont le suc est réfrigérant.

La distance de Tiririca à Parati n'étant que de trois lieues, nous arrivâmes bientôt à cette 
fazenda à travers des marais et des sables couverts de bois. Elle est située au milieu d'une prairie. Notre hôte de la veille nous avait fait espérer que nous y serions reçus amicalement : c'était autrefois un couvent; l'église est grande ; tout auprès sont les bâtimens d'exploitation. Nous y avons vu, pour la première fois, une maladie qui, dans le Brésil méridional, est très-commune parmi les nègres, c'est un gonflement des pieds qui se recouvrent d'une peau dure comme dans l'éléphantiasis.

Nous demandâmes au maître de la fazenda à passer la nuit chez lui; bien différent des planteurs brésiliens que nous n'avions connus jusqu'alors que sous un côté avantageux, il nous indiqua une méchante écurie ou grange dont le toit nous mettait à couvert de la pluie, mais dont les côtés ouverts nous exposaient à toute l'inclémence du temps. A notre arrivée, le propriétaire s'éloigna et nous prouva ainsi qu'on lui avait fait trop d'honneur à Tiririca en le qualifiant d'homme hospitalier. L'ayant fait prier de nous vendre du riz pour nous, et du maïs pour nos mulets, il refusa, sous prétexte qu'il n'avait rien, et dit que si l'on, voulait nous donner de l'eau, il ne s'y opposerait 
pas. Il fallut envoyer des gens à cheval dans le voisinage pour acheter des provisions dans d'autres fazendas. Le lendemain matin, après avoir fait partir de bonne heure notre tropa, nous allàmes à la maison du capitaine, auquel on annonça que nous désirions prendre congé de lui. Il parut; nous le remerciâmes trèspoliment de sa bonté et de ses prévenances, en ajoutant que nous instruirions le prince régent de la manière dont on s'était conformé à Parati aux recommandations bienveillantes du gouvernement en notre faveur; cet homme eut d'abord l'air étonné, puis il s'écria, en écumant de rage : «Et que me fait le prince régent!)

Nous atteignîmes bientôt dés marais entourés de hautes broussailles, et sur les bords desquels le quer-quer (1) ou vanneau du Brésil (vanellus cayennensis) était très-commun. On a nommé ce bel oiseau quer-quer, parce qu’à l'aspect d'un homme ou d'un objet étrange, il articule, d'une voix perçante et désagréable,

(1) Mawe parle de cet oiseau, p. 80 ( tom. I, p. 156 ). Je tuai, dit-il, de beaux vanneaux qui avaient à chaque aile un éperon ronge: ces oiseaux font beaucoup de bruit. 
le cri quer, quer, quer, qui effraie et fait enfuir tous les autres oiseaux. On le rencontre dans toutes les prairies, les pâturages et les marécages du Brésil. La grande hirondelle à collier blanchâtre est de même commune en ce lieu (1).

La chaleur devenait de plus en plus accablante; on ne sentait pas le moindre soufle d'air; le sable sec et profond dans lequel les rayons du sóleil se réfléchissaient, augmentait l'ardeur brûlante de l'atmosphère.

Nos chasseurs tuèrent dans une belle forêt que nous traversions une jolie espèce de maracana (psittacus guianensis, L.) qui volait en troupes innombrables. Au sortir de cette forêt nous arrivâmes à un endroit où un grand nombre d'Indiens de San-Pedro étaient occupés à réparer le chemin. Cette réunion d'hom-

(1) Cette hirondelle que j'ai nommée hirundo collaris est nouvelle, elle est de la grosseur du martinet noir d'Europe. Son plumage est d'un noir brunâtre avec des reflets verts ; le cou est entouré d'un anneau blanchâtre. Les tiges des pennes de la queue se terminent en pointes aigues longues d'une ligne. Le tarse est nu, les doigts très-forts, rapprochés, pourvus d'ongles arqués, aigus, très-propres à soutenir l'oiseau sur les rochers; je l'ai d'abord trouvé sur ceux de Rio-de-Jaueiro. 
mes d'une teinte cuivrée élait pour nous un spectacle nouveau et intéressant.

Après avoir franchi quelques collines, nous aperçûmes tout à coup la grande lagune de Araruama qui a six legoas de long sur une largeur considérable; elle communique avec la mer à une legoa et demie au nord du cap Frio. On dit que l'on récolte du sel en quelques endroits de ses bords; elle est très-poissonneuse (1). Des forêts et des maisons entouraient le rivage opposé; sur une pelite hauteur dans le lointain s'élevait l'église du village de San Pedro. Ayant fait le tour d'une partie de la lagune, nous fîmes halte à la venda du village; bientôt arrivèrent nos chasseurs fatigués de la chaleur et de la longueur de la course à pied; ils avaient tué en chemin plusieurs animaux curieux.

San Pedrodos Indios est un village d'indiens, (Aldea), que les jésuites ont formé en réunissant d'abord des Indiens Goayatacas (2). L'église est

(1) Cette lagune porte aussi le nom de Lagoa de Iraruama ou Aruama.

(2) Le Corografia brasilica (tom. II, p. 45), raconte ainsi la maissance de ce village d'Indiens; il fut établi quand 
grande; le village a plusieurs rues, mais les maisons ne sont que des huttes en terre; toules, ainsi que celles qui sont isolées dans ce canton, sont habitées par des Indiens qui ont un capitaine Mor ou commandant de leur nation: rien ne le distingue que son titre. A l'exception des ecclésiastiques, on ne trouve que peu de Portugais dans ce lieu. Les Indiens que j'y vis ont la plupart la physionomie pure de leur race, telle que je l'ai décrite plus haut; mais elle est encore plus caractérisée qu’à San-Lourenzo. Ils ont adopté l'habillement et le langage des Portugais de la classe inférieure, et ne savent plus qu'imparfaitement leur ancien idiome. Ils ont la vanité de vouloir être Portugais, et regardant avec dédain leurs frères qui continuent à vivre sauvages dans les forêts, ils leur donnent le nom de Caboclos ou Tapouyas. Leurs femmes suivent la mode des Portugaises, et réunissent en une touffe au-dessus de la tête leur chevelure d'un noir foncé.

Salvador Correa de Sa, les trois frères Gonsalo, Manuel et Duarte Correas, le capitaine Miguel-Ayres-Maldonado et plusieurs autres expulsèrent, en avril 1 629, les Indiens Goaytacasés, d'un grand territoire qu'on leur arait coucédé au mois d'août 1553 . 
Les hamacs de la famille sont suspendus dans les coins des huttes; ces Indiens fabriquent des poteries d'argile grise. Les hommes sont généralement bons chasseurs et tireurs trèsadroits au fusil. Les enfans s'exercent d'abord à tirer avec des arcs de bois d'äri nommé bodoc, qui ont deux cordes tenues à moins d'un pouce de distance l'une de l'autre par deux petits bâtons terminés en fourche, dans chacune desquelles ils font passer l'extrémité des cordes. Vers le milieu de leur longueùr, elles sont réunies par un petit filet formé de ficelles; il sert à y placer des balles d'argile ou de petites pierres rondes (pelotta): on bande l'arc en tirant en arrière avec l'index de la main droite le cordon et la balle, puis on les lâche subitement, et la balle est lancée en avant. M. Langsdorf a déjà parlé, dans la relation de son voyage, de cette espèce d'arcs qu'il vit à Sainte-Catherine; il est en usage tout le long de cette côte; et sur le Rio-Doce, les hommes faits s'en servent quand ils n'ont pas d'armes à feu, pour tirer sur les boutocou'dys ; ils l'emploient avec beaucoup d'adresse, et tuent un petit oiseau à une distance considérable, même des papillons posés sur des fleurs, comme 
M.Langsdorf le raconte. Azara, dans le voyage de l'Amérique méridionale, dit qu'au Paraguay on tire plusieurs balles à la fois avec cet arc(1).

Koster, dans son Voyage de la capitainerie de Pernambouc, a peint les Indiens demi civilisés de Séara d'une manière assez exacte, quoique sous un jour un peu trop défavorable; cependant il est possible qu'ils ne soient parvenus qu'à un moindre degré de civilisation que ceux de San-Pédro. Au reste, je dois observer à cette occasion qu'une partie du peu de progrès des Indiens dans la civilisation, et souvent de leur mauvais caractère, doit être attribuée au traitement déraisonnable et à l'oppression qu'ils ont autrefois endurés de la part des Européens; souvent ceux-ci les reconnaissaient à peine pour des hommes, et aux noms de Caboclos ou de Tapouyas qu'ils leur donnaient, joignaient l'idée d'êtres uniquementcréés pour être maltraités et tyrannisés. Ce que dit Koster de leur caractère en géneral est vrai : ou observe en eux un penchant excessif à l'indolence; ils aiment les boissons fortes, travaillent avec répugnance, sont sujets à manquer de

(1) Tome II, page 67. 
parole, et l'on n'a encore rencontré chez eux qu'un bien petit nombre d'hommes distingués. Cependant ils ne manquent pas d'intelligence; ils saisissent avec facilité tout ce qu'on leur apprend, ils sont fins et dissimulés. Le trait le plus frappant de leur caractère est un orgueil indomptable, et une prédilection décidée pour leurs forêts. Beaucoup sont encore attachés à leurs anciennes superstitions, et les prêtres se plaignent que ce sont de mauvais chrétiens. La carrière sacerdotale leur est ouverte, et cependant il est très-rare qu'ils s'y consacrent. Il y avait dans le Minas-Geraës un prêtre indien qui appartenait à une des tribus les plus grossières ; il était généralement estimé, et vivait depuis plusieurs années dans sa cure: tout à coup il disparut, il avait laissé tous ses habits. Bientôt on apprit qu'il éiait retourné chez ses fières au milieu des forêts, et qu'il avait pris plusieurs femmes. Cet homme avait pourtant paru pénétré de la doctrine qu'il avait prêchée pendant plusieurs années. Quelle diflërence eutre ces Indiens et les nègres qui vivent au Brésil ; on trouve chez ceux-ci beaucoup de dispositions et de persévérance pour s"iustruire dans les arts et dans les sciences:

I. 
ils. ont même produit des personnages disingués ( 1 ).

Les Indiens ont-ils suffisamment à manger, on ne les décide pas aisément à travailler, ils passent le temps à danser et à boire. C'est des Portugais qu'ils ont appris les danses aujourd'hui en usage chez eux; la baducca est celle qu'ils préfèrent. Les danseurs, accompagnés du son de la guitare, et placés l'un vis-à-vis de l'autre, prennent toutes sortes de postures indécentes, font claquer leurs doigts et leurs langues (2), ensuite ils se régalent de caouy (3). Aujourd'hui cette boisson se prépare uniquement avec

(1) Voyez à ce sujet l'ouvrage de Blumenbach, intitulé : Beytrâge zur Naturgeschichte, tom. I, pag $9^{4}$. Il vient à l'appui de ce que je dis sur les facultés intellectuelles des nègres, et de l'attrait irrésistible que le sol paternel et la manière de vivre exercent sur les peuples sauvages.

(2) Eschwiège, Journal von Brasilien, tom. I, pag. 59 .

(3) Simon de Vasconcellos décrit toutes les especes de caouy préparées jadis par les Indiens côtiers; ils versaient cette boisson dans des talhas qu'ils nommaient igaçabas. Quelques-uns en comptaient trente-deux sortes : ils en faisaient a vec de l'acaya et de l'aypi, qu'ils nommaient caüy caraçu et caiiy machachera; avec le pacoba, pacouy; avec le naais, abatiuy; avec l'ananas, uanavy : il est fort et enivre aisément; avec des patates, jetiiiy; avec du geni- 
de la racine de manioc, du maïs et des patales: la racine est raclée, coupée en petits morceaux, bouillie, puis mâacbée : on la retire de la bouche avec les doigts, on la met dans un vase que l'on remplit d'eau, et on la laisse fermenter (1). Il en résulte une boisson enivrante, aigrelette et nourrissante, dont le goût approche beaucoup de celui du petit-lait. On le boit ordinairement chaud. La manière de vivre des Indiens de San-Pedro ressemble encore à celle des anciens Indiens côtiers. Les Portugais ont adopté plusieurs de leurs usages, entre autres

paba, du beju ou du manioc, tepiociiy; avec du miel sauvage ou du sucre, garapa : avec de l'acajou, etc. : ils préféraient ce dernier. (Noticias curiosas do Brazil, pag. 86 et 87 .)

De Lery parle aussi du caony. Il ajoute que les sauvages le nomment ca-ouiii. “Qu'il me soit permis de dire, s'é"crie-t-il, arrierré Alemans, Flamans, lausquenets, "Suisses, et tous qui faites carhous et profession de boire, " par deçà ; car tout ainsi que vous-mêmes, après avoir " entendu comme nos Amériquains s'en acquittent, con" feśserez que vous n'y entendez rien au prix d'eux, aussi " faut-il quie vous leur cédiez en cet endroit. " (Voyage, pag. 130-132.) (E.)

(i) Celte préparation rappelle celle de l'ava ou kava dans les îles du grand Océan. (Voy. Jes Voyages de Cook.) (E.) 
la préparation de la farine de manioc. Les sauvages en avaient autrefois une espèce fort cuite et dure, qu'ils portaient dans leurs guerres, parce qu'elle se conservait mieux, et une autre moins cuite et plus tendre : la première nommée ouy-entan, la seconde ouy-pou, ( laquelle, dit de Lery, est d'autant meilleure ) que la première, que, quand elle est fraîche, )) vous diriez en la mettant en la bouche et en ) la mangeant que c'est du mollet de pain blanc ») tout chaud : l'une et l'autre en cuisant chan) gent aussi ce premier goût, que j'ai dit en ») un plus plaisant et plus souef (1). »

Ces Indiens civilisés connaissent encore le mot ouy : de tout temps ils ont préparé leur mingant, en jetant la farine de manioc dans du bouillon qui s'y incorpore, et donne une bouillie très-nourrissante. Les Portugais ont aussi emprunté ce mets des sauvages : quand ceux-ci mangeaient, ils avaient auprès d'eux de petits tas de farine de manioc sèche, et, la prenant avec les quatre doigts, ils la jetaient dans leur bouche avec tant de dextérité, qu'il ne s'en per-

(1) De Lery, pag. 124. 


\section{AU BRÉSIL.}

dait pas un brin : cet usage se retrouve encore chez leurs descendans, de même que chez les planteurs portugais (1). Les anciens Toupinambas connaissaient, sous le nom d'aypi, une excellente espèce de racine de manioc, qu'ils faisaient rôtir dans les cendres, et ensuite bouillir dans l'eau (2). Ces mêmes opérations ont lieu chez leurs descendans.

Quoique ces Indiens fassent profession de la religion chrétienne, un grand nombre ne va à l'église que pour l'apparence, et même que trèsrarement; en revanche ils sont très-superstitieux, et ont une infinité de préjugés. Koster a même trouvé les maraccas (3) dạns une maison indienne de Pernambouc (4), ce qui fait voir que quelques-uns tiennent encore à cet usage de leurs pères. A mesure que ce peuple se civilisera, son caractère original, ainsi que les derniers restes de ses moeurs et de ses usages, disparaîtront de plus en plus; de sorte que sur

(1) De Lery, pag. 125.

(2) Ibid., pag. 127.

(3, Pl. 314 ( tom. II, pag, 181 ).

(4) Hans Staden les nomme tamaracas, ch. XXXII; ce sont des espèces de fétiches. 
le lieu même où la nature avait fixé sa demeure, on n'en apercevra plus de vestiges, et son souvenir ne se conservera que dans les relations de Jean de Lery et de Hans Staden (1).

Nous nous entretînmes le soir avec les habitans assis devant leurs portes pour jouir de la fraîcheur. Le capitaine mor, Indien âgé et fin, ne put, non plus que les habitans de San-Pedro, nous cacher qu'ils nous soupçonnaient d'être des espions anglais; la vue de notre portaria ne suffit pas même pour lè tranquilliser complètement. Les Anglais sont détestés au Brésil; on regarde comme appartenaus à cette nation tous les étrangers chez lesquels des cheveux blonds et une peau blanche indiquent qu'ils sont originaires du nord.

Le pays des environs promettant une matière abondante à nos recherches, nous

(1) Histoire d'un voyage fait en la terre du Brésil, autrement dite antarclique, par Jean c'e Lery, 1585. ( Lā première édition est de 1578 .) - Haps Staden wahrhaftige historia und Beschreibung einer Landischaft, etc. (Histoire véritable et description d'un pays du nouveau monde, l'Amérique, habité par des peuples sauvages; nus, cruels et anthropophages, écrite par Hans Staden, quiy a fait un voyage). - Francfort, 1556, 1 vol. in- $4^{\circ}$. 


\section{AU BRÉSIL.}

passâmes plusieurs jours à San-Pedro; nos voyageurs nous apportèrent quelques micos ( simia fatuellus ou sahoui cornu), le paresseux à collier noir (1), espèce encore peu connue, etc. Nous l'avons ensuite trouvée dans des cantons pluś au sud; au contraire, nous ne l'avons pas rencontrée dans ceux qui sont plus au nord.

Le lendemain dimanche, tous les habitans des environs arrivèrent en foule à la messe à San-Pedro. Nous allâmes à l'église, devant laquelle des branches de palmiers desséchées formaient une allée élevée à l'occasion d'une fête qui avait eu lieu quelque temps auparavant.

La vue des visages bruns des Indiens et de leur physionomie originale était faice pour intéresser un étranger, elle attira notre attention. Le soir ils dansèrent dàns la maison de

(1) Le paresseux à collier est une espèce nouvelle et non encore décrite. Par sa taille et sa forme, il diffère peu de l'aï, mais il s'en écarte par son pelage, qui offre un mélange de gris et de rougeâtre: la tête est plus rougeàtre et mêlée de blanchâtre; sur la partie supérieure du cou se trouve une grosse tache de longs poils noirs. Celte espèce a d'ailleurs trois ongles comme l'aï, et non pas deux, comme le dit Illiger dans son Prodomus. 
leur capitaine mor; la danse et le caouy les mirent en gaté. Le prêtre assista aussi au bal, mais il me parut que, hors de l'église, on ne prenait pas gardè à lui.

M. Carvalho, capitaine, qui habitait le voisinage, et qui se trouvait à San-Pedro, nous fit beaucoup de prévenances. Indépendamment do sa plantation près du village, il avait à Villado-Cabo-Frio une maison dans laquelle il nous pressa de prendre notre logement quand nous serions dans cette ville. Il se fit notre conducteur à San-Pedro, et nous invita à plusieurrs reprises à aller le voir chez lui. M. Sellow profita de cette offre. Cette visite mit M. Sellow à même d'acquérir des renseignemens précieux sur les productions des grandes forêts qui entourent San-Pedro. Elles sont remplies de bois utiles, et de diverses plantes usuelles. M. Carvalho, accusé précédemment d'exporter des bois dont la couronne s'esti iéservé le monopole, avait été arrêté. On reconnut son innocence; il fut remis en liberté.

On trouve abondamment dans les forêts voisines de San-Pedro le bois de Brésil, pao brazil, (caesalpinia brasiliensis), l'ipé (bignonia) de plusieurs espèces, avec de grandes fleurs 
jaunes et.blanches : une espèce se nomme ipéamarello; une autre, qui donne un bois extrêmement solide pour la construction navale, s'appelle ipé-tabacco, parce que le cour quand on le fend donne une poudre d'un vert clair trèsmenue. On y voit aussi le pékéa dont l'homme mange le fruit, qui d'ailleurs est la nourriture ordinaire des singes; le pitoma, l'oleo-pardo (laurus), l'ipeuno (bignonia), le plus dur de tous les bois : comme il est élastique et trèsléger, les Indiens en font leurs arcs; l'imbiu, le jaqua, le grubu, le grumbari, le mazaranduba, qui, entre l'écorce et l'aubier, contient un suc. laiteux, dont les Indiens font de la glu pour prendre les oiseaux; le grauna, le sergeira, espèce de cassia ou de mimosa qui perd ses feuilles, arbre très-beau et très-gros: son bois très-léger remplace le tilleul et le peuplier, on en fait des pirogues; le jarraticupitaya à écorce épicée, qui est un des médicamens des Indiens; e jacaranda, ou bois de rose (mimosa) d'une belle couleur brune noirâtre, compacte et lourd, utile pour les ébénistes, donnant une odeur de rose faible, mais agréable; l'aubier, de couleur blanche, n'est pas employé, on ne fait usage que du cour; le cuiranna (cerberc 
ou gardenia), bois léger dont on fait des cuillers et des assiettes, et dont l'écorce rend un suc laiteux; le péroba, bois dur et compacte, propre aux constructions navales, employé par le gouvernement qui s'en est réservé la propriété exclusive; le canella (laurus) très-aromatique, ayant l'odeur de la canelle; le caübi (mimosa), le mojolé, le sepepira, le putumuju nommé arariba à Rio-de-Janeiro; enfin une infinité d'autres espèces. Les principales plantes usuelles que l'on cueille communément dans ces forêts sont l'herva moeïra do sertam, dont le goût ressemble à celui du girofle; le costus arabicus, employé dans une certaine maladie fort incommode; l'ipécacuanha prèta (ipecacucantra officinalis d'Arruda)(1); l'ipécacuanha branca (viola ipecacuaniha ou pombalia ipecaeuanha Vandelli); le buta, dont la vertu égale, dit-on, celle du quinquina (2).

Après avoir fait de fréquentés chasseś avec

(1) C'est sans doute le raïz prèta, représenté dans le premier cahier du Journal von Brasilion de ill. d'Eschwège."

(2) N'ayant vir ni la fleur ni le fruit de cette plante, nous ne pouvons déterminer ni sa famille ni son genre; c'est peut-être un convolvulus. 
les Indiens de San-Pedro, dans les environs de leur village, noús en partîmes un après-midi pour aller au cap Frio, éloigné de deux lieues. Nous eûmes l'occasion de tirer en route une jolie espèce de maracana, connue sous le nom de psittacus macavuanna. Il se tient en troupes dans les forêts, d'où il se répand dans les halliers et les plantations de maïs voisines des maisons des Indiens, et y cause de grands dégâts.

Nous traversâmes dans l'obscurité la lagune près de Villa-do-Cabo Frio. M. Carvalho, capitaine mor de celieu, nous reçut dans sa maison. Le cap Frio, un des plus connus du globe, est un promontoire rocailleux, en avant duquel sont situés quelques îlots de même nature; sur un de ces îlots voisin de la côte est un petit fort qui défend un port. Une lagune s'étend dans lintérieur des terres en forme de demi-cercle; sur ses bords est située Villa-doCabo-Frio, qui est petite : elle a plusieurs rues non pavées; les maisons en sont basses, quelques-unes se distinguent par un extérieur trèspropre et très-gai. La pointe de terre sur laquelle la ville est bâtie est marécageuse; dans son voisinage, près de la mer, on voit des sables 
profonds, dans lesquels croissent divers arbrisseaux. Nous découvrîmes quelques espèces nouvelles, entre autres deux andromèdes frutescentes (1); l'une à fleurs jaunes pâles, l'autre à fleurs roses. Tout le pays voisin est rempli de grands étangs et de marais, aussi passe-t-il pour fiévreux : toutefois les habitans prétendent que les brises de mer netioyent et purifient l'atmosphère.

Villa-do-Cabo-Frio exporte de la farinha et du sucre; quelques lanchas entretiennent ce petit commerce de cabotage. Jadis ce pays, ainsi que toute la contrée qui s'étend jusqu'à Rio-de - Janeiro, était habité par les puissantes tribus des Toupinambas et des Tamoyos, qui, du temps de Lery, étaient alliées des Françąis contre les Portugais. Saléma les attaqua en 1572 au cap Frio, et les défit complètement; ils se retirèrent dans l'intérieur. Les Portugais s'établirent ensuite dans le pays. Dans la dernière moitié du dix-septième siècle, un petit

(1) M. Schrader, professeur à Goettingen, qui a eu la bonté de déterminer la plupart des plantes dont je parle dans cet ourrage, a reconnu que ces deux espèces sont entièrement nouvelles, et n'ont pas encore été décrites. 
nombre demeuraient à Villa-do-Cabo-Frio; le village de San-Pedro était déjà fondé. Southe y dit que la Villa était munie d'un petit fort à peu près sans garnison.

Un capitam qui demeurait à Villa-do-CaboFrio, nous ayant invités à aller voir sa plantation de sucre, nous nous embarquâmes un dimanche de bonne heure, accompagnés de notre hôte M. Carvalho et d'un ecclésiastique. Suivant l'usage, on étendit des nattes de roseaux (esteïras) dans le fond de la pirogue, pour nous y asseoir. Les anciens Toupinambas et les tribus qui avaient de l'affinité avec eux se servaient déjà de cette espèce d'embarcation; les Portugais se sont bornés à en conserver l'usage. Elles sont creusées dans un tronc d'arbre, et très-légères. Les Indiens entendent à merveille l'art de les conduire. Il y en a de toutes les dimensions. Quelques unes sont si petites, que l'on n'ose pas s'y rcmuer beaucoup, de crainte de les faire chavirer; d'autres au contraire sont si grandes que l'on y navigue en sûreté même en pleine mer, lorsqu'elle n'est pas trop agitée. L'homme qui gouverne la pirogue se tient debout, et sait si bien se maintenir en équilibre, que ses mouvemens n'occa- 
sionnent pas le moindre balancement. L'extrémité des rames ou pagaies est oblongue; dans les petites pirogues on les manie avec la main libre. Deux canoeirros habiles peuvent faire marcher une pirogue légère aussi vite que le vent.

L'eau de la lagune était pou profonde et si claire que l'on voyait distinctement le fond sablonneux garni de madrepores; sonvent nous touchions, à cause du peu de profondeur du fond. Des troupes nombreuses de mouettes, d'hirondelles de mer, d'aigrettes et de vanneaux, couvraient la lagune et ses rives. Deux espèces de cormoran sont très-communes dans cet endroit; le nigaud gris brun (1), et un autre qui ressemble beaucoup à notre cormoran : tous deux pêchent et viennent très-près des maisons de la Villa. La fazenda de M: le capitam, entourée des cases à nègrès, est 'dans une jolie position sur une colline verdoyante. Tout autour on aperçoit des montagnes boisées et des monticules couverts de buissons, dont la teinte forme un contraste agréable avec le vert clair et brillant des cannes; à gauche, plusieurs flaques d' eau, des

(1) Peut-être le petit-fou de Cayenne, Buffon; planches euluminées, p. 973. (Pelicanus paryus.) 
maisons et des monts que leur éloignement fait paraître bleus, animent ce paysage. Le moulin à sucre est bien tenu : pour épaissir et purifier le jus dont on veut extrairel'eau-de-vie, on y jette une forte lessive de cendres d'une espèce de polygonum, nommé catoya par les Indiens, et herva de bichu par les Portugais. Cette plante a un goût très-amer et poivré; on l'emploie dans plusieurs maladies (1).

La plupart des fazendas un peu considérables ont une église, une chapelle ou une grande chambre arrangée de manière que les dimanches et les fêtes on y peut dire la messe. Les voyageurs ne doivent jamais négliger d'y assister, parce que les habitans attachent une grande importance à cet acte de dévotion; on nous montrait beaucoup de bienveillance et même

(1) On dit que sur les bords du Rio-San-Francisco l'on emploie avec avantage cette plante dans la maladie nommée o largo ou l'élargissement. D'après la description d'un vieux médecin hongrois, qui a long-temps vécu dans cette contrée, et qui en a étudié les maladies, c'est un élargissement du canal intestinal, causé par l'affaiblissement. On fait bouillir la plante, on en laisse refroidir la décoction, et on l'emploie en lavement et en bain. 
de prévenance, partout où nous nous conformions à cette règle; et quand nous ne l'observions pas, on nous témoignait ouvertement de la froideur et de la mauvaise volonté. A près la messe, nous retournâmes avec le maître de la plantation à la Villa, où nous examinâmes une curiosité de ce lieu: c'est le vrai cocotier, arbre très-commun plus au nord, et extrêmement rare au sud. Il porte, le long de la côte orientale, le nom de cocos de Bahic.

On m’a assuré que dans une fazenda voisine du cap Frio il y avait deux dattiers qui portaient du fruit; on en a abattu un; et l'autre est devenu stérile.

Nous fìmes des parties de chasse de tous les côtés, aux environs du cap Frio. Nous avions pris à notre service deux nouveaux chasseurs, Joâo et Ignaçio, qui connaissaient bien le pays. Entre autres animaux, ils nous apportèrent des guaribas, espèce de singes. C'est probablement celle que l'on a décrite sous le nom de Stentor, ou de Mycetès Ursinzus; sa voix forte retentit dans toutes les furêts voisines. Ce singulier animal est remarquable, comme on le sait, par la grandeur de son larinx: particularité que M. de Humboldt a décrite d'après une autre 
espèce de ce genre ( 1 ). La barbe touffue du guariba mâle lui a fait donner sur cette côte le nom de barbado; à Saint-Paul il porte celui de bujio, et plus au nord celui de guariba. Indépendamment de ce singe, nous eûmes aussi le sajou cornu qui a sur la tête deux longs bouquets de poils (simia fatuellus, $L$.), et le marikina ou petit sahoui rouge (simia rosalia, $L$.). Ils ne sont pas rares dans les environs du cap Frio; mais nous ne les avons pas trouvés un peu plus au nord.

Sur le bord des lagunes et des marais, notamment dans le voisinage des mangliers ( $R h i$ zophora, Conocarpus et Avicennia), nous trouvâmes dans la terre un grand nombre de trous qui sont les repaires des crabes; on nomme ici cette espèce guayamu; on ne doit pas la confondre avec une autre qui vit dans le sable sur le bord de la mer, et qui porte le nom de ciri. Marcgraf fait mention des deux espèces. Le guayamu est plus grand que le ciri, de couleur bleu d'ardoise, se rapprochant un peu du gris-

(1) Recueil d'observations de zoologie, pl. IV, $\mathrm{n}^{\circ} 9$. Cette espèce est nommée singe barbu dans les Tableaux de la nature, tom. I, pag. 60.

I. 
de-fer sale, sans aucune tache. Ces crustacés sont difficiles à prendre, car au moindre bruit ils rentrent dans leurs trous; ce qui me fit prendre le parti de les tuer avec du petit plomb. Ils font une des principales nourritures des Brésiliens, dont l'indolence va quelquefois si loin, que, lorsqu'ils manquent de poissons, ils mangent ces guayamus, qui, d'après notre expérience, sont un mets bien misérable.

Je trouvai dans les buissons des sables, deux espèces de lézạrd qui y étaient très-communes : la plus grande était le lacerta ameïca de Daudin, à dos vert avec les côtés tachetés de diverses couleurs. On me donna ici la peau d'ur boa constrictor. Daudin a tort d'indiquer l'Afrique comme étant exclusivement la patrie de ce serpent gigantesque, car il est le plus commun de ce genre au Brésil; on les connaît généralement sur la côte orientale sous le nom de jiboya.

Notre collection, déjà considérable, s'était beaucoup augmentéè Villax do Cabo-Frio, notamment d'oiseaux aquatiques et d'oiseaux des marécages. M. Carvalho nous promit de l'envoyer à Rio-de-Janeiro; mais nous eûmes bientôt sujet de nous défier de la complaisance 


\section{AU BRÉSIL.}

que cet homme nous avait témoignée avec excès, car il fit voir que l'intérêt seul le guidait, et il le poussa au point de nous obliger à lui donner un certificat des services importans qu'il nous avait rendus. Nous n'eûmes pas plus à nous féliciter d'avoir fait la connaissance de l'apothicaire du lieu, qui avait l'air de s'intéresser beaucoup à nos travaux, et auquel nous supposâmes d'abord quelque instruction; mais nous remarquâmes bientôt qu'il avait la tête un peu dérangée. Nous fûmes même forcés de finir par lui parler sérieusement, parce qu'il avait répandu dans la villa des bruits désavantageux sur notre compte. Sa sotte malice ne lui profita pas; nous apprîmes ensuite que la police l'avait puni de ses calomnies par quelques jours de prison. 


\section{CHAPITRE IV.}

Voyage du cap Frio à Villa de San-Salvador dos Canipos dos Goaytacasés. - Campós Novos. - Rivière et Villa de San-Joao. - Rio das Ostras. - Fazenda de Tapebuça. Rivière et Villa de Macahé. - Paulista. - Coral de Battuba, - Barra do Furada. - Rio Barganza. - Abbaye de San-Bento. - Vilia de San-Salvador sur le Paraïba.

LE 7 septembre nous fîmes traverser la lagune à notre bagage, qui fut suivi de nos mulets. Ils avaient passé le temps de notre séjour à Villa do Cabo-Frio, dans une fázenda isolée au-delà de la lagune, où on les avait mis au vert. Le 8 , accompagnés de M. Carvalho, nous quittâmes le canton du cap Frio, en nous acheminant lentement le long de la lagune; lorsque nous entrâmes dans les forêts, quelques-uns de nos animaux s'échappèrent; on eut beaucoup de peine à les rattraper; mais bientôt après, accoutumés, par notre long séjour au cap Frio, à errer en liberté dans les 
pàturages, ils nous occasionnèrent un bien plus grand désagrément au milieu d'un chemin creux. J'allais lentement en avant de la tropa, lorsque j'entendis tout à coup les mulets chargés du gros bagage courir au grand galop derrière moi. Celui que je montais prit aussi son essor avec une telle pétulance, qu'il n'y avait pas moyen de le retenir. Pour ne pas avoir les jambes fracassées par le choc des caisses des mulets chargés, je poussai le mien de côté ; aussitôt toute la troupe se dispersa dans la forêt; quelques-uns jetèrent leur charge à terre, en déchirant et brisant leurs harnois. Nous étions hors d'haleine et épuisés de fatigue; ne pouvant deviner la cause de cette catastrophe tragi-comique, nous parcourûmes dans toutes les directions les halliers voisins; et ce ne fut qu'après un espace de temps assez long, qu'avec le secours de nos tropeiros qui suivaient les animaux à la piste, nous pûmes tous les rassembler. Des chasseurs portugais qui poursuivaient des cerfs dans cette forêt, et cherchaient un chien égaré, nous remirent dans notre chemin. Les cerfs de ce canton sont de deux espèces; l'une décrite par Azara sous les noms de guazupita et de guazubira, et nom- 
mée à tortfallow-deer ou daim, par Mawe (1). Koster dit même, en parlant d'une de ces deux espèces de cerf (2), que c'est une antilope, tandis que ce genre de quadrupède, comme on le sait, n'existe pas dans le Nouveau-Monde. En général on trouve au Brésil quatre espèces de cerfs, qu'Azara a décrites le premier, et il paraît qu'elles sont répandues dans presque toute l'Amérique méridionale. La plus commune est la veado mateïro des Portugais, le cerf rouge ou le guazupita, dont Azara a donné une trèsbonne description; on le rencontre dans toutes les forêts et les halliers; on mange fréquemment sa chair, quoiqu'elle soit sèche et filandreuse.

La tropa remise en ordre, nous continuâmes notre route au milieu d'une forêt d'arbres gigantesques, souvent interrompue par des clairières où des prairies coupées de marécages et de touffes de roseaux nourrissent une quantité de hérons, de canards, de vanneaux et d'autres oiseaux semblables. Le cri du querquer retentit partout, et dans toutes les forêts

(1) P. 80 (tom. I, pag. 155 ).

(2) P. 136 (tom. I, pag. 242). 
on entend fréquemment la voix sonore de l'araponga. Plusieurs espèces d'eugenia frutescentes étaient couvertes de fruits mûrs; ils sont noirs, très-savoureux, et de la grosseur d'une petite cerise. On voyait çà et là de grands nids de termites; ils devaient ètre très-vieux, car ils avaient huit à dix pieds de hauteur. Nos mulets nous occasionmèrent de nouveaux dérangemens, en s'enfonçant profondément dans des eudroits marécageux. Enfin les marimbondes(1), espèce de guêpe très-méchante, nous tourmentaient continuellement; leur piqûre produit un bouton et une douleur très-vive, mais de peu de durée. Nous avions pour compensation à tous ces inconvéniens la beauté des arbres de la forêt que nous traversion; ; leurs troncs élancés, revêtus d'une écorce blanchâtre ou d'un rouge brunâtre, avaient quelque chose de vénérable; tandis qu'aüdessous, dans les parties les plus épaisses, les fleurs des mimosas et des justicias répandaient une odeur suave. Le buginvillæa brasiliensis étalait ses belles fleurs rouges, et des bignonia

(1) Mawe les nomme à tort mirabundé, p. 134 (tom. I, pag. $2.56 \mathrm{~J}$. 
couverts de grandes fleurs d'un jaune doré élevaient leurs tiges sarmenteuses jusqu’à lá cime des arbres les plus hauts.

Le jabiru (ciconia americana ou tantalus locutator, L.), et des hérons de diverses espèces, surtout des aigrettes blanches, se promenaient dans une grande prairie marécageuse, où le bétail s'enfonce profondément dans l'eau; le çipo vert (coluber bicarinatus), serpent long de six à huit pieds, s'éloignait de nous avec la vitesse d'une flèche, pour' se cacher, dans les hautes herbes, et des troupes de maracanas se reposaient sur les buissons qui bordaient la prairie. Un voyageur que nous avons rencontré nous ayant appris que nos chasseurs, qui nous précédaient avaient tué une quantité de beaux oiseaux, nous avons pénétré plus avant dans les profondeurs de la forêt où nous nous sommes rafraîchis avec le suc des oranges sauvages (laranja da terra), dont le goût est d'une douceur fade; leurs fleurs répandaient une odeur délicieuse et attiraient une multitude de colibris (1). En sortant de cette forêt nous avons

(1) Au Brésil, les orangers ont besoin d'être greffés pour donner de bons fruits; faute de celte opération, ceux qu'ils produisent sont fades et amers. 
aperçu une prairic ouverte, où la grande fazenda de Campos-Novos, mieux nommée fazenda do Re, est bâtie sur une colline médiocrement élevée. Les cases des négres forment, auprès de la maison du propriétaire ou capitam, un carré qui a donné naissance à un petit village. Celte fazenda, ou au moins l'église voisine, a été construite par les jésuites.

Forcés d'attendre un mulet resté en arrière, nous séjournâmes quelques jours dans ce lieu, et nous les mîmes à profit pour parcourir les environs. Un chasseur, natif de Naples en Italie, vint dans la venda, et nous montra la peau d'un singe nommé mono par les habitans, et qui vit dans certaines parties de la forêt. Nous poursuivîmes long-temps cet animal sans succès; nous finîmes par être plus heureux, et un examen attentif me le fit reconnaître pour une espèce du genre ateles ( 1$)$; c'est le grand singe dont les chasseurs, dans les cantons que nous avions parcourus, emploient la peau pour mettre

(1) Ateles hyporanthus, à longs membres et à queue forte €t longue; pelage gris jaunâtre sale, souvent jaune rougeâtre à la naissance de la queue; face couleur de chair, parsemée de points et de taches noires. Longueur de la 
la batterie de leur fusil à couvert de la pluie. Les forêts, à quelque distance autour de la fazenda de Campos-Novos, sont remplies de cette espèce de singe. Nos chasseurs avaient tué plnsieurs guaribas ou barbados; un vieux mâle fut apporté encore vivant à notre maison. M. Mawe, qui n'a probablement pas fait une étude approfondie de la zoologie, dit assez plaisamment, en parlant de cet animal, qu'il ronfle si fort en dormant que les voyageurs en sont étonnés (1).

Nous avons trouvé au milieu des herbes et des joncs des marais voisins, les jolis œufs couleur de rose du limaçon des marécages, nommé helix ampullacea, qui étaient réunis en tas. Ce limaçon est très-commun dans les marais desséchés du Brésil, sa coquille est d'un brun olive foncé; 'le grand limaçon de terre se rencontrait fréquemment dans toutes les forêts que nous avons traversées; on le regarde comme une variété de l'helix ovalis; l'animal

pointe du nez à l'extrémité de la queue quarante-six pouces six lignes. Le pouce des mains ne consiste que dans un rudiment court. C'est par là que cette espèce se distingue de l'ateles arachnoïdes, ou coaïta fauve de Geoffroy.

(1) P. 135 (tom. I, pag. 233 ). 
est de couleur orange pâle, sa coquille est ordinairement d'un brun jaunâtre pâle. Nous vîmes sur les branches des arbrisseaux le nid d'une espèce de guêpe (pelopceus lunatus)(1); il est construit en terre, il a la forme et la grosseur d'une poire; quand on le brise, on trouve éparpillées dans la masse cinq, six à sept larves, ou insectes dẻjà formés: cette espèce est la même que la guêpe décrite par Azara (2), ou bien elle s'en rapproche beaucoup; elle attache de petites maisonnettes, ou cellules d'argile, aux parois des édifices ou des chambres des maisons de la côte orientale du Brésil. Je la regarde comme identique avec celle qui fixe son nid aux branches des arbres.

A notre départ, le joli paysage qui nous entourait nous parut encore plus agréable qu'auparavant; la prairie était entourée de petites collines boisées; des buissons d'une verdure brillante et douce nous rappelaient le printemps de l'Europe; ils consistaient en une espèce de gardenia, nommée ici cuiranna, qui n'a probablement pas encore été décrite; elle forme

(1) Fabricius, S. Piez, pag. 203).

(2) Voyages, tom. I, pag. 173. 
un arbre dont le bois est utile. Comme la mer est assez éloignée, les forêts sont remplies de singes et de gibier. L'antique et belle forêt (mato virgem) qui s'étend depuis Campos-Novos, presque sans interruption, jusqu'au Rio San-Joao, sur une longueur de quatre legoas, et dans les profondeurs de laquelle nous étions enfoncés, mérite une mention particulière. Nous arrivâmes bientôt à un marécage pittoresque environné de jeunes cocotiers et d'héliconias touffus. Ces végétaux forment les broussailles au-dessus desquelles s'élancent les arbres gigantesques de la forêt. Le surucua ou couroucou vert, bleu et jaune (trogon viridis. L.) y était très-commun, et se faisait entendre au milieu du feuillage le plus épais; nous imitâmes sa voix et nous en tuâmes plusieurs, $\tan t$ mâles que femelles. On le rencontre fréquemment dans tout le voisinage.

La forêt s'embellissait de plus en plus, des fleurs magnifiques et nouvelles donnaient de nombreuses occupations à nos botanistes. Des cipos ou lianes, entortillés autour des arbres de la manière la plus singulière, notamment de superbes banisteria, la plupart avec des fleurs jaunes, des cocotiers à tige de forme 
remarquable et quelquefois entrelacés d'une façon extrêmement pittoresque, sont pour ces forêts un ornement qui ne se peut décrire: les bromelias paraient de leurs fleurs les branches élevées. La voix d'oiseaux que nous ne connaissions pas excita notre curiosité; l'araponga on procnias blanc était extrêmement commun (1).

Le chemin sablonneux nous fatiguait beaucoup; mais la beauté de la forêt nous offrait un ample dédommagement à nos peines. Sur un arbre tortu, je trouvai un serpent de conleur gris de plomb et long de six à sept pieds, que je nommai coluber plumbeus (2); il nous laissa passer sans bouger : je lui fis tirer un coup de fusil par un de nos chasseurs; ce fut avec bien de la difficulté que je parvins à engager un nègre qui était chargé de nos plantes, à porter sur son épaule au bout d'un long bâton le

(I) Procnias, genre d'oiseaux formé par Illiger. Il comprend les cotingas blancs ou guirapunga, à gorge nue, et averano.

(2) Ce reptile avait six pieds un pouce quatre lignes de long. Il avait deux cent vingt-quatre plaques abdominales, et soixante-dix-neuf paires de caudales. Le dessus du corps est de couleur de plomb foncé ; le dessous blanc jaunàtre, brillant comme de la porcelaine. 
reptile mort que nous avions empaqueté danś une toile. Le nègre cheminait depuis quelque temps, lorsqu'il aperçut encore un petit mouvement dans son fardeau; sa frayeur en fut si grande, qu'il le jeta bien loin de lui, et prit la fuite. A quelque distance, nous trouvâmes nos chasseurs qui se reposaient au pied d'un arbre; ils avaient tué plusieurs toucans, des arassaris, des surucua et un petit sahoni rouge.

Le soir nous arrivâmes au bord du Rio SanJoao qui se jette dans la mer, près de la villa bâtie dans cet endroit. Il a trois à quatre cents pieds de large; on le passe en pirogue; nos inulets le traversèrent à gué un peu plus haut. Nous abordâmes de l'autre côté à Villa da Barra do San-Joao, bourgade qui a plusieurs rues et d'assez bons bâtimens, à la manière du pays. L'église, bâtie du temps des jésuites, est isolée sur un rocher près de la mer. Barra do San-Joao est un des lieux où les voyageurs et les marchandises qui viennent de Minas-Geraës sont visités pour empêcher l'exportation illicite des pierres précieuses. Le fleuve étant navigable; il y avait cing à six brigs à l'ancre. Un forgeron anglais, établi dans la villa, nous raconta que déjà des navires de son pays 
étaient venus dans ce coin solitaire, ce qui lui avait donné l'idée de se faire nommer viceconsul de sa nation. Ses idées ambitieuses ne l'empêchèrent cependant pas, à notre grande satisfaction, de mettre la main à l'ouvre pour réparer des armes que nous lui remîmes. Le manque de bons ouvriers en ce genre est trèspénible pour le naturaliste qui parcourt le Brésil; car il est très-rare de trouver des gens qui entendent même la partie la plus grossière du travail de l'armurier. L'on cultive près de San-Joao beaucoup de riz et de manioc: on dit que le terrain, surtout en remontant le fleuve, est très-fertile; le sable même est fécond dans les endroits oú il est suffisamment arrosé.

En quittant la pointe sablonneuse située entre le fleuve et la mer, et sur laquelle la villa est bâtie, nous suivîmes la côte au nord. Dans une plaine couverte d'arbrisseaux variés, croissaient un amaryllis d'un rouge écarlate, avec. des spathes à deux fleurs', des banisterias à fleurs jaunes, et de jolies espèces de myrtes.

A gauche nous avions le Monte do San-Joao, haute montagne isolée, en avant de laquelle desforêts, et au-delà de celles-ci des marécages 
couverts de broussailles s'étendaient dans la plaine vers la mer.

Après avoir traversé des champs de manioc mis en culture depuis peu de temps, ainsi que le prouvaient des souches brûlées que l'on voyait éparses, nous arrivâmes par un chemin sablonneux et pénible au bord de la mer, près d'une jolie colline rocailleuse plantée de cocotiers, qui s'avançait en mer, et au pied de laquelle le Rio das Ostras avait son embouchure; nous remontâmes, à la distance d'une centaine de pas, cette petite rivière qui est très-limpide; la tropa fut déchargée, et nous passâmes l'eau. Les bords du Rio das Ostras sont enchanteurs; de grands arbres touffus les couvrent de leurs branches pendantes, et des cocotiers les ombragent. Un Portugais, marié à une Indienne, demeure seul en ce lieu avec sa famille. Il fait partie de la milice, et surveille le passage de la rivière. Accablé du poids de cette double besogne, cet homme me parut très-mécontent de sa position. Il serait très-facile d'établir en cet endroit un petit pont qui épargnerait une perte de temps considérable au voyageur; car à peine $\mathrm{a}-\mathrm{t}$-on le matin eu l'embarras de charger une tropa à San-Joao, 
que deux heures après il faut défaire ici tout le bagage.

Ayant trouvé au-delà de la rivière de petites huttes en terre qui étaient vides, nous nous y sommes mis à l'abri de la pluie. Avant d'arriver de nouveau sur le rivage par cette route, on franchit des collines couvertes de taquarussu, grand roseau qui s'élève à trente et quarante pieds de hauteur. Ses tiges colossales, qui ont jusqu'à six pouces dediamètre, se recourbent doucement à leur estrémité; les feuilles sont pinnées, les branches sont armées de piquans courts et forts, qui rendent impénétrables les buissons que forme cette espèce de bambusa ; ils sont d'ailleurs extrêmement touffus; le grand nombre de feuilles sèches et de spathes desséchés qui tom!sent et restent entre les tiges produisent au moindre soufle de vent un bruit particulier. Le chasseur rencontre ces halliers avec plaisir, car en coupant une tige au-dessous du noud, il en découle une eau fraîche et agréable, quoique un peu fade, qui apaise l'ardeur de la soif. Cette plante remarquable aime les terrains montagneux et secs: c'est pourquoi elle est très-commune dans -la capitainerie de Minas Geraës, où l'op fait I. 
des gobelets de ses tiges. En marchant le long de la mer nous avons rencontré près de quelques maisons isolées une autre plante également utile le pitte (agave fatida). Ses feuilles à bords lisses, roides, longues de huit à dix pieds, forment des haies solides; de leur centre s'élève une hampe robuste haute de trente pieds, qui porte des fleurs d'un jaune verdâtre, et' donne au paysage un aspect singulier. La moelle de la tige, nommée pita, tient lieu de liége aux naturalistes qui recueillent des insectes, Sur le hord de la mer des palmiers nains, des bromelia et d'autres plantes que le vent empêche de s'élever forment des halliers impénétrables. Nous fûmes très-bien reçus à la fazenda de Tapebuçu, par le propriétaire, qui est enseigne (alferez) de la milice. Cette fazenda est dans une charmante situation sur une colline près 'de la mer; derrière s'élèvent des forêts, elles n'en sont séparées que par une lagune dont les eaux réfléchissent l'image des arbres; la vue se porte sur une vaste plaine couverte de forêts inaccessibles et au milieu de laquelle s'éleve la serra de Iriri, montagne isolée et remarquable par ses cinq cimes coniques et boisées; plus au sud on 
voit le Monte de San-Joào qui est de même solitaire.

Les terres de la fazenda ont une liene de long, et sont cultivées en partie en manioc et en maïs; on y récolte aussi un peu de café. La lagune est poissonneuse. On a planté autour de la maison des orangers dont les fleurs odorantes attirent une quantité de colibris. Des chasseurs trouvèrent une riche proie dans les forêts voisines; ils tuèrent des perroquets, des maracanas, des toucans, des pavos et d'autres beaux oiseaux. Notre herbier s'enrichit aussi ; je trouvai plusieurs espèces de cocotiers, entre autres l'aïri, dont les fruits venaient de mûrir , et le tucum ou palmier épineux des marais, dont la tige, haute de quinze palmes, est pourvue, ainsi que le petiole, d'aiguillons minces. Mawe donne à cet arbre des feuilles dentées en scie et lanceolées (1), tandis qu'elles sont pinnées avec des folioles lisses, entières et acuminées. Arruda en donne une meilleure description (2), mais il n'en avait pas examiné les fleurs.

(1) P. 127 (tom. I, pag. 223).

(2) Voyage de Koster, Appendice, p. 484 ( $10 \mathrm{~m}$. II, pag. 472 ). 
M. Sellow pense avec beaucoup de vraisemblance que cet arbre n'appartient pas au genre des cocotiers. Marcgraf, Mawe et Koster ont suffisamment fait connaitre son utilité. Les folioles ont des fibres très-fortes qui restent à nu lorsqu'on brise le parenchyme qui les recouvre; on les tord et on fait des cordes fines, solides, et de couleur verte, qui servent principalement à fabriquer d'excellens filets pour la pêche. Ce palmier est très-commun dans ce canton, et porte une petite noix dure et noire quï renferme un amande bonne à manger. On prend les feuilles avant qu'elles soient développées, on les dépouille de leur enveloppe, et, après les avoir dégagées du mucilage qui les retient collées, on s'en sert pour couvrir les maisons, on en fait aussi des nattes et des corbeilles fort jolies.

Nous avons trouvé dans les forêts épaisses de cet endroit une quantité de beaux arbres. Lipè était couvert de grandes fleurs d'un jaune foncé, une antre bignonia à fleurs blanches croissait dans les marais. Le quatelé, ou sapucaya, s'élevait au-dessus des arbres les plus hauts; il est remarquable par ses petites feuilles et ses fruits pendans qui ressemblent à un pot muni de son 


\section{AU BRÉSIL.}

couvercle, et qui renferment des amandes bonnes à manger (1). Les singes, et surtout les grands, ainsi que les aras rouges et bleus (psittacus macao et ararauna, L.), en sont très-friands. Sans les ailes des perroquets et sans l'agilité des singes à grimper aux arbres, il est très-difficile d'obtenir ces fruits qui pendent à une hauteur considérable: ordinairement on coupe l'arbre; les Indiens y grimpent à l'aide des cipos ou lianes entortillées autour des troncs, ce qui leur facilite beaucoup le moyen d'arriver. Dans une autre partie de chasse nous avons examiné un palmier que $\mathbf{M}$. Sellow regarde comme un nouveau genre : son spadix jaune était pendant, le spathe, en forme de nacelle, était grand, et de même que les feuilles pinnées, d'une beauté remarquable. En travaillant à abattre cet arbre, le bois en parut très-dur; mais dès qu'on fut parvenu au coeur, très-poreux, il tomba aussitôt.

Le 16 septembre nous prîmes congé de la famille de notre hôte, et nous nous mîmes en

(x) Ce fruit est représenté dans le cinquième cahier de la Ménagerie du Iruséum d’histoire naturelle, sur la même planche que l'agouti. 
route pour Macahé. La pluie et le vent troublèrent l'atmosphère; nous ne pûmes jouir de la belle perspective du pays où la serra de Iriri s'élevait du milieu de forêts sombres, et le morro de San-Joào se montrait dans le lointain. La route de Tapebuçu au Rio-Macahé traverse pendant quatre legoas des sables profonds, et suit presque toujours le bord de la mer; çà et là des monticules rocailleux avancent au milieu des flots; on trouve sur lesurs flancs une quantité de mousses et de moules, mais d'espèces peu variées. Un vent violent poussait les lames contre le rivage où elles venaient briser avec grand bruit. Depuis la plage s'élève une rangée de collines couvertes d'arbres et d'arbrisseaux que le vent empêche de croître très - haut, et qui ont l'air d'avoir été rasés. Nous distinguâmes au milieu de ces végétaux une grenadille et un cactus quadrangulaire, tous deux ornés de grandes fleurs blanches.

Le printemps régnait dans cette contrée : jusqu'à présent nous avions trouvé le temps généralement frais; il ne nous avait pas paru plus chaud qu'il ne l'est en Allemagne dans le cour 
de l'été. Nous parcourûmes le dernier mille à travers une antique et épaisse forêt où nous tuâmes des toucans, des arassaris, et le petit coucou noirâtre (cuculus tenebrosus). Plusieurs arbres étaient dépouillés de leurs feuilles; car quoique la plupart les conservent pendant l'hiver, les espèces les plus délicates les perdent. Presque tous faisaient leur pousse en ce moment; les extrémités des branches, couvertes d'un feuillage vert foncé, offraient de jeunes feuilles jaunâtres ou d'un vert jaune, souvent d'un rouge doux ou foncé qui ornent extrêmement les bois ; d'autres étaient en fleurs, d'autres enfin portaient en même temps des fleurs et des fruits. Cette réunion du printemps et de l'automne dans les forêts des tropiques présente le coup d'œil le plus intéressant aux voyageurs nés dans les pays du Nord. Nous arrivâmes, traversés par la pluie, à villa de Macahé, sur la rivière de mêmé nom, qui se jette dans la mer après avoir, dans son cours de quinze legoas, baigné la serra de Iriri : elle est assez considérable. Lery dans son voyage fait mention de ce canton que les indigènes nommaient $M a q-$ $H e^{\prime}$; il était alors habité par des sauvages qui 
combattaient avec les Ouètacas ou les Goaytacasés sur le Paraïba (1).

La petite villa de San-Joao de Macahé est composée de maisons éparses sur le bord de la rivière au milieu des bois. Le Macahé décrit à son embouchure un coude autour d'une langue de terre saillante. Les maisons, quoique hasses, sont en partie propres et jolies, construites en terre soutenue par des jambages de bois, et souvent enduites de blanc. Des cours (quintaés) formées par des tiges de cocotiers les entourent, et sont remplies de chèvies, de cochons et de volailles. Les habitans font un petit commerce de farinha, de haricots, de maïs, de riz et de sucre; ils exportent aussi des bois : c'est pourquoi il y a toujours quelques sumacas ou lanchas, espèce de navires caboteurs, mouillés devant la villa. On dit que dans le Sertam, sur la partie supérieure de la rivière, des Indiens Garoulhos, ou Guaroulhos, habitent dans des aldeas ou villages. L'ouvrage intitulé Corografia brasilica parle de cette tribu sous le nom de Guaru, et dit que dans la serra dos

(1) Voyage, pag: 53. 


\section{AU BRÉSIL.}

Orgaos on en trouve encore un reste nommé sacourous, qui sont entièrement civilisés; mais ils ont presque entièrement disparu. Il en existe entre autres, ajoute-t-on, dans la Freguesiade-Nossa-Senhora-das-Nevès (1). La pluie nous retint quelques jours dans cet endroit, ce qui nous donna le loisir derassembler des graines de coulequin (cecropia) et d'autres plantes à capsules. Nous en partîmes un dimanche après midi.

Une pluie violente nous surprit et nous accompagna, pendant une lieue et demie, au milieu des forêts et des broussailles le long du bord de la mer jusqu’à la fazenda de Baretto, où nous arrivâmes pendant la nuit et prîmes possession d'une maison vide. Les prairies et les forêts marécageuses que nous avions traversées nous avaient offert le spectacle d'une multitude d'insectes lumineux qui volaient de tous côtés, entre autres le taupin-lanterne (elater noctilucus ), dont Azara fait mention, et qui a sur le corselet deux points verts, clairs et luminenx (2).

(1) Corografia brasilica, tom. II, pag. 45.

(2) Voyages, tom. II, pag. 211. 
L'engoulevent était très-commun : il volait doucement dans les sentiers obscurs de la forêt, et se posait souvent à terre à nos pieds. Cet oiseau a le cri très-fort, et, suivant les Portugais, répète les mots joc̀o corta pao, Jean coupe du bois : il nous rappela la hulotte (strix aluco, L.), qui, au crépuscule, fait retentir sa voix dans les forêts d'Europe. L'engoulevent la remplace dans ce pays.

Comme le mauvais temps continuait, nous restâmes le 18 septembre à Baretto, et nous $\mathrm{y}$ augmentâmes nos collections de plusieurs oiseaux intéressans. Dans un moment où je cherchais à surprendre le coucou décrit par Azara sous le nom de $\operatorname{chochi(1),~que~je~guettais~en~}$ vain depuis long-temps, je vis voler tout à coup au-dessus de moi un couple de milans noirs et blancs à queue fourchue (falco furcatus, L.), dont la blancheur éclatante était rehaussée par la couleur sombre des nuages; $j$ 'en tuai un, je me cachai, et je fis aussi tomber l'autre, ce qui

(1) Coucou brun varié de roux. Buffon, Histoire naturelle, tom. XII, pag. 77 , et planches enluminées, $\mathrm{n}^{\circ} 812$, sous la dénomination de coucou tacheté de Cayenne ( cusulus ncevius, L. ). 
me dédommagea bien du coucou qui m'avait échappé.

Nous fümes bien contens de pouvoir quitter Baretto, parce qu'il y avait dans cet endroit deux vendas ou cabarets qui avaient occasionné des batteries sérieuses parmi nos gens. Le voyage le long du bord de la mer en allant au nord est pénible, à cause des sables profonds qu'on y rencontre; c'est pourquoi nous ne sommes arrivés que fort tard à notre destination. Nous avons vu sur notre route de jolies haies de mimosas autour de quelques jardins, et un cocotier cultivé chargé de fruits, ce qui est une véritable rareté dans cette contrée. Nous avons traversé ensuite des champs de manioc. Les plantes étaient bien alignées entre des troncs d'arbres abattus et brûlés, et buttées comme les pommes de terre dans nos pays. Plus loin nous avons trouvé des marécages où croissaient de grands arbres et des buissons de bignonia it fleurs blanches.

Les ruines d'une maison considérable et d'autres objets qui nous entouraient semblaient annoncer que ce canton fut autrefois plus cultivé qu'il ne l'est aujourd'hui. Nous eûmes aussi l'occasion d'y observer une quantité incroy able 
d'urubus (vultur aura, L.) qui s'étaient rassemblés surle cadavre d'un bœuf, et qui étaient si peu farouches qu'ils partageaient tranquillement leur proie avec un gros chien, et ne s'enfuirent pas du tout à notre vue. Nous avons vu aussi de grandes volées de perroquets à longue queue, ou de maracanas et de périkittos, qui remplissaient l'air en criant de toutes leurs forces. Tous ceux que nous avons tués avaient le bec bleu, pour avoir mangé un fruit qui venait de mûrir. Dans un endroit de la forêt où les arbres étaient très-hauts, nous avons tiré des toucans; sur les branches sèches et les plus élevées des arbres, nous apercevions ordinairement des oiseaux de proie solitaires qui se tenaient anx aguets, surtout le faucon couleur de plomb ( falco plumbeus,L.), qui se précipite d'un vol hardi et rapide sur la proie qu'il a aperçue.

Nous vîmes ici entre autres arbres celui qui est nommé tento par les Portugais (1). Ses feuilles sont d'un vert foncé, et pinnées; il porte

(1) Ormosia coccinea. Jackson, Transactions of the Linnean society. Nouveau genre qui a d'abord été trouvé en Guinée. Il ne se trouve pas dans le Species plantarum de Wildenow. 
des gousses courtes et larges qui renferment des graines d'un rouge vif dont les Portugais se servent comme de marques au jeu (tentos). Nous n'en vîmes pas les fleurs. Les buissons qui croissent dans les sables de ce canton produisent une quantité de plantes intéressantes. Dans les endroits marécageux nous avons trouvé un arbre haut de huit à dix pieds qui porte de grandes fleurs blanches, et qui paraît avoir de l'affinité avec le bonnetia palustris; une belle espèce d'évolvulus (1); une petite casse à fleurs jaunes; une asclepiadea (2) rampante à fleurs blanches et roses; une andromeda (3) à fleurs rouges; les deux espèces que nous avions déjà vues au cap Frio, et plusieurs autres.

Vers le soir notre caravane atteignit le bord de la mer; les ruines d'une ancienne chapelle dans un lieu triste, solitaire et sablonneux, étaient parfaitement en harmonie avec le fracas des vagues qui brisaient sur le rivage; des bois très-bas et rabougris qui se prolongeaient jus-

(1) Nouvelle espèce dont ni Persoon, ni Wildenow, ni Ruiz n'ont fait mention.

(2) Eclites.

(3) Nouvelle espèce : ses fleurs sont d'un rouge vif. 
qu'aux forêts dans, l'Ouest attestaient la violence des vents qui règnent dans ce canton. Nous avons continué à marcher jusqu'à la nuit le long d'une langue de terre étroite entre la mer agitée et une longue langune, et nous sommes arrivés à Paulista, bergerie isolée, où nous n'avons trouvé pour apaiser notre faim qu'un peu de farinha pour nous et du maïs pour nos chevaux. Heureusement nous nous étions pourvus à Baretto d'une petite quantité de viande desséchée (carne secca) et de haricots (feigoës). La maison étant assez grande, nous y sommes restés toute la journée dủ lendemain pour nous reposer de nos fatigues.

Nous avons tué beaucoup d'huitriers du Brésil (haematopus), qui couraient en troupes le long de la côte dans les forêts entremêlées d'un grand nombre de cocotiers, et diverses petites chouettes que les habitans appellent cabouré, mais qu'il ne faut pas confondre avec celle que Marcgraf nomme ainsi (1). Cette

(1) Strix ferruginea. Longueur : six pouces sept lignes; couleur de rouille; taches jaunes, pâles ou blanchàtres, sur les plumes scapulaires et les grandes pennes rectrices; une grande tache blanche au-desso us du cou; queue couleur de 


\section{AU BRÉSIL.}

chouette nouvelle paraît avoir de l'affinité avec le cabure d'Azara. Nous avons abattu plusieurs palmistes abondans en ce lieu pour a voir leur moelle. Cet arbre appartient aux plus élégans el aux plus sveltes, de la forme des cocotiers. Sa tige est mince, élancée, annelée. Sa cime, composée de huit à dix feuilles pinnées, d'un vert brillant, se balance majestueusement en l'air. Au-dessons de ce beau panache, sa tige d'un gris argenté offre à son extrémité un bouton qui a la verdure vive du feuillage, et dans la partie supérieure duquel les jeunes feuilles sont roulées et plissées les unes sur les autres: elles renferment dans leur centre les fleurs non encore développées; celle qui est déjà formée brise son spathe verdoyant. Si l'on coupe le bouton à l'extrémité de la tige, ou le spathe des jeunes fleurs, on en trouve l'intérieur si tendre el si moelleux, qu'on le peut manger cru; mais cuit il est encore plus savoureux. Le bois de cet arbre est fort dur; nous eûmes beaucoup de peine à l'abattre avec la serpe (jaçcio). Le palmier tucum fleurissait

rouille unie; ventre jaune rougeàtre clair, mêlé de blanc, avec de longues raies brunes; iris jaune foncé. 
aussi dans les lieux marécageux; et dans les plaines sablonneuses ouvertes, une nouvelle espèce de stachytarpheta fort jolie, et un beau cactus conique, semblable au mamillaris, qui à sa partie supérieure renferme une laine blanche au milieu de laquelle se trouve sa petite fleur d'un rouge foncé. M. Sellow regarda cette espèce comme nouvelle.

Nos collections d'oiseaux ne recurent pas en ce lieu un accroissement considérable; car, à l'exception de quelques oiseaux de marais, nous n'en rencontrâmes pas beaucoup de nouveaux. Le sabia da praya (turdus orpheus, $L$.), dont le plumage est peu éclatant, mais qui chante admirablement, et qui sous ce rapport est un des plus remarquables du Brésil, fait entendre sa voix mélodieuse tout le long de la côte sur les buissons où il se perche. Le petit gecko blanchâtre (1), qui court sur les murs les plus droits, était commun dans les bâtimens; de même que le lézard à collier noir (2). Ils

(1) C'est vraisemblablement le gecko spiricanda de Dandin. (Histoire naturelle des reptiles, tom. IV, pag. I15.)

(2) Stellio torquatus : il paraít avoir de l'affinité avec le stellio quetz-paleo de Dandin (Hist. natur. des reptiles, 
AU BRESIL.

abondent dans toute la contrée que j’ai vue. Sur le rivage nous trouvâmes peu de moules. Les branches des arbrisseaux, dans les marais, servaient de support aux nids pyriformes en terre, de l'espèce de guêpe dont j’ai parlé plus haut (1).

En quittant Paulista, nous suivîmes les dunes. De vastes marais et des lagunes couvertes de roseaux, dans lesquelles les boufs et les chevaux, en nombre considérable, ont de l'eau jusqu'à la moitié du ventre en

tom. IV, pag. 26). La couleur de cette espèce varie beaucoup; l'animal a dans sa jeunesse, le long du dos, de longues raies sombres qui disparaissent avec l'àge; il devient ensuite gris argenté, avec des reflets pourpres et cuivrés et comme parsemés de points clairs : toutefois, le caractère distinctif de l'espèce est immuable; c'est une tache noire, oblongue, au côté du cou, en avant de l'épaule, et trois raies sombres qui s'élèvent perpendiculairement au-dessus de la paupière fermée. Les descriptions du quetz-paleo sont en général trop incomplètes; cependant il est impossible de le méconnaittre. Le lézard à collier noir porte le nom de lagarta le long de la côte orientale.

(1) Pelopoeus lunatus, Fabr.

I. 
paissant, se prolongent vers l'intérieur du pays. Des quantités de vanneaux (vanellus cayennensis), de hérons, de mouettes, d'hirondelles de mer et de canards, remplissaient ce canton. Les vanneaux quer-quer, dont j’ai déjà parlé comme d'oiseaux très-incommodes pour les chasseurs, volent de même que ceux d'Europe autour de la tête de quiconque s'approche de leur nid.

Les broussailles des dunes consistent ordinairement en bromelias et en cactus mêlés à diverses plantes à feuilles. Les fleurs blanches des cactus à tiges verticales venaient de s'épanouir; quoique plusieurs individus eussent des branches à cinq et à six angles, ils paraissent appartenir tons à une seule espèce, ou en former tout au plus deux, car ce singulier végétal épineux offre, suivant son âge, de grandes variétés dans le nombre de ses angles; il est très dangereux pour les pieds des mulets et des chevaux qui voyagent; un piquant qui pénétre dans le sabot ou dans la jointure d'un de ces animaux ne tarde pas à le rendre boiteux.

Nous avons trouvé dans le sable le turnera ulmifolic, et dans les marais deux espèces de nymphoea à fleurs blanches; l'indica et une 
autre nommée erosa par.M. Sellow; celle-ci a des fleurs très-grandes; enfin un grand fluteau (alisma) à fleurs blanches, et à feuilles étroites et allongées, qui probablement est de même nouveau. Il n'était pas facile de cueillir cette belle plante qui croissait au milieu des marais. M. Sellow s'enfonça profondément dans l'eau et la vase noirâtres; je n'eus pas une meilleure chance en cherchant à attrapper les oiseaux des marécages.

Cette vaste plaine déserte est remplie de boufs errant en liberté à cinq et six milles de distance de toute habitation humaine. Chaque propriétaire des fazendas voisines rassemble une ou deux fois par an dans un corral, ou emplacement entouré de pieux, tous les animaux qui lui appartiennent; ils sont comptés et marqués.

Nous avons fait halte au corral de Battuba, éloigné de cinq légoas de Paulista; il comprend dans son enceinte une grande cabane $\epsilon$ terre. La plaine d'alentour (campo) s'étend à perte de vue. Lues eaux restent fréquemment dans les lieux les plus bas, ce qui donne naissance à des lagunes. Tout l'espace est revêtu d'une herbe courte, que paissent les bestiaux errans. 
Quand on s'approche d'eux ils lèvent la tête en l'air, respirent fortement, et s'enfuient au galop, la quene élevée et flottante. Il est trèsremarquable que, grâce à l'activité et aux soins des Européens, cet animal utile se soit déjà répandu sur la plus grande partie du globe. Dans le nord, le boenf paît au milieu de forêts de bouleaux, où le sol est durci par la gelée : dans la zone tempérée, c'est dans de charmantes prairies entre des bois de hêtres touffus; dans les régions du Tropique, c'est sous des bananiers et des palmiers; dans les îles du grand Océan, c’est sous des melaleuca, des metrosideros, des casuarina. Partout cet aninal indispensable à l'homme civilisé prospère et lui assure l'accroissement de son bienêtre.

A l'approche de la soirée, la troupe éparse de nos chasseurs se réunit pour réparer par un bon repas les fatigues de la journée; malheureusement nos provisions n'étaient pas suffisantes pour nous satisfaire tous. Cependant, comme il était impossible qu'une compagnie de chasseurs souffrît de la faim au milieu de troupeaux de bestiaux sauvages, nous courûmes dans la plaine, et nous nous parta- 
geâmes sur une longue ligne, espérant bien tuer un jeune bouf; la nuit vint trop tôt, les boufs étaient trop farouches, nous eûmes les pieds blessés par des piquans de cactus épars sur đa surface de Ta plaine; il fallut done pour aujourd'hui renoncer à notre dessein et remettre au lendemain la chasse commandée par l'appétit.

La maison où nous passions la nuit tombait en ruines; la pluie pénétrait à travers les trons du toit; couchés dans nos hamacs, nous fummes tourmentés par des essaims de bichos do pé (pulex penetrans) qui nous laissèrent goûter peu de repos. Le lendemain nous en tirâmes de nos pieds des quantités innombrables. Cet insecte, très-commun dans toutes les maisons inhabitées qui se trouvent dans les lieux sablonneux, s'introduit dans les pieds, dans le voisinage de la semelle, dans les doigts des pieds, et aussi entre les ongles des mains. Il n'est pas vrai qu'il entre jusque dans les muscles; il se tient toujours entre cuir et chair. On s'apercoit bientôt de sa présence à une démangeaison trèsvive, qui finit par devenit nne douleur peu considérable; alors il faut creuser avec une aiguille dans l'endroit qui fait mal, en prenant bien 
garde de ne pas crever son corps qui ressemble à une vessie, et quı est rempli d'oufs (1). On fait bien, pour éviter l'inflammation, quand l'animal a été enlevé, de frotter la petite plaie avec du tabac en poudre ou de l'onguent basilic, qui se trouve chez tous les apothicaires du Brésil.

Cette nuit désagréable fut suivie d'un jour sombre et pluvieux; mais nos estomacs nous rappelèrent bientôt la chasse de la veille, commencée et interrompue. Le bétail épouvanté courait de côté et d'autre; nos mulets servirent à le poursuivre. Enfin on tua un bouf d'un coup de fusil; il fut bientôt dépecé, et lorsque chacun ent été rassasié, on se dispersa pour la chasse. Elle fut heureuse. Francisco, l'Indien Coropo, tua un ibis à face couleur de chair, décrit par Azara sous le nom de curucou rose (2); d'autres chasseurs tuèrent deux espèces de fau-

(1) Olof Swartz sienska vetenskaps Acadèmiens nya handiingar ( Nouveaux mémoires de l'académie des sciences a'e Suède), tom. IX, 1788 , pag. 40 , etc., avec figures. Cet insecte est connu sous le nom de chique dans les colonies françaises; Marcgraf lui donne celui de tunga. (E.)

(2) Voyages, etc., tom. IV, pag. 222. 
cons : l'une un joli milan nouveau (1) qui, de même que le falco cyanéus, a la tête garnie de plumes disposées en rayons comme les chouettes, et le falco busarellus qui a le corps roux et la têted'un blanc jaunâtre. Je trouvai près de notre maison un nid de bentavi (lanius pitangas) avec des œufs; il a la forme d'un four, et est fermé par en haut.

Au nord de Battuba, de grandes lagunes qui s'étendent dans la plaine fourmillent de canards, de hérons et d'autres oiseaux sentblables. C'est un des endroits où l'on peut le mieux les étudier. On nous avait dit que nous y trouverions la jolie spatule couleur de rose, nous y en vîmes effectivement les premières; elles étaient réunies au nombre d'une trentaine dans un lieu marécageux, et offraient à l'oil

(1) Falco palustris. Longueur, dix-neuf pouces huit lignes. Une collerette de plumes blanc jaunâtre mèlé de brun noir entoure chaque côté de la tête; une raie blanchâtre règne au-dessus de l'œil ; le dessous est jaume rougeàtre pâle, avec des raies longitudinales brun noir; le dessous du cou brun noir; les cuisses et la queue d'un rouge de rouille; toutes les parties supérieures brun noir; plumes rectrices et de la queue bleu cendré, a vec des bandes transversales brun noir. 
l'apparence d'une grande tache rose. Nos chasseurs s'approchèrent avec la plus grande precaution, et lorsquils en furent près se couchèrent à terre; ce fut en vain, les oiseaux effarouchés s'envolèrent, on leur tira des coups de fusil en l'air avec aussi peu de succès; nous. fûmes réduits à parer nos huttes avec quelquesunes de leurs grandes plumes que nous trouvâmes dans le marais. Des hérons, des ibis noirs (1), des canards, des vanneaux et des cormorans animaient toute la contrée. Les lagunes étaient séparées l'une de l'autre par des digues, sur lesquelles croissaient des buissons, où les oiseaux de proie se tiennent toujours en embuscade: nous en tuâmes quelques-uns. Sur les bords d'une lagune j'aperçus l'anhinga que

(3) Le guara (tantalus ruber) se distingue avantageusement par son plumage d'un rouge éclatant, dans la nombreuse famille des oiseaux à bec en faucille qui habitent les marécages du Brésil. Je n'ai trouvé ce bel oiseau en aucun endroit de celte côte. La Corografia brasilica ( tom. II , pag. Ig) constate qu'on ne le rencontre plus à la Ponta-deGuaratyba, où autrefois il était extrêmement commun. Hans Staden nous apprend que les Tupin-Inbas tiraient de cet endroit les plus belles plumes rouges du guara pour se parer. 


\section{AU BRÉSIL.}

je poursuivisinutilement. A quatre ou cinq lieues de Battuba on arrive à la Barra do Farado ou la lagune de Feia communique avec la $\operatorname{mer}(\mathbf{1})$.

Nous prîmes aussitôt des mesures pour faire transporter en pirogue, à l'endroit où nous

(1) La lagune de Feia consiste en deux parties réunies par un canal. Sa forme n'est pas représentée avec exactitude sur ma carte parce que je n'ai fait que la traverser en pirogue, et que je n'ai pas aperçu toute son étendue. Suivant la Corografia brasilica (tom. II, pag. 49), sa partie septentrionale a environ six legoas de long de l'est à l'ouest, et quatre legoas de large : la partie méridionale a cinq legoas de long sur une et demie de large; l'eau en est douce, elle est poissonneuse. Les vents agitent ordinairement sa surface, de sorte qu'elle est souvent dangereuse pour les pirogues; elle n'est pas assez profonde pour que les grandes embarcations y puissent vaviguer. La Barra do Farado est bouchée à l'époque des basses eaux. Toute cette contrée contient le long de la côte maritime une grande quantité de lagunes : plusieurs ne sont pas marquées sur la carte. Avec cette abondance d'eau douce et un sol très-fertile, cette étendue de pays pourrait devenir une des plus fécondes du Brésil, si elle était habitée par un peuple plus industrienx et plus actif.

La carte d'Arrowsmith marque la communication de la lagune de Feia avec la mer. 
devions faire halte, et que nous apercevions, notre bagage et quelques-uns de nos chasseurs restés en arrière. Un homme qui demeurait seul à la Barra do Farado nous loua sa grande pirogue à cet effet. Ensuite nous continuâmes notre marche le long des dunes: nous nous divertissions à voir les divers oiseaux de rivage attendre qu'une vagıie eût brisé sur la plage pour y recueillir une quantité de petits insectes. De pauvres pêcheurs qui habitaient des cabanes sur cette rive solitaire nous montrèrent le chemin que nous devions prendre. Il était bordé du côté de terre par de vastes marais, dans lesquels paissaient un grand nombredechevaux et de boufs. La quantité d'oiseaux aquatiques et des marais qui se trouvait en ce lieu était vraiment prodigieuse. Des troupes innombrables de l'anas viduata, et l'espècenommée ipecuturi par Azara (1), s'envolèrent à nos premiers coups de fusil, et formèrent en l'air comme un nuage épais. Ce canard est le plus commun dans les parties du Brésil que ¡’ai parcourues; il a le cri aigu et l'épaule verte.

(1) Voyages, tom. IV, pag. 345. 


\section{AU BRÉSIL.}

Il commençait à faire sombre; un nègre qui nous servait de guide nous mena au travers de l'eau à une île marécageuse, disant que son maître viendrait nous chercher en pirogue à cel endroit, pour nous transporter au-delà de la lagune; mais nous ne vîmes paraître personne. Comme nous étions menacés d'une forte pluie, quelques-uns de nos compagnons proṕosèrent de retourner à une petite cabane éloignée d'une demi-lieue, dans laquelle nous avions vu une demi-douzaine de soldats qui veillent à ce que l'on ne fasse pas la contrebande des diamans qui viennent de Minas Geraës. On suivit cet avis; les soldats allumèrent un bon feu, nous régalèrent de farinha et de viande sèche, et nous causâmes avec eux pendant toute la soirée. Ces soldats de milice ont le teint hâlé par le soleil; ils sont vêtus de chemises et de pantalons de coton blanc; ils vont le cou et les pieds nus; ils portent de même que tous les Brésiliens leur chapelet suspendu au cou; ils n'ont pour arme qu'un fusil sans baïonnette. La lagune dans laquelle ils pêchent fournit à leur subsistance avec la farinha et la viande sèche qu'on leur donne. Ils font sécher le poisson à des cordons de peau de bœuf ten- 
dus auprès de leurs demeures. La cabane contenait plusieurs chambres où l'on voyait quelques hamacs et des escabelles de bois.

Le lendemain matin nous vîmes arriver la pirogue avec les chasseurs; occupés la veille à poursuivre les canards, ils avaient été surpris par la nuit. Nous commençâmes alors à traverser la lagune en pirognes, ce qui exigea plusieurs voyages. Dès qu'un détachement avait débarqué, il se mettait tout de suite à chasser. On tua entre autres le carao ou ibis à face rouge, et le caracara ( falco brasiliensis). Réunis sur l'autre rive de la lagune, nous nous y sommes trouvés dans une position très-désagréable; nos mulets qui paissaient dans la prairie avaient suivi des chevaux, de sorte que nous restâmes toute la journée exposés à la pluie qui tombait par torrens; enfin, un pêcheur qui arriva dans la soirée nous conduisit à sa cabane où nous attendîmes nos animaux égarés.

Nous nous mîmes ensuite en route à travers des halliers, jusqu'aux bords du Barganza, rivière qui sort de la lagune de Feia, et nous y fûmes reçus de la manière la plus cordiale dans deux pauvres cabanes de pêcheurs: chacune consistait en un simple toit en roseau qui 


\section{AU BRÉSIL.}

posait sur la terre; elles avaient dans l'intérieur quelques séparations; notre troupe étant trèsnombreuse, nous ne púmes tous y trouver place : ceux qui étaient accoutumés à supporter en plein air les nuits du Brésil restèrent en dehors. Nous autres Européens nous nous assîmes avec la famille des pêcheurs sur la pailie autour du feu; on nous régala de poisson étuvé et de farinha. L'hospitalité et la bienveillance de ces braves gens allégèrent nos fatigues et nous firent oublier l'incommodité de notre gîte. Dans celle où je me trouvais, une grosse femme très-bavarde, à peau un peu jaune, et très-légèrement vêtue, dominait exclusivement; de même que la plupart des Brésiliennes de la classe inférieure, elle avait sans cesse la pipe à la bouche. Les Brésiliens font plus généralement usage pour fumer de cigares de papier : quand ils ne s'en servent pas, ils les mettent derrière l'oreille. Cette manière de fumer n'a pas été apportée au. Brésil par les Européens, elle vient des Toupinambas et des autres Indiens des côtes. ( A près ) qu'ils ont cueilli le petun, dit Lery, et par » petite poignée pendu et fait sécher en leurs ») maisons, ils en prennent quatre ou cinq „) feuilles qu'ils enveloppent dans une autre 
) grande feuille d'arbre en facon de cornet

) d'épices; mettantalors le feu par le petit bout,

) et le mettant ainsi allumé dans leur bouche,

)) ils en tirent en cette façon la fumée (1). ))

Les pipes dont les pêcheurs de même que les pauvres gens et les nègres du Brésil font usage, consistent en une petite tête d'argile noirâtre à laquelle est adapté un tuyau fait de la tige du samambaya (mertensia dichotoma), espèce de grande fougère. Mais la généralité des Brésiliens de toutes les classes aime bien mieux prendre le tabac en poudre que fumer. Le pauvre esclave a sa tabatière qui est ordinairement de fer blanc ou de corne; ce n'est quelquefois qu'un bout de corne de boeuf avec un bouchon.

Dès que le jour parut, les pêcheurs récitèrent leurs prières avec beaucoup de ferveur, puis lavèrent leurs enfans avec de l'eau tièle, usage général parmi les Portugais, mais qui paraissait ne pas plaire à ceux qu'on y soumettait. On étendit des nattes de roseaux devant les cabanes, on apporta du poisson, et nous nous assîmes tous à terre pour déjeûner. Le repas fini, les

(1) Voyage, p. 200 


\section{AU BRÉSIL.}

pêcheurs préparèrent leurs pirogues pour ramener nos mulets à la nage le long du Barganza. Ceite rivière est remplie près des huttes de grosses touffes de roseaux dans lesquelles nichent des quantités innombrables d'oiseaux aquatiques, surtout de hérons, de cormorans, de poules d'eau, de plongeons, etc.; l'on y voit même quelquefois des spatules. Parmi les pêcheurs qui firent traverser l'eau à notre tropa, je distinguai un vieillard avec une longue barbe; il portait un sabre au côté. Un plus jeune monta un petit cheval, et nous promit de nous montrer le chemin au travers de la plaine inondée. Sa mise était originale : il avait un petit manteau de drap, une veste courte, des culottes qui n'allaient pas au genou, enfin des éperons attachés à ses pieds nus. C'était un homme bon et obligeant; il allait toujours en avant dans la prairie où l'eau dans quelques parties était très-haute, et chercha, non sans danger, le meilleur shemin, qui sans doute parut désagréable à nos mulets, car leurs mouvements nous faisaient éprouver sans cesse les alarmes les micux fondées de leur voir jeter notre bagage dans l'eau. La pluie qui tombait par torrens ajoutait encore à notre embarras : toutefois nous 
arrivâmes sans accident à l'extrémité de la vaste prairie que nous traversions.

Ayant débarqué près de l'église de SaintAmaro qui est entièrement isolée, nous parcourûmes une plaine verdoyante qui s'étend à perte de vue. Elle fait partie des plaines des Goaytacasés qui se prolongent jusqu’au Paraïba, et dont Villa de San-Salvador tire son surnom de dos campos dos Goaytacasés. Sur les pelouses de cette contrée, de même que dans tous les pâturages de la côte orientale du Brésil, croît le sicla carpinifolia à tige ligneuse et frutescente et à fleurs jaunes: cette plante est très-touffue, et sert fréquemment de retraite à une espèce d'inamba à laquelle on a donné le nom de perdrix ( perdiza). Cet oiseau, encore peu connu, ressemble par le plumage à notre caille : il est pourtant un peu plus gros, et j’ai éprouvé qu'il tient les chiens en arrêt comme la perdrix d'Europe.

Nous avons voyagé toute la journée dans ces pâturages où des bestiaux paissaient en grand nombre, et nous sommes arrivés le soir à SanBento, grand monastère où nous nous flations de trouver le repos et les commodités dont nous étions privés depuis long-temps. Ce cou- 
vent, qui appartient à l'abbaye de San-Bento de Lisbonne, póssède de grands biens en fonds de terre. Le bâtiment est vaste; il comprend une belle église, deux cours et un petit jardin. intérieur dans lequel les plates-bandes sont entourées de petits murs en pierre : on y voit des balsamines, des tubéreuses, elc. Il y avait dans une des cours deux cocotiers chargés de fruits. Le couvent possède cinquante nègres; leurs cases forment devant sa façade une grande place carrée, au milieu de laquelle s'élève une. croix sur un piédestal en pierres. Il y a aussi en cet endroit un grand moulin à sucre, et plusieurs bâtimens d'exploitation. Ce riche couvent est propriétaire de métairies considérables, de gros iroupeaux de chevaux et de boufs, ainsi que de plusieurs corralés et de fazendas situés duns le pays d'alentour; enfin il tire du voisinage une dîme cn sucre.

Notre espoir ne fut pas trompé, don José Ignacio de San-Mafaldas, ecclésiastique, économe de ce couvent, nous reçut de la manière la plus affectueuse. Nous dormîmes dans de bons lits. Les fenêtres de nos chambres n'avaient pas de vitres. On jouissait à l'aise de la belle perspective de la plaine, et l'air était frais dans I. 
les longs corridors de ce premier étage. La cuisine et la fabrique de farinha occupaient le rez-de-chaussée ; nous eûmes la facilité de faire sécher nos collections dans les grandes chaudières, et on poussa la complaisance jusqu'à faire débarrasser de son enveloppe le coton dont nous avions besoin pour nos opérations. Nous employâmes notre séjour dans ce couvent le mieux que nous pûmes, et nous nous divertîmes à la chasse des canards, dont des troupes innombrables couvraient les marais et les lagunes.

Quand nous partîmes, on nous donna pour guide un mulâtre qui avait un stylet à la boutonnière, un sabre au côté, et des éperons à ses pieds nus; c'est le costume du pays. Il nous fit traverser la grande plaine. De lieue en lieue, à mesure que nous avançions, les maisons devenaient plus fréquentes; les traces des voitures montraient aussi que nous nous approchions d'une contrée plus habitée. La route était bordée de haies d'agavés et de mimosas; derrière, on voyait des orangers en fleurs et des bananiers, et près des maisons, des cafeyers couverts de leurs fleurs d'un blanc de lait; bocage magnifique, surtout aux yeux d'un Européen. On trouve dans tous les lieux situés sur cette route 
des vendas dont les maîtres montrent, comme leurs semblables en Europe, une politesse très intéressée.

Le soleil était encore très-haut sur l'horizon quand nous sommes arrivés à Villa de San-Salvador, situé sur la rive méridionale du Paraïba, dans un canton fertile et d'un aspect enchanteur. Notre hôte bienveillant de San-Bento nous avait invités à occuper sa maison dans cette ville, durant notre séjour. Nous y descendîmes, et nous y lûmes les premières gazettes que nous eussions reçues depuis notre départ de Rio. Elles nous apprirent l'issue de la bataille de $\mathbf{W a -}$ terloo, nouvelle à laquelle les habitans de cette ville prirent une part très-vive. 


\section{CHAPITRE V.}

Séjour à Villa de San-Salvador. - Villa de San-Salvador. - Excursion à San-Fidelis. — Les Indiens Coroados. - Les Pourys.

LES plaines qui se prolongent au sud du Paraïba étaient autrefois habitées par la tribu guerrière des Ouetacas (1) ou Goaytacasés, que Vasconcellos range parmi les Tapouyas, parce qu'ils parlaient un idiome différent de la lingoa geral. Ils se divisaient en trois tribus ; les Goaytaca-Assù, les Goaytaca-Jacorito, et les Goaytaca-Mopi (2); et vivaient dans un état d'hostilités continuelles entre eux et avec tous leurs voisins. Contre la coutume des autres Indiens ils laissaient croître leurs cheveux dans toute leur longueur, se distinguaient des sauvages de ce pays par une couleur plus claire,

(1) Lery, p. 50.

(2) Vasconcellos noticias, etc., p. 39. 
un corps plus robuste, une fërocité plus grande, et combattaient bravement en rase campagne. La vie da père José de Anchieta donne à ce sujet des détails curieux : « Ces hommes, dit )) l'auteur, étaient les plus sauvages et les plus )) inhumains de toute la côte, ils avaient une ) taille gigantesque, étaient doués d'une grande ) force, habiles à manier l'arc, et ennemis de ) toutes les autres nations, etc. ) Il ajoute ensuite : «Leur territoire n’était pas très-grand; » il ne s'étendait que depuis le Rio Paraïba jus) qu'au Macahé, etc. (1). ) Le père Joao de

(1) Era esta sorte de gente a mais feros e deshumana que havia portoda a costa, em corpos eram agigantados de grandes forças, destro em arco, inimigos de todas as naçôes, etc.....

$O$ destricto que habitabam era pequeno dentro dos termos dos Rios Paraïba e Machaé, elc.

Voici comment s'exprime J de Lery :

“ Les Ou-Étacas sont sauvages si farouches et étranges, que comme ils ne peuvent demeurer en paix l'un avec l'autre, aussi ont-ils guerre ouverte et continuelle tant contre tous leurs voisins, que généralement contre tous les étrangers... Contre la coutume plus ordinaire des hommes de ce pays (lesqueis se tondent Je devant de la tête et rognent 
Almeida trouva dans leurs forêts, à sa grande frayeur, un squelette humain debout (1). Leurs cabanes, suivant son récit, ressemblaient à des colombiers juchés șur un poteau; ils dormaient sur des tas de feuilles, ils ne buvaient ni eau de rivière ni eau de source ; ils ne se désaltéraient qu'avec celle qui se rassemblait dans des trous qu'ils avaient creusés dans le sable (2). La colonie portugaise d'Espirito Santo eut surtout à souffrir de leur humeur belliqueuse. En 163o ils éprouvèrent une rude défaite; ensuite ils furent successivement détruits, ou soumis, ou civilisés, ce qui donna naissance à la colonie du Paraïba, qui est aujourd'hui la contrée la plus riche et la plus florissante entre

leur perruque sur le derrièred, eux portent les cheveux longs et pendans jusqu'aux fesses. Bref ces diablotins d'OuÉtacas demeurant invincibles en cette petite contrée, et au surplus comme chiens et loups, mangeant la chair crue, même leur langage n'étant point entendu de leurs voisins, doivent être tenus et mis au rang des nations les plus barbares, cruelles et redoutées qui se puissent trouver en toute l'Inde occidentale et terre du Brésil, p. 50."

(1) Voyez sa vie.

(2) Southey history of Brazil, tom. II, p. 665. 
Rio-de-Janeiro et Bahia; elle est couverte de fazendas et de plantations isolées.

Sur la rive méridionale du Paraïba qui arrose cette plaine fertile, s'élève à huit lieues de la mer Villa de San-Salvador dos Campos dos Goaytacases, qui mérite le nom de (Ciudad). On y compte à peu près 5,000 habitans, et 24,000 dans son comarca ou district. On la nomme ordinairement Campos par abréviation; elle est assez bien bâtie; ses rues sont régulières, la plupart pavées, les maisons propres et jolies, quelques-unes à plusieurs étages; elles ont encore des balcons fermés avec des jalousies en bois, suivant l'ancienne mode portugaise. Sur une place publique, près du fleuve, se trouve un édifice dans lequel le tribunal tient sés séances, et qui renferme aussi les prisons. On compte dans cette ville sept églises, cinq apothicaires et un hôpital dans lequel il y avait une vingtaine de malades. Un chirurgien est à la tête du lazaret. On dit au reste que ce district possède de meilleurs médecins que les autres également situés le long de cette côte, où souvent l'on en cherche vainement un qui mérite la confiance.

Cette ville s'étend le long des rives du $\mathrm{Pa}$ raïba et offre un coup d'œil agréable, surtout 
quand on la voit de la route en descendant le fleuve : ses bords sont animés par une foule d'hommes, la plupart de couleur, que le commerce et d'autres occupations tiennent dans une activité continuelle. Campos est un lieu très-conmerçant; la contrée arrosée par le Paraiba et par la petite rivière de Muriàhé qui se jette dans ce fleuve vis-à-vis de la ville, produit beancoup de sucre, de café, de coton et d'autres denrées : on voit même au marché des plantes potagères d'Europe. La production principale du pays est le sucre et l'ean-de-vie que l'on en tire. Plusieurs habitans sont très-riches. Quelques-uns ont surleurs plantations cent cinquante esclaves et plus, et fabriquent dans une année à peu près 5,000 arrobes de sucre, indépendamment de l'eau-de-vie. On s'occupe d'améliorer les procédés de la fabrication; et l'on songe à employer les machines à vapeur. Le moulin à sucre de M. le capitam Netto Fiz, qui nous a comblés de politesses, est très-beau et très-bien entendu; sa plantation est considérable ; ce propriétaire possède encore deux autres fazendas sur le Muriàné. En 1801, on complait dans la contrée arrosée par cette rivière et par le Paraïba, deux cent quatre-vingts 


\section{AU BRÉSIL.}

moulins à sucre, dont quatre-vingt-neuf plus considérables étaient très-productifs (1).

On remarque à Campos un grand luxe, surtout dans la parure, pour laquelle les Portugais dépensent beaucoup; au Brésil, du moins, cette nation, même dans les classes inférieures, est genéralement d'une propreté très-soignée. Si l'on visite les parties intérieures du pays, ou les villas moins considérables, on observe que les planteurs conservent la plupart leurs anciens usages, sans songer aucunement à rendre leur demeure commode et agréable. On y trouve tel homme très-riche qui, dans une année, envoie à la capitale plusieurs tropas chargées de marchandises dont la valeur se monte à de grosses sommes, qui y vend mille à quinze cents têtes de bœufs, et dont la maison ne vaut pas la car bane du plus pauvre paysan d'Allemagne; ces espèces de huttes n'ont qu'un rez-de-chaussée, et sont construites en terre que l'on n'enduit pas même de blanc; tout le reste de la manière d'être est proportionné à la demeure, mais la

(I) Corografia brasilica, tom. It, p. 47. 
mise du propriétaire est ordinairement trèspropre.

On dit que le pays baigné par le Paraïba n'a pas assez de bestiaux, quoique ces grandes plaines soient très-propres pour les pâturages. On y élève quelques mulets qui ne sont ni aussi forts ni aussi beaux que ceux de Minas-Geraës et de Rio-Grande. Les moutons et les chèvres sont de petite taille; les cochons ne réussissent pas si bien que dans d'autres cantons. Comme j'étais venu à Campos, non pour y recueillir des renseignemens statistiques sur le pays d'alentour, mais simplement pour connaitre ce que les habitans et ses productions naturelles offrent de curieux, cet objet fut bientôt rempli. Ainsi, après un court séjour, je me hâtai d'aller voir la curiosité la plus intéressante que les bords dn Paraïba pussent m'offrir; c'était une tribu de Tapouyas encore sauvages, qui vivent à peu de distance.

M. Manoel Carvalho dos Santos, commandant du comarca ou district de San-Salvador, et colonel du régiment de milice, nous avait accueillis de la manière la plus obligeante. Lui ayant témoigné mon désir de visiter la mission de San-Fidelis, située plus haut sur le Paraïba, 
il eut la bonté de nous donner pour guides un officier et un soldat. Nos préparatifs pour ce voyage intéressant furent bientôt faits, et le 7 octobre nous partîmes de San-Salvador, où nous laissâmes notre bagage.

Le Paraïba prend sa source dans la capitainerie de Minas-Geraës, coule à l'est entre la Serra dos Orgaos et celle de Mantiqueïra; on le trouve marqué sur la petite carte qui est jointe au voyage de Mawe. Il reçoit le Parahibuna, le Rio-Pomba et d'autres rivières, et coule au milieu de forêts antiques entre des montagnes, jusque dans les plaines des Goaytacasés près de son embouchure. Tout est cultivé et animé dans cette partie inférieure de son cours; mais quand on la quitte pour entrer dans les forêts, on trouve ses bords encore habités par des indigènes que l'on n'a civilisés qu'en partie.

Nous avons d'abord suivi les rives du fleuve qui sont ornées de bois de mimosas, de bignonias et d'autres arbres semblables. Près de la ville on voit quelques cocotiers épars, ensuite on rencontre de belles prairies, des bocages et des fazendas isolées. Bientôt nous nous sommes éloignés du fleuve que nous avons perdu de vue. 
Nous avons fréqriemment trouvé dans les pâturages l'annù branco (cuculus guira, L.), ou coucou tacheté, de compagnie avec l'ani auquel il ressemble beaucoup par les mours et la forme. Cet oiseau, nommé pirigua par Azara, n'est pas connu depuis long-temps dans les environs de Campos; l'on dit qu'il y est venu des montagnes de Minas-Geraës.

Tout nous annonçait la fertilité du beau pays que nous parcourions; le fleuve est bordé de fazendas considérables; de vastes champs de cannes à sucre et d'immenses pâturages se succèdent dans la plaine; on $\mathrm{y}$ voyait des boufs, des chevaux et quelques mulets. Dans le voisinage de plusieurs maisons, nous avons admiré le figuier sauvage, arbre colossal nommé figueïras par les Portugais, et qui est un des présens les plus agréables que la nature ait pu faire aux pays chauds; l'ombre de cet arbre magnifique ranime le voyageur qui se couche sous l'épais feuillage de ses branches, dont l'étendue est incroyable. Les figuiers de toutes les régions de la zone torride deviennent ordinairement très-gros, et étalent une cime colosșale composée de branches extrêmement fortes. Ils m'ont paru véritablement majestueux au 


\section{AU BRÉSIL.}

Brésil; aucun ne peut pourtant se comparer au fameux dragonier d'Orotara qui, d'après la mesure de M. de Humboldt, a quarante-cinq pieds de circonférence (1). Nous avons trouvé dans les branches supérieures de ce figuier le nid remarquable du petit todier vert à ventre jaune; il étail de forme conique, construit en coton, fermé par en haut, et n'avait qu'une entrée étroite. Le nombre des oiseaux qui font de ces nids fermés est bien plus considérable au Brésil que dans nos pays, probablement parce que leurs petits ont beaucoup plus d'ennemis à craindre.

A quelques lienes de San-Salvador, les montagnes commencent à s'élever; et au-delà des champs de sucre, nous avons aperçu dans le lointain la cime élevée des forêts antiques. On remarque au milieu des arbres des forêts des taches rouges; elles sont produites uniquement par les jeunes pousses du Sapucaya qui sont couleur de rose. Nous étions dans la saison la plus favorable pour voyager; tout annonçait le prin-

(1) Ansichten der Natur, p. 179 et 236.

Tableaux de la nature, tom. II, p. 3o et 108. 
temps; la verdure tendre du feuillage nouveau répandait un air de gaîté sur toute la contrée; et la douceur de la température plaisait infiniment à đles hommes du Nord, peu accoutumés, comme nous, aux grandes chaleurs.

Après trois heures de route, nous nous sommes rapprochés de nouveau des bords $\mathrm{du} \mathrm{Pa}-$ raïba, qui nous surprirent par leur beauté dans cet endroit. Trois îles couvertes en partie de grands bois interrompent le cours du fleuve, dont la largeur ne le cède pas à celle du Rhin; il coule avec rapidité; ses rives offrent alternativement des collines couvertes de bois, des forêts, et des fazendas dont les toits en tuiles rouges forment un contraste agréable avec la verdure des arbres, et autour desquelles les cases des nègres forment de petits villages. Les vallées entre les collines sont remplies de marais, où des touffes d'une espèce de bignonia très-haute offrent fréquemment le triste aspect d'un bois desséché. Ce tronc et les branches de cet arbre, qui sont d'une couleur cendrée claire, et son feuillage vert brun foncé, le font ressembler à un arbre mort, d'autant plus qu'il croît toujours en groupes serrés : d'ailleurs sa fleur est belle, grande, et de 
couleur blanche. On voit dans ces endroits une quantité de belles plantes, entre autres une cléomé arborescente, couverte de gros bouquets de fleurs blanches et roses. Des bignonias à fleurs jaune foncé et blanches s'entrelaçaient en grimpant aux arbres le long de la route, et les buissons du bord du fleuve étaient parés des grandes fleurs jaunes de l'allamanda cathartica, L., arbrisseau qui pousse des tiges verticales.

Quand nous eûmes parcouru la muitié du chemin, notre conducteur nous mena dans une fazenda dont le maître, qui était un capitam, nous invita très-poliment à dîner. Devant sa maison, située sur une hauteur d'où l'on jouissait d'une vue magnifique du fleuve, croissait un ipé amarello ( bignonia ) couvert de grandes fleurs jaunes qui éclosent avant les feuilles. Le bois de cet arbre est très-compact; on le travaille aisément. Après le dîner nous avons continué notre voyage, mais un orage violent rendit cette charmante route un peu désagréable.

Ayant gravi le Morro de Gamba, montagne escarpée sur le bord du fleuve, nous avons traversé à son sommet une forêt épaisse, et arrivés dans un endroit où elle s'ouvrait, nous 
avons été surpris par le coup d'oil magnifique du fleuve qui coulait à nos pieds. Au milieu des sommets dentelés et couverts de bois qui s'offraient à notre vue, le Morro de Sapateira, masse de rochers remarquable par sa forme, attirait principalement les regards, et, par l'opposition qu'il offrait avec les jolies collines verdoyantes sur lesquelles les habitans ont bâti leurs demeures, rehaussait le charme de ce paysage. Immédiatement à nos pieds, au-dessous de la paroi d'une montagne à pic, on voyait une petite prairic où quelques maisons ombragées de cocotiers composaient le groupe le plus riant. Le chemin étroit, après avoir suivi la montagne jusqu’à son sommet, redescend daus la vallée, où, à chaque fazenda, l'on est embaumé de l'odeur suave des fleurs des orangers. Des bignonia, gris à fleurs blanches, et hauts de vingt à treute pieds, couvraient la surface d'un marais; des bihoreans (ardea nycticorax) avaient placé leurs nids sur cet arbre : cet oiseau, un peu plus gros que celui d'Allemagne, paraît d'ailleurs être le même. Il couvrait les branches des bignonias, et semblait regarder curieusement les passans; nos chasseurs en tuèrent plusieurs, mais ils ne purent les aller ramasser 


\section{AU BRÉSIL.}

dans les ravines, tant elles sont profondes. On dit que les crocodiles sont cummuns dans ces gorges, mais nous n'en avons aperçu aucun.

A notre arrivée à la fazenda do Collegio, après avoir traversé un pays agréablement varié, la nuit avait commencé ; cependant avant qu'il fît complétement obscur, nous atteignîmes les bords du Rio-do-Collegio, petite rivière profonde et rapide que nous devions passer; nous en vînmes heureusement à bout, mais bien mouillés, et quoique nos chevaux et nos mulets, pour parvenir au bord del'eau, eussent été obligés de se traîner sur leur croupe par une descente rapide que la pluie avait rendue extrêmement glissante.

Nous avons ensuite marché dans une forêt sombre le' long du Paraỉba, jusqu'à une lieue et demie de San-Fidelis. La nuit était noire, et le sentier très-étroit, inégal, embarrassé de branchages et d'arbres tombés, se trouvait souvent sur le bord de rochers escarpés. Le soldat qui nous servait de guide descendait fréquement de chevál pour débarrasser la route, et nous étions obligés d'en faire autant, et de mener pendant un assez long espace nos chevaux par la bride. Enfin nous nous trouvons sur. les bords d'une 
ravine profonde et roide, au-dessus de laquelle on avait jeté un petit pont de trois troncs d'arbres; malgré les entailles que l'on avait pratiquées sur leur surface pour que les chevaux pussent y prendre pied, quelques-uns des nôtres firent de fréquentes chutes, et peu s'en fallut qu'ils ne fussent précipités dans l'abîme. Avec un peu de patience nous avons surmonté cet obstacle. Le silence de la nuit était interrompu par les cris de l'engoulevent, par la voix des grosses cigales ( cigarcas), et par le croassement singulier des grenouilles, tandis que des insectes lumineux resplendissaient de tous côtés au milieu de l'obscurité de la forêt. Enfin nous sommes parvenus à une prairie unie sur les rives du Paraïba, et nous nous sommes trouvés tout à coup parmi les cabanes des Indiens Coroados de San-Fidelis. Notre guide alla aussitôt à la maison du père Joào, curé du lieu, et lui fit demander par un de ses esclaves un gîte pour la nuit; mais le bon ecclésiastique refusa très-sèchement, et toute tentative ultérieure pour le ramener à des sentimens plus charitables fut inutile. Sans la bonté du capitam chez qui nous avions si bien dîné, nous aurions certainement été obligés de coucher à 
Ia belle étoile; heureusement il avait une maison dans cet endroit. Quoiqu'elle fût dénuée de toute espèce de meubles, c'était un asile à ne pas dédaigner; nous y suspendîmes nos hamacs, et nous y dormîmes très-bien.

San-Fidelis, situé sur la rive droite du $\mathbf{P a -}$ raïba qui est ici assez large, est un village d'Indiens Coroados ou Coropos, et une mission fondée il y a environ trente ans par des capucins italiens. Les míssionnaires étaient alors au nombre de quatre, l'un est le curé actuel, l'autre remplit les mêmes fonctions à l'aldea da Pedra, à huit legoas en remontant le fleuve, les deux autres sont morts. Les Indiens appartiennent à la tribu des Coroados, des Coropos et des Pourys : ces derniers, encore sauvages et libres, errent dans les solitudes situées entre la mer et la rive septentrionale du Paräba, et s'étendent jusqu'au Rio-Pomba dans le gouvernement de Minas-Geraës (1). Ils se conduisent paisiblement vis-à-vis de San-Fidelis, mais der-

(1) La Corografia brasilica, tom. II, p. 59, fait un tableau inexact de l'état des Pourys sur le Paraïba inférieur, en représentant ces sauvages comme vivant déjà réunis dans des villages, ce qui n'est nullement fondé, 
nièrement ils ont fait la guerre aux Coroados de l'aldea da Pedra. La demeure principale de ces deux tribus est dans le Minas-Geraës; ils viennent pourtant jusque sur les bords $\mathrm{du} \mathrm{Pa}-$ raïba et sur les côtes maritimes. Les Coroados habitent sur la rive droite ou méridionale du fleuve; on voit aussi à San-Fidelis quelques Coropos qui sont civilisés, c'est-à-dire fixés : leur tribu occupe la rive méridionale du Paraïba en remontant jusqu'au Rio-Pomba; sur la rive droite de cette dernière rivière ils vivent encore dans l'état sauvage, mais ils ont des huttes mieux faites que celles des Pourys avec lesquels ils sout en guerre, et dont on dit qu'ils sont redoutés. M. Freyress les avait dẻjà visités dans son voyage à Minas-Geraës; il les ąvait trouvés non pas entièrement sauvages, mais plus grossiers que leurs compatriotes du Paraïba (1). Ainsi que je l'ai déjà dit, ces Indiens sont la plupart civilisés, savoir tous les Coropos et la plus grande partie des Coroados. Toutefois ils ont à peine commencé à se défaire de leurs mours, de leurs usages et de leur caraclére de sauvages : un mois avant notre arrivée, ayant

(1) Eschwege, Journal von Brasilien, tom. I, pag. 119. 
tué un Poury dans une excursion, ils avaient à cette occasion fait de grandes réjouissances pendant trois jours. Ces trois tribus appartiennent à la même souche, comme le prouve l'affinité de leurs langues ( 1 ). Ils cultivent du manioc, du maïs, des patates, des courges, et d'autres plantes potagères; ils sont chasseurs nés, et se servent très-habilement de leurs arcs et de leurs flèches.

Au point du jour nous sommes allés aux cabanes bâties par les missionnaires pour les Coroados et pour les Coropos. Ces Indiens ont le teint brun foncé, leur visage porte le caractère original de leur race, leurs traits sont extrêmemẹt marqués, leurs cheveux très-noirs. Leurs cabanes sont grandes, bien construites en bois et en terre, et couvertes de toits en fenilles de palmier et en roseaux comme celles des Portugais; on y voit leurs hamacs suspendus

(x) Eschwege, Journalvon Brasiliero, tom. I, pag. 159. La Corografia brasilica, tom. II, p. 53, ditque les Corados descendeut des anciens Goaytacasès; mais cela n'est pas vraisemblable, car ces derniers laissent pousser leurs chereux dans toute leur longueur, et au contraire les Coroados ont èté nommés ainsi, il y a bien long-temps, d’après leur usage de les couper en rond. 
au milieu, et leurs flèches avec leurs arcs. appuyés contre les parois dans un coin; leurs meubles très-simples consistent en pots, plats et jattes faits de gourdes et de calebasses (1), corbeilles (panacum) de feuilles de palmier tressées, et quelques autres objets. Ils ont pour vêtement des chemises blanches et des culottes de toile de coton; les dimanches ils sont mieux mis, et alors on ne les distingue pas des Portugais pauvres; ces jours-là même les hommes vont souvent les pieds et la tête nus; les femmes sont plus élégantes, elles mettent quelquefois un voile, et se parent volontiers. Tous parlent le portugais, mais entre eux ils s'entretiennent ordinairement dans leur idiome. Les langues des Coroados et des Coropos ont beaucoup d'affinité l'une avec l'autre, et chacun de ces peuples comprend ordinairement le poury. Francisco, notre jeune Indien Coropo, parlait toutes ces langues.

La diversité des langages parmi les nombreuses peuplades des habitans indigènes du Brésil, est un objet bien propre à exciter l'in-

(1) Crescentia cujete, $\boldsymbol{L}$. 
térêt et à faire entreprendre des recherches suivies. La plupart des tribus Tapouyas ont des idiomes particuliers. Des écrivains ont allégué la ressemblance de quelques mots isolés dans ces langues pour en inférer que les peuples qui les parlent sont d'origine européenne; mais c'est à tort: quoique les mots papa et mama signifient chez les Cambecas ou Omaguas(1)la même chose que chez nous, et que le mot $i a$ soit dans la langue des Coropos comme dans les langues germaniques le signe affirmatif, l'on ne peut rien conclure de ces conformités insignifiantes et accidentelles; car du reste on ne trouve pas la moindre ressemblance entre ces langues et celles d'Europe.

Les Coropos tiennent encore beaucoup à leurs arcs et à leurs flèches, qui ne diffèrent pas essentiellement des armes du même genre dont les Pourys font usage; les plumes rouges dont ils garnissent leurs flèches sont généra-

(1) La Condamine : Voyage de la rivière des Amazones, p. 56. Les habitans de la Nouvelle-Zélande, qui sont les antipodes de l'Europe, appelent leur père Pahpah. Collin's Account of the english colony in New-South Wales, $179^{8}$, 1 vol. in $-4^{\circ}$, p. 535. 
lement celles de l'arara (psittacus macao, L.), que l'on commence à trouver sur les bords dı Paraïba supérieur, dans l'aldea da Pedra. De même que les autres sauvages, les Coroados, qui se servent de cette arme avec beaucoup d'habileté, chassent fréquemment dans les grandes forêts qui prennent naissance à la porte de leurs huttes. La Corografia brasilica ( ) dit que plusieurs familles de Coroados habitent ensemble dans la mêne cabane; ce nombre se borne à deux. Autrefois ce peuple enterrait ses chefs dans de longs vases de terre nommés camucis, où on les plaçait assis. Au point du jour tous se baignaient; mais depuis long-temps ils ont renoncé à ces usages.

Le lendemain de notre arrivée à San-Fidelis étant un dimanche, nous sommes allés à la messe à l'église du couvent, où la curiosité de voir des étrangers avait attiré beaucoup d'habitans du voisinage. Le père Joào fit un long sermon dont je ne compris pas un mot. La messe finie, nous parcourûmes le couvent inhabité. L'église est grande et claire, elle a été

(1) Tome II, page 5ł. 
peinte par le père Victorio, mort depuis quelques mois. Ce missionnaire s'était occupé trèsactivement du bien-être des Indiens qui chérissent sa mémoire : ils paraissent au contraire ne pas avoir beaucoup d'affection pour celui qui est actuellement à leur tête; ils l'ont chassé une fois, en disant qu'il n'était pas en état de les instruire, puisqu'il valait moins qu'eux. On ne peut pas qualifier de belles les peintures de l'intérieur de l'église, mais elles sont supportables; c'est un véritable ornement dans cette contrée peu fréquentée, et les voyageurs sont bien surpris de l'y trouver. Derrière l'autel les noms des quatre missionnaires sont inscrits sur le mur, et de chaque côté sont suspendus beancoup de tableaux votifs, parmi lesquels on en voit un qui représente un nègre qui a ses bras pris entre les rouleaux d'un moulin à sucre. Le nègre ayant dans son angoisse invoqué un certain saint, le moulin s'arrêta à l'instant ( $\mathrm{I}$ ). Le couvent quoique peu considérable renferme un assez grand nombre de jolies cellules; le clocher n'est pas très-haut. Nous y avons

( 1) Koster raconte des accidens de ce genre, p. 348 (tom. II, p. 240). 
grimpé par un escalier à moitié en ruines, et nous avons été récompensés de notre peine par la vue de la vallée pittoresque dans laquelle le monastère est situé.

Le père Joào aurait pu la veille nous y donner sans peine un logement, mais il poussa l'impolitesse au point de nous refuser des provisions. Cependant ayant appris dans la matinée que nos passeports étaient bien en règle, et conçus en termes très-flatteurs pour nous, il commença à devenir plus honnête, et nous fit offrir un mouton de son troupeau : nous l'achetâmes pour notre déjeuner. Après la messe il vint nous parler, et nous fîmes la paix. Les habitans de San-Fidelis ayant appris l'histoire de notre réception, avaient hautement exprimé leur mécontentement de la conduite du révérend père.

Notre affaire principale était de faire connaissance avec les Pourys qui sont encore sauvages, nous sommes allés à la fazenda de M. Furriel, située sur la rive opposée du fleuve, et nous y avons été très-bien accueillis: M. Furriel eut même la complaisance d'envoyer son frère dire aux Pourys, dans la forêt où ils demeurent, qu'il était arrivé des étrangers qui désiraient leur 
parler. Cette invitation était de sa part un sacrifice qu'il faisait à l'envie de nous obliger, car ces sauvages, bien loin de lui être de la moindre utilité, lui causent quelquefois un tort considérable. Quand on les traite doucement, ils s'établissent dans le voisinage des plantations, et usent de leurs productions comme si on les cultivait pour eux; ils volent même les chemises et les culottes des nègres qui vont travailler dans les forêts voisines des habitations.

Cette horde de Pourys (1) habite depuis peu de temps dans le voisinage de San-Fidelis : on croit qu'ils appartiennent à celles qui commettent des hostilités à Muribecca sur la côte maritime. Du moins il est certain qu'ils ont

(1) M. Eschewege dome ainsi l'explication du nom de ces sauvages, Journal von Brasilien, tom. I, p. 108.

“ Les Pourys se partagent en plusieurs tribus qui se font la guerre entre elles. Le nom de Poury, qui désigne toute la nation, tire son origine de la langue des Coroados, chez lesquels les Pourys faisaient souvent des incursions, surtout quand ils étaient absens, mettaient le feu à leurs aldeas, et pillaient tout ce qui leur tombait sous la main. En conséquence les Coroados les nommèrent Pourys, mot qui signifie homme audacieux ou brigand. Les Pourys à leur tour appellent les Coroados Pourys pour les injurier.” 
reçu très-promptement à San-Fidelis la nouvelle d'un meurtre commis par ces sauvages sur la côte, ce qui prouve qu'ils communiquent directement entre eux à travers les forêts; on dit même qu'ils entretiennent une correspondance constante depuis la côte jusqu'à Minas-Geraës (1).

La position de la fazenda de M. Furriel sur les bords du Paraïba, qui a ici dans plusieurs endroils la largeur du Rhin; est très-riante. Le fleuve est bordé alternativement de hautes montagnes couvertes de forêts épaisses et sombres, et de jolies collines sur lesquelles on aperçoit plusieurs fazendas. Quelquefois ces forêts romantiques se prolongent jusque sur le bord du fleuve, et s'étendent sans interruption dans lintérieur du pays; des vallées profondes descendent du haut des montagnes et coupent le vaste désert : elles sont remplies d'arbres gigantesques, serrés les uns contre les autres; le

(1) Ils sont encore nombreux à Minas; on a voulu dans cette capitainerie les transporter ailleurs et les réduire en esclavage pour les civiliser; mais cette entreprise a complètement échoué. ( Journal yon Brasilien.) 
silence de cette solitude obscure est rarement interrompu par les pas de quelque Poury.

Au-delà de la fazenda, nous avons gravi une colline rocailleuse, du haut de laquelle nous avons joui d'une perspective ravissante, quoique dans le genre terrible, de l'immense solitude qui s'étendait devant nous. A peine eûmes-nous rejoint le reste de notre compagnie au bas de la montagne, que nous vîmes les sauvages sortir d'une petite vallée latérale et venir à notre rencontre : c'étaient les premiers que nous apercevions. Le plaisir que nous causait leur vue était extrême comme notre curiosité; nous pressâmes le pas pour les joindre, et, surpris de la nouveauté du coup d'œil, nous nous arrêtâmes devant eux. Cinq hommes et quatre femmes avec leurs enfans s'étaient rendus à l'invitation de venir nous voir. Ils étaient tous de petite taille; aucun n'avait plus de cinq pieds trois pouces de haut, la plupart, ainsi que les femmes (1), étaient carrés et trapus. A l'exception de quelques-uns qui avaient des mor-

(1) Les Pourys sont les plus petits des sauvages de la côte orientale que j'ai vus. Suivant M. Freyreiss, ils sont plus forts et robustes que les Coroados, dans la capitainerie de 
ceaux de toile noués autour des reins, ou qui portaient des culottes courtes que les Portugais leur avaient données, tous étaient entièrement nus. Les uns avaient la tête rasée, d'autres avaient les cheveux coupés seulement au-dessus des yeux et de la nuque; quelques-uns avaient la barbe et les sourcils rasés, en général ils avaient peu de barbe : chez la plupart elle ne formait qu'un entourage mince autour de la bouche; et pendait à peu près à trois pouces au-dessous du menton (1). Les uns s'étaient peint sur le front et sur les joues des taches rondes et rouges avec du rocou; et tous s'étaient tracé sur| les bras des raies bleu foncé avec le suc du fruit du genipayer (genipa americana): ce sont les deux ingrédiens colorans dont tous les Tapouyas font usage. Ils avaient autour du

Minas-Geraës : je n'ai pas trouvé cette observation confirmée à San-Fidelis, car ces derniers y étaient généralement plus grands et plus forts.

(1) Beaucoup d'auteurs ont commis une erreur en disant que les Américains étaient dépourvus de barbe; elle n'est chez la plupart que faible et peu touffue. On dit que sur le Sypotuba habitait jadis une tribu d'indigènes remarquables par leur forte barbe, et auxquels les Portugais donnaient par sette raison le nom de Barbados. 


\section{AU BRÉSIL.}

cou ou au dessus de la poitrine et d'une épaule, des colliers composés de graines noires et dures, et au milieu desquels étaient suspendues des dents canines de singes, de jaguars, de chats, ou d'autres bêtes carnassières; quelques colliers étaient dépourvus de ces dents; d'autres sont faits de l'écorce de certaines excroissances végétales, probablement des épines d'un arbrisseau (1). Les hommes portaient à la main leurs longs arcs et leurs flèches, qu'ils échangèrent contre des bagatelles ainsi que tout ce quỉls avaient, aussitôt que nous leur en eûmes témoigné le désir.

Nous accueillîmes ces sauvages très-affectueusement. Deux d'entre eux avaient été élevés dans leur enfance parmi les Portugais dont ils parlaient un peu la langue, ce qui les rend souvent très-utiles à la fazenda. Nous leur avons donné des couteaux, des chapelets, de petits

(1) Cet ornement d'un brun-foncé, creux, allongé, dont la figure ressemble absolument à un ratelier de dents, était regardé par conséquent comme une production animale: l'expérience a fait voir qu'il était formé d'une écorce d'arbre, et que sans doute c'était le revêtement de certaines épines. On dit que la plante croit sur les bords des chutes d'eau du Paraïba. 
miroirs, etc., et nous avons partagé entre eux quelques bouteilles de rhum; présent qui les a mis de très-bonne humeur et nous a gagné leur confiance. Nous leur avons annoncé pour le lendemain notre visite dans leurs forêts, s'ils voulaient bien nous y recevoir; et leur ayant promis de leur porter des choses qui leur seraient agréables, ils nous quittèrent très-contens, et retournèrent dans leur solitude en poussant de grands cris et en chantant.

Le lendemain matin, à peine étions-nous sortis de la maison que nous aperçûmes les sauvages qui sortaient de leur vallée. Nous courûmes à leur rencontre, nous les régalâmes de rhum, et nous nous empressâmes de les suivre dans leurs forêts. Dès que nous fûmes au-delà du moulin à sucre de la fazenda, nous vîmes toute la horde des Pourys couchés sur l'herbe. Cette réunion d'hommes bruns tout nus présentait un coup d'œil très-singulier et intéressant. Hommes, femmes, enfans étaient serrés les uns contre les autres, et nous contemplaient d'un air curieux et timide. Tous s'étaient parés le mieux qu'ils avaient pu. Un petit nombre de femmes avaient un morceau de toile autour des hanches ou devant la poitrine; mais la plupart 
étaient sans aucun vêtement; quelques hommes avaient noué autour de leur front, comme ornement, un morceau de peau de l'espèce de singe nommé mono (1); d'autres avaient leurs cheveux complètement rasés. Les femmes portaient leurs petits cnfans, les unes dans des liens d'écorce d'arbre attachés au-dessus de l'épaule droite, d'autres sur le dos au moyen d'une large bandelette qui passait sur le front. C'est la manière dont elles portent généralement leurs corbeilles de provisions quand elles voyagent.

Quelques hommes et quelques filles avaient prodigué la couleur pour se peindre; ils avaient le point rouge sur le front et sur les jọues, et même des raies rouges sur le visage; d'autres s'étaient tracé sur le corps des lignes en long et des rangées de points qui les coupaient; plusieurs enfans avaient la peau comme tigrée de points noirs. La peinture du corps paraît être arbitraire chez eux et dépendre du goût de chacun. Quelques filles portaient des bandeaux autour de la tête; d'ailleurs les femmes ont en général un cordon ou un lien d'écorce serré.

(I) Ateles.

I. 
autour des poignets et des jointures, pour orner ces parties et les rendre plus minces.

Les hommes, comme je l'ai dit plus haut, sont généralement carrés, trapus, et fréquemment très-charnus; ils ont la tête grosse et ronde, le visage large, les pommettes des joues ordinairement saillantes, les yeux noirs, petits et quelquefois obliques, le nez court et large, les dents très-blanches; quelques-uns se distinguent pourtant par'des traits plus prononcés, de petits nez recourbés, et des yeux très-vifs, qui sont agréables chez un petit nombre, sombres au contraire, sérieux et cachés sous un front avancé chez la plupart. Un des hommes nous frappa par sa physionomie de Calmouk; il avait la tête grosse et ronde, les cheveux coupés à un pouce de longueur, le corps musculeux et trapu, le cou large et court, le visage grand et plat, les yeux disposés obliquement, un peu plus grands que ceux des Calmouks, très-noirs, fixes et hagards; les sourcils noirs, épais, très-hauts, arqués; le nez petit, les narines larges, la bouche un peu grande. Cet homme, qui suivant le témoignage de nos conducteurs n'avait pas été vu dans cet endroit, nous sembla si redoutable, que chacun de nous. 
avoua qu'il ne voudrait pas sans armes le rencontrer seul dans un endroit écarté. La petitesse de la taille est commune aux Pourys et à tous les peuples du Brésil, qui à cet égard le cédent aux Européens et encore plus aux nègres (1).

Tous les hommes étaient armés d'arcs et de flèches. Quelques peuples de l'Amérique méridionale, surtout ceux du Maranham, ont de petites lances de bois dur, ornées de plumes; d'autres, tels que ceux du Paraguay, de MatoGrosso, de Cuyaba et de la Guyane, de même que les Toupys de la côte orientale du Brésil, se servent encore de courtes massues de bois dur; mais l'arc et les flèches sont les armes principales de tous les peuples de l'Amérique, à l'exception de ceux qui habitent les vastes pampos de Buenos-Ayres et quelques contrées du Paraguay: ceux-ci, étant toujours à cheval, ont pour arme principale une longue lance, et comme la plupart des peuples d'Afrique un petit arc et des flèches courtes (2). Il n'en est pas de même des Tapouyas de la côte orientale; leur

(1) Eschwège, Journal von"Brasilien, tom. I, p, 162.

(2) Azara, Voyages, etc., tom. II. 
seule arme est l'arc colossal et la flèche; comme elle est très-longue ils ne la mettent pas dans un carquois, et la tiennent à la main de même qué les Payaguas du Paraguay (1). L'arc des Pourys et des Coroados a six pieds et demi de long. II est fait de bois de palmier ä̈ri, qui est dur, compact, brun noir, et muni pour corde d'une fibre de gravathà (bromelia). Les flèches des Pourys ont six pieds de long et sont faites avec le taquara, roseau solide et noueux qui croît dans les forêts sèches; ils les ornent à leur extrémité inférieure de plumes bleues ou rouges, ou de celles du hocco muti ( $\operatorname{crax}$ alector, L.), ou du jacutinga (penelope leucoptera). Celles des Coroados sont faites d'un autre roseau qui n'a pas de nouds. Parmi les flèches dont ces diverses peuplades font usage, on en distingue trois espèces qui diffèrent par leur pointe: la première est la flèche de guerre qui a une pointe de roseau taquarussù (bambusa), large, à côtés tranchans, et très-aiguë'; celle de la seconde est longue, barbelée d'un cốté, ét faite de bois d'aïri; celle de la troisième est obtuse,

(1) Ibid., p. 145. 
et quelquefois garnie de bourrelets; on s'en sert pour tuer les petits animaux. Aucune des peuplades que j'ai vues le long de la côte orientale n'empoisonne ses flèches; heureusement leur art n'est pas allé jusque là; encore moins ont-ils songé à empoisonner l'ongle de leur pouce, comme les Ottomaques de l'Orénoque(1), ou à se servir, comme les $\mathbf{Y}$ ameos des bords de l'A ma. zone, de sarbacanes faites du chaume de grami * nées colossales (2).

Notre première curiosité satisfaite, nous avons prié les sauvages de nous mener à leurs huttes. Toute la troupe a marché devant, et nous les avons suivis à cheval. Nous avons d'abord traversé des champs de cannes à sucre dans la vallée latérale; ensuite nous avons suivi un sentier étroit, et enfin nous avons rencontré dans la forêt quelques huttes (couaris dans la langue poury). Ce sont les plus simples que l'on puisse imaginer. Le hamac, tressé avec l'embira, écorce d'une espèce de coulequin (cecropic),

(1) Itumboldt Ansichten der natur, p. 45 et 154.

Tableaux de la Nature, tom. I, p. 64 et so8.

(2) La Condamine, Voyage à la rivière des Amazones, pag. 67. 
est suspendu à deux troncs d'arbres auxquels on attache plus haut avec des lianes une perche transversale; on appuie obliquement contre celle-ci, du côté du vent, de grandes feuilles de palmier, qui sont garnies par le bas de feuilles d'heliconia ou de pattioba, et dans le voisinage des plantations, de feuilles de bananier. A terre, près d'un petit feu, on voit quelques flacons faits avec des gourdes ou des écuelles de calebasse (1), çà et là un peu de cire, diverses bagatelles pour la parure, des roseaux pour des flèches et pour les pointes de cette arme; quelques plumes, des provisions, telles que des bananes et d'autres fruits; l'arc et les tlèches du chef de la famille sont appuyés contre un arbre; des chiens maigres accueillent par de forts aboiemens l'étranger qui s'approche de ces demeures solitaires.

Ces huttes sont petites, et exposées de tous côtés aux vicissitudes de l'atmosphère, de sorte que dans le mauvais temps leurs habitans se tiennent serrés les uns contre les autres, assis dans les cendres autour du feu. D'ailleurs

1) Crescentia cujete. 
l'homme est tranquillement couché dans son hamac, tandis que la femme entretient le feu et fait rôtir quelque morceau de viande fichée au bout d'un morcean de bois pointu. Le feu, nommé poté par les Pourys, est un besoin de première nécessité pour tous les peuples du Brésil ; jamais ils ne le laissent éteindre; ils l'entretiennent toute la nuit, car n'étant pas vêtus ils auraient froid alors s'ils en étaient privés; il leur procure en même temps l'avantage d'éloigner les bêtes féroces de leurs huttes. Les habitans d'une cabane semblable l'abandonnent sans regret quand le canton voisin ne leur fournit plus de vivres en suffisance; ils se transportent dans un autre où ils espèrent trouver plus de singes, de pecaris, de cerfs, de pacas, d'agoutis et d'autre gibier.

On dit que les Pourys tuent dans la contrée où nous étions beaucoup de singes barbados(1), ils nous en présentèrent effectivement plusieurs morceaux à moitié grillés pour nous les vendre. C'était une tête, ou bien une poitrine avec les bras, mais à laquelle la tête manquait; vue dé-

(1) Mrycetes (Illiger), alonate ou hurleur. 
goûtante pour un Européen, parce qu'ils ne dépouillent pas le gibier de sa peau qui noircit en brûlant. Ils déchirent avec les dents ce mets friand qui est coriace et à moitié cru. On dit même qu’ils dévorent par vengeance la chair humaine, mais on ne rencontre plus aujourd'hui chez les Tapouyas de la côte orientale la moindre trace de cette coutume; elle leur est attribuée par d'anciens écrivains qui prétendent que ces peuples mangent leurs morts pour leur donner une dernière marque d'affection(1). Les Portugais des environs du Paraïba prétendent que les Pourys mangent la chair des ennemis qu'ils ont tués, et cette assertion, comme, on le verra par la suite de cette relation, ne paraît pas entièrement denuée de vérité; mais ces sauvages ne voulurent pas en convenir avec nous. Interrogés sur ce point, ils répondirent que les Boutocoudys seuls avaient cette coutume horrible. Au reste M. Mawe raconte que les Indiens de Canta-Gallo mangent des oiseaux crus, non vidés et non plumés. Ceux du Paraïba n'en font pas autant; je les ai même vus vider

(1) Southey, History of Brazil, tom. I, pag. 379. 


\section{AU BRESIL.}

leur gibier. Peut-être ceux de Canta-Gallo ontils voulu faire un tour de force devant M. Mawe, pour l'amuser (1).

Quand nous fümes arrivés à leurs huttes, il s'ouvrit aussitôt un commerce d'échange. Nous fìmes présent aux femmes de chapelets qu'elles aiment beaucoup; toutefois elles en ôtèrent la croix et se moquèrent de ce signe réveré de l'église catholique ; elles recherchaient beaucoup les miroirs, mais ne se souciaient guère des ciseaux. Tous reçoivent volontiers des bonnets de laine rouges, des mouchoirs rouges, des couteaux. Ils nous donnèrent préférablement en échange des arcs et des flèches, et des paniers qui leur tiemnent lieu de hottes; ils sont en feuilles vertes de palmier tressées, la partie qui touche le dos et les côtes offre une surface continue, la partie supérieure est ouverte et seulenent garnie de cordons en écorce. J'ai di plus haut que c'est dans cette machine que les femmes portent leurs enfans sur le dos, elle est attachée à une courroie qui passe ou sur le front ou par-dessus les épaules.

Les sauvages apportent fréquemment pour

(1) Travels, p. 124 : Voyages, tom. I, pag. 216. 
échange de grosses boules de cire quils recueillent dans le creux des arbres qui servent de ruches aux abeilles. Ils emploient cette cire de couleur brune noire à la fabrication de leurs flèches et de leurs arcs, et en font aussi des bougies qu'ils veudent aux Portugais; elles brûlent fort bien. Le centre, extrêmement mince, est en cire; ils l'entourent d'une mèche de coton, et roulent le tout pour lui donner de la solidité. Ils mettent un grand prix à leur couteau qu'ils attachent à un cordon noué autour de leur cou, et qu'ils laissent pendre sur leur dos ; ce n'est quelquefois qu'un simple morceau de fer; mais ils l'aiguisent constamment sur une pierre et le conservent ainsi extrêmement tranchant. Quand on leur donne un couteau, ils en cassent ordinairement le manche, et en mettent un nouveau à leur goût; ils placent la lame entre deux morceaux de bois, autour desquels ils entortillent un cordon qu'ils serrent fortement.

Nos échanges terminés nous, sommes remontés à cheval pour aller à d'autres huttes situées plus loin dans la forêt. Le sentier était étroit, difficile, encombré de hautes racines d'arbres, inégal, montant et descendant le long des 
collines; quelques sauvages montèrent en croupe derrière nous, et nous suivirent de cette manière ; une troupe d'Indiens Coroados de SanFidelis nous accompagnait à pied. Nous avons rencontré đans une petite vallée solitaire, au milieu de l'épaisseur des bois, la maison d'un Portugais qui demeure parmi les Pourys ; ensuite nous avons gravi une hauteur assez douce, et nous sommes bientôt arrivés à des huttes de sauvages où des chiens maigres nous ont accueillis en aboyant. On dit que les Pourys ont reçu des Européens ces animaux qu'ils nomment joaré: j'en ai trouvé chez tous les indigènes de la côte orientale (1). Il y avait dans les huttes beaucoup de femmes et beaucoup d'enfans; on voyait plusieurs hamacs suspendus dans quelques-unes; mais dans la plupart il ne s'en trouvait qu'un seul. Le don d'un couteau me valut d'un Poury son hamac, qu'il détacha sur-lechamp; d'autres échangèrent leurs tours de tête

(1) M. de Humboldt a rencontré dans l'Amérique espagnole beaucoup de chiens noirs sans poils, Ansichten der Natur, pag. 9o : Tableaux de la Nature, tom. I, pag. 121. Nous n'en avons pas vu de semblables le long de cette côte. 
en peau de singe, leurs colliers et autres objets semblables.

M. Freyress proposa à un Poury de lui acheter son fils, et lui offrit en échange beaucoup d'objets. Les femmes délibérèrent tout haut sur cette offre ; leur ton était chantant et traînant, la plupart des mots se terminaient en $a$, ce qui. produisait un singulier concert : elles l'accompagnaient de gestes de douleur. Il était évident qu'elles ne cédaient pas volontiers le petit garçon; mais le chef de la famille, homme âgé, grave et de bonne mine, prononça quelques mots d'un air pénétré, puis se mit à réfléchir, la tête baissée. On lui donna successivement une chemise, deux couteaux, un mouchoir, quelques colliers de verroterie et des petits miroirs; il ne put résister à tant de richesses : il entra dans la forêt, et revint bientôt après tenant à la main un jeune garçon qui était fort laid, et avait un gros ventre. M. Freyress le refusa; le sauvage en amena un autre plus joli. L'indifférence avec laquelle le jeune homme entendit la décision portée sur son sort est incroyable; il ne changea nullement de visage, ne dit pas un mot d'adieu, et monta gaiement en croupe sur le cheval de M. Freyress. On rencontre cette 
apathie extraordinaire dans les événemens gais ou tristes chez tous les peuples d'Amérique : la joie ni les souffrances ne produisent sur eux aucune impression vive; on les voit rarement rire, il est difficile de les entendre parler haut. Leur besoin le plus important est leur nourriture; leur ventre demande constamment à être plein; ils mangent très-vite avec des yeux avides et fixes, leur attention étant uniquement occupée par leur repas; du reste ils peuvent supporter la faim très-long-temps. Les champs de cannes à sucre des fazendas près desquelles ils s'établissent sont ordinairement l'appât qui les attire : on les voit assis une demi-journée, su- çant une canne. Ils en coupent des quantités considérables, et les emportent dans leurs forêts. Les Tapouyas ne sont pas d'ailleurs les seuls qui aiment à sucer la canne, tous les Brésiliens de la classe inférieure partagent le même goût, et dévastent de même les champs de cannes : M. Koster le dit des habitans de Pernambouc (1):

Quand notre commerce d'échange dans la forêt a également été fini, nous sommes remon-

(1) Travels, pl. 345. Voyages, tom. II., pag. 238. 
tés à cheval, un Poury s'est placé derrière cha• cun de nous, et nous avons repris le chemin de la fazenda. Toute la bande des sauvages, hommes et femmes, n'a pas tardé à y arriver, et tous ont demandé à manger. Pendant que nous cheminions, le Poury que j'avais derrière moi tira mon mouchoir de ma poche; je le surpris à l'instant où il voulait le cacher, et je lui dis qu'il devait me donner un arc en échange : il me le promit sans hésiter, mais ensuite il se perdit dans la foule, et ne tint pas sa parole. Quelques hommes avaient bu trop d'eau-devie, ils devinrent bruyans et incommodes; on les aurait aisément éloignés en les traitant doucement, mais les planteurs, qui regardent ces hommes comme des bêtes brutes, tiennent envers eux une conduite opposée, et commencent par parler de la chicoté ou du fouet, ce qui irrite naturellement les passions de ces sauvages, et engendre de la haine et des ressentimens. Ils furent donc très-contens de nous autres étrangers, qui leur montrâmes de la bonté et de la franchise; ils remarquèrent bien à nos cheveux blonds que nous n'étions pas de la même nation que les Portugais. Ils donnent à tous les blancs le nom de rayon. 


\section{AU BRÉSIL.}

N'ayant pu obtenir à la fazenda assez de farinha pour nourrir tous ces hommes, nous avons cherché à satisfaire d'une autre manière à leur demande de vivres. Le maître de la fazenda nous a donné un petit cochon dont nous leur avons fait présent en leur disant de le tuer à coups de flèche. Nous avons pu juger à cette occasion de la cruauté avec laquelle ils font mourir les animaux dont ils se nourrissent. Le cochon mangeait auprès de la maison; un Poury s'en approcha tout doucement, le visa, mais l'atteignit trop haut au-dessous du dos; l'animal s'enfuit en criant et traînant la flèche après lui. Le sauvage saisit une seconde flèche, frappa le cochon à l'abajoue, et l'abattit ; sur ces entrefaites les femmes avaient allumé du feu à la hâte. Nousétions arrivés auprès des sauvages, ils portèrent encore des coups à l'animal pour le tuer, d'abord à la nuque, ensuite à la poitrine. Cependant le cochon n'était pas mort; étendu à terre, il poussait des hurlemens affreux et perdait son sang; en un clin d'œil, sans se laisser apitoyer par ses cris, ils le jettèrent vivant dans le feu pour le flamber et se mirent tous à rire des gémissemens que la douleur lui arrachait. Commele mécontentement que nous exprimions 
tout haut de cette barbarie croissait à chaque instant, un d'eux, prenant son couteau, coupa la gorge au pauvre animal, et mit fin à ses tourmens; ils raclèrent aussitôt son poil, découpèrent la chair et se la partagèrent (1). Comme il n'était pas bien gros, plusieurs s'en allèrent le ventre vide et en grognant. A peine la troupe etait-elle partie, qu'il arriva pour eux de SanFidelis un sac de farinha que nous leur envoyâmes.

Une insensibilité farouche est, d'après cet exemple et plusieurs autres dont j’ai été témoin, un des principaux traits du caractère des sauvages. C'est une suite nécessaire de leur manière de vivre, analogue à celle qui rend les lions et les tigres sanguinaires. Le désir de la vengeance, un peu de jalousie, un penchant irrésistible pour la liberté et pour la vie vagabonde et indépendante composent le fond du caractère de ce peuple. Ils ont ordinairement plu-

(1) Je n'ai trouvé ni dans cette occasion ni dans d'autres la confirmation d'un fait cité par M. Freyress dans le Journal von Brasilien, tom. I, pag. 208; il raconte que les sauvages ne mangent pas la chaur des animaux qu'ils ont tués. 
sieurs femmes, quelquefois jusqu'à cinq, quand ils peuvent les nourrir. En général ils ne les maltraitent pas, mais ils les regardent comme leur propriété ; il faut qu'elles fassent ce qu'ils veulent; en conséquence, elles sont chargées comme des bêtes de somme dans les voyages, tandis que l'homme marche auprès d'elles n'ayant que ses armes à la main.

La langue des Pourys, qui diffère de celle de la plupart des autres tribus, a de l'analogie avec celle des Coroados et des Coropos. Quelques écrivains, et entre autres Azara, ont prétendu que tous ces peuples de l'Amérique n'ont aucune idée religieuse; mais cette assertion semble d'autant moins fondée que cet auteur cite quelques opinions des Indiens du Paraguay, qui sans doute ont pour base une religion encore informe. M. Walckenaer, son traducteur, fait avec raison en plusieurs endroits la même remarque (1). Quant à moi j’ai trouvé chez toutes les tribus de Tapouyas que j'ai vues, des preuves manifestes d'une croyance religieuse, et je regarde comme une vérité certaine et incontestable qu'aucun peuple de la terre n'est dépourvu de

(1) Voyages, tom. II, pag. 34, à la note.

I. 
religion (1). Les sauvages du Brésil croient à différens êtres puissans; ils donnent le nom de Tapa ou Toupan au plus grand et au plus fort, qui est dans le tonnerre; plusieurs tribus, et même quelques:unes des Tapouyas, s'accordent entre elles et avec les Toupys, ou avec les Indiens de la Lingoa-Geral, sur le nom de cet esprit céleste. Les Pourys lui donnent celui de Toupan cité par Azara comme étant de la langue des Guaranys; nouvelle preuve de l'affinité de ce peuple avec les tribus de la côte orientale. On ne voit pas d'idoles chez les Tapouyas, pas même des maracas ou la parure magique qui protége les Toupinambas. Ce n'est que sur les bords du fleuve des Amazones que l'on prétend avoir trouvé certaines figures d'idoles, qui semblent avoir des rapports avec la religion des

(1) Le curé de San-Joào-Batista prétend n'avoir trouvé aucune idée religieuse chez les Indiens; mais cette assertion ne prouve rien, car puisqu'il admet l'existence de ces idées chez les Pourys, bien plus grossiers que les Corcados, elles doivent certainement n'avoir pas été étrangères à ceux-ci. Il'est incontestable qu'ils reconnaissent un être puissant et surnaturel, auquel ils donnent le nom de Toupan, et qu'ils redoutent. Journal won Brasilien, pag. 165. 


\section{AU BRÉSIL.}

habitans (r). La plupart des Indiens de I'A mérique méridionale ont aussi une idée confuse d'un déluge universel, et diverses traditions qui sont rapportées entre autres dans les Noticicas curiosas de Vasconcellos (2).

Notre hôte obligeant nous avait invités à passer la nuit chez lui; nous n'avions pas pu accepter son offre, et le même jour nous avons repassé le Paraïba pour retourner à San-Fidelis. Les Coroados y étaient très-mécontens de nous, disant que nous ne leur avions fait aucun présent, tandis que nous avions donné beaucoup de choses aux Pourys. Pour les calmer un peu nous leur avons encore acheté des arcs et des flèches. Nous sommes ensuite allés faire une visite au père Joào. Le Paraỉba coule sous ses fenêtres; c'est le fleuve le plus considérable de la capitainerie de Rio-Janeiro; on y compte soixantedouze îles jusqu’à sa cascade ( caxoeira) audessus de San-Fidelis. Il n'élait pas alors très-haut; mais dans la saison des pluies, en décembre et janvier, il déborde.

Un chemin mène à travers les montagnes de

(1) Southy. History of Brazil, tom. I, pag. $6<0$.

(2) Ibid., pag. 47. 
San-Fidelis à Canta-Gallo, un autre à Minas Geraës. Canta-Gallo, établissement formé par des Paulistes qui cherchaient de l'or, resta longtemps inconnu au milieu des grandes forêts qui l'entourent, jusqu'à ce qu'enfin le cri d'un coq le fit découvrir, ce qui lui valut son nom (1). On dit que lorsque les jésuites s'établirent dans le Brésil, une tribu d'Indiens très-blancs habitait le canton de Canta-Gallo: les premiers y ayant trouvé de la poudre d'or, la faisaient apporter au Paraïba dans des sacs de papier par les Indiens, auxquels ils donnaient des bagatelles de peu de valeur.

Notre séparation d'avec le père Joào a été plus affectueuse que notre première entrevue avec lui; mais nous dîmes un adieu plus cordial au bon-vieillard qui nous avait si généreusement donné l'hospitalité. Nous avons traversé de nouveau le Paraïba pour aller à la fazenda de M. Furriel, et nous avons encore vu les Pourys venir au moulin à sucre pour y sucer des cannes. On leur amena le petit garçon que M. Freyress avait acheté la veille, pour juger

(I) Mawe, p. 120 , tom. I, pag. 209. Le chapitre IX contient la description de ce canton. 
de l'impression que sa présence produirait sur eux; à notre grande surprise, pas un ne daigna lui jeter un coup d'oil; de son côté il ne chercha pas ses parens et ses amis, et s'assit au milieu de nous. Je n'ai retrouvé cette indifférence chez aucune autre tribu, elle paraît cependant n'avoir lieu qu'envers les jeunes gens, car ces sauvages ne manquent pas de tendresse pour les petits enfans. Jusqu'à ce que le jeune garçon puisse se nourrir, il est absolument la propriété de son père; dès qu'il est en étal de se procurer sa subsistance, son père ne s'embarrasse plus de lui.

Quelques Pourys passèrent près de nous avec leurs femmes complètement chargées de leurs enfans et de corbeilles pleines de bananes, d'oranges, d'amandes de quatelé, de roseaux pour faire des pointes de flèches, de cordons de coton et de quelques objets de parure. L'homme portait un enfant, ses trois femmes portaient les autres et les corbeilles.

Ayant pris congé de notre hôte et des Indiens, nous avons suivi à cheval la rive gauche du Paraïba pour l'examiner. Elle est aussi agréablement variée et aussi bien cultivée que la rive droite. Nous avons vu de grandes fazendas 
entourées de beaux arbres, entre autres de quatelés, couverts de leur feuillage tendre, qui était coulcur de rose, et de leurs grandes fleurs, de forme singulière et de couleur lilas. Nous avons fait halte à la maison du Senhor Moralès. Ce planteur bienveillant avait préparé pour nous quelques objets d'his oire naturelle qu'il nous offrit, et fit aussitôt seller ses chevaux pour nous accompagner. Pendant que nous étions chez lui quelques familles de Pourys sont venues camper auprès de sa maison : ils aiment beaucoup ce brave homme, qui les traite toujours avec franchise et amitié. Il ne fait pas attention aux dommages quils lui causent, quoiqu'ils soient quelquefois considérables; il leur permet toujours de piller ses orangers et ses bananiers, de même que ses champs de cannes à sucre; souvent ils les dévastent. Un hormme semblable, qui possède leur estime et leur amitié, et qui sait les traiter convenablement, serait bien propre à les a! racher à la vie sauvage, ét à les réunir dans des aldées ou villages. M. Moralès nous accompagna par des chemins montueux le long du fleuve; il y eut souvent des passagés dificiles dans des montées et des descentes trèsroides. Ensuite nous sommes entrés dans une 
forêt sombre où volaient des papillons magnifiques. Tout à coup nous avons aperçu près des bords du fleuve une petite île entourée de rochers escarpés : on y voyait quelques vieux arbres couverts entièrement de nids de guach (cassicus hoemorrhous), qui ont la forme de bourses pendantes. Des plantations de cannes à sucre, de riz, de café, celles-ci moins fréquentes, et même de maïs, s'offraient alternativement à nos regards. Au milieu du fleuve s'élevaient de jolies îles, en partie cultivées, en partie couvertes de forêts. Vers le soir nous sommes arrivés à une plaine le long du fleuve, occupée par des pâturages et une grande fazenda. Nous y avons été si bien reçus que nous avons résolu d'y passer la nuit. Au-delà de la vallée on voyait de hautes montagnes, et pa: derrière le Morro de Sapateïra, chaîne primitive avec plusieurs sommets.

Le lendemain à midi nous sommes arrivés au Muriàhe, rivière peu large, mais profonde et rapide, qui dans la saison des pluies cause souvent de grands dégâts ; elle prend sa source à la Serra do Pico, dans le pays des Pourys : on dit qu'elle est navigable pendant sept legoas, jusqu'à une cataracte. Une petite pirogue nous a portés 
del'autre côté du Paraïba, et le soir nous sommes. arrivés à Villa de San-Salvador. Nous avons rencontré dans notre route l'aldéa de San-Antonio, qui était autrefois un villaged'Indiens-Gorulhos, fondé par les jésuites : aujourd'hui l'on ne trouve plus un seul Caboclo parmi ses habitans. 


\section{CHAPITRE VI.}

Muribecca. - Hostilités des Pourys. - Quartel das Barreiras.

- L'Itapemirim. - Villa-Nova de Benevente sur l'Iritiba.

- Goaraparim.

A notre arrivée à Villa de San-Salvador, nous apprîmes que l'on avait reçu la confirmation de la victoire de Waterloo, et nous partageâmes la joie que cette nouvelle causait aux habitans; aussitôt nous fìmes des préparatifs pour continuer notre voyage au nord le long de la côte; nous prîmes deux nouveaux chasseurs; et le colonel Carvalho dos Santos, commandant du lieu, qui nous avait comblés d'honnêtetés, nous donna un soldat pour guide.

Nous sommes partis le 20 novembre, et nous avons suivi la rive du fleuve jusqu'ạ son embouchure dans la mer. L'aspect de la villa est trèspittoresque de ce côté; elle s'étend assez loin le long du Paraïba ; la masse des toits, entrecoupée de tiges de cocotiers, s'élève immédiatement du bord de l'eau ; le fond du tableau dans le lointain 
est formé par de hautes montagnes bleuâtres. Le fleuve, que traversent sans cesse des pirogues menées par des nègres, est bordé de bois, de petites prairies et de jolies maisons.

Notre journée a été assez fatigante. Le long repos avait rendu nos mulets peu dociles : en passant devant les nombreuses fazendas, il fallait s'arrêter afin d'ouvrir les clôtures élevées pour retenir le bétail ; nos animaux profitaient de ce délai pour s'échapper. Les bœufs que nous vîmes dans cette contrée étaient très-beaux; ils sont en général, dans le Brésil, grands bien faits et charnus; ils ont des cornes incomparablement plus grandes quene sont ordinairement celles des boufs d'Europe. Les peaux de bœuf de Buenos-Ayres, de Monte-Vidéo, de RioGrande, et des autres pays des possessions portugaises et espagnoles en Amérique, sont renommées par leur grandeur. On élève aussi beaucoup de chevaux dans le pays que nous traversions.

Le paysage était varié et agréable. Nous avons vu plusieurs oiseaux nouveaux, entre autres le beau martin-pêcheur bleu (alcedo alcyon, L.). Nous en avons tué plusieurs. Vers midi nous sommes arrivés à la maison d'un lieutenant. 


\section{AU BRÉSIL.}

Il était absent ; sa femme nous a donné l'hospitalité. Le lendemain, quand nous nous préparions à partir, le lieutenant, qui était arrivé pendant la nuit, a fait seller son cheval, et nous a accompagnés jusqu’à Villa de San-Joào da Barra. Le temps était extrêmement chaud; les flaques d'eau des forêts étaient presque desséchées et couvertes d'une multitude de papillons jaunes et blancs qui y cherchaient de la fraîcheur. Ces amas de papillons dans les endroits humides sont tonjours un signe de l'approche de la saison chande; on en voit quelquefois voler dans le voisinage de l'eau des troupes si grosses qu'elles ressemblent à des nuages.

Des bois nous cachaient la vue du Paraïba; le sol sablonneux nous indiquait l'approche de la mer. De jolis oiseaux, entre autres des martinpêcheurs, augmentèrent ici nos collections. Arrivés sur les bords du fleuve, nous aperçûmes un animal objet d'une chasse nouvelle; c'était le jacaré ou le crocodile de ces contrées (crocodilus sclerops) (1). Cet amphibie habite dans tous les

(1) Il est doutenx que le jacaré d'Azara soit le crocodilus sclerops. Sa description est trop vague; d'ailleurs la couleur 
fleuves du Brésil, surtout dans ceux qui n'ont pas. beaucoup de pente, et où par conséquent les lieux marécageux et les bras à eau dormante sont nombreux : on reconnaît ces derniers aux larges feuilles de certaines grandes plantes aquatiques telles que le nymphæa, le pontedéria, etc., dont les tiges poussent du fond de l'eau, et qui étalent horizontalement leurs fleurs à la surface. C'est là qu'il faut chercher le jacaré, et que l'observateur expérimenté voit sa tête, que l'animal avance au-dessus de l'eau pour guetter sa proie; cependant on le trouve aussi au milieu des rivières, surtout de celles qui sont peu considérables et coulent lentement. D'épais halliers formés par un arbre à tiges minces, hautes de dix-huit à vingt pieds et à feuilles larges, entières et cordiformes, probablement d'un Croton voisin du Tridesmys, couvrent les rives du Paraïba. On peut s'avancer doucement entre ces arbres jusqu'au bord de l'eau, et l'on aperçoit le jacaré aux aguets. Dans le commencement nous nous approchions du fleuve à

de l'animal est très-différente. Voyez Escais sur les quadrlpèdes du Paraguay, etc., tom. II , p. 380. 
cheval sans garder le silence nécessaire, et nous n'entendions que le bruit que faisait le jacaré en plongeant; mais nous étant avancés avec plus de précautions, pour voir d'où provenait ce bruit, nous avons découvert près de la rive le jacaré qui le causait. Je lui envoyai la charge complète de mon fusil à deux coups et je l'attrapai à la nuque; il fit un bond en l'air, se retourna sur le dos, et plongea. Quoique je fusse sûr qu'il avait reçu un coup mortel, il n'y avait cependant aucun moyen de le tirer du fond de l'eau. Nous en avons en peu de temps tué ainsi jusqu’à quatre qui nous ont tous échappé.

Très-peu de temps après notre dernière mésaventure de ce genre, nous avons entendu devant nous quelques coups de fusil. En arrivant au lieu d'où ils partaient nous avons reconnu que deux de nos chasseurs placés sur le pont d'un ruisseau qui coulait lentement avaient frappé un jacaré de deux coups à la nuque; nous nous sommes procuré une pirogue à des cabanes de pêcheurs qui étaient dans le voisinage; un pêcheur fouilla dans l'eau avec une fourche de fer, atteignit l'animal, et le retira. Ce jacaré avait à peu près six pieds de long; sa couleur était 
d'un gris verdâtre, traversée surtout à la queue par des raies plus foncées; le dessous du corps était partout jaune clair. Nous étions bien contens d'avoir ce bel animal, nouveau pour nous. Nous l'avons chargé sur nos mulets : il répandait une odeur de musc extrêmement désagréable. Le jacaré n'égale pas à beau coup près en grosseur le crocodile colossal de l'ancien monde, ni même celui des contrées de l'Amérique méridionale voisines de l'équateur. M. de Humboldt trouva le corps des derniers tout couvert d'oiseaux, et il ajoute qu'il a même vu des flamands ou phénicoptères se reposer tranquillement sur leur tête (1).

Le Paraiba contient beaucoup de jacarés: les nègres mangent sa chair. On débite toutes sortes de fables sur cet animal.Cependant on nele craint pas, quoiqu'il ait huit à neuf pieds de long, et que des pêcheurs nous aient montré à leurs doigts des traces de ses morsures : peut-être lui arrivet-il quelquefois d'attraper et de manger un chien qui traverse la rivière à la nage. Ces jaca-

(1) Ansichten der natur, p. 141 .

Tableaux de la nature, tom. I, p. 46 et 61 . 
rés étaient si nombreux dans le ruisseau où l'on venait d'en tuer un, que de dessus le pont l'on. en pouvait d'un coup d'œil compter plusieurs ; mais nous en avons tiré quelques-uns de trop loin, ce qui les a effarouchés, et nous ne nous en sommes procuré qu'un seul.

A une petite distance de ce ruisseau nous avons rencontré dans les terrains sablonneux des buissons d'Eugenia pedunculata, joli arbrisseau très-connu; il était en ce moment tout couvert de ses fruits rouges, charnus, quadrangulaires, savoureux, connus dans le pays sous le nom de pitanga, et qui en ce moment offrent un rafraîchissement agréable. Les acajous (anacardium orientale, L.) étaient en fleur: nous vîmes dans une prairie voisine un beau taureau à quatre cornes.

Enfin nous sommes arrivés heureusement à Villa de San-Joào da Barra, située à peu de distance de l'embouchure da Páraïba dans la mer. Grâce à l'attention de M. le lieutenant, notre guide, on nous fit loger dans la casa da Camara, ou maison destinée aux employés de la couronne : elle est grande; elle a plusieurs chambres, ainsi qu'une cour plantée d'orangers et de goyaviers, qui étaient alors en fleurs. Villa de 
240

San-J.jào da Barra est un bourg qui ne peut pas se comparer à San-Salvador; il n'a qu'une église; ses rues, non-pavées, sont bordées de maisons basses à un seul étage, bâties en bois et en terre. Le fleuve est navigable pour des brigs assez gros et des sumacas; de sorte que ce port fait ses expéditions directement par mer. Tous les bâtimeus qui veulent remonter jusqu'à SanSalvador sont obligés de passer devant SanJoào da Barra, quoique le bras du fleuve qui baigne ce bourg soit peu profond, et que le chenal se trouve au-delà de quelques îles. La plupart des habitans sont marins et pêcheurs; le commerce des productions des environs de San-Salvador les fait vivre.

Nos chasseurs, qui nous avaient précédés à San-Joào, a vaient tué différens ánimaux, et apporté avec eux deux tatous vivans. Ce singulier animal est très-commun au Brésil, où l'on en trouve plusieurs espèces. Ceux-ci étaient de celle que l'on nomme tatu-peba, mais plus généralement vrai tatou (tatuverdadeiro) (1): il est excellent à manger rôti. On mit le soir

(1) C'est le Tatou noir d'Azara. Voyez Essais, etc., tom. II, p. 175 . 


\section{AU BRÉSIL.}

un de ces animaux dans un sac, et l'autre dans un coffre; le lendemain quand on voulut leur donner à manger, on trouva que le premier, après avoir fait un trou dans le sac, en avait pratiqué un autre dans le mur épais de la maison, et s'était échappé.

Nous avons passé deux jours à San-Joào pour préparer notre jacarè, opération qui nous a pris une journée entière. Le juiz, juge ou maire du lieu, nous avait procuré quatre grandes pirogues et des matelots pour transporter notre bagage de l'autre côté du Paraïba. Le vent, qui soufflait avec force, élevait de si gros-. ses lames sur la surface du fleuve, que de petites pirogues auraient couru le risque de chavirer. Nous entendîmes constamment le bruit des brisans de la mer, tandis que nous doublions en descendant le fleuve une île couverte de jolis arbrisseaux. On y voyait entre autres un cléome frutescent, à gros bouquets de fleurs d'un blanc: jaunâtre, à étamines pourprées, une malvacée, haute d'une quinzaine de pieds, à fleurs d'un jaune tendre et à feuilles cordiformes (1), l'a-

(1) Arruda nomme cette plante Guachuma do Mangue. (Hibibcus pernambucensis.)

I. 
ninga espèce de gouet à haute tige (arum liniferum. Arruda) à grands fruits oviformes, et à fleurs blanchâtres (1).

A près avoir traversé le second bras du fleuve, nous sommes entrés dans un petit canal qui conduit entre deux îles, et dans lequel l'eau, entourée de tous côtés de grands arbres, est extrêmement tranquille; aussi cet espace est-il rempli de jacarès. Pendant que notre pirogue avançait lentement, nous en apercevions tout autour de nous. Les mangliers (conocarpus et avicennia) forment, avec leurs racines nues, arquées et partant d'une partie élevée de la tige, un singulier entrelacement. Nous apercevions quelquefois entre ces arbres des jacarès qui se reposaient sur de vieilles souches ou sur des pierres le long du rivage. Mon fusil était toujours prêt à leur envoyer une balle, mais je ne pus en tirer aucun; souvent la pirogue balançait, et avant qu'elle eut repris l'aplomb nécessaire pour que je pusse viser, le jacarè s'était replongé dans l'eau. A l'issue du canal

(1) Ibid. Voyez sa description des plantes do Pernambouc dans l'appendice du voy age de Koster. 


\section{AU BRÉSIL.}

nous avons trouvé sur l'île beaucoup de martinpêcheurs; de grandes troupes de cormorans semblables au nôtre (carbo cormoranus), plongeaient pour attraper leur proie," mais ils étaient un peu farøuches. Faute d'objets plus importans, nous avons recueilli deux espèces de goemon, que l'on rencontre aussi près de Riode Janeiro (1); et dans une petitelagune, longue et étroite, située derrière les dunes, nous avons tué un cormoran plongeur.

Au nord de ce lieu, la côte, à une certaine distance du rivage, est couverte de divers arbrisseaux, parmi lesquels on distinguait le pitangeira (eugenia pedunculata), rne nouvelle espèce de sophora à fleurs jaunes, le cactus hexagone et d'autres plantes de ce genre que le vent tient très - basses. Nous avons atteint avant la nuit la fazenda Mandinga, qui est isolée sur le bord de la mer; nos gens et nos mulets, qui avaient été arrêtés par un canal, n'arrivèrent que le lendemain matin. Nous avons rencontré en ce lieu le correo ou le courrier de la poste, qui va

(1) Fucus lindigerus. $\boldsymbol{L}$. $\boldsymbol{F}$. incisifolius et $\boldsymbol{F}$. latifolius. Turn. hist. fuc. 
de Rio jusqu’à Villa de Victoria, où il borne sa course au nord. Nous reçûmes des lettres qui nous procurèrent pour la soirée un entretien agréable.

En allant de Mandinga au nord, nous avons voyagé le long du rivage dans un sable profond qui est toujours humecté par la mer. Cette route sablonneuse est commode et agréable pour les hommes, mais les mulets et les chevaux, qui ne sont pas encore accoutumés à la vue et au fracas des brisans, s'effraient souvent dans ce chemin. Une tropa, vue de loin sur la surface blanche et unie de la plage sablonneuse le long de la mer azurée, offre un coup d'œil intéressant dans les endroits où la côte ne forme pas des enfoncemens considérables, les bêtes de somme paraissent dans l'éloignement comme des points. Sur les pointes de terre qui ont à soutenir les chocs les plus violens des lames, on observe des rochers que l'eau a percés de la manière la plus singulière. Quelques espèces de vanneaux et de pluviers animent la côte, sur laquelle on ne rencontre que peu de coquillages et de goemons.

Ayant suivi cette plage l'espace de quelques legoas, un sentier nous conduisit à des lagunes environnées de hauteurs boisées. Une soif ar- 


\section{AU BRÉSIL.}

dente tourmentait notre tropa, tout le monde mit pied à terre pour se désaltérer, mais, à notre grand chagrin, le débordement de la mer avait salé l'eau des lagunes; des huttes, dans lesquelles nous espérions trouver quelque chose pour apaiser notre soif, 'étaient vides. Heureusement des pitangas, qui croissaient en abondance dans tout le canton, nous dédommagèrent en quelque sorte de ce que nous avions espéré y rencontrer.

Un sentier, qui, en s'éloignant de la mer, se dirigeait vers des bois touffus, ne tarda pas à nous faire entrer dans la forêt. J'étais en avant de la tropa, j'observais les belles plantes, et je pensais aux Tapouyas qui infestent quelquefois cette contrée, lorsqu'à ma grande surprise j’aperçus tout à coup devant moi deux hommes bruns tout nus. Dans le premier moment je les. pris poúr des sauvages, et je me préparais it saisir mon fusil à deux coups pour me défendre contre une attaque possible, quand je reconnus que c'étaient des chasseurs de lézards. Les planteurs qui habitent ces déserts aiment la chair $\mathrm{d} \mathrm{a}$ teiù (lacertc teguixin, L.), grand lézard, ainsi nommé dans la lingoa geral des Indiens côtiers, et vont souvent dans les forêts et les bois 
sablonneux à la chasse de ces animaux avec des chiens dressés à les poursuivre. Dès que les chiens s'approchent d'un lézard, celui-ci s'enfuit avec une vitesse inconcevable dans son trou, que le chasseur creuse, puis tue l'animal. La chaleur étant excessive, ces deux hommes, dont tout le corps était tellement hâlé du soleil qu'on aurait pu les prendre pour des Tapouyas, s'étaient dépouillés de toute espèce de vêtement ; ils étaient armés de haches; ils avaient pris deux lézards, longs de près de quatre pieds, la queue comprise.

Ces chasseurs, qui connaissaient bien la contrée, nous dirent qu'en moins d'une heure de route nous arriverions à la fazenda de Muribecca, où nous voulions passer la nuit. Effectivement nous n'avons pas, tardé à entrer dans l'enceinte qui nous annonçait ses limites. Nous avons trouvé de belles plantes dans la forêt. Le haut des arbrisseaux était couronné de liserons à belles fleurs en cloche azurées. Le juo (1)

(1) Tinamus noctivagus. Espèce de tinamou ou ynambou, non encore décrite. Il est plus petit que le macouca (Tinamus Brasiliensis), Iongueur treize pouces cinq lignes; partie 
faisait entendre sa voix forte sur trois ou quatre tons; dans ces forêts immenses elle frappe les oreilles à toutes les heures du jour, et même au milieu de la nuit. La chair de cet oiseau a aussi bon goût que celle de tous ses congénères, que lon comprend ordinairement sous le nom de tinamous ou ynambous.

En sortant de la forêt nous nous sommes trouvés dans de vastes plantations nouvellement établies. De dessus une élévation, où de grands arbres abattus étaient couchés les uns en travers des autres, comme pour faire un retranchement, nous eûmes la vue ravissaute de la belle solitude baignée par l'Itabapuana, qui, semblable -à une ligne argentée, sort en serpentant de la forêt sombre, et traverse une prairie verdoyante au milieu de laquelle s'élève la fazenda de $\mathbf{M u -}$

supérieure gris foncé, mêlé de brun rongeâtre; dos brun marron ; sommet de la tête fortement parsemé de gris cendré, et un peu tacheté de noirâtre ; bas du dos et croupion brun de rouille rougeâtre; toutes ces parties du dos sont coupées de lignes transversales d'un brun noir; dessous du bec et gorge blanchâtre; dessous du cou gris cendré; poitrine d'un jaune de rouille brunâtre vif; ventre plus pâle. 
ribecca entourée de vastes plantations. Des forêts immenses bornent l'horizon de tous les côtés. Les nègres occupés à travailler à la terre restaient ébahis à la vue de notre tropa, qui s'avançait hors de la forêt, comme une apparition venant d'un monde étranger.

Nous sommes d'abord arrivés à Guttinguti, qui, conjointement avec Muribecca, porte le nom de fazenda de Muribecca. Cette propriété, avec un territoire de neuf legoas de longueur, appartenait autrefois aux jésuites; aujourd'hui elle est possédée par indivis par quatre particuliers. On y compte encore trois ceuts nègres, parni lesquels il n'y en a qu'une cinquantaine de vigoureux et propres à toutes sortes de besognes. Ils sont sous la surveillance d'un économe (feitor) portugais, qui nous fit l'accueil le plus gracieux. Les travaux qui consistent principalement dans le défrichement des forêts, sont très-pénibles pour les nègres. On cultive dans cette fazenda le manioc, le maïs, le coton, et un peu de café.

L'Itabapuana petite rivière qui coule à peu de distance de Guttinguti, arrose les prairies quand ses eaux sont hautes. La Corografia Brasilica lui donne à tort le nom de Reri- 
tigba (1) qui est le Benevente. Il prend sa source dans la Serra do Pico à peu de distance de celle du Muriàhe. Les forêts qui environnent Muribecca sont habitées par des Pourys errans qui commettent des hostilités en cet endroit, et à une journée de route au nord. J'ai dit plus haut qu'on les regarde comme les mêmes qui vivent en bonne intelligence avec les planteurs de San-Fidelis. Au contraire, sur les bords de l'Itabapuana (2), ils ont encore attaqué au mois d'août dernier les troupeaux de la fazenda, et ont tué par méchanceté trente boufs et un cheval. lls parvinrent à séparer de ses camarades armés un jeune nègre qui gardait les troupeaux, le firent prisonnier, le tuèrent, et, suivant ce qu'on assure ici, le rôtirent et le mangèrent. On supposa qu'ils avaient coupé et emporté les bras et les jambes, ainsi que la chair du derrière, car lorsqu'on vint sur le lieu bientôt après, on vit que toutes ces parties manquaient au corps du

(1) Tom. II, pag. $6 \mathbf{r}$

(2) Cette rivière est désignée sur plusieurs cartes sous le nom de Comapuam; quelques habitans lui donnent aussi celui de Campapoana; ces deux noms sont inexacts. 
malheureux nègre. Les sauvages avaient promptement fait retraite dans la forêt. On trouva ensuite les mains et les pieds rôtis qui portaient encore des traces visibles des dents.

Le feitor, qui est ainsi exposé aux attaques des sauvages, montrait contre eux une haine incroyable. Il répéta plusieurs fois qu’il tuerait volontiers notre jeune Poury d'un coup de fusil. ( Il est inconcevable, ajouta-t-il, que le gouvernement ne prenne pas des mesures plus vigoureuses pour exterminer ces animaux. ) Pour peu que l'on remonte la rivière, on rencontre tout de suite leurs cabanes. Certainement leur voisinage est très-incommode; mais d'un autre côté il faut considérer que les planteurs, par les mauvais traitemens qu'ils ont autrefois fait éprouver aux sauvages, sont en grande partie cause des dispositions hostiles de ceux-ci. Dans les premiers temps l'avidité et la soif de l'or étouffaient tout sentiment d'humanité dans l'âme des colons européens; ils ne regardaient les hommes cuivrés et nus que comme des animaux, qui n'avaient été créés que pour eux; on trouve la preuve de cette opinion absurde dans la dispute élevée entre des ecclésiastiques espagnols sur la question de savoir si les Amé- 
ricains étaient des hommes semblables aux Européens?

Indépendamment du fait que je viens de raconter, plusieurs témoignages s'accordent, dans cette contrée, à certifier que les Pourys mangent les corps des ennemis qu'ils ont tués. Le père Joào, curé de San-Fidélis, nous assura que, voyageant le long de l'Itapémirim, il avait trouvé dans les forêts, sans bras et sans jambes, le corps d'un nègre tuépar les Pourys ; une troupe d'ouroubous l'entourait. Quoique ceux de ces sauvages auxquels nous avions parlé à San-Fidélis n'eussent pas voulu convenir qu'ils mangeaient de la chair humaine, leur dénégation ne peut détruire les témoignages que je viens de citer. Notre jeune Poury avoua que les gens de sa tribu fichaient au haut d'une perche la tête d'un ennemi tué, et dansaient à l'entour. D'ailleurs M. Freyress m'a raconté que les Coroados de Minas Geraës ont la coutume de mettre Ia jambe ou le bras d'un ennemi dans un pot avec du caoui, et de le sucer à la ronde.

Notre séjour a Muribecca fut très-productif pour nos collections d'histuire naturelle. Malgré l'abondance des pluies nos chasseurs profitèrent très-avantageusement des courts intervalles 
de beau temps. Le canard musqué (Anas moschata, L.) nichait dans les forêts et dans les marais sur les bords de l'Itabapuana. Ce bel oiseau, que l'on élève fréquemment dans les basses cours et les faisanderies de l'Europe sous le nom de Canard de Barbarie, est reconnaissable à la membrane ronge et verruqueuse qui entoure le voisinage du bec et de l'œil. Le plumage est noir, changeant au vert et pourpre, le haut des ailes est blanc de neige chez les vieux, et noir chez les jeunes. Les vieux mâles sont gros et lourds; leur chair est un peu coriace; celle des jeunes est tendre, savoureuse, et par conséquent très-recherchée des chasseúrs.

Nous autres Européens nous rencontrions souvent de grands obstacles en chassant dans les marécages le long du fleuve; nos chasseurs indigènes à demi nus pénétraient au contraire avec la plus grande facilité dans ces lieux non fréquentés. Trois nègres de la fazenda nous offrirent aussi de chasser pour nous; nous leur donnàmes des fusils, de la poudre et du plomb, et tous les soirs ils nous apportaient beaucoup d'oiseaux, entre autres des hérons, des courlis, des canards musqués, et l'ipecutiri d'Azara (anas viduata) ou le canard à épaules vertes, 


\section{AU BRÉSIL.}

le héron blanc à calotte noire, garça real, bel oiseau qui n'a encore été décrit qu'imparfaitement, dont le corps est blanc jaunâtre et le bec bleu (1); la grande et la petite aigrette au plumage d'un blanc éclatant, et beaucoup d'autres.

L'Itabapuana nous procura aussi plusieurs choses rares. M. Freyress et $\mathbf{M}$. Sellow, qui se promenaient le long de ses bords en remontant, aperçurent une grande lroupe de loutres (lutra brasiliensis) qui, sans marquer la moindre crainte, jouaient devant eux dans l'eau en grondant et sifflant. Cet animal diffère principalement de celui d'Europe par sa queue un peu comprimée : ce caractère, qui a été aussi reconnu par Azara, ne s'observe pas ordinairement dans les individus empaillés, et a par conséquent été oublié dans les ouvrages d'histoire naturelle. Leur pelage est doux et fort beau. Cette loutre acquiert souvent une taille colossale dans les grandes rivières de l'intérieur du Brésil; par exemple dans le Rio San Francisco, où on la nomme non pas lontra, mais ariranha (arirannia). Nous avons trouvé ici une de ces grandes

(1) Ardea pileata. Latham. Voyez aussi le Buffon de Sonnini, tom. XXI, pag. 192. 
loutres. On vint nous dire que l'on avait vu dans l'eau un animal mort qui avait des mains d'homme. Nous y avons couru pour voir cette bête singulière, et nous avons reconnu une loutre longue de près de six pieds qui était encore en assez bon état pour entrer dans nos collections. Nous ne pûmes deviner qu'elle avait été la cause de la mort de cet animal, qui ne paraissait avoir reçu aucune blessure ex térieure. Les jacarès fréquentent aussi la partie supérieure de l'Itabapuana. Les forêts retentissaient de la voix forte et éclatante de l'alouate ( $m y$ cetes ursinus) et de la voix non moins forte mais rauque du sauassù (callithrix personatus. Geoffroy) ou sagouin à masque, qui étaient extrêmement communs dans cet endroit. Nos chasseurs tuaient quelquefois quatre à cinq de ces jolis singes en peu de temps, car lorsqu'ils en rencontraient une troupe ils tiraient aussitôt dessus, et rechargeaient leurs fusils, tandis qu'une ou plusieurs personnes de la troupe cherchaient à ne pas perdre de vue les animaux dans leur fuite sur les branches. Le sauassù n'a encore été représenté dans aucun ouvrage d'histoire naturelle; il est fort agréablement bariolé; il a la tête et les quatre mains noires, le corps 
d'un blanc sale gris brunâtre ; sa longue queue lâche est jaune rougeâtre. Plusieurs de ces singes portaient leurs petits sur leurs épaules. Nous avons bientôt reconnu que cet animal peut s'élever et s'apprivoiser aisément. Parmi les oiseaux que nous avons tués se trouvait une nouvelle espèce de pic fort belle, que j'ai nommée picus melanopterus. Il est tout blanc, à l'exception des ailes, du dos et d'une partie de la queue, qui sont noirs; l'œil est entouré d'une membrane nue orangée.

Nous avions pris à Campos deux chasseurs, qui étaient allés en avant à l'embouchure, ou Barra de l'Itabapuana, pour y chasser, et qui devaient nous rejoindre à Muribecca: le temps que nous leur avions fixé étant écoulé depuis longtemps, et nos meilleurs armes se trouvant dans leurs mains, nous conçûmes de vives inquiétudes que ces hommes ne prissent la fuite. En conséquence nous fìmes monter secrètement une pirogue par nos gens, qui descendirent le fleuve jusqu'à son embouchure dans la mer, surprirent les chasseursà l'improviste, leur retirèrent leurs armes, et les laissèrent aller où ils voulurent.

Le voyage des bords de l'Itabapuana au nord exige quelques précautions; car pour gagner 
ceux de l'Itapemirim il faut traverser un espace de six à huit legoas, où les Pourys se sont constamment montrés en ennemis; comme ils y ont souvent commis des meurtres affreux, on a été obligé d'y établir un poste militaire, nommé le Quartel ou le Destacamento das Barrëras. Le feitor de Maribecca voulut nous accompagner jusqu'à ce poste.

Nous avons traversé alternativement des forêts et des lieux ouverts et sablonneux, où l'on voyait des traces nombreuses de tapirs et de cerfs; arrivés à une haute croix de bois, nous avons cheminé sur la plage. On apercevait une vaste baiequi se terminait au loin par une pointe de terre élevée, sur laquelle était situé le Quartel. Nous nous étions préparés à repousser une attaque des sauvages, dansle cas où nous en rencontrerions. Nous avions vingt coups de fusil à tirer, et même quelques-uns de nous s'étaient fait des cartouches pour charger plus promptement. Les soldats du Destacamento ont coutume de venir à la rencontre des voyageurs quand ils apercoivent dans le lointain une tropa s'avancer le long de la côte; effectivement lorsque nous avons eu suivi la plage l'espace d'une lieue à peu près, nous avons rencontré une patrouille de six hom- 
mes, la plupart nègres et mulâtres que l'officier du poste nous euvoyait. Il nous reçut très-affectueusenent à notre arrivée. Ce poste consiste en un officier et vingt hommes de milice armés de fusils sans baïonnette. Le corps-de-garde comprend deux maisons en terre, bâties sur le bord de la mer, et entourées de champs de manioc et de maïs, qui servent à la nourriture des soldats. La côte est composée d'une terre argilleuse; elle est coupée à pic comme un mur (barreiras). Sur la partie la plus haute est placée le quartel, de sorte qu'il commande la vue de la mer, ainsi que de la côte au nord et au sud, ét les gardes aperçoivent aisément les Tropas de fort loin. Du côté de terre le bâtiment du quarte est contiguë à une forêt ou l'on a commencé à faire des défrichemens. Au mois d'août précédent les Pourys avaient tenté une attaque contre le poste; ils étaient venus pour ravager les champs des soldats; ils combattirent abrités par des buissons et des arbres: un soldat et deux chiens du corps-de-garde furentblessés; les Pourys perdirent trois hommes tués ou blessés, qui furent emportés par les autres. Le poste a été tranquille depuis, et les sauvages ne se sont plus fait voir dans cette parI. 
tie de la côte. On conserve comme trophée dans le corps-de-garde les flèches des Tapouyas.

L'officier qui commande ce poste fournit toujours un détachement de trois hommes à l'embouchure de l'Itabapuana : le terme de sa résidence n'est pas fixé; celui que nous y avons vu y était depuis près d'un an. Triste garnison dans un désert semblable, où la nourriture même est mauvaise, et où le logement ne consiste qu'en cabanes de terre couvertes de feuilles de palnier. La maison de l'officier est pourtant assez grande, et renferme plusieurs chambres, où se trouvent des siéges en bois; mais le toit qui tombe en ruines n'empêche pas la pluie de pénétrer. On construisit ce corps-de-garde parce que différens meurtres avaient été commis sur le bord de la mer, dans le voisinage de ce lieu. Il y à peu près six ans sept personnes, qui revenaient de l'église de l'Itapemirim, furent attaquées par les Pourys, six furent tuées; une seule eut le bonheur d'échapper. Une jeune fille avait d'abord pris la fuite; mais les sauvages l'atteignirent et l'égorgèrent; on retrouva ensuite les corps de ces infortunés mutilés. Peu de temps après les Pourys attaquèrent aussi un soldat dans ce canton, et le tuèrent. 
L'officier nous donna beaucoupde renseignemens intéressans sur les Pourys. Il nous assura que ces sauvages témoignent actuellement le plus grand desir de vivre en paix avec les Portugais, ce qui s'accorde parfaitement avec les intentions qu'ils ont manifestées à M. Moraès à San-Fidelis. Cette bonne intelligence serait trèsavantageuse pour toute la côte ; car les habitations étant fort éloignées les unes des autres, on y est sans cesse exposé aux attaques de ces barbares impitoyables, et cette contrée court le risque d'être dépeuplée, si l'on ne prend pas d'autres mesures que celles qui ont été suivies jusqu'à présent. Les sauvages, maîtres dans leurs forêts, paraissent subitement tantôt dans un endroit, tantôt dans un autre, et disparaissent avec la même rapidité, comme on l'a éprouvé à l'attaque de Ciri. Ils connaissent les repaires des forêts les plus cachés, sont circonspects et dissimulés; enfin ils n'ignorent pas l'état de faiblesse des colons portugais, et plusieurs d'entre eux parlent assez passablement la langue de ces derniers.

Le jour de repos que nous avons passé à Barreïras a été employé à des excursious dans les bois et les marais voisins; les soldats nous 
y accompagnèrent, et furent nos guides. Notre butin s'est borné à quelques canards (anas vicluata) et à un oiseau nouveau de la famille des cotingas (1). On voyait nager le long de la côte de grandes tortues de mer (tartarugas), qui au printemps fréquentent le rivage et élèvent lentement leur grosse tête ronde au-dessus de la surface de l'eau. Un orage violent s'éleva au milieu de la nuit; la pluie tombait à torrens; nous eûmes beaucoup de peine à nous en garantir dans notre logis, dont le toit était percé.

Le lendemain nous faillîmes à faire la triste expérience de la négligence avec laquelle on entretient cette route, la seule qui règne le long de la côte, et qui est dépourvue de ponts $t$ t de passages praticables. 'Tout près du quartel nous courûmes le risque de perdre quelquesuns de nos meilleurs mulets. Ayant encore quatre legoas à parcourir dans cette contrée

(1) Procnias Melanocephalus, tête noir foncé; iris de l'œil rouge éclatant; toutes les parties supérieures vert changeant; les inférieures vert jaunâtre avec des raies transversales foncées; longueur huit pouces sept-lignes. 
exposée aux incursions des Pourys, entre l'Itabapuana et l'Itapemirim, nous avons eu soin de ne pas nous écarter les uns des autres dans notre marche, et de bien maintenir cet ordre essentiel à notre sûreté; nous avions de plus une escorte de soldats. Nous avons cheminé ainsi lentement sur la plaine sablonneuse, ferme et parfaitement unie le long du rivage qui forme une falaise composée d'argile jaune ou blanche et rouge brun (1), et de couches de grès ferrugineux. Les ravines et les parties élevées du rivage sont couvertes d'épaisses forêts, où personne n'ose pénétrer un peu avant, à cause des sauvages. Les vingt coups de fusil que nous avions à tirer nous mettaient à couvert de tout danger de la part de ces barbares, toutefois plusieurs de nos gens ne purent contempler sans frissonner le lieu où ils avaient assassiné les six malheureuses victimes.

(1) Les expériences de M. Hausmann, professeur à Goettingen ont prouvé que ce fossile, qui compose une grande partie de l'étendue de cette côte du Brésil, appartient a l'argile lithomarge durcie, qui comprend aussile WunderErde de Saxe. Ses caractères sout analogues à ceux de l'argile lithomarge. 
Après quelques heures de marche nous sommes arrivés dans un endroit où la côte s'abaisse au Povoaçao ou hameau de Ciri(1), qui est aujourd'hui absolument abandonné. C'est là qu'au mois d'août dernier les Pourys ou d'autres 'Tapouyas firent une attaque soudaine, égorgèrent trois personnes dans la première maison, et répandirent une terreur si grande que tous les habitans prirent aussitôt la fuite. Il n'y a plus que deux maisons au-delà d'une petite lagune qui soient encore habitées par des personnes bien armées, condition essentielle de leur sécurité. Les sauvages emportèrent les ustensiles en fer et les provisions qu'ils trouvèrent, et se retirèrent dans leurs forêts. Instruit de cette attaque, le sargento mor ou major d'Itapemirim, à la tête de cinquante soldats, fit une battue dans la forêt : il trouva une route large et commode pour les cavaliers qui le conduisirent à des huttes, puis plus avant dans l'intérieur; mais il ne rencontra pas un seul Indien, et fut forcé par le manque de vivres de revenir bientôt sur ses pas.

(1) Povoaçao est le nom que l'on donne aux villages qui n'ont pas d'église. 
Les soldats prirent cougé de uous aux maisons habitées qui sont situées au-delà de la lagune de Ciri. Bientôt nous nous sommes éloignés de la mer, et nous sommes entrés dans une belle forêt, où nous avons rencontré quelques plantations; elles sont exposées aux attaques des Pourys, mais les propriétaires sont bien munis d'armes. La forêt devenait à chaque instant plus belle, plus haute, plus sauvage; les tiges élancées des arbres y forment par l'entrelassement de leurs branches une ombre épaisse, de sorte que la route, garnie de feuillage de tous les côtés, ressemble à une allée couverte, étroite et sombre. Des faucons, notamment le faucon plombé, étaient perchés sur les branches sèches les plus hautes des vieux arbres pour guetter leur proie; cet oiseau est très-commun dans ce canton. Le milan blanc à queue fourchue (falco

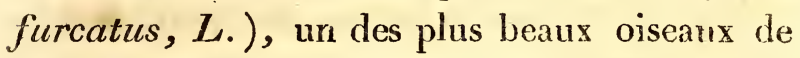
proie, volait fréquemment an-dessus de la forêt. Notre chasse y eût été fort agréable si nous n'eussions pas été tourmentés par des essaims innombrables de moustiques. Nos mains et notre visage en étaient couverts dans un clin d'ceil; et les mulets ainsi que les chevaux souffraient beaucoup de la, piquâre des mu- 
tuccas ( 1 ). Bientôt nous avons atteint des prairies ouvertes, où les marais et les lagunes fourmillaient de canards, de mouettes et de hérons.

Vers midi nous sommes arrivés à la rivière d'Itapemirim, sur la rive méridionale de laquelle est située Villa de Itapèmirim, éloignée de sept legoas de Muribecca (2): elle est petite et nouvellement bâtie; l'on y voit quelques maisons assez grandes, mais elle ne mérite encore que le nom de village; elle a pour habitans de pauvres planteurs qui ont leurs propriétés dans le voisinage, des pêcheurs et quelques ouvriers. Le capitam commandant, ou capitam mor $d u$ comarca d'Itapemirim, réside ordinairement sur sa fazenda; un sargentor mor de la milice demeure.à la Villa. Le fleuve, quoique peu large, peut recevoir de petits brigs, qui viennent charger du sucre, du coton, du riz, un peu de maïs et de bois.

Une pluie d'orage, tombée dans les monta-

(1) Southey écrit à tort Mutuça. History of Brazil, tom.I, p. 618.

(2) Lery parle déjà de ce lieu isous le nom de Tapemiry, pag. 49. 
gnes, m'offrit un exemple de la rapidité avec laquelle les rivières de la zone torride s'enflent et deviennent souvent dangereuses; l'Itapemirim fut soudainement sur le point de déborder; du reste, il est toujours plus considérable que l'Itabapuana. Il sort. de la Serra de Itapemirim, montagnes qui montrent dans le lointain leurs cimes coniques dentelées; les lavages d'or, connus sous le nom de minas de castello, et situés dans leur voisinage à cinq journées de route en remontant le fleuve, les ont rendues fameuses. On fut obligé, il y a une trentaine d'années, d'abandonner ce canton, qui était sans cesse infesté par les Tapouyas, et le petit nombre de colons portugais qui s'y trouvaient vint s'établir à la Villa et dans les environs.

Des hordes de Tapouyas encore sauvages, des Pourys, et notamment, suivant le témoignage des Mineïros, un autre tribu aussi farouche, les Maracas, habitent sur les bords de l'Itapemirim supérieur. On attribue aussi à ces dernicrs les meurtres commis à Ciri. Mais les Boutocoudys, véritables tyrans de ces déserts, errent encore le long de la partie inférieure du fleuve. On raconte que dans 'une fazenda, située sur le $\mathrm{Mu}$ riàhé, les Portugais, après avoir eniendu un 
grand bruit et des cris affreux dans la forêt voisine, virent des Pourys blessés qui venaient chercher un asile chez eux, en disant que les Boutocoudys les avaient attaqués, et avaient tué plusieurs des leurs. Il résulte de tous ces faits que ces forêts sont remplies de sauvages indépendans et ennemis les uns des autres; l'on disait généralement que les Tapouyas ont, dans une période de quinze ans, massacré quarante-trois colons portugais le long de l'Itapemirim. On a pourtant ouvert, à travers ces déserts périlleux, une route, par laquelle on va de Minas de Castello aux frontières de Minas Geraës, qui en sont éloignées de vingt-deux legoas.

Le capitam mor du comarca nous avait, sur la présentation de notre passeport, accueilli très-obligeamment; il envoya du bois, de l'eau et toutes sortes de provisions à notre logement: en conséquence nous sommes allés à la fazenda lui faire nos remercîmens; elle est situce sur le bord du fleuve, et entourée de belles prairies, où paissent une quantité de bestiaux et de chevaux.

Après quelques jours de repos nous avons quitté Villa de Itapemirim, et à une certaine 
distance nous avons traversé le fleuve près de son embouchure. Le jatropha urens était trèscommun dans les marais que nous avons traversés; les piqûres de cette plante furent bien plus douloureuses pour les pieds nus de nos chasseurs que celles de l'ortie, car ces petits aiguillons percent même les vêtemens. Le tijé à plumage rouge foncé (tanagra brasilia, $L$.) est très-commun dans les lieux bas et marécageux, el sur les bords des fleuves de cette côte, mais plus rare au contraire dans les montagnes et les grandes forêts de l'intérieur. De grandes troupes de mouettes et d'hirondelles de mer remplissaient l'air à l'embouchure de l'Itapemirim; les pluviers et les vanneaux fourmillaient le long de la côte, où l'on trouve aussi fréquemment dans le sable le petit engoulevent (1); dans les forêts voisines on en voit une plus grande espèce. Selon Marcgraf les Brésiliens des environs de Pernambouc nomment cet oiseau ibiyaou; mais le long de la côte que j’ai parcourue il porte le nom de bacouraou.

La grande chaleur nous faisait beaucoup

(1) Caprimulgus. 
souffrir de la soif. Notre jeune Poury nous enseigna un moyen infaillible de l'apaiser; c'est de détacher les feuilles roides qui se trouvent dans la partie moyenne des tiges de bromelia, et dans l'angle desquelles se rassemble une très-bonne eau, produite par les pluies et les rosées; l'on avale ce nectar en approchant promptement la plante de la bouche.

Les pointes saillantes de la côte maritime offraient des collines pierreuses sur lesquelles croissaient entre autres des cocotiers, dont le beau feuillage, agité par le vent de la mer, se balançait dans les airs. Le rivage était couvert d'huîtriers, de pluviers et de vanneaux. Nous sommes ensuite entrés dans une forêt qui retentissait de la voix d'une foule d'oiseaux, ̀̀ laquelle, aux approches de la nuit, se mêla celle du curujè, espèce de chouette; on distinguait , au milieu des sons divers qui se faisaient entendre dans cette solitude, les cris perçans du perroquet, et les accens plus doux du tinamou, répétés au loin.

Nous avons passé la nuit à la fazenda de Aga, où l'on cultive du manioc ainsi qu'un peu de coton et de café. De grandes forêts, animées par toutes sortes d'animaux sauvages, abou- 
tissent du côté de terre tout près des plantations. La nuit précédente un gros jaguar avait tué une jument du propriétaire : celui-ci envoya ses chasseurs avec leurs chiens à la poursuite du ravisseur; ils parcoururent vainement es forêts voisines.

Le Morro de Aga, haute montagne isolée et arrondie, s'élève du milieu des forêts près de la fazenda; elle est rocailleuse, et offre des parois à pic et nues; elle est entourée de hautes collines; on dit qu'on y jouit d'une vue magnifique. Il y a près de la maison de la fazenda un petit marais, où, à l'entrée de la nuit, la voix remarquable d'une grenouille, que je ne connaissais pas encore, me causa une surprise extrême : elle ressemblait absolument au bruit que produit un ferblantier ou un chaudronnier en travaillant avec son marteau, excepté que le son était plus plein. J'ai plus tard vu cette grenouille que les Portugais, à cause de sa voix, nomment le ferreiro (forgeron).

Un autre objet du domaine de l'histoire naturelle qui attira aussi notre attention, fut un buisson épais composé d'une nouvelle espèce d'heliconia, dont les hampes à fleurs, parvenues 
a une certaine élévation : se courbent constamment en arc, et ensuite relévent leurs extrémités; de nombreuses fleurs, cnuvertes de spathes écarlates, ornent la portion courbe de la hampe. Ce beau végétal forme une allée couverte. Nous avons vu sur la plage quelques espèces de coquillages bivalves et univalves.

A peu de distance de Aga nous sommes arrivés au povoaçao Piuma ou Ipiuma, où un ruisseau de même nom, qui n'est navigable que pour des pirogues, se jette dans la mer. On voit dans cet endroit un pont de bois long de trois cents pas, et calculé pour les crues du fleuve; c'est une véritable curiosité dans ces contrées. Les bords de l'Ipiuma sont couverts de bois épais; ses eaux, de même que la plupart de celles des ruisseaux des forêts et des petites rivières de ce pays, ont une teinte couleur de café. M. de Humboldt a fait la même observation sur les eaux de l'Atabapo, du Temi, du Tuamini, du Guainia ou Rio-Negro, et d'autres rivières. Il pense qu'elles doivent cette couleur singulière à une dissolution de carbure d'hydrogène, à l'abondance de la végétation 
et à la multitude de plantes dont est couvert le sol qu'elles traversent (1).

Quand nous avons passé le pont la curiosité de voir des étrangers a rassemblé autour de nous une foule d'Indiens. Un matelot espagnol, établi en ce lieu, nous a reçus chez lui, a baragouiné toutes sortes de langues, nous a parlé de tous les pays qu'il avait vus, et nous a fait entendre assez clairement qu'il nous prenait pour des Anglais.

- Dans les vallées, et même sur les hauteurs arides, on rencontre fréquemment des buissons épais d'un gros roseau, haut de seize à dix-huit pieds, qui, sur une tige un peu comprimée, porte de longues feuilles lancéolées, entières, disposées en éventail; elles sortent presque toutes d'un point commun; de leur centre part une longue hampe lisse, à laquelle les fleurs sont suspendues comme un petit drapeau. Ce beau roseau se nomme ici $u b a$, et plus au nord, à Rio-Grande de Belmonte, canna brava; les sauvages l'emploient à faire leurs flèches. Il

(1) Ansichten der Natur, p. 198.

Tableaux de la Nature, tom. II, p. 192. 
forme des halliers impénétrables, et couvre quelquefois des cantons entiers.

Nous avons trouvé dans une petite vallée une forêt remplie de beaux arbres, tels que des coulequins, des cocos, des melastomes; elle est arrosée par l'Iriri, petit ruisseau à eau noire que l'on traverse sur un pont pittoresque fait de troncs d'arbres. Nos chasseurs ont tué dans cet endroit beaucoup de toucans et de maïtaccas, (psittacus menstruus, L.) Mais les singes couraient avec tant de vitesse d'une branche à l'autre que l'on ne put en atteindre un seul. Nous avons aperçu dans le creux d'un d'un vieil arbre une araignée colossale ( aranha caranguejeira), que nous avons voulu emporter, mais un obstacle nous en empêcha.

Après avoir voyagé à travers un pays montueux, couvert alternativement de forêts et de pâturages, nous sommes arrivés le soir à la dernière éminence, située le long du Rio Benevente, d'où nous avons contemplé une vue magnifique; au pied d'une colline sur la rive septentrionale du fleuve on découvre le hourg de Villa Nova de Benevente, à droite la mer, à gauche le fleuve; qui s'élargit comme 
un lac, et tout autour de soi des forêts sombres; au-delà de hautes montagnes terminent l'horizon.

Villa-Nova de Benevente a été bâtie sur l'Iritiba ou mieux Reritigba (1) par les jésuites qui avaient rassemblé en ce lieu un grand nombre d'Indiens convertis. Leur église et le couvent adjacent existent encore; on en a fait la Casa da Camara, et nous y avons logé : elle est siluée sur une hauteur au-dessus du bourgr; et on $\mathrm{y}$ jouit d'une très-belle vue, notamment de dessus le balcon de la façade du nord. Le disque du soleil touchait à la surface de la mer, et la changeait en une plaine de feu; la cloche du. couvent sonnait l'Ave-Maria; chacun sortait de sa cabane pour aller à la prière du soir; un silence profond régnait dans la campagne, et n'était interrompu que par la voix des tinamous et d'autres animaux sauvages qui se faisaient entendre au-delà du fleuve.

Plusieurs petits brigs étaient à l'ancre dans le port de Villa-Nova. Nous en conclûmes que

(1) Cefleuve porte sur la carte de Faden le nom d'Iritibu, et sur celle d'Arrowsmith, celui d'Iritiba; mais la Villa n'est marquée sur aucune des deux cartes.

I. 
ce bourg fait un assez grand commerce; bientôt nous fûmes mieux informés. Le trafic de ce lieu est très-peu important; ces navires y étaient simplement venus chercher un refuge contre le mauvais temps. Jadis les jésuites y avaient rassemblé 6000 Indiens, et fondél'Aldéa la plus considérable de cette côte; mais la gêne du service royal, et les mauvais traitemens chassèrent la plus grande partie de ces nouveaux colons, qui se répandirent dans d'autres cantons, de sorte qu'aujourd'hui le territoire de Villa-Nova, en y comprenant les Portugais, ne compte pas plus de 800 habitans, dont 600 sont Indiens. Quoique leur nombre soit diminué, le commerce a ensuite pris de l'accroissement; il y a une vingłaine d'années, l'exportation ne se montait qu'à 100,000 reis ( 680 fr. 10 c. ); aujourd'hui elle s'élève à 2000 cruzades ( $6000 \mathrm{fr}$.$) , et pourtant la valeur du sucre$ n'est pas comprise dans cette somme. Autrefois les Indiens indépendans, surtout les Goaytacasès et les tribus des Tapouyas, dans lesquelles orr comprend principalement les Pourys et les Maracas, inquiétaient beaucoup cette colonie de l'Tritiba; mais aujourd'hui, d'après le témoignage du curé, ces hordes sauvages ne se 
montrent plus depuis que l'on célèbre annuellement dans tout le district une grande fête du Saint-Esprit, accompagnée de processions et d'actes de dévotion.

On voit à Villa-Nova quelques maisons bien bâties; ce bourg me parut encore plus vivant le dimanche, parce que tous les habitans du voisinage y vinrent à la messe. La milice de ce canton fait partie du régiment d'Espirito-Santo, dont le colonel, M. Falcìo, réside au chef-lieu de la capitainerie. 11 vint nous voir, et, sur notre demande, nous envoya deux bons chasseûrs qui connaissaient bien le terrain; nous eûmes l'occasion de leur joindre un Indien très-bon tireur, renfort qui nous fut très-avantageux, car nous obtînmes plusieurs animaux intéressans, entre autres des singes-saüassus qui faisaient fréquemment entendre leurs voix le long du fleuve. Deux de nos chasseurs tronvèrent dans la forêt un grand serpent venimeux; il était tranquillement couché dans un creux, ce qui rendail son approche dangereuse. En conséquence, un des chasseurs grimpa sur un petit arbre, d'où il tua le reptile. On lui donne dans le pays le nom de Curucucù, il a huit à neuf pieds de long sur une grosseur considérable; sa 
couleur est jaune rougeâtre sale, avec des taches en lozange brunes foncées sur le dos. La forme des plaques ventrales et caudales prouve que c'est la grande vipère des forêts de Cayenne et de Surinam (1), décrite assez inexactement par Daudin sous le nom de Lachesis. On redoute beaucoup sa morsure, qui, dit-on, tue en moins de six heures.

Après l'Iritiba on rencontre le Goaraparim. L'intervalle qui sépare ces deux fleuves est rempli par des marais et des prairies marécageuses qui s'étendent à peu de distance de la mer; de temps en temps on voit des bois, enfin de belles forêts réjouissent quelquefois les regards du voyageur. Nous entendions constamment la mer briser contre les hautes collines qui forment le rivage, et qui sont couvertes de forêts. Le sentier ressemblait à une allée couverte, qui se

(1) Marcgraf a fait mention de ce serpent sous le nom de Curucucù; mais M. Merrem, un des naturalistes de nos jours qui s'est occupé avec plus de succès de l'étude des reptiltes, a décrit et figuré dans le premier volume des Annales de la Société d'Histoire Naturelle de Wetteravie (Aunalen der Wetterauischen Gesellschaft für Naturgeschichte), wn peau entière de cet animal. 
prolongeait entre des arbres gigantesques dont l'écorce offrait une multitude de petits végétaux, et dont les branches étaient couvertes de plantes grasses : de jeunes cocoliers ornaient les halliers que des plantes grimpantes rendaient impénétrables, et dont le feuillage nouveau brillait des plus belles teintes rouges ou jaune verdâtre; la cime des vieux cocotiers se balançait en l'air, et leur tronc se courbait de côté et d'autre en gémissant. Nous vîmes dans un endroit un petit bois composé uniquement de palmiers aïri, qui avaient vingt à trente pieds de haut; leur tige droite et noirâtre, entourée de cercles épineux , était surmontée de leurs belles feuilles pinnées qui préservaient le sol bumide des ardeurs du soleil; d'autres plus jeunes, non encore pourvus de tiges, formaient le sous-bois, au-dessus duquel les vieux palmiers morts, desséchés et pourris, s'élevaient comme des colonnes brisées : ces troncs voués à la destruction étaient en butte aux coups de bec du pic à tête jaune (picus flavescens, L.), ou de la belle espèce à huppe et cou rouge (picus robustus, L. )(1).

(1) Ce pic a été ainsi nommé par les naturalistes de 
Les fleurs de l'heliconia couleur de feu, couvraient les buissons les plus bas, qu'entourait un beau liseron à superbes fleurs azurées. Les plantes grimpantes ligneuses se montraient dans cette forêt majestueuse avec leurs formes et leurs circonvolutions singulières. Nous contemplions avec étonnement le caractère de grandeur de cetse solitude qui n'était animée que par des toucans, des pavos ou pies à gorge ensanglantée, des perroquets et d'autres oiseaux. Nos chasseurs se mirent à tirer de tous les côtés, et eurent bientôt rempli leurs gibecières.

En sortant de la forêt, nous sommes arrivés au Povoaçào de Obie, composé de quelques cabanes de pêcheurs, à deux legoas de VillaNova. Ces hameaux, entourés de forêts ou de bois épais, sont souvent plus pittoresques que ceux qui se trouvent dans des cantons ouverts. Le soir nous avons pris notre gîte à Miaïpè-Povoaçào, habité par une soixantaine et plus de familles de pêcheurs. Nons nous étions logés dans mue maison bâtie sur un tertre; il y vint aussitôt

Berlin; Azara l'a décrit dans le quatrième volume de ses voyages, pag. 6, soirs le nom de Charpentier à huppe et cou rouge. 
plusicurs personnes qui admirérent surtout notre jeune Poury, et observèrent tous ses mouvemens. Du reste nous fümes bien reçus dans cette maison assez grande: notre chambre était vaste; on alluma à terre un bon feu qui spervit à sécher nos vêtemeus traversés par la pluie. A peu de distance de Miaïpè, on trouve Villa de Goaraparim, où mène un chemin qui traverse des masses de rochers formant une saillie en mer. Près de la Villa, le Goaraparim, bras de mer étroit, pénètre dans les terres; on lui donne généralement le nom de rivière; son eau est salée.

Villa de Goaraparim a environ 1,60o habitans; on en compte 3,000 dans son territoire. Elle est un peu plus grande que Villa-Nová de Benevente; ses rues ne sont point pavées; il $y$ a seulement le long des maisons des trottoirs en pierres, mais ils sont en mauyais ćtal. Ha plupart des maisons n'ont qu'un élage. Ce bourg est pauvre; cependant le roisinage renferme des fazendas considérables; on remarque en tre autres la fazenda de Campos avec quatre cents nègres, et 'Engenho Velho qui en a deux cents. A la mort du dernie: propriétaire de la première, le désordre devint géuéral; les es 
claves se révoltèrent et ne voulurent plus travailler : un ecclésiastique instruisit de ces événemens les héritiers qui se trouvaient en Portugal, et leur offrit de remettre les choses en ordre si on consentait à lui accorder une partie de la proprićté. Sa proposition fut acceptée; mais les instigateurs des esclaves l'assássinèrent dans son lit, s'armèrent, el formèrent dans les forêts une république de nègres qu'il n'était pas facile de détruire. Ils gardèrent les fazendas pour eux, sans pourtant beancoup travailler, vécurent libres, el se mirent à chasser dans les forêts. Les esclaves de l'Engenho suivirent l'exemple des autres; une compagnie de soldats les attaqua inutilement. Les nègres s'occupèrent surtout de recueillir quelques-unes des principales productions de ces forêts, telles que le baume de Copahu et quelques autres. On tire ce baume d'un arbre nommé Pao de Olea : on y pratique des entailles, et quand la substance résineuse commence à couler, l'on remplit ces ouvertures de coton qui s'imbibe de suc; l'on croit ici qu'il faut percer l'arbre à la pleine lune, et recueillir l'huile au décours de cet astre. Les nègres ou les Indiens apportent cette huile aux Portugais dans de petits cocos sauvages, qu'ils bouchent 
avec un peu de cire. Cette substance a tant de ténuité, que dans les grandes chaleurs elle pénètre à travers l'enveloppe solide de la noix. Même dars ce pays on lui attribue plus de vertus qu'elle n'en possède réellement (1).

Les nègres marrons des deux fazendas, dont je viens de parler, reçoivent bien les étrangers, et par leur conduite se distinguent entièrement des nègres échappés de Minas Geraës et d'autres endroits, auxquels on donne le nom de Quilombos (Gayambolos), d'après les villages qu'ils ont établis dans les bois. Ceux-ci, surtout dans le Minas, attaquent les voyageurs, les pillent et souvent les tuent. C'est pourquoi il y a dans cette province des chasseurs de nègres Gayambolos que l'on nomme Capitciës do IMato (2), qui s'occupent uniquement de prendre ou de tuer les nègres dans leurs repaires.

Le capitaine commandant de Goaraparim nous avait reçus très-poliment, et nous avait procuré une maison pour y passer la nuit. Le

(1) Murray, apparatus medicaminum, tom. IV , p. 32 .

(2) A Pernambouc ils portent le nom de Capitaës do campo.

Koster, p. 399, tom. II, p. 526. 
lendemain nous nous sommes embarqués sur le fleuve; il coule entre de jolis bocages de mangliers (conocarpus), et plus haut entre des montagnes verdoyantes. Un village de pêcheurs est bâti à sa rive septentrionale, où nous avons débarqué. Nous avons traversé ensuite de grands marais'parsemés de buissons de Rhexia à belles fleurs violettes, des collines ornées d'äri et de cocotiers, dont les espèces diverses donnaient beaucoup d'occupations à notre curiosité; enfin dans le voisinage du Perro Cao, de vastes espaces couverts de haies d'Uba ou roseau en éventail; puis nous avons passé la petite rivière sur un pont de bois, et nous avons suivi le rivage jusqu'à la Ponța da Fruta, où des maisons éparses dans un bois forment un Povoaçào. Les habitans, issus d'un mélange de nègres et de Portugais, nous reçurent trèsbien. Ils vivent pauvrement de leur pêche et de la culture de la terre. A quelque distance on aperçoit déjà sur une montagne le couvent de Nossa Senhoro da Penba, qui est près de Villa do Espirito-Santo, éloignée de cinq legoas. Des forêts, des prairies, des bois couvrent le terrain alternativement avec de grands marais remplis de roseaux, et où des hérons blancs et d'autres 
de diverses couleurs se promenaient dans l'eau; on $\mathrm{y}$ voit aussi un grand nombre de belles plantes, nouvelles pour un étranger. Je trouvai dans l'herbe sur la rive sablonneuse d'une lagune, le serpent cibo vert (1); sa forme svelte et sa souplesse lui ont valu son nom; il est de couleur olive foncée, jaune par dessous, et a cinq à six pieds de longueur; quoiqu'il ne fasse pas de mal, les Brésiliens le tuent quand ils le trouvent, par haine pour tous les serpens. Ceux-ci étaient extrêmement nombreux dans cet endroit. J'en trouvai le squelette d'un trèsgrand.

Au-delà d'un petit village de pêcheurs, situé sur le bord de la mer, nous avons passé le Juçu avec précaution sur un pont très-long et en mauvais état; ensuite nous avons traversé une grancle forêt, et nous sommes arrivés à Villa do Espirito-Santo, bâtie sur le fleuve de même nom.

(1) Ce nom signifie serpent liane; c'est le coluber bicarinatus, espèce probablement nouvelle. Son caractère distinctif est d'avoir de chaque côté du dos une rangée d'écailles. carinés; plaques ventrales, 155 ; caudales, 157. 


\section{CHAPITRE VII.}

SÉJOUR A ESPIRITU-SANTOET VOYAGE AU RIO-DOCE.

Villa Velha do Espirito-Santo. - Cidade de Victoria. - Barra de Juçù. - Araçatiba. — Coroaba. - Villa nova de Almeïda. - Quartel do Riacho. - Rio-Doçe. - Linharés. - Les Boutocoudys, ennemis invetérés des Portugais.

LE fleuve d'Espirito-Santo, qui a son embouchure dans la mer, est considérable; il prend sa source dans les montagnes sur les frontières de la capitainerie de Minas-Geraës, serpente dans les grandes forêts des Tapouyas, où les Pourys et les Boutocoudys vivent errans, puis passe au pied d'une chaîne de montagnes, qui se détachent de monts plus hauts pour se diriger vers la mer, et dans laquelle le Monte de Mestre Alvaro est la plus élevée.

Les établissemens des Portugais à l'embouchure de ce beau fleuve sont très-anciens; ils ont ensuite beaucoup souffert par les guerres avec les Tapouyas, surtout avec les trois tribus des 
Ouetacas ou Goaytacasès, qui demeurent sur le Paraïba (1). Dans la dernière moitié du dixseptième siècle, le territoire d'Espirito-Santo ne contenait pas plus de 500 Portugais et quatre villages indiens (2). Aujourd'hui on voit dans un enfoncement à la rive méridionale du fleuve, à peu de distance de son embouchure, Villa Velha do Espirito-Santo, petite ville laide et ouverte qui forme à peu près un carré; l'église est à une extrémité; à l'autre, près du fleuve, la Casa da Camara. Le fameux couvent de Nossa Senhora de Penha un des plus riches du Brésil, et qui dépend de l'abbaye de SanBento de Rio-de-Janeiro, est sur une haute montagne boisée et contiguë à la ville. On dit qu'il possède une image miraculeuse de la Sainte-Vierge, et c'est en conséquence un pélerinage très-fréquenté; il ne s'y trouvait en ce moment que deux moines. Nous n'avons pas

(1) Y por este tempo anno 1594 pomo mais ou menos, moreram guerra os moradores desta capitania do EspiritoSanto contra huma nacao de gentios perniciosa, barbaro, cruel, e terribel per nomen goyataca cujas noticias queror da aqui brevemente, etc.

Vie du père J. D. Anchieta.

(2) Southey, History of Brazil, tom. I, p. 667. 
regretté la peine que nous avons prise de gravir la montagne, tant la vue dont on y jouit est magnifique. Elle défie toutes les descriptions. On découvre à la fois la mer, des chaînes de montagnes, des cimes élevées et séparées par des vallées d'où le fleuve s'échappe. La Villa consiste en maisons de terre basses; elle n'est pas pavée et n'offre que des signes de décadence depuis que l'on a bâti, une demi-liene plus haut sur la rive septentrionale du fleuve, Villa de Victoria, jolie petite ville, qui, depuis mon départ, a été élevée au rang de cité (cidade). Espirito - Santo qui n'était d'abord qu'un gouvernement inférieur, est devenu depuis une capitainerie.

Cidade de Nossa Senhora da Victoria a d'as sez grandes maisons avec des balcons garnis, suivant l'ancienne mode portugaise, de grillages en bois; ses rues sont pavées. L'ancien convent des jésuites est un bâliment assez considérable; il sert de casa da camara et de demeure an gouverneur, qui a ici sous ses ordres une compagnie de milice régulière. Indépendamment de plusieurs couvens, cette ville renferme une église, quatre chapelles et un hôpital; elle est cependant peu vivante, et les 
étrangers y attirent la curiosité générale. Le commerce de cabotage est assez important : des lanchas, des sumacas, et d'autres petits navires sont constamment mouillés dans le port; les frégates peuvent remonter jusqu’à la ville. Les fazendas du voisinage produisent beaucoup de sucre, de farinha, de riz, de bananes, et d'autres denrées qui s'exportent. Plusieurs forts défendent l'entrée du Rio do Espirito-Santo. Il y en a un à son embouchure même : plus hant une batterie en pierre, montée de huit canons de fer, et plus haut encore entre celle-ci et la ville, une troisième de dix-huit canons, dont quelques-uns sont en bronze. La ville est située sur des collines, ce qui en rend le sol inégal; le fleuve au-dessous est entouré de tous les côtés de hautes montagnes; elles consistent en partie en rochers, souvent nus et escarpés, el quelquefois tapissés de plantes grasses. Le lit du fleuve est coupé de plusieurs îles verdoyantes, et, lorsque l'on suit de l'oeil son cours vers l'intérieur, la vue se repose sur de hautes montagnes boisées.

Nous nous sommes logés à Villa-Velha do. Espirito-Santo, parce qu'il y avait auprès de bons pâturages pour nos mulets et nos chevaux. Une 
grande pirogue nous a transportés à Cidade de Victoria, trajet que la violence du vent de mer et la largeur du fleuve ont rendu assez dangereux. Le gouverneur, à qui nous avons rendu visite, nous a en apparence reçu très-poliment. Lui ayant demandé un logement à la campagne dans le voisinage de la ville, il nous en indiqua un à Barra de Jucu, à l'embouchure de la petite rivière de même nom, à quatre lieues de Cidade de Victoria. C'était une maison commode et bien bâtie, appartenant au colonel Falç̀o, commandant du régiment de milice, et un des plus riches planteurs de ce canton. Je retrouvai ici les premières nouvelles d'Europe, car la poste de Rio-de-Janeiro ne va pas plus loin. Tandis que nous parcourions les lettres de notre pays, que nous attendions depuis si longtemps, des gens de toutes les couleurs, rassemblés autour de nous, faisaient les observations les plus singulières sur notre patrie, et sur le motif de notre apparition en ce lieu; tout le monde, ici comme dans les autres endroits où nous avions passé, nous prenait pour des Anglais.

De retour à Villa-Velha, nous avons trouvé quelques-uns de nos gens malades de la fièvre; 
et cette maladie se répandit avec une telle räpidité, qu'en peu de jours la plupart furent sur le grabat. On en attribuait la cause à l'eau, mais elle était due certainement au climat et à la nourriture. Grâces au quinquina, nous avons rétabli promptement la santé de tous nos malades, puis nous nous sommes hâtés de gagner aussitôt qu'il nous a été possible notre demeure de Barra de Jucu, où l'air pur et frais de la mer acheva la guérison de nos convalescens. Nous fîmes nos dispositions pour rester plusieurs mois en ce lieu, parce que nous voulions y passer toute la saison des pluies. Cependant nos chasseurs parcouraient les forêts.

Barra de Jucu est un petit village de pêcheurs à l'embouchure du Jucu dans la mer; ce petit fleuve, après avoir arrosé les grandes fazendas de Coroaba et d'Araçatiba, poursuit son cours sinueux à travers les forêts; il est très-poissonneux : ses bords offrent un grand nombre de points de vue pittoresques. Les maisons des pêcheurs de Barra de Jucu sont en partie éparses; au centre, près d'un pont jeté sur le fleuve, se trouve la maison du colonel Falcào, qui possède aussi plusieurs fazendas dans les environs : la plus considérable est celle d'Araçatiba, ì

I. 
quatre legoas de distance. Il avait coutume de venir tous les étés à Barra de Jucu pour prendre les bains de mer; aussi fut-il très-mécontent de ce que le gouverneur nous avait assigné un logement dans sa maison; circonstance dont nous ne fûmes instruits que plus tard. Tontefois il vint à Barra de Jucu, et se fit arranger une autre maison dans le voisinage, en attendarit que nous eussions quitté la sienne.

Les excursions de chasse les plus intéressantes que nous entreprîmes pour connaître le pays, nous meuérent d'abord au-delà du pont du Jucu, dans la belle forêt qui se prolonge jusqu'à Villa Velha de Espirito-Santo. Nous y avons trouvé une jolie espèce de sahui(sagouin), nouvelle pour nous ( iacchus lecuocephalus, Geoffroy ). Il va en petites troupes, et est trèsfriand des noix des cocotiers sauvages; nous avons aussi rencontré le couy d'Azara, ou porcépic à queue prenante, et plusieurs autres quadrupèdes. Les oiseaux les plus communs dans celte forêt étaient le beau grimpereau bleu (nectarinia cyanea)(1); diverses espèces de manakins (pipra, pareola: P. erythrocephala, et

(1) Certhia cyanea, $L$. 
P. leucocilla), une petite espèce qui n'a pas encore été décrite, que je nommerai strigilata (1); une nouvelle espèce de tangara (tanagra elegans)(2), et un très-beau cotinga (procnias cyanotropus) (3), dont le plumage chatoie à la lumière. On pouvait toujours espérer de rencontrer les jolis manakins à couleurs si belles, sur un arbre dont ils aiment beaucoup les baies.

Cette forêt renfermait aussi des cerfs. Le colonel Falcào fit venir ses chiens d'Araçatiba pour que nous prissions le plaisir de la grande chasse. Voulant rencontrer des animaux de grande taille et rares qui fuient le voisinage de l'homme, nous nous sommes enfoncés jusqu'à

(I) Il est plus petit que le Pipra erythrocephala: le sommet de la tête est d'un rouge éclatant; le dessus du corps vert olive; le dessous blanchâtre, rayé de brun rougeâtre.

(2) Tête d'un jaune doré ; dos noir rayé de jaune; dessous du cou et poitrine bleu de ciel verdâtre éclatant ; ventre et côtés verdâtres.

(5) Si l'on regarde cet oiseau contre la lumière, il est d'un bleu de ciel magnifique; vu dans un sens contraire, il paraît d'un vert clair éclatant. Les ailes, la gorge et le menton sont noirs; le dessous du corps blanc. On l'a nommé Procnias ventralis au musée de Berlin. 
trois lienes dans la vaste forêt qui s'étend jusqu'auprès de la fazenda d'Araçatiba. La route que nous avons suivie était extrêmement agréable. Nous avons d'abord traversé de grandes plaines sablonneuses et marécageuses, remplies d'une multitude de plantes; ensuite nous avons franchi des collines, où de jeunes cocotiers et d'autres beaux arbres très-serrés les uns contre les autres répandaient une ombre impénétrable; une espèce de roseau couvre tous les lieux ouverts dans lesquels le tarin bleu d'acie: (fringilla nitens, L.) est très-commun. Je rencontrai au milieu d'un sentier étroit de la forêt un gros serpent tranquillement roulé sur luimême; il ne voulut pas nous céder la place; mon cheval eut peur; je tuai le serpent d'un coup de pistolet. Nous reconnûmes en l'examinant que c'élait une espèce non malfaisante, et nous apprîmes que dans le pays on le nommait caninana; il est du genre coluber (1). Ce ne fut quaprès de longs pourparlers que je pus engager un nègre du colonel Falcào

(1) C'est très - probablement la couleuvre changeante (Veránderliche Natter de M. Merrem). Beyträgè zur naturgeschishte der amphibien. Z Zweites Heft. tom. XII, p. 51. 


\section{AU BRÉSIL.}

qui m'aecompagnait à prendre le serpent sur son cheval.

La forêt d'Araçatiba offrait une solitude imposante; de toutes parts des perroquets s'envolaient en poussant de grands cris, et la voix du singe saùassù retentissait de tous côtés. Des lianes ou cipos entortillées autour des arbres formaient des halliers impénétrables; les superbes fleurs des plantes grasses, les festons pendans des fougères qui enveloppaient les arbres, étaient dans leur développement le plus complet. De jeunes cocotiers paraient les parties les moins hautes de cette masse de végétaux, surtout dans les lieux humides. Le coulequin ombiliquè (cecropia peltata) (1), avec ses tiges d'un gris argenté, annelées, formait des buissons particuliers.

Tout à coup nous sommes soris de l'obscurité mystérieuse qui nous entourait; un conp d'œeil magnifique nous a fait éprouver la surprise la plus agréable au moment où notre vue n'était plus bornée. Au pied du Morro de Araçatiba, montagne boisée, nous avons aperȩu dans une

(1) C'est le bois trompette des colonies françaises. 
belle prairie verdoyante le grand bâtiment blanc de la fazenda de Araçatiba, surmonté de deux petites tours. Cette propriété a quatre cents nègres; les plantations, șurtout celles des cannes à sucre, sont très-étendues. Les fils du colonel habitent des fazendas particulières, à peu de distance de celle-ci, qui était la plus considérable que j'eusse vue dans mon voyage. Le bâtiment principal a une large façade, deux étages et une église. Les cases à nègres, les moulins à sucre et les bâtimens d'exploitation sont au pied d'une colline à peu de distance de la maison.

A peu près à une lieue, dans ce canton sauvage, environné de toutes parts de hautes forêts, et sur les bords du Jucu, se trouve la fazenda de Coroaba qui appartient à un autre propriétaire. Le gouverneur avait commencé à faire bâtir une église à San-Agostinho, à peu de distance de Coroaba; c'est pourquoi il demeurait dans cet endroit où l'on a établi un poste militaire contre les sauvages; on travaillait alors à ouvrir une route pour aller à Minas-Geraës; déjà un officier y avait fait un voyage pour tracer la communication à travers les forêts. Le gouvernement a transplanté à San-Agostinho une 


\section{AU BRESIL.}

quarantaine de familles venues des Açores, surtout de Terceira et de San-Miguel, quelques-unes aussi de Fayal. Ces gens sont dans la misère, et se plaignent hautement de leur triste position; on leur avait fait de belles promesses que l'on n'a pas tenues.

Nous aurions volontiers passé notre temps de repos à Coroaba; mais la difficulté d'y placer notre suite nombreuse nous obligea de rester à Barra de Jucu.

On avait envoyé à Caravellas plusieurs objets que nous attendions à Espirito-Santo, circonstance qui mit notre troupe dans un assez grand embarras. Afin d'y remédier nous résolûmes, M. Freyress et moi, d'aller au plus tôt à Caravellas pour y mettre nos affaires en ordre. Équipés à la légère et suivis de quelques hommes à cheval, bien armés, nous partîmes le 19 décembre de Barra de Jucu. Le reste de notre tropa se rendit à Coroaba pour y travailler. Nous eussions pu voyager beaucoup plus promptement par mer; mais la navigation le long de la côte, dans de petits bâtimens in commodes, est fort désagréable dans la saison. des mauvais temps et des orages. Ainsi nous gagnâmes Pedra d'Agoa, maison isolée sur une. 
hauteur baignée par le fleuve, afin de le passer avec nos quatre chevaux de monture et nos deux mulets de somme. Nous aperçûmes de là sur les montagnes de la rive opposée le rocher remarquable de Jucutucoara, qui est à peu de distance de Villa de Victoria, et qui de loin ressemble à la Dent de Chaman dans le pays de Vaud; il s'élève sur des hanteurs en pente douce, et couvertes en partie de petits bois. En avant, plus près du fleuve, est située la jolie fazenda Rumào, devant laquelle l'ilha das Pombas (l'île aux Pigeons) partage le cours du fleuve, dont la vue, prise du haut de Pedra d'Agoa, est fort belle; des lanchas et des pirogues de pêcheurs à la voile ajoutaient au charme du coup d'œil.

Nous aurions voulu passer tout de suite, par malheur il n'y avait pas une seule pirogue pour nous transporter de l'autre côté; il fallut donc demander un gîte au vieillard qui habite Pedra d'A goa; sa réception amicale nous dédommagea de l'incommodité d'être mal défendus de la pluie et du vent dans sa petite cabane. A l'approche de la nuit tout le bétail errant s'étant rassemblé autour de l'habitation, nous aperçûmes un mouton d'une figure singulière; nous 
apprîmes ensuite qu'il provenait de l'accouplement d'un bélier et d'une chèvre; il ressemblait à sa mère, il était gros, fort et arrondi, son poil était fort doux, ses cornes étaient un peu courbées en dehors (1). Parmi les agneaux que leurs jeunes gardiens renfermèrent, il y en avait beaucoup dans la cavité ombilicale encore mal formée desquels on trouvait une quantité de vers; on frotte cette partie de mercure, pour la gnérir de cette maladie très-ordinaire dans les pays chauds; dès qu'un animal est blessé, des mouches viennent aussitôt déposer leurs oufs dans la plaie. Un autre insecte du Brésil dépose aussi ses oeufs dans la chair ou sous la peau des animaux vivans, même de celle de l'homme; quand on a été piqué de cet insecte on éprouve une petite douleur locale; il survient ensuite un gonflement. Nos gens, qui connaissaient bien ce mal, tiraient de la partie gonflée un petit ver blanc allongé; la plaie se guérissait aussitôt. C'est probablement du même insecte que parle Azara (2); il croit

(1) Buffon, supplément, tom. V, pag. 4 de l'édition in -12 .

(2) Voyages, etc., tom. I, pag. $21 \%$ 
pourtant que' le ver pénètre d'abord dans la peau, ce qui est contraire à notre expérience.

Lè lendemain nos pirogues sont arrivées, et nous avons passé de l'autre côté du fleuve qui a près de mille pas de largeur. Nous avons voyagé dans une vallée qui serpente immédiatement au pied de la hauteur sur laquelle est situé le Jucutucoara. A peu de distance nous avons aperçu une fazenda qui appartient à un M. Pinto; nous avons traversé sur un pont de bois ordinairement fermé par une porte la petite rivière de Muruim ou Passagem, et, à l'extrénité d'un marais couvert de mangliers ( rhizophora, conocarpus, avicennia), nous nous sommes trouvés sur le bord de la mer. En regardant en arrière, on reconnaîl distinctement la chaîne de Espirito-Santo, que l'on aperçoit tant que l'on se trouve immédiatement entre ses parties extrêmes. A trois lieues de Villa de Victoria, nous avons fait halte au peit Povoaçào de Praya-Molle.

Il consiste en plusieurs maisons éparses sur une plaine verdoyante peu élevée au-dessus de la mer. Nous y fümes accueillis amicalement, et les habitans étant bons musiciens, la soirée se passa fort agréablement à faire de la musique 


\section{AU BRÉSIL.}

et à danser. Le fils de la maison où nous étions, qui s'entendait très-bien à fabriquer des guitares (violas), en joua, et la plupart des autres jeunes gens dansèrent la baduca. Ils prirent toutes sortes de postures singulières, battant la mesure avec leurs mains, et faisant alternativement claquer deux doigts de chaque main, en imitation des castagnettes espagnoles. Quoique les Portugais aient beaucoup de dispositions pour la musique, on ne voit pourtant au Brésil, dans la campagne, d'autre instrument que la guitare. Si l'amour de la danse et de la musique est commun parmi les habitans, le goût de l'hospitalité l'est autant au moins parmi le plus grand nombre. Nous l'éprouvâmes encore en ce lieu : on nous offrit à l'envi tout ce qui pouvait nous divertir et nous faire passer le temps plus vite.

Partis de bonne heure de Praya-Molle le lendemain matin pour le Povoaçào de Carapebuçu, nous avons voyagé dans des forêts qui, s'étendant le long de la côte, entourent les baies et couvrent les pointes de terre; on y voyait voltiger une multitude de papillons, surtout de nymphales. Nous avons trouvé le joli nid en forme de bourse, d'une espèce d'oiseau 
du genre du todier. Il le construit toujours dans le voisinage de celui du marimbondo, espèce de guêpe, afin, dit-on, d'être en sûreté contre les poursuites de ses ennemis. Ayant voulu m'approcher de ce nid, les guêpes se montrèrent aussitôt, et m'en tinrent éloigné.

Les bois le long de la côte sont habités par de pauvres familles qui se nourrissent de la pêche et du produit de la culture des terres. Ce sont en général des nègres, des mulâtres, ou d'autres gens de couleur; on voit peu de blancs parmi eux ; ils se plaignent au voyageur de leur pauvreté et de leurs besoins, qui ne peuvent être dus qu'à leur paresse et à leur manque d'industrie, car le sol est fertile; mais trop pauvres pour acheter des esclaves et trop indolens pour mettre la main à l'ouvrage, ils aiment mienx mourir de faim.

En avançant au nord on arrive dans un canton habité non par des créoles et par des mulâtres, mais par des Indiens civilisés. Leurs maisons isolées sont éparses dans des bocages touffus. Des sentiers ombragés conduisent d'une cabane à une autre; on roit jouer les enfans dans de petits ruisseaux limpides, dont la surface reflète les belles plantes de la forêt. Nous y 
avons rencontré de beaux oiseaux : le jacamar vert doré (galbula magna), perché sur les branches basses, guettait sa proie; des voix inconnues retentissaient dans ces solitudes. Nous en sortîmes après y avoir parcouru quatre lieues, et nous aperçûmes devant nous, sur une hauteur baignée par la mer, Villa-Nova de Almeida.

C'est une grande aldéa d'Indiens civilisés, qui a été fondée par les jésuites. Elle a une église en pierre; son territoire, qui a environ neuf légoas de circonférence, renferme à peu près 1200 habitans. La plupart de ceux de la Villa sont Indiens; on y voit aussi quelques Portugais et des nègres. Plusieurs y ont des maisons où ils ne viennent que les dimanches et les jours de fête; le reste du temps ils restent sur leurs plantations. Le couvent des jésuites où demeure aujourd'hui le curé contient d'anciens écrits de la société, ce qui est une rareté, car dans toutes les autres maisons l'on n'a pas pris soin des bibliothèques, qui ont été dispersées et perdues. Jadis les jésuites enseignaient principalement ici la lingoa géral. On dit que leur chapelle dos Reys Magos (des Rois Mages) était fort belle. Villa-Nova de Almeïda est un lieu mort, et paraît peu habité; il y règne beaucoup de 
misère. Les Indiens cultivent un peu de manioc et de maïs, exportent du bois et de la poterie; leur pêche dans la mer et dans le Saüanha ou Rio dos Reyes Magos est assez importante. M. Sellow, qui revint ensuite ici, eut occasion de voir leur singulière manière de pêcher avec les branches du tingi, procédé dont La Condamine fait mention dans sa Relation de la Rivière des Amazones (1). Après avoir coupé des branches de cet arbre, on les bat pour les écraser, on les lie en faisceau et on les jette dans l'eau, surtout aux endroits où elle a peu de pente; quelquefois on barre la rivière pour retenir le poisson, qui, enivré par le suc de la plante répandu dans l'eau, meurt ou se prend aisément à la main. Les plantes qui produisent cet effet sont quelques espèces de paullinia, et

(1) Toyage à la rivière des Amazones, p. 195. - Vasconcellos donne des détails sur ce sujet. Il dit que les Indiens de la côte employaient pour cette pêche les feuilles du japicay, le timbo putyana, ou tingy ou tiniuiry, sorte de liane, le fruit du curaruape, la racine du manglier, etc. (Noticias curiosas, etc., p. 76.) Voyez aussi les notes de IV. Blumenbach sur le voyage de Van Berkel à Rio de Berbice, en 1670 (en allemand), p. 180; et le voyage de Kruseustern autour du monde, tom. I, p. 180. 
le jacquinia obovata, arbuste à baies rouges et à feuilles oviformes renversées, qui croît dans les halliers le long de la côte, et porte en conséquence le nom de tinguy (tingi) da praya.

On parlait encore à Villa-Nova de Almeïda d'un animal de mer, inconnu, tué à coups de fusil sur la côte voisine peu de temps auparavant. Il était fort grand; on nous dit qu'il avait des pieds comme les mains d'un homme; on en avait tiré beaucoup d'huile. Le gouverneur avait envoyé la tête et les mains au chef lieu de la capitainerie. Malgré les recherches les plus assidues, nous ne pûmes nous procurer de renseignemens plus précis sur cet animal, d'autant plus qu'on avait brisé et fait bouillir le squelette, et qu'on en avait enterré une partie. D'après le peu que nous avons appris, il paraît que c'était un phoque ou un lamentin.

Les forêts traversées par le Saùanha, nommé Apyaputang dans l'ancienne langue des Indiens, sont, dit-on, habitées par des Coroados et des Pourys. On parle aussi de la tribu des Xipostos (Chipostos), qui vivent plus haut, entre le Rio-Doçe et le Saùanha; mais tous ces renseignemens sur les noms des diverses peuplades indigènes sont défectueux. Depuis le Saùanha 
jusqu'au Mucuri, la côte maritime est habitée presque uniquement par des familles d'Indiens côtiers. Ils parlent ici généralement le portugais, et ont échangé leurs arcs et leurs flèches contre le fusil. Leurs maisons diffèrent peu de celles des colons portugais; leur principale occupation est la culture des champs et la pêche.

Au nord du Saùanha, une forêt épaisse couvre toute la côte. En quelques heures on arrive au Pyrakâassù (grande rivière des poissons), nom qui vient des Indiens. On voit d̀ son embouchure un petit, povoaçào nommé Aldea velha; il ne renfermequ'un petit nombre de maisons; un peu plus haut en remontant le fleuve on rencontre un gros village fondé par les jésuites, qui dans le temps de leur domination avaient rassemblé dans ce lieu un grand nombre d'Indiens. Les poissons et les coquillages leur procuraient la nourriture la plus nécessaire, ce qui est cause qu'aujourd'hui on trouve encore sur le bord du fleuve de gros tas de coquilles de moules. On a voulu assigner une autre origine à ces amas, mais plusieurs auteurs (1) confirment que ces sauvages se

(1) Southey, History of Brazil, tom. I, pag. 36. 


\section{AU BRÉSIL。}

nourrissaient de coquillages, et les circonstances expliquent suffisamment la chose; on ne peut donc pas douter que ces entassemens de coquilles ne proviennent des repas des anciens habitans de ces lieux. Plusieurs Portugais s'étant dans la suite établis à Pyrakàassù, les jésuites emmenèrent, dit-on, une partie des Indiens qui y demeuraient, et fondèrent avec eux Villa-Nova pour qu'ils fussent éloignés des Européens.

Nous sommes arrivés à Aldea-Velha à la fraîcheur du soir; on fait le tour d'une pointe de terre qui avance dans la mer, puis on se trouve tout à coup sur les bords du fleuve, qui a une largeur considérable, et qui sortant d'un terrain couvert de bois, se jette dans l'Océan. Six à sept huttes en paille dans une petite vallée composent Aldea-Velha; une plus considérable que les autres est habitée par le commandant du territoire, qui est un lieutenant de la garnison d'Espirito-Santo, et qui nous accueillit très-bien. Les habitans de cette maison étaient contens de pouvoir une fois causer avec des hommes. Ils regardent ce poste comme une espèce de bannissement. L'officier se plaignait beaucoup d'être privé de divertis-

I. 
semens et des autres agrémens de la vie. Il est même obligé de renoncer à plusieurs choses de nécessité dans ce coin isolé du monde entier. L'on n'y a pour subsistance que de la farinha et un peu de poisson. Les habitans d'Aldea-Velha sont de pauvres pêcheurs; cependant le fleuve est poissonneux, son embouchure est profonde, et ses lanchas le remontent assez haut à la voile.

Ce lieu ne pouvant nous retenir long-temps, nous avons le lendemain pris congé de notre hôte, qui avait eu pour nous beaucoup deprévenance, et nous avons traversé le fleuve, qui étail haut, large et rapide; un de nos mulets de monture a failli à se noyer, ce qui aurait été une perte irréparable dans cette contrée. Un jeune Indien, au service du commandant, qui gouvernait avec beaucoup d'adresse la pirogue ballottée par les vagues, nous fut très-utile. Dans les endroits peu profonds et sur les bords, nous avons observé des mouettes, des hirondelles de mer et des volées nombreuses de bec-enciseaux (rynchops nigra, L.) oiseau connu par la forme bizarre de son bec. Au-delà dá fleuve s'étendent des forêts dans lesquelles les plantations des Indiens sont éparses; ils cultivent 
surtout du maïs, du manioc et du baga ou ricin, dont les graines fournissent l'huile pour les besoins du ménage. Nous sommes entrés de nouveau dans une belle forêt sombre, où des papillons magnifiques voltigeaient autour des fleurs les plus variées; nos oreilles étaient sans cesse frappées du bruit de la mer qui brisait contre le rivage. Le cri des jacupemba (penelope marail, $L_{.}$), oiseau forestier de la famille des faisans, fixa l'attention de nos chassenrs; mais ils n'en purent tuer aucun, tant cet oiseau est farouche.

Nous n'avons pas tardé à nous trouver de nouveau sur la côte de la mer, et nous avons encore parcouru quatre legoas jusqu'au soir que nous sommes arrivés au poste militaire nommé quartel do Riacho. La mer forme dans ce canton plusieurs baies, d'où il résulte une monotonie fort ennuyeuse pour les voyageurs, car dès qu’ils ont franchi une langue de terre, ils en aperçoivent aussitôt une antre dans le lointain. Nous avons trouvé sur ces côtes plusieurs espèces de goémon que la mer y avait jetées; mais peu de coquillages. L'hirondelle bleu d'acier (hirunclo violacea) niche dans des groupes de rochers avancés en mer. 
On rencontre dans les bois', à de grandes distances les unes des autres, les cabanes solitaires des Indiens; quelques-uns s'aventurent au large dans leurs pirogues pour pêcher. Un petit ruisseau dont le fond était si mou que nos mulets et nos chevaux y enfonçaient profondément, nous arrêta long-temps; enfin nos tropeïros trouvèrent à l'aide de nos cheváux de selle, et en se déshabillant, un endroit plus ferme. Nous avons passé heureusement; mais un peu mouillés, et avant l'obscurité nous sommes arrivés au quartel.

Le quartel do Riacho est un poste militaire composé d'un sous-officier et de six soldats; il est chargé de transmettre les ordres, et communique avec celui du Rio-Doçe. Deux petites maisons situées sur le bord de la mer servent de demeure, l'une aux familles de quelques-uns des soldats qui tirent leur subsistance des plantations voisines, l'autre au sous-officier. Celui qui commandait alors était un homme intelligent, qui nous donna beaucoup de renseignemens intéressans. Il nous communiqua, sur la guerre que l'on fait aux Boutocoudys dans les forêts du Rio-Doçe, des détails d'autant plus exacts que nous étions arrivés sur les frontières 
des déserts habités par ce peuple. Il avait été blessé d'un coup de flèche qui lui avait traversé les épaules, quand il servait dans un des quartels du Rio-Doçe; heureusement il était parfaitement guéri de cette blessure dangereuse.

Les Boutocoudys, ainsi nommés par les Européens, errent dans les forêts qui s'étendent sur les bords du Rio-Doçe jusqu'à sa source dans la capitainerie de Minas-Geraës. Ces sauvages se distinguent par leur coutume de manger de la chair humaine, et par leur caractère belliqueux. Ils ont jusqu'à présent opposé une résistance opiniâtre aux Portugais. Quelquefois ils se montraient dans un endroit avec toutes les marques de dispositions pacifiques, et dans un autre ils faisaient des incursions et commettaient des hostilités; la bonne intelligence avec eux n'a pu par conséquent être de durée. Il y a plusieurs années, on avait établi un poste militaire à une dixaine de legoas en remontant le Rio-Doçe, dans l'endroit où est aujourd'hui le povoaçao de Linhares; ce poste était composé de sept soldats, et pourvu d'un canon poưr couvrir la route que l'on ouvrait du côté de Minas. D'abord les sauvages furent effectivement intimidés; mais ensuite s'étant familiarisés avec les Européens 
et avec leurs armes, leur crainte se dissipa peù à peu. Un jour ils attaquèrent le quartel, et tuèrent un soldat. Ils auraient aussi attrapé et égorgé les autres, qui avaient pris la fuite, si ceux-ci ne se fussent pas réfugiés dans la rivière, et n'eussent pas été sauvés par la pirogue, qui, par le plus grand des hasards, arrivait avec le détachement destiné à les remplacer. Les Boutocoudys ne pouvant les atteindre, bouchèrent le canon avec des pierres, puis se retirèrent daus leurs forêts. Alors le ministre d'état comte de Linhares, qui est mort depuis peu, leur déclara formellement la guerre prar une proclamation. Les postes militaires établis sur le Rio-Doçe furent renforcés et angmentés, pour protéger les plantations des Européens et les communications avec Minas-Geraës. Ensuite on n'eut plus aucun ménagement pour les Boutocoudys; on les tua sans distinction de sexe ni d'àge, seulement, dans quelques occasions particulières, on épargna des enfans en bas âge, que l'on éleva.

Cette guerre d'extermination se fit avec d'autant plus d'animosité et de cruauté, que l'on était fermement persuadé qu'ils tuaient toutes les personnes qui tombaient entre leurs mains, et dévoraient leur chair. On apprit depuis 


\section{$\Lambda U$ BRÉSIL.}

qu'ils s'étaient montrés en plusieurs endroits sur les bords du Rio-Doçe en frappant des mains, ce qui est chez eux l'indice de dispositions pacifiques, et que des Portugais, pleins de confiance dans ces démonstrations de paix, s'étant rendus parmi cux, avaient été traîtreusement percés par les flèches de ces barbares; alors s'éteignit toute idée de pouvoir trouver chez eux le moindre sentiment d'humanité. Mais un fait démontre évidemment que l'on est allé trop loin dans ce jugement qui offense la dignité de l'homme, et que la manière dont on traite ces sanvages contribue au moins autant que leur férocité naturelle à les řendre incorrigibles. La conduite modérée et humaine de M. le comte Dos Arcos, gouverneur de la capitaineric de Bahia, envers les Boutocoudys qui vivent sur les bords du Rio-Grande de Belmonte, a produit les effets les plus heureux. Le contraste que le voyageur observe lorsque quittant le théâtre de la guerre inhumaine qui se fait sur les bords du Rio-Doçe, il arrive, après un intervalle de quelques semaines, dans les contrées du Rio-Grande de Belmonte, et qu'il voit les habitans vivre dans la meilleure intelligence avec les sauvages, depuis la paix 
conclue avec eux il y a trois à quatre ans, et qui leur assure la tranquillité, la sûreté et les avantages les plus importans, ce contraste, disje, le. surprend extrêmement, et lui inspire les réflexions les plus sérieuses.

Afin de bien connaître les contrées remarquables baignées par le Rio-Doçe, dont on nọ avait fait un tableau extrêmement séduisant à Espirito-Santo, nous sommes partis de bonne heure du quartel do Riacho, accompagnés de deux soldats, et nous avons traversé le ruisseau ou riacho qui lui donne son nom. Nous avions ¿̀ parcourir une distance de huit fortes legoas, par un chemin difficile dans des sables profonds, et par les chaleurs brûlantes du mois de décembre. Le sol, qui est un mélange de sable, de quartz et de petits cailloux, fatigue beaucoup les pieds des hommes et des chevaux ; du côté de l'intérieur, de petits buissons formés entre autres de cocotiers nains couvrent le sable; audelà s'élève une forêt dans laquelle, à peu de distance de la plage, est situé le quartel dos Comboyos, où trois soldats sont postés pour assurer les communications. Nous y avons trouvé des traces de grosses tortues de mer, qui sortent de l'eau pour venir à terre pondre leurs œufs dans 
le sable. En plusieurs endroits on apercevait encore des débris de ces animaux, entre autres des carapaces et des squelettes; nous fûmes surpris de la grosseur des crânes : j’en rencontrai un qui pesait au moins trois livres. Les Indiens mangent la chair de ces tortues, et en retirent une quantité de graisse; ils recherchent aussi leurs œufs, dont on trouve quelquefois jusqu’à douze et seize douzaines dans un trou. Ces oufs sont ronds, blancs, couverts d'une membrane coriace et élastique, et remplis d'un albumen clair comme de l'eau, et d'un jaune de belle couleur dorée, qui est savoureux quoiqu'il ait un peu le goût de poisson. Nous avons rencontré des familles indiennes qui portaient chez elles de pleins paniers de ces œufs. On peut juger de la grandeur de ces tortues, par celle des carapaces que nous avons trouvées sur la plage, et dont quelques-unes avaient cinq pieds de long.

Lorsque la chaleur accablante du milieu du jour commença à se faire sentir, notre tropa se trouva dans un état voisin de l'épuisement, parce que l'eau douce manquait pour apaiser la soif brûlante de nos bêtes de somme, et surtout celle des hommes qui allaient à pied, et qui étaient 
trempés de sueur. Nous fîmes halte pour chercher un abri à l'ombre des buissons, mais la terre était si chaude que nous ne trouvâmes que peu d'adoucissement à l'incommodité dont nous souffrions : nos pieds seuls se reposèrent; nous débarrassâmes les mulets de leur charge, ce qui leur procura un peu de soulagement. En cette occasion, l'expérience de nos jeunes Indiens nous fut très-utile; ils s'enfoncèrent dans les buissons avec des vases, et y rassemblèrent l'eau qui se trouvait entre les feuilles et les tiges des bronélias. Quand la pluie vient de tomber, cette eau est claire et pure; or, comme il n'avait pas plu depuis long-temps, l'eau était noire et sale, et contenait même du frai et de petites grenouilles. On la fit passer à travers un linge, on y mêla un peu d'eau-de-vie, du jus de citron et de sucre : ainsi préparée, elle nous rafraîchit et nous ranima. Une petite grenouille jaunâtre (1) était commune sur les tiges de bromélias; cet animal, ainsi que plusieurs autres de cette famille, dépose ses oufs au-dessus du sol; nous

(1) Petite raine non encore décrite, hyla luteola de couleur jaune pàle avec une raie foncée sur les yeux. 
avons aussi trouvé fréquemment sa petite larve noire. On ne doit pas s'étonner de ce que les reptiles de ces contrées élèvent leur postérité sur des arbrisseaux, puisque l'homme lui-même, dans cette partie du monde si féconde en choses singulières, vit en plusieurs endroits sur les arbres. On en a un exemple dans les Guaranys, sur lesquels M. de Humboldt donne des détails si intéressans (1).

Après quelques instans de repos, nous nous sommes remis en rouse, et nous avons continué à voyager jusque bien avant dans la nuit; la lune a commencé à luire, nous nous sommes trouvés dans une plaine sablonneuse et nue à peu de distance de l'embouchure du Rio-Doçe. Les deux soldats quenous avions pris pour guides se sont égarés, et malgré notre lassitude, nous avons été obligés d'attendre long-temps jusqu'à ce qu'ils aient découvert le chemin par lequel ils nous ont conduits droit au quartel da Regencia. C'est un poste militaire de cinq soldats, placé à l'embouchure du fleuve pour transmettre

(1) Ansichten der Natur, p. 26.

Tableaux de la Nature, tom. I, p. 58. 
plus loin les ordres du gouvernement, pour faire passer l'eau aux voyageurs, et entretenir la communication avec le povoaçao de Linhares. Nous avons passé la nuit dans la maison des soldats, qui est assez grande; elle renferme plusieurs chambres garnies d'escabeaux en bois. Il s'y trouvait aussi un tronco, machine destinée à punir les militaires qui ont commis des fautes. C'est une longue planche placée de champ, dans laquelle sont creusés des trous ronds, on y passe la tête des délinquans, dont la planche entoure le cou, et leur corps est étendu horizontalement à terre (1). Ces soldats vivent misérablement. Le poisson, la farinha, les haricots noirs, et quelquefois un peu de viande salée, font leur unique nourriture. C'étaient tous des hommes de couleur, créoles, Indiens, mulâtres ou mamelus.

Le lendemain dès le point du jour la curiosité nous a fait sortir pour voir le Rio-Doçe, qui est le fleuve le plus considérable entre Riode-Janeïro et Bahia. Il roulait majestueusement vers la mer ses eaux, qui étaient très-hautes en ce moment. Son lit nous parut une fois aussi

(1) Eschwége, Journal von_Brasilien, tom. I, p. 128 . 
large que celui du Rhin, dans les endroits où il l'est le plus; au bout de quelques jours il était un peu diminué. Ce n'est que dans les mois d'hiver, surtout en décembre, qu'il devient aussi considérable; dans les autres saisons, surtout pendant les sécheresses continues, on voit partout des bancs de sable au milieu de son lit; en ce moment l'on n'en découvrait pas la moindre trace. En tout temps néanmoins son embouchure, malgré sa largeur, est inaccessible aux grands navires, à cause des sables et des hauts-fonds; les lanchas mêmes ne peuvent y entrer que lorsque les eaux sont très-hautes.

Le Rio-Doçe prend sa source dans la capitainerie de Minas-Geraës, où il se forme de la jonction du Rio-Piranga et du Ribeïrào do Carmo; après cette réunion il porte le nom de Rio-Doçe (1). Il traverse une vaste étendue de pays plat, et fait plusieurs petites cascades dont trois, qui se suivent immédiatement, sont appelées les escandinhas. Les rives de ce beau fleuve sont ombragées de forêts épaisses où vivent différentes espèces d'animaux. On y trouve

(1) Eschwège, Journal von Brasilien, tom. I, pag. 52. 
fréquemment le tapir, le pecari ou caytetù (1), et le taytetou ou porco à quechada branca (2); le guazupita et le guazubira, deux espèces de cerfs, et plus de sept espèces de chats, dont l'yaguareté et l'yaguareté noir, sont les plus grandes et les plus dangereuses.

Cette contrée est encore très-peu habitée, de sorte que la communication n'a lieu que par les rivières. Depuis quelques semaines on avait ouvert un picadé ou sentier dans la forêt, le long de la rive méridionale du fleuve, mais il n'est achevé que depuis peu de temps, et on ne peut y passer que bien armé, à cause des sauvages. Le comte de Linhares avait fixé son attention sur ce pays fertile; il établit de nouveaux postes militaires, et fonda à une dixaine de legoas en remontant le fleuve le povoaçào qui porte son nom, à l'endroit où le premier quartel avait été placé. Il y envoya pour peupler la nouvelle colonie des déserteurs et d'autres condamnés. Sans doute ces nouveaux établissemens n'auraient pas tardé à prendre de l'accroissement, mais il est ả craindre que la

(1) Pecari tajassu (dicotyles labiatus, Fred. Cuvier).

(2) Pecari à collier (dicotyles torquatus, Fred. Cuvier). 
mort de ce ministre ne soit arrivée trop tôt pour leur prospérité : depuis cette époque ils ont été complètement oubliés, et si l'on ne prend pas des mesurcs efficaces, ces contrées pourront bien avant peu redevenir entièrement désertes.

Nous étions impatiens de remonter le RioDoçe pour connaître par nous-niêmes, s'il était possible, le théâtre de la guerre avec les Boutocoudys. Un coup de vent violent, qui le 25 décembre souleva trop fortement les eaux du fleuve, nous fit, d'après le conseil des soldats, différer notre départ d'un jour. Le lendemain le temps étant chand et calme, nous nous sommes embarqués au point du jour dans une grande pirogue menée par six soldats; nous étions en tout neuf personnes bien armées. Pour remonter le Pio-Doce quand ses eaux sont hautes, il faut au moins quatre hommes qui poussent la pirogue en avant en s'appuyant sur de longues perches. Comme il se trouve partout des eudroits peu profonds, on peut toujours, même dans lès hautes eaux, y atteindre le fond, de sorte que lorsque toutes les circonstances sont favorables, il est possible d'arriver à Linharès en un jour, mais le soir et tard. Le temps était très-beau. Quand nous fümes 
accoutumés au balancement de la pirogue, occasionné par le mouvement continuel des soldats qui allaient d'une extrémité à l'autre pour la faire avancer, nous trouvâmes la navigation très-agréable.

Lorsqu'il fit grand jour, le vaste miroir du fleuve s'étendit à nos yeux réfléchissant les rayons du soleil levant; les rives lointaines étaient bordées de forêts si épaisses et si continues, que nous n'aperçûmes pas dans toute notre route un espace libre d'étendue suffisante pour une maison. Un grand nombre d'îles de dimensions et de formes différentes s'élevaient au-dessus de la surface de l'eau; des forêts les couvraient: chacune a son nom particulier; on dit que plus haut leur nombre augmente toujours. Quand le Rio-Doçe est gonflé, ses eaux sont troubles et jaunâtres, et, d'après le témoignage général des habitans, engendrent aisément des fièvres; le poisson y abonde; on dit même que la scie (pristis serra) remonte au-dessus de Linharès jusqu'au lac de Juparanàn, où l'on prend souvent de ces grands squales.

On entend retentir dans les forêts les cris d'une multitude de singes, notamment du barbados (mycetes ursinus) 2 du saùassù (calli- 
thrix personatus, Geoffroy), etc. Un des plus grands ornemens des forêts du Brésil, le magnifique arara (psittacus macao, $L_{\text {. }}$ ), que nous nommons ara en Europe, ne s'était pas encore présenté à notre vue dans l'état sauvage; sa voix forte et rauque frappa nos oreilles, et nous l'aperçûmes juché sur la cime des sapucayas ou quatelés. On reconnaissait de loin cet oiseau magnifique à sa longue queue; son plumage, d'un rouge resplendissant, brillait d'un éclat extraordinaire à la vive clarté du soleil. Des troupes de perruches, de maracanas, de maïtaccas, de tiribas, de curicas, de camutangas, de nandayas et d'autres espèces de perroquets, volaient en criant d'une rive du fleuve à l'autre; des canards musqués se reposaient au bord de la forêt, sur des branches de coulequin. Le bec-en-ciseaux, la tête cachée dans les plumes de son cou, se tenait immobile sur les bancs de sables (corrocas). Les toucans et le curucua ou couroucou (trogon viridis,.$L$ ) remplissaient l'air de leur voix forte. Les bords du flenve ne sont habités que par ces oiseaux sauvages, et par les Boutocoudys qui ne le sont pas moins. On ne voit des colons établis que dans deux endroits; ils n'y restent que parce qu'ils sont suf-

I. 
fisamment munis d'armes pour se défendre. Ils portent toujours un fusil quand ils vont à leurs plantations, et ceux qui n'ont pas d'armes à feu se pourvoient au moins d'un bodock pour lancer des balles ou des pierres. Les Boutocoudys ne se font voir dans la partie inférieure du fleuve que de temps en temps et en passant.

Vers midi nous sommes arrivés à la petite île, que sa forme a fait nommer carapuça ( bonnet). Nos bateliers fatigués s'y sont reposés, et nous avons reconnu qu'il était impossible d'arriver aujourd'hui à Linharès. Afin d'être en sûreté contre la force du courant du fleuve, nous avons débarqué entre le continent et une île, dans un petit canal où volaient une quantité de beaux oiseaux, notamment de perroquets, parmi lesquels le magnifique arara se distinguait par l'éclat de son plumage rouge. Les bords de ces îles et du canal étaient rendus plus touffus par le grand roseau en éventail ( $u b a)$, de la hampe florale duquel les Boutocoudys font leurs flèches. A l'approche de la soirée, nos soldats tinrent conseil pour savoir. s'il valait mieux passer la nuit sur l'ilha Comprida (l'île longue) ou sur une autre. La première fut rejetée, parce qu'elle n'est séparée de 


\section{AU BRÉSIL.}

la terre-ferme que par un canal étroit et peu profond, et qu'en conséquence nous n'y étions pas à l'abri d'une visite des sauvages. Nous avons donc gagné l'ilha de Gambin, où jadis les gouverneurs passaient la nuit quand ils visitaient les colonies du Rio-Doce. Le gouverneur n'a pas continué ses visites; de sorte que les bois étaient tellement touffus sur le rivage, qu'un de mes chasseurs fut obligé d'ouvrir le passage avec le couteau de chasse pour que nous pussions mettre le pied à terre. Un grand feu ne tarda pas à s'allumer dans un endroit, d'où un grand hibou curuja et un canard musqué s'envolèrent effrayés d'une visite si inattendue. Malgré la multitude des moustiques qui nous incommodèrent un peu, nous dormîmes tranquillement jusqu'au matin.

Nous avons quitté l'île de très-bonne heure; et passant devant plusieurs autres, nous sommes entrés dans un canal situé entre l'Ilha Comprida et la rive septentrionale du fleuve. Le courant n'y était pas à beaucoup près si fort, mais nous y avons trouvé des arbres renversés et de grosses branches qu'il a fallu écarter pour pouvoir continuer à remonter. Les buissons et les grands arbres qui entourent ce canal sont 
variés et magnifiques. Différentes espèces de cocos, surtout le coco de palmitto, nommé ailleurs jissara, avec leur tige haute et mince, et leur petite cime d'un vert éclatant et formant de beaux panaches, ornent ces forêts touffues, du fond desquelles des milliers de voix singulières d'oiseaux se font entendre. Au-dessous, presque à la surface de l'eau, des plantes, encore nouvelles pour nous, déployaient leurs fleurs, entre autres un liseron ou un végétal d'un genre voisin qui en avait de grandes toutes blanches, et une légumineuse qui parait les buissons de longs festons jaunes. Un jacarè, qui se chauffait tranquillement au soleil, s'enfuit au bruit de nos pagaies. Bientôt nous sommes arrivés à plusieurs îles où les colons de Linharès ont éiabii des plantations, car ce n'est que sur ces points séparés du coninent que l'on est en sûreté contre les sauvages qui n'ont pas de pirogues, et qui par conséquent ne peuvent franchir le fleuve que dans les endroits où il a neu de largeur et de profondeur. Le guarda mor de Linharès demeure sur l'Ilha do Boï ( lle aux Bœufs), et le curé sur l'Tlha do bom Jesus. Vers midi nous avons aperçu Linharès, et nous avons débarqué sur la rive septen- 
trionale après avoir coupé le courant rapide du fleuve, en faisant de si grands efforts, que deux de nos longues perches en ont été cassées.

En arrivant à Linharès, nous sommes allés à la maison de M. Cardoso da Piosa, alferés ou enseigne qui conmandait le détachement posté sur le Rio Doçe. Il était en ce moment de l'autre côté du fleuve sur la fazenda de Bomjardim, où nous fùmes bientôt invités de nous rendre. Des nègres de la fazenda nous ont fait traverser le fleuve en pirogue avec la rapidité d'une flèche, et nous avons été reçus de la manière la plus obligeante dans la maison de M. le lieutenant Joào Felippe Calmon, où une société fort aimable et fort gaie était réunie; nous y avons trouvé entre antres M. Cardoso da Rosa, à qui nous avons fait part dı motif et du but de notre voyage. Ensuite nous avons visité la fazenda dont le moulin à sucre est le premier qui ait été établi sur le Rio Doçe.

Les plantations de cannes à sucre, de maïs, de manioc, etc., offraient la végétation la flus riche. Le manioc est la plante qui réussit le moins bien dans ce canton. M. Calmon a par son activité et ses connaissances rendu les plus grands services à la contrée roisine, son exemple 
ayant encouragé à entreprendre des cultures. Avec dix - sept esclaves nègres il a défriché un grand espace de forêt, et prouvé par le succès de ses plantations que le terrain le long du fleuve est extrêmement fertile, et propre à la production de tous les végétaux utiles.

Nous avons passé toute la journée du 28 décembre chez M. Calmon, qui s'est empressé, ainsi qque M. Cardoso, da Rosa, de nous rendre notre séjour agréable.

Linharès n'est encore qu'un établissement peu considérable, quoique le ministre-comte de Linharès se soit donné, ainsi que je l'ai dit beaucoup plus haut, beaucoup de peine pour lui faire prendre de l'accroissement. On a par son ordre bâti les maisons près du bord du fleuve, sur une côte argileuse et escarpée; elles sont en terre disposées en carré, petites, basses, couvertes de feuilles de cocotiers ou d'uricanna. On n'a pas encore construit d'église; on dit la messe dans une petite maison. Une croix en bois s'élève au milieu du carré formé par les maisons; c'est un tronc de sapucaya dégrossi, et, auquel on a adapté une solive transversale. Les plantations des habitans sont les unes dans la forêt qui entoure le village, les autres dans les 
îles du fleuve. Jusqu'à présent M. Calmon est le premier et le seul qui ait établi une fazenda et un moulin à sucre. Quand il voulut former son établissement vis-à-vis de Linharès, il prit avec lui une quarantaine d'hommes armés, et tomba sur une troupe de Boutocoudys qui se préparaient à lui disputer le terrain. Un de ces sauvages fut tué; mais on s'aperçut bientôt que l'on ne parviendrait pas par la violence seule à chasser cette troupe forte, de cent cinquante guerriers; on eut donc recours à la ruse; on les menaça par-derrière, et par ce moyen on les dispersa. Depuis trois ans que M. Calmon a fondé son établissement en ce lieu, les Boutocoudys ne l'ont plus inquiété.

On pourrait avec un peu de commerce tirer parti, ainsi qu'il le fait sur sa fazenda, des différentes espèces de bois précieux qui remplissent les forêts. Le peroba, bois excellent pour la construction navale, est regardé comme appartenant au monopole de la couronne. Mais IM. Calmon a obtenu la permission d'en construire de grandes pirogues propres à tenir la mer; il les charge de bois, et les expédie à Espirito-Santo et d'autres endroits. Pour mettre les colons à l'abri des attaques et des cruautés 
des Boútocoudys, on a établi huit postes militaires sur différens points des forêts; ils sont en même temps et spécialement destinés à protéger les relations commerciales, que l'on s'est efforcé d'ouvrir avec Minas Geraës en remontant le fleuve. Il est déjà arrivé de ce gouvernement un bon nombre de soldats bien armés, et pourvus de cuirasses (gibào d'armas), qui sont indispensables pour se préserver des flèches dangereuses des sauvages; il s'en trouve dans tous les postes. Ce sont des casaques faites en toile de coton et rembourrées de plusieurs doubles d'ouatte; elles ont un collet montant roide qui couvre le cou, et des manches courtes qui protégent le haut du bras; elles descendent jusqu'aux genoux; mais leur pesanteur, surtout quand il fait chaud, les rend extrêmement incommodes. La flèche la plus acérée, même tirée de près, ne perce pas aisément cette cuirasse; et lorsqu'elle la pénètre, il ne lui reste pas assez de force pour blesser dangereusement le corps. On a d'ailleurs trop de confiance dans ces cuirasses, car on nous assura qu'elles résistaient aux balles. Pour me convaincre de la vérité, je fis tirer un de mes chașseurs à la distance de quatre-vingts pas sur une cuirasse; la. 
balle la perça de part en part. Cependant d'autres expériences nous ont prouvé qu'à la distance de soixante pas le plomb le plus gros ne pénétrait pas ces cuirasses, qu'il tombait aplati à terre, et qu'elles offraient ine résistance suffisante aux flèches des sauvages.

A Villa de Victoria et ailleurs on fabrique des cuirasses de soie plus légères, mais beaucoup plus chères que celles de coton. Au dernier combat livré à Linharès, un Boutocoudy, extrêmement vigoureux, lança d'assez près une flèche très-forte à un soldat portugais; elle traversa la cuirasse, et ne fit au soldat qu'une blessure légère au côté; les flèches causent toujours, même en rebondissant, une secousse violente.

On a récemment ouvert un chemin qui va de la fazenda de Bomjardim au quartel do Riacho, et passe devant le lac nommé Lagoa dos Indios (1). Il s'y trouve un second poste que I'on a nonmé Quartel d'Aguiar. Quelques familles indiennes y demeurent, et huit soldats indiens font le service; car ces hommes une

(1) Après mon départ de Linharès, au mois d'avril ${ }_{1} 816$, trois soldats ont été tués sur cette route par les Boutocoudys. 
fois civilisés sont de très-bons soldats contre leurs compatriotes encore sauvages. Ceux-ci les détestent, et dans une escarmonche tirent d'abord sur eux parce qu'ils les regardent comme des traîtres. Dans les forêts, un peu en avant de Linharès, se trouve le quartel segundo ou second poste de Linharès; le village étant compté pour le premier, ce quartel segundo a une garnison de vingt-irois soldats. On a établi sur la rive méridionale du Rio-Doçe deux postes au-dessus de Bomjardin; le quartel d'Anadya consiste en douze soldats, et le quartel de Porto de Souza, qui est le plus éloigné, en a vingt. Il y a huit cuirasses à Linharès, quatre à Porto de Souza, et une au quartel d'Anadya. Les hommes qui en sont revêtus doivent attaquer les premiers.

L'officier qui commande à Linharès a un service très-pénible, car il doit une fois par mois, n'importe qu'il pleuve ou que la chaleur soit excessive, faire la revue de tous les postes, ce qui lui occasionne un voyage de quatrevingt-dix legoas. M. Cardoso da Rosa, qui occupe cet emploi depuis long-temps, fait faire par les postes des battues dans les forêts, pour la sûreté des habitans. Si la patrouille ren- 
contre des sauvages, deux coups de fusil rassemblent tous les hommes qui ont des armes à feu. Souvent les sauvages attaquent les plantations ; ils ont déjà tué de cette manière plusieurs habitans de Linharès. Au mois d'août dernier un accident semblable était arrivé au quartel segundo de Linharès; ce poste était pourtant commandé par un Mineïro, homme brave et résolu, qui repoussa les sauvages. Les habitans actuels de Linharès sont la plupart des soldats avec un enseigne, un chirurgien et un prêtre; il s'y trouve aussi quelques planteurs qui tirent du profit de leurs cultures. L'ecclésiastique était, me dit-on, un protégé du gouverneur d'Espirito-Santo; s'arrogeait une autorité qui ne lui appartenait pas, et se mêlait de toutes les affaires, lors même qu'elles ne concernaient pas ses fonctions; on le craignait d'autant plus, qu'il demeurait alternativement à Linharès et à Villa de Victoria près du gouverneur. Cette colonie, qui pourrait devenir aisément un des lieux les plus importans de la côte orientale, était durant mon sejour traitée de la manière la plus déraisonnable et la plus tyrannique : quiconque en voulait partir devait d'abord demander la permission; une famille ne 
pouvait en trois mois consommer plus d'une bouteille d'eau-de-vie; et ainsi du reste. Aujourd'hui cet établissement pourrait bien être près de sa fin, s’il n'a pas été soutenu; dans la suite de cette relation j'aurai l'occasion de raconter les événemens qui s'y sont passés plus tard.

Mon séjour sur les bords du Rio-Doçe a été certainement une des circonstances les plus intéressantes de mon voyage au Brésil, car le naturaliste trouve de l'occupation pour long-temps et des jouissances extrêmement variées dans cette contrée si riche en tableaux de la plus grande magnificence et en productions remarquables. Mais sa récolte serait bien plus importante s'il pouvait parcourir sans obstacle et sans danger ces forêts, qui n'ont pas encore été visitées. Il est rare de trouver des perspectives plus riantes que celle du lac de Juparanan (1), à peu de distance de Linharès, et qui commu-

(1) Le mot juparanan ou proprement juparanâ, ne dérive pas de la langue des Boutocoudys qui habitent aujourd'hui ce canton; il vient de la lingoa geral, dans laquelle parana signifie mer ou grande eau. Ce lac n'est pas marqué sur la carte d'Arrowsmith; Faden au contraire la désigne sous son véritable nom : mais il s'est trompé sur sa position. 
nique avec la rive septentrionale du fleuve par un canal étroit. Les anciens écrivains sur le Brésil en ont fait mention. Selastiam Fernandès Tourinho, qui remonta le Rio-Doçe en 1572 , dit qu'il a trouvé à l'ouest de ce fleuve un lac qui est vraisemblablement celui dont je parle; cependant la position du ruisseau qui tombe dans le Rio-Doçe et celle de la chute d'eau, ne ressemblent pas à ce qui existe : la distance offre aussi des différences (1).

M. Freyreiss, qui a visité encore une fois Linharès quelques mois plus tard, m'a communiqué son voyage à ce lac. Je le raconterai avec ses propres expressions : «Un canal qui a rarement plus de soixante pieds de largeur, mais qui est profond et dont la longueur peut être d'une legoa et demie, conduit au lac, qui est très-poissonneux; les bords de ce canal sont encore habités par les Boutocoudys ou les anciens Aymorès; ils avaient établi sur le milieu un passage avec des lianes, auquel les Portugais donnaient mal à propos le nom de pont; ceux-ci l'ont coupé depuis plusieurs années, sans que les antropophages aient essayé de le rétablir, ou

(1) Southey history of Brazil. Vasconcellos noticias, etc. 
d'en tendre un nouveau; trompé par ces apparences, on se livrait à une funeste sécurité; tout à coup les Boutocoudys se montrèrent au quartel segundo de Linharès, placé sur le bord du canal, et tuèrent un soldat à coups de flèche. Cet événement s'était passé peu de jours avant notre arrivée; les sauvages n'avaient cependant $\mathrm{pu}$, cette fois, s'emparer du corps de l'homme qu'ils avaient assassiné. C'est à cause de cet accident et du peu de largeur du canal que les colons du Rio-Doçe choisissent ordinairement la nuit pour aller pêcher dans le lac. 11 est entouré de collines; sa longueur est à peu près de sept legoas du sud-est au nord-ouest, et sa largeur d'une demi-legoa; il peut avoir seize à dix-huit legoas de circuit : sa profondeur est inégale; en plusieurs endroits elle est de huit à douze brasses (quarante à soixante pieds). Cette grande masse d'eau doit sa formation à une petite rivière et à plusieurs ruisseaux qui s'y jettent au nord-nord-ouest. J'ai déjà dit qu'il se décharge dans le Rio-Doçe près de Linharès par le canal dont je viens de parler; il gonfle considérablementlorsque de forts vents du sud font refouler l'eau dans cette embouchure. Le fond et les bords dé ce lac sont d'un 
sable fin, où l'on trouve par intervalle des morceaux de grès ferrugineux. A peu près à quatre legoas de l'entrée s'élève une jolie petite île de granit, que les sauvages ne visitent pas à cause de son éloignement du rivage, et qui offre par conséquent une retraite sûre aux pêcheurs. )

Dès l'année 166:, Vasconcellos nomme parmi les tribus qui habitent le long de RioDoce, les Aymorès Boutocoudys, les Pourys et les Patachos; quoique les premiers dominent dans cette contrée, les autres y poussent quelquefois leurs excursions. Le même voyageur observe avec beaucoup de justesse que quelques Aymorès ou Boutocondys sont presque aussi blancs que les Portugais. La guerre déplorable que l'on fait aux Boutocoudys, sur les bords du Rio-Doçe, met obstacle à ce que l'on y puisse bien connaître ces hommes dignes de fixer l'attention. Dès qu'on les aperçoit il faut s'attendre à l'instant à recevoir une flèche; mais plus au nord, sur le Rio-Grande de Belmonte, où l'on vit en paix avec eux , on peut les y observer sans danger; je réserve donc des détails ultérieurs sur cette tribn intéressante des indigènes, jusqu'au moment où je décrirai mon séjour dans cette dernière contrée. 
Le sẻjour de Linharès est très-agréable pour quelqu'un qui aime la chasse. Au point du jour les singes viennent si près des maisons qu'ils évitent la peine d'aller les chercher bien loin; les perroquets s'y rassemblent en grandes troupes, et les magnifiques araras y sont attirés, dans la saison froide, par certaines espèces de fruits. Ces beaux perroquets ont coutume de nicher tous les ans dans le même arbre, quand ils ont trouvé un trou qui leur convienne dans une forte branche ou dans un tronc. On en tue fréquemment; on mange leur chair; on se. sert des grosses plumes de l'aile pour écrire, les sauvages en garnissent leurs flèches, et s'en font aussi des parures. Dans ces solitudes peu fréquentées il n'est pas difficile de revenir cher. soi le soir avec un canot plein de gibier; mais dans ces parties de chasse il est nécessaire de se tenir constamment en garde contre les sauvages. L'expérience a appris aux soldats de Linharès la manière de poursuivre les sauvages dans les forêts; tous conviennent pourtant que les Boutocoudys sont bien meilleurs chasseurs qu'eux et connaissent beaucoup mieux la forêt; il est par conséquent indispensable d'user de la plus grande prudence dans ces combats et dans 
ces excursions au milieu des forêts. Les Minë̈ros ou habitans de Minas-Geraës passent généralement pour les meilleurs chasseurs de sauvages, parce qu'ils sont familiarisés avec leur manière de vivre, et avec la petite guerre des forêts, et que d'ailleurs ils sont braves et robustes. La dernière escarmouche importante qui avait eu lieu contre les sauvagés près de Liuharès avait été conduite par le Guarda-Mor, qui était un Mineïro banni de Minas-Greraës.

On nous fit présent à Linharès d'armes et d'ornemens de Boutocoudys, et on nous offrit aussi un petit enfant qui avait éte élevé à Bomjardim après la mort de sa mère, tuée dans un combat. Ayant rempli l'objet de notre voyage à Linhárès, nous en sommes partis pour continuer notre voyage au nord le long de la côte. Nous nous sommes embarqués dans une grande pirogue très-commode que M. Calmon nous avait louée; il a eu la complaisance de nous accompagner. En descendant le fleuve nous avons rendu une visite au Guarda-Mor, dans l'Ilha do Bö̈, où il a établi de belles plantations de manioc et de maïs. Nous nous aperçûmes bientôt chez lui qu'il est un mineïro, car il mange plus volontiers du maïs que de la I. 
farinha, habitude caractéristique des habitans de cette province. Pour réduire le maïs en farine, on se sert d'une masse de bois nommée preguiza ou paresseux; M. Mawe en a donné la description dans son voyage à Tejuco(1). Notre excellente pirogue était couverte d'un tendelet en toile et bien pourvue de vivres. Nous sommes arrivés en quatre heures à Regençia à l'embouchure du Rio-Doçe, distance que nous avons mis un jour et demi à parcourir en remontant.

(1) Page 34 , ( tome I, pase 23 ) arec une planche qui représente cette machine. 
B)

\section{CHAPITRE VII.}

VOYAGE DU RIO-DOÇE A CARAVELLAS, AU RIO D'ALCOBAÇA, ET RETOUR AU MORRO D'ARARA. SUR LE MUCURI.

Quartel de Juparanan da Praya. - Rivière et barras de SanMatéo. - Le Mucuri. - Villa Viçoza. - Caravellas. - Ponte do Gentio sur l'Alcobaça. - Séjour en cet endroit.

Ayant passé la nuit avec nos amis an quartel de Regençia, nous avons fait traverser le fleuve à nos mulets dans la grande pirogue, le Ђo décembre dans la matinée : ce ne fut pas sans peine.Nous les avons bientôt suivis, avançant pendant deux lieues le long d'une côte sablonneuse et déserte, avec nos deux compagnons de Linharès, et nous sommes arrivés au quartel de Monserra ou de Juparanan da Praya, occupé par sept soldats. Une lagune longue et étroite, nommée lagoa de Juparanan da Praya, pour la distinguer du grand lac situé près de Linharès, touche ce poste. Dans les hautes 
eaux l'embouchure de cette lagune dans la mer est très-considérable, et on ne peut alors la traverser qu'en pirogue; en ce moment elle était basse, et nos mulets de charge purent la passer à pied sec avec leurs fardeaux. Le poste est entre la mer et la lagune; au-delà s'élève une forêt sombre, dans laquelle nous avons aperçu une quantité de cocotiers sauvages. Les soldats ont établi dans son voisinage quelques plantations qui leur fournissent du manioc, du maïs et même des melons d'eau en quantité suffisante pour leurs besoins. Ils ont aussi des pirogues, et ajoutent aux resscurces de leur culture celles que leur procurent la chasse et la pêche.

Nous avons trouvé en ce lieu un homme très-remarquable; c'était un vieillard nommé Simam (Simon), qui depuis plusieurs années vit absolument seul dans une petite maison voisine du quartel, et n'a pas la moindre crainte des sauvages. Quoique très-âgé il est encore robuste et gai; aussi ses voisins l'aiment-ils beaucoup. Il cultive lui-même ses champs, est, chasseur et pêcheur habile, et connaît bien la contrée voisine. Nous lui avons fait plusieurs visites dans son petit ermitage : il a peu de besoins; il est non-seulement très-content de 
sa position, mais encore si enjoué et si jovial que sa bonne humeur se communiqua à toute la compagnie qui l'entourait. Il me fit présent de la peau d'un grand fourmillier (myrmecophaga jubata L.), que l'on nomme ici tamandua cavallo; il l'avait tué depuis peu de temps.

- Nous avons obtenu à Monserra plusieurs autres curiosités en histoire naturelle; par exemple le scarabée hercule, le plus grand coléoptère du Brésil, qu'un soldat avait pris et qu'il nous apporta vivant. On nous donna ensuite quatre ou cinq têtes de cet insecte qui n'est pas commun; et comme je demandais pourquoi on l'avait ainsi mutilé, j'appris que dans plusieurs endroits les dames portent ces têtes suspendues au cou en guise d'ornement.

Ayant à traverser, pour arriver à San-Mateo, un désert long de dix-huit legoas et entièrement inhabité, nous avions prié M. Cardoso da Rosa de nous donner une escorte de deux soldats, parce que les papiers que nous tenions du ministre - comte d'Aguiar nous permettaient expressément de la demander. Nous avions montré ces papiers au gouverneur à Villa dé Victoria, en sollicitant le nombre d'hommes 
nécessaire pour continuer notre voyage. Il nous avait donné un écrit qui ordonnait à l'alferès de Linharès de nous accorder un seul soldat. La longueur de la route jusqu'à San-Mateo et son pên de sûreté firent penser à cet officier qu'envoyer un seul homme serait l'exposer à courir des dangers à son retour; nos discours l'en persuadèrent complètement, et nous obtînmes deux soldats pour nous accompagner. Mais nous apprîmes ensuite que le gouverneur l'avait tenu long-temps aux arrêts pour avoir outrepassé ses ordres, punition très-injuste et déraisonnable qui nous fit regretter bien sincèrement d'avoir attiré à ce galant homme un traitement si rigoureux.

Ayant pris congé de notre brave et obligeant compagnon de voyage, nous avons encore suivi pendant six à sept legoas la côte maritime, fatigante par son uniformité. Nos deux soldats, l'un nègre et l'autre Indien, s'arrêtaient souvent pour chercher dans le sable des œeufs de tortue, dont ils remplissaient leurs havresacs. Quoique ces pauses fréquentes nous déplussent beaucoup par les retards qu'elles nous occasionnaient, nous eûmes le soir sujet de nous en réjouir. J'ai déjà dit que toute la contrée comprise entre 
le Rio-Doege et San-Mateo est un désert entièrement dépourvu d'habitans, où l'on ne trouve qu'en très-peu d'endroits de l'eau à boire; il ne faut donc pas les manquer en passant, et c'est ce motif qui rend très-nécessaire un guide connaissant bien la route. Par malheur aucun de nos deux soldats n'avait encore fait ce voyage. Nous avons ainsi manqué $\mathbf{C a}-$ çimba de San-Joào, le premier endroit où l'on trouve de l'eau; mais nous avons été plus heureux pour Piranga, le second, qui est une lagune dans une petite vallée à côté de la route; nous l'avons rencontrée à midi, parce que nous nous étions partagés dans toutes les directions pour chercher de l'cau; nos chevaux et nos mulets purent aussi se rafraîchir. Mais dans l'endroit où nous fûmes obligés de faire halte le soir toutes nos recherches furent inutiles; nous n'en pûmes découvrir, et il nous fut impossible de profiter des provisions que nous avions apportées, car il fallait qu'elles fussent cuites à l'eau pour être mangeables. Il ne nous restait donc d'autre ressource pour apaiser notre faim que de la farine de maïs sèche et les œufs de tortue ramassés par nos soldats, et qui pouvaient se cuire à l'ealu de mer. On s'occu- 
pait à les tirer du havresac et à ramasser sur le rivage du bois flottant, lorsqu'à peu de distance de notre foyer nous avons trouvé, je ne reviens pas encore d'un incident si merveilleux, une tortue de mer colossale (1), qui se disposait à pondre. Il ne pouvait rien arriver de plus heureux pour des gens affamés comme nous l'étions; cet animal semblait être venu là tout exprès pour nous fournir notre repas. Notre présence ne dérangea pas la tortue dans sa besogne; nous pûmes la toucher, et même la soulever, ce qui exigeait quatre hommes réunis. Malgré le bruit que nous faisions en témoignant tout haut notre étonnement, et délibérant sur le parti que nous prendrions, elle ne donna d'autre marque d'inquiétude qu'en soufflant comme les oies quand on s'approche de leur nid. Elle continua lentement de ses deux piećs de derrière le travail qu'elle avait commencé, en creusant dans le sable, au-dessous de la partie inférieure de son corps, un trou cylindrique et large de huit à douze ponces; elle jetait des deux côtés avec beancoup d'adresse et de régularité, et pour ainsi dire en mesure, la terre qu'elle retirait du

(x) Testudo mydas, L., tortue franche. 


\section{AU BRÉSIL.}

trou, puis elle commença immédiatement à pondre ses oufs.

Un de nos soldats s'étendit tout de son long sur le sable à côté de la tortue, mit la main dans le trou qu'elle avait fait, et en retira les oeufs à mesure qu'elle leś pondait; nous en obtînmes ainsi une centaine en dix minutes. Nous délibérâmes ensuite s'il convenait de joindre ce bel animal à notre collection; mais son poids considérable, car il aurait fallu un mulet pour la porter, et la difficulté de placer et de déplacer cette charge nous déterminèrent à faire grâce de la vie à la tortue, et à nous contenter du tribut de ses oufs.

Cette espèce colossale, ainsi que la tortue luth (testudo coriacece), et le caret ou la caouanne (testudo careta, L.), pondent leurs œufs dans le sable de cette côte inhabitée entre le Riacho et le Mucuri, surtout durant les mois les plus chauds de l'année. Elles viennent à terre à la fin du jour, et, s'étant traînées sur la côte, $\mathrm{y}$ creusent un trou, y déposent leurs oufs, puis le remplissent de sable qu'elles battent fortement, et deux ou trois heures après le coucher du soleil retournent à la mer. Effectivement, quand nous sommes au 
bout de quelques heures revenus à l'endroit où nous avions laissé la tortue qui nous avait si abondamment pourvu de ses oufs, nous ne l'avons plus trouvée; elle avait bouché le trou, ẻt une large trace sur le sable faisait voir qu'elle avait regagné son élément. Une seule tortue de cette espèce peut fournir avec ses œufs un repas suffisant à une compagnie assez nombreuse, car elle en pond dix à douze douzaines à la fois; et la tortue luth, qui est la plus grande, en pond dix-huit à vingt douzaines. Ces œufs sont trèsnourrissans; aussi sont-ils recherchés avec empressement le long de ces côtcs inhabitées, par les sauvages, et dans le voisinage des colonies par les blancs.

Notre frugal repas terminé, nous avons allumé entre les buissons de palmiers nains plusieurs feux pour écarter les bêtes féroces de nos mulets. Le lendemain matin des traces toutes fraîches, distinctement empreintes sur le sable, indiquèrent qu'un gros animal était venu rôder autour de nous. C'était peut-être celles de l'yaguarété noir d'Azara (felis brasiliensis ), car le vieux Simam nous avait assuré qu'il est assez commun dans cette contrée; les Portugais le nomment tigre ou onça preta. 
Koster, parlant de cet animal redoutable (1), le nomme felis discolor, dénomination impropre, puisque son pelage est d'une couleur uniforme. Le meilleur nom pour désigner cet animal est celui qui se tire de celui de son pays, car on le trouve exclusivement au Brésil: Azara qui en parle nous dit qu'il ne se rencontre pas au Paraguay. Nous supposâmes que nous avions entendu sa voix, mais notre sommeil n'en avait pas été interrompu.

Le $1^{\text {er }}$ janvier 1816 nous nous sommes remis en route: dans notre patrie c'est un jour de neiges et de glaces; ici dès sept heures du matin nous sentîmes la chaleur des rayons du soleil; à midi elle devint insupportable. La veille; tourmentés par la soif, nous avions campé sans le savoir à peu de distance d'un lieu où il se trouvait de l'eau douce; nous nous en sommes aperçu aujourd'hui, car nous avions à peine parcouru une lieue, que nous sommes arrivés à la BarraSecca, embouchure d'une lagune dans la mer; l'eau y est si basse à certaines époques, qu'elle ne communique plus avec l'Océan, et que l'on y peut entrer à cheval sans que l'animal

(1) P. 102 (tom I, pag. 183 ). 
ait les pieds mouillés; en ce moment au contraire l'eau était haute et rapide, et le passage de cette embouchure profonde nous prit beaucoup de temps. Toutes les bêtes de somme furent déchargées; les Indiens et les nègres qui connaissaient les localités se déshabillèrent, portèrent sur leurs têtes les coffres de l'autre côté, et ensuite revinrent pour transporter les Européens. Nous avons trouvé sur la rive opposée les ruines d'un quartel, dans le voisinage duquel il y avait de bonne eau. Des Indiens avaient passé la nuit dans cet endroit, vraisemblablement pour chercher des tortues et pour pêcher, car la lagune est très-poissonneuse; dans les environs s'étendent aussi de vastes campos ou plaines ouvertes, très-convenables pour le bétail. On voyait encore les huttes des Indiens, construites en feuilles de palmier.

A midi nous sommes arrivés à une cavité dans laquelle coulait une source d'eau fraîche et limpide, découverte d'un prix inestimable pour nous dans ce moment. Nous avons encore passé la soirée et la nuit dans ce désert sur la côte. Le remira littoralis formait en quelques endroits des touffes de gazon au milieu du sable de cette plage, où les palmiers nains sont très- 


\section{AU BRÉSIL.}

communs; au-delà, vers l'intérieur, s'élèvent des forêts. Des traces de bêtes féroces empreintes sur le sable furent les seuls signes de la présence d'êtres vivans qui errent dans ce désert. Nous n'avions ici pas d'eau à boire, et presque rien à manger; à l'approchẹ de la nuit nous eûmes fini une hutte de fevilles de cocotier : nous y avons tous travaillé; nous espérions nous y reposer des fatigues de la journée; mais des essaims innombrables de moustiques nous tourmentèrent tellement, que nous ne pûmes fermer l'œil; une violente pluie d'orage nous empêchait de nous en débarrasser en nous mettant à l'air. Au point du jour, nouvel inconvénient, tous nos mulets, qui mouraient de soif et qui voulaient boire, étaient retournés à la source où ils s'étaient désaltérés à midi; ainsi nous perdîmes une demi-journée à les aller chercher et à les ramener; heureusement nos chevaux de selle ne s'étaient pas autant écartés, de sorte que, les ayant rattrapés plutôt, nous pûmes marcher quelque temps en avant de notre troupe.

Le soir nous sommes arrivés à l'embouchure du Rio San-Mateo, qui est un fleuve considérable dont les bords sont couverts de bois de 
mangliers (conocarpus et avicennia), et plus haut de forêts. Deux lanchas étaient à l'ancre près de la rive méridionale; de l'autre côté est le Povoaçào, nommé Barra de San-Mateo ; il consiste en vingt-cinq maisons. Le fleuve sort de forêts habitées par des Tapouyas libres, et forme plusieurs petites chutes; il est navigable pour les Sumacas jusqu'à neuf legoas au-dessus de son embouchure. Ses bords sont les plus féconds du Comarca, parce que les fourmis y causent, dit-on, peu de dégâts; et l'on trouve dans les forêts voisines beaucoup de jacarandas, de vinhaticos, de putumajus, de cergeiras, et d'autres bois utiles. Le Rio San-Mateo reçoit plusieurs rivières, parmi lesquelles le Rio de Santa-Anna, le Rio Preto ou Mariricu, et le SanDomingos, sont les plus considérables. Comme la marée montait à l'instant où nous sommes parvenus sur les rives du Rio San-Mateo, il était très-gros, et malgré nos cris pour qu'on vînt de l'autre côté nous prendre en pirogue, personne ne voulut se hasarder à le traverser. Fatigués d'appeler en vain, nous nous promenions sur le sable au milieu des buissons, et nous nous étions finalement résignés à notre malheureux sort, qui nous condamnait à passer la nuit sans 


\section{AU BRÉSIL.}

feu et sans provisions, lorsque nous vîmes arriver une pirogue conduite par deux nègres, qui nous transporta de l'autre côté. Notre tropa n'arriva que fort avant dans la nuit; elle put facilement supporter le bivouac, parce qu'elle était pourvue de provisions, de feu et de couvertures. De plus, une belle source peu éloignée de la côte maritime nous fournit abondamment de quoi se désaltérer.

Nous descendîmes à Barra de San-Mateo, à une veuda dont on nommait le maître capitam Regente. Nos papiers et les lettres de recommandation du ministre nous procuraient partout un très-bon accueil; il en fut de même ici.

Suivant la carte d'Arrowsmith, l'embouchure du Rio San-Mateo est située par $18^{\circ} 15^{\prime}$ de latitude australe, suivant d'autres auteurs par $18^{\circ} 50^{\prime}$, ou à une très-petite distance; cette dernière détermination paraît la plus exacte, car dans l'endroit où la carte anglaise place la bouche du Rio San-Mateo doit se trouver celle du Mucuri.

A peu près à huit legoas au-dessus de l'embouchure du fleuve est Villa de San-Mateo, dont on dit que la position n'est pas très-saine à cause des marais qui l'environnent; cette 
ville compte une centaine de feux; son territoire renferme 3,ooo habitans blancs et gens de couleur. Elle est une des plus nouvelles villas du comarca de Porto Seguro, et s'accroît avec rapidité; ses habitans cultivent beaucoup de manioc; tous les ans elle exporte 6o,ooo alkerès de farinha, ainsi que des planches qu'elle tire des forêts voisines. Les terres cultivées ne s'étendent au-delà qu'à huit legoas de distance jusqu'au quartel de Galveyas, qui est le poste militaire le plus avancé contre les sauvages.

A une demi-legoa au-dessus de la Barra on trouve le povoaçào de Santa-Anna, composé d'une vingtaine de familles indiennes, et qui compte soixante-dix têtes. Peu de temps après notre départ un Boutocoudy fut tué à SantaAnna ; c'était un homme âgé, qui portait aux oreilles et à la lèvre inférieure de gros morceaux de bois. MI. Freyress, qui visita de nouveau ce canton au mois de février, prit la tête de ce sauvage, qui se tronve actuellement dans les mains de $\mathbb{M}$. le professenr Sparmann.

Les forêts des bords du Rio San-Mateo renferment encore beaucoup d'Indiens non civilisés, qui vivent en état d'hostilité contre les blancs; l'année dernière ils tuèrent dir-sept personnes. 
Sur les rives septentrionales du fleuve errent les Patachos, les Cumanachos, les Machacalis, nommés aussi Machacaris par les Portugais: les sauvages ne prononcent pas bien la lettre $R$; on en rencontre encore quelques autres jusqu'à Porto-Seguro. Les Boutocoudys se montrent aussi très-fréquemment dans cette contrée, et occupent principalement la rive méridionale du fleuve. Les autres tribus les redoutent, et ils sont les ennemis de toutes celles qui, étant peu nombreuses, font cause commune contre eux. Le propriétaire d'une fazenda située sur la partie haute du fleuve, voyant ses plantations souvent dévastées par les sauvages, s'avisa d'un moyen singulier de se débarrasser de ces hôtes incommodes. Il avait chez lui un vieux canon de fer; il le chargea de mitraille de fer et de plomb, et y ayant adapté une batterie de fusil, il le posa dans un sentier étroit par lequel les sauvages arrivaient toujours en colonne; puis il mit en travers, au milieu du chemin, un morceau de bois qui communiquait par un cordon avec la détente de la batterie. Les Tapouyas, arrivant à la brune, marchèrent sur le morceau de bois; l'explosion eut lieu comme on s'y était attendu; elle fut terrible. Lorsqu'on sortit pour en con- 
naître les résultats, on trouva le canon crevé, et trente Indiens tués et mutilés, les uns sur le lieu même, les autres épars dans la forêt. On ajoute que les hurlemens de ceux qui s'enfuyaient s'entendirent au loin dans la contrée. Depui scette catastrophe affreuse la fazenda n'a plus été inquiétée.

Le Rio San-Mateo, dont le nom brésilien primitif est Cricaré, offre une production de la nature que l'on ne rencontre guère aujourd'hui dans les fleuves de la côte orientale ; c'est le manati ou le lamantin, peixe boü des Portugais. L'histoire naturelle de ce singulier animal est encore enveloppée de beaucoup d'obscurité; sa structure intérieure surtout n'a pas encore été convenablement examinée. Il est assez commun dans le Rio San-Mateo; on dit qu'il va aussi dans la mer, suit la côte et entre dans d'autres rivières; ainsi l'on en a pris dans l'Alcobaça. Le manati préfére dans le Rio SanMateo un lac où croissent beaucoup d'herbes et de roseaux. Sa chasse n'est pas exempte de difficultés. Le chasseur, embarqué dans une petite pirogue, s'avance avec précaution et sans bruit à travers les roseaux et les herbes : s'il aperçoit l'animal avec le dos au-dessus de l'eau, 
posture qui lui est familière quand il pâture, il s'en approche tout doncement, et lni lance un harpon attaché à une corde. Le manati donne une grande quantité d'huile; sa chair est trèsrecherchée. La trompe de son oreille est regardée par le vulgaire ignorant comme un remède puissant, et se vend très-cher. Maigré les plus grondes promesses pour obtenir un de ces animaux durant un séjour de près de quatre mois dans ces contrées, mes espérances ne fur ent pas remplies, et je fus obligé de me contenter de la vue d'ún lamantin empaillé que je vis dans un cabinet d'histoire naturelle de Lisbonne, à mon retour du Brésil.

Le Rio San-Mateo nourrit aussi une grande quantité de poissons. On trouve en plasieurs endroits sur l'herbe, an temps des inondations, diverses espéces de piaon, notamment une gue le genre de sa nouriture a fait nommer picau de cairpim (piaou d'horbe). Ici les Indiens civilisés s'embarquent dans leurs petites pirogues légères, et tuent ces poissons à coups de flèche. Cette manière d'aller à la chasse du poisson est ordinaire chez diverses tribus d'Indiens. L'arc dont ils se servent dans ces occasions est luig de deux pieds et demi à trois pieds, et de la 
grosseur de l'arc à balles : la flèche, longue de trois pieds, est de roseau (taquara), et munie d'une pointe de bois ou de fer barbelée d'un côté.

A une demi-legoa environ de San-Mateo, le Guajintiba se jette dans la mer. On s'y embarque ordinairement pour aller à la fazenda d'As-Itaünas, qui appartient à M. Marcelino da Cunha, ouvidor du Comarca de Porto-Seguro. Cette rivière, qui est assez forte, a des bords couverts de bois épais : du côté de la mer ce sont des mangliers, dont l'écorce s'emploie avec avantage à tanner les cuirs. L'eau de ce petit fleuve est de couleur brune foncée comme celle de toutes les rivières du Brésil qui traversent des forêts. Des pêcheurs avaient, un peu avant notre arrivée, pris plein une pirogue de beaux poissons.

Nous avons débarqué à une plantation solitaire et comme abandonnée, où les ananas croissaient naturellement; ces fruits étaient gros, juteux et aromatiques; ce végétal n'est pas indigène au Brésil; mais comme on en cultive beaucoup dans les plantations, il se multiplie de même qu'une plante sauvage. On en tire de l'eau-de-vie, et l'on fait le même usage du fruit du cajueiro ou acajou à pommes (anacar- 
dium, L. ; cassuvium, Jussieu). Cet arbre croît dans tous les terrains sablonneux de la côte orientale du Brésil; il est de la grandeur et de la forme de nos pommiers, tortueux, plein de nœuds, garni de branches fortes, noueuses, placées sans ordre; ses feuilles isolées donnent peu d'ombre, la fleur est petite et d'un rougeâtre clair; le fruit, qui est une noix reniforme et noirâtre, est attaché extérieurement au sommet d'un réceptacle charnu, pyriforme. On mange eette partie du fruit, qui est pourtant d'un goût acide assez âpre ; on fait rốtir la noix, dont le goût est agréable; mais il faut en ôter soigneusement la coque. Le suc de la partie charnue est diurétique; c'est un remède efficace dans les maladies lymphatiques et dans l'hydropisie.

Notre navigation vers la fin du jour fut d'autant plus agréable que nous n'étions pas tourmentés par les moustiques, qui avaient si souvent gâté les plus belles soirées. Une forêt haute et toufrue formait des groupes pittoresques sur les bords du fleuve; la clarté de la lune dans son plein qui se levait en ce moment, complétait le charme du tableau.

Les nègres conservent autant quiils peuvent 
les usages de leur pays ; c'est pourquoi l'on voic parmi eux tous les instrumens de musique dont. parlent les relations de voyages en Afrique, et entre lesquels le tambour jone le rôle principal. Quand plusieurs nègres habitent ensernble sur une plantation, ils célèbrent leurs fêtes, ainsi que je l'ai déjà dit, se peignent et se vêtissent comme dans leur patrie, et exécụtent leurs danses nationales. C'est ce que l'on voit, par exemple, effectué d'une manière très-originale à Rio-deJaneiro, sur une place destinée à cet objet, à peu de distance de la ville.

Nous avons trouvé à la fazenda d'As-Itaünas un jeune Poury qui est élevé par l'ouvidor; il parlait déjà le portugais; on nous dit qu’il est d'un caractère fort doux. Le peu de mots de sa langue naturelle que nous savions nous eurent bientôt gagné sa confiance. Nons éprouvâmes bien du regret d'avoir laissé sur les bords du Jucu notre jeune poury de San-Fidelis.

Itaünas est une fazenda destinée à l'éducation du bétail, avec un coral ou parc pour les boufs, et une méchante hutte où demeurent les nègres et les Indiens qui soignent les animanx. Le propriétaire y a réuni quelques fanilles indiennes, qui avec le temps formeront une 


\section{AU BRĖSIL.}

colonie; elles étaient auparavant destinées à protéger la côte maritime contre les Tapouyas; G'est pourquoi Itaünas est proprement regardé comme un quartel.

Des Indiens qui suivaient la même route que nous, nous ont accompagné au nord d'Itaünas ; ils étaient munis d'armes, et connaissaient parfaitement le chemin; nous avons passé à gué deux petits ruisseaux, le Riacho-Doçe et le Rio das Ostras, tous deux très-peu considérables; mais comme ils sortent d'une forêt sombre, pittoresque et remplie de cocotiers, ils forment un paysage extrêmement romantique. Nous sommes ensuite arrivés à un endroit très-mal famé, parce qu'on y a souvent rencontré des Taponyas; il porte le nom d'Os Lenzoès (les draps blancs), qui est dû à ce qu'une pointe rocailleuse offre des alternatives de sable blanc et de pelouse, et que, vue de la mer, elle paraît comme revêtue de draps blancs. Les Patachos qui habitent ce canton s'étaient depuis long-temps tenus en paix; mais un de leurs compatriotes ayant été tué, ils ont commis de nouvelles hostilités.

A peu de distance du Rio das Ostras nous avons rencontré fortuitement sur la plage 
sablonneuse un jacaré long de cinq pieds; il avait probablement voulu aller par terre d'un ruisseau à un autre, et c'était dans ce voyage que nous l'avions surpris : un rocher escarpé s'élevait à sa droite, la mer s'étendait à sa gauche; ne pouvant s'échapper, il restait immobile; agacé vivement avec un bâton, il mordait autour de lui, mais on pouvait l'attaquer sans danger. Cet animal, qui dans sa jeunesse est agile et vif, paraît en vicillissant extrêmement lourd dans ses mouvemens quand il se trouve à terre, car celui-ci ne rampait en avant qu'avec beaucoup de lenteur.

Ayant parcouru deux legoas, nous summes arrivés au ruisseau de Barra-Nova, où se trouve un petit povoaçào de quelques maịsuns bâties sur une hauteur médiocre, mais escarpée. Nous nous y sommes reposés pendant la chaleur du milieu du jour, puis dans la soirée nous avons atteint l'embouchure du Mucuri, beau fleuve pen considérable, qui sort du milieu de forêts touffues; les buissons de mangliers donnent à ses boids un aspect riant.

Villa de San-José do Port Allègre, ordinairement nommée de Mucuri, est située sur la rive septentrionale du fleuve, à peu de distance 
de son embouchure; c'est un lieu très-petit, composé d'une quarantaine de maisons, formant une place carrée ouverte du côté $d u$ fleuve; au milieu se trouve une petite chapelle. Les maisons sont basses, et couvertes en chaume; les moutons, les chèvres, les cochons paissent en liberté sur la place publique. Les habitans, la plupart Indiens, sont pauvres; ils ne font aucun commerce; quelquefois seulement ils exportent un peu de farinha; il n'y a pas de moulins à sucre le long du fleuve; l'escrivam (greffier du tribunal ou de la villa) vend de l'eaude-vie et quelques denrées. Les autres fonctionnaires publics sont le curé et le juiz ou juge; deux habitans en remplissent alternativement les fonctions, de même que dans toutes les villas du Brésil.

M. Vigario Mendes, curé, est le seul habitant de ce canton qui possède une fazenda un peu considérable; il y entretient du bétail qui lui fournit du lait, véritable rareté le long de cette côte. Cet ecclésiastique, auquel le comte de Barca nous avait recommandés, nous fit l'accueil le plus gracieux. Ce ministre a sur le Mucuri des propriétés considérables; on était alors occupé à les assurer contre les attaques des 
362 VOYAGE

sauvages. Les forêts sont remplies d'une quantité de bois précieux; on avait le projet, pour en tirer parti, d'établir un moulin à scie; et un Allemand, natif de Thuringe, nommé Kramer, qui avait dirigé ces sortes d'usines, était chargé de former celle que l'on avait en vue. Le jacaranda, l'oitiçica, le jiquitiba, le vinhatico, le cedro, le caicheta, l'ipè, le peroba, le putumujù, le pao brazil, etc.; en un mot, les meilleures espéces de bois de la côte orientale se trouvent presque toutes réunies dans cette contrée; mais comme elle est encore entièrement possédée par les Patachos et les bêtes féroces, et qu'ainsi l'établissement de la scierie ne pouvait pas s'effectuer, le ministre avait donné ordre à M. Da Cunha de se rendre à Villa de Mucuri, d'y réunir le nombre d'hommes nécessaires pour fonder une fazenda, et les cultures propres à entretenir les habitans et les esclaves, et de mettre ces gens en sûreté contre les incursions des Tapouyas. Le hasard voulut que le capitam Bento Lourenzo Vas de Abreu Lima, habitant de Minas--Novas; qui avec vingtdeux hummes armés était parti des confins de Minas-Geraès, et avait descendu le Mucuri en traversant des solitudes immenses, arrivât heu- 
reusement à la côte maritime à l'époque dont il est question. Le ministre, frappé de son apparition inattendue à Villa de Mucuri, chargea aussi M. Da Cunha de fournir à l'intrépide Mineiro Bento Lourenzo les secours nécessaires en hommes pour qu'il pût ouvrir à travers les forêts un chemin praticable pour les voyageurs, au lieu du sentier qu'il avait percé.

J'eus le plaisir de rencontrer ici cet homme intéressant, et $\mathrm{j}$ 'appris de lui les détails de son entreprise remarquable par sa hardiesse et par les dangers qu'il avait courus. Occupé de la re-cherche des pierres précieuses, son séjour continuel dans les forêts lui inspira l'idée de pénétrer à travers la contrée solitaire qu'il avait devant lui, et de s'avancer le long du fleuve qu'il prenait pour le Rio San-Mateo. Durant plusieurs années de suite, il fit commencer et continuer à ses frais une route à travers la forêt, et quand ce travail fut avancé à un certain point, il entreprit à pied le voyage avec vingtdeux soldats et des hommes de bonne volonté, tous armés. Il parvint à l'aldéa du capitam Tomé, célèbre chef indien, qui avait réuni dans les forêts sur le haut Mucuri des indigènes de différentes tribus, et précédemment en avait 
baptisé plusieurs dạns le même lieu. Aujourd'hui l'aldéa n'existe plus, parce que le chef est mort ; mais on voit encore à l'endroit où elle était située des bananiers et d'autres végétaux devenus sauvages, et dont les indigènes errans tirent parti. Après une marche de cinquante jours, le brave Mineïro atteignit la côte maritime, et ce ne fut que là qu'il reconnut qu'il avait suivi le cours du Mucuri et non celui du San-Mateo.

Ce voyage avait été accompagné de difficultés et de peines fort grandes. Souvent l'on manqua de vivres, car quelquefois l'on n'apercevait pas d'animaux dont on pût se nourrir, et la pêche n'était pas ahondante. Alors on était réduit à manger des fruits et des racines, ou bien on se sustentait avec les sommités des palmites ou le miel sauvage que l'on trouvait dans les forêts, jusqu'au moment où un heureux hasard conduisait un animal sur les pas des voyageurs. Par bonheur ils ne rencontrèrent pas de Boutocoudys qui vivent dans la partie supérieure de ces forêts; mais ils virent souvent des huttes où ils avaient demeuré, et ils crurent même que ces sauvages les avaient quelquefois observés. 
Les soldats indiens du capitam Bento Lourenzo lui avaient été fort utiles pour aller à la chasse, et pour préserver sa troupe des attaques des sauvages; ces Indiens se composaient de Capouchos et d'hommes d'autres tribus, ainsi que d'un Boutocoudy élevé chez les Portugais. La troupe avait perdu ses bagages aux cataractes de la partie supérieure du Mucuri, qu'elle avait mis quatre jours à franchir; pour en venir à bout on avait construit un radeau en troncs d'arbres, sur lequel on avait chargé les armes, les vivres, les habits et d'autres objets; mais le radeau fut emporté par le torrent, et les buissons du rivage dispersèrent toute la cargaison; ce ne fut qu'avec la plus grande difficulté que l'on put retirer les armes hors de l'eau. Le dernier jour de leur course hardie et périlleuse à travers les forệts, les voyageurs éprouvèrent une disette totale; quelques-uns étaient même épuisés de fatigue et de besoin quand ils parvinrent inopinément à la dernière plantation inhabitée sur le fleuve, qui appartient au Morro d'Arara, et qui est éloignée de deux journées de route de Villa de Mucuri. La troupe affamée tomba sur des racines de manioc crues, parmi lesquelles il s'en trouvait 
malheureusement plusieurs de mandioca brava; espèce dangereuse (1). Un vomissement violent qui suivit l'usage de ces racines affaiblit encore plus les aventuriers; ils étaient près de perdre le courage, quand quelques-uns de leurs chasseurs furent assez heureux pour tuer un gros tapir. Chacun put alors réparer ses forces par une nourriture saine. Le lendemain vit finir les longues et dures épreuves de ces hommes courageux; ils atteignirent le but de leurs efforts, et entrèrent à Villa de Mucuri aux cris d'allégresse des habitans, qui allumèrent des feux de joie pour leur faire fète.

On devait, comme je l'ai dit plus hant, ouvrir une route le long du sentier que le capitam Bento Lourenzo s'était frayé, et l'on n'attendait pour l'entreprendre que l'arrivée de l'ouvidor Da Cunha. Des ouvriers étaient successivement venus des bords du Rio Sar Matéo, de Viçoza, de Porto-Seguro, de Trancozo et d'autres endroits de la côte orientale; la plupart étaient des Indiens.

(1) Le suc de cette espèce de manioc est vénéneux et tue les animaux, par exemple les moutons : Koster en cite un exemple, p. 370 , tom. II ( p. 276). 


\section{AU BRÉSIL.}

Entre les montagnes de Minas - Geraës et la côte orientale peu habitée, s'étendent de vastes solitudes dans lesquelles de nombreuses hordes d'indigènes sauvages errent encore en liberté, et qui vraisemblablement se maintiendront long-temps indépendantes des Portugais. On cherche de différens points à percer des routes praticables dans cette solitude, afin de conduire avec plus de facilitéles productions du Minas-Geraës aux côtes peu habitées et paurres, et de lui procurer une correspondance directe avec les capitales et la mer : or les fleuves offrant la communication la plus prompte, l'on a décidé de continuer ces routes en suivant leur cours; on en a onvert une sur le Mucuri, une autre sur le Rio-Grande de Belmonte, une troisième sur l'ilheos, et l'on s'occupe d'en établir deux de plus sur l'EspiritoSanto et sur l'Itapémirim pour aboutir à Minas-Geraës.

Les forêts du voisinage du Mucuri sont principalement habitées par les Patachos. Les Boutocoudys ne les fréquentent que par intervalles pour descendre jusqu'à la côte. Dì reste plusieurs autres tribus de Tapouyas vivent dans ces solitudes; sur leurs frontières demeurent les 
Maconys, les Malalys et d'autres, dans des habitations fixes. Les Capouchos ou Capochos, les Coumanachos, les Machacalys et les Panhamis (Paniamys) au contraire mènent encore une vie errante dans les forêts. On dit que les quatre dernières tribus ont fait alliance avec les' Patachos, et peuvent tenir tête aux Boutocoudys. Si l'on en juge par la ressemblance du langage, des mours et des usages, ces tribus doivent avoir beaucoup d'affinité entre elles. Un grand nombre de Maconys, tribu qui vit isolée, ont été baptisés il y a une vingtaine d'années; d'autres ont reçu le baptême du capitam BentoLourenzo lorsqu'il se trouvait au milieu d'eux. Une partie s'est fixée sur les bords du Mucuri; une autre habite plus au nord sur le Rio Belmonte. Cette tribu passe, sur les bords du Rio Doce, pour extrêmement grossière ; mais c'est à tort, suivant des renseignemens plus exacts. Les Malalys, tribu beaucoup plus faible, demeure sur le Rio Doce supérieur, près du poste de Passanha; ils se sont établis dans son voisinage, sous la protection des Portugais, pour être à l'abri des attaques de leurs ennemis les Boutocoudys. La langue de ces deux tribus diffère beaucuup de celles des autres peuplades. 
Ces cinq tribus, comme je viens de le dire, ont en général entre elles une affinité de mœurs, de langage et de figure. Elles se percent ordinairement la lèvre inférieure, et placent dans cette ouverture un petit morceau de roseau mince, qu'elles teignent à une extrémité avec du rocou. Elles coupent leurs cheveux en rond à la nuque et par devant; quelques sauvages se rasent même la plus grande partie de la tête. Du reste ils se peignent le corps, ainsi que tous les Tapouyas, en rouge et en noir; tous croient qu'il existe dans le tonnerre un être puissant qu'ils nomment Toupan, mot qui appartient à plusieurs tribus, et entre autres aux Pourys, et qui était aussi en usage chez les tribus côtières des Toupys. Les proches parens ne peuvent pas se marier ensemble; mais d'ailleurs ils ne s'astreignent à aucune règle, et suivent entièrement leur inclination. La plus grande marque de faveur qu'une jeune fille puissedonner à un jeune homme, c'est de le peindre; voilà pourquoi toutes portent ordinairement du rocou avec elles(1). Les Patachos se sont toujours

(r) Indépendamment des tribus d'indigènes qui viennent d'ètre citées, la Corografia Brasilica, tom. II, p. 74, en I. 
montrés en ennemis le long du Mucuri; assez récemment ils ont tué un Indien à la porte de la maison de la fazenda de M. Joào Antonio.

Après avoir passé dix jours en ce lieu nous avons continué notre voyage; nous partîmes le soir pour profiter de la fraîcheur de la nuit; la lune brillait dans tout son éclat; sa douce lumière, réfléchie par la surface tranquille de la mer, nous dédommageait de l'uniformité de la route le long de la côte sablonneuse. Le grand engoulevent planait sans bruit au-dessus de nous, mais à une élévation trop grande pour que nos armes pussent l'atteindre ( 1 ).

La distance du Mucuri au Peruipe, autre fleuve, est de cinq legoas. Avant de parvenir à la pointe formée par la côte, on rencontre le

nomme encore d'autres dans ce canton; mais je n'en ai pas entendu parier à la cốte orientale.

(1) C'est une espèce non encore décrite; je l'ai nommée caprimulgus aethereus, parce qu'il s'élève en l'air à une hauteur considérable, et y plane comme un oiseau de proie. Il a vingt-deux pouces de long, son plumage est rougeâtre de rouille, bruu foncé, et tacheté de noirâtre. Les petites plumes supérieures de l'aile forment une tache brune noirâtre. Une bande transversale foncée de taches brunes noires marque l'extrémité de la poitrine. 
chemin de Villa Viçoza; nous nous sommes égarés en cet endroit, et nous sommes arrivés à l'embouchure du Peruipe, près de laquelle des cabanes de pêcheurs sont éparses. Nous fûmes obligés de rebrousser chemin; il était grand jour quand nous atteignîmes, au travers des buissons, une prairie sur le bord du fleuve. De là nous aperçûmes, sous un charmant bocage de cocotiers, Villa-Viçoza, qui renferme une centaine de maisons, et nous reconnûmes au premier coup d'oil une grande maison blanche pour la Casa da Camara. L'ouvidor s'y trouvait en compagnie de deux capitaines de vaisseaux, M. José da Trinidade et $\mathbf{M}$. Silveïra José Manoel de Aranjo : ces deux officiers étaient chargés par le gouvernement de déterminer par des observations astronomiques la côte voisine, et d'en dresser une carte.

La suite de l'ouvidor offrait la composition la plus étrange que l'on puisse imaginer, car indépendamment de Portugais et de nègres, on y comptait une douzaine de jeunes Boutocoudys de Belmonte, et un jeune Machacaly. L'aspect des Boutocoudys nous surprit au-delà de toute expression; jamais nous n'avions vu des êtres aussi singuliers, et dont la laideur fût aussi 
surprenante. La forme originale de leur visage était défigurée par les gros morceaux de bois qu'ils portaient à la lévre inférieure et aux lobes des or eilles; leur lèvre formait une saillie considérable en avant, et les oreilles de quelques-uns leur pendaient comme de grandes ailes jusque sur les épaules; leur corps, de couleur brune, était couvert d'ordure. Ils étaient déjà familiarisés avec l'ouvidor, qui les avait constamment auprès de lui dans sa chambre pour gagner de plus en plus leur confiance : il s'en faisait entendre par le moyen d'interprètes; il nous fit donner des essais de leur chant, qui ressemble à un hurlement inarticulé. La plupart de ces jeunes Indiens venaient d'avoir la petite-vérole; ils étaient tout couverts de cicatrices et de taches, ce qui, joint à la majgreur de leur corps, causée par la maladie, augmentait considérablement leur laideur naturelle.

La petite-vérole, apportée dans ces contrées par les Européens, est extrêmement dangereuse pour les indigènes; beaucoup de tribus ont été entièrement exterminées par cette maladie. Plusieurs Indiens de la suite de l'ouvidor en étaient morts à Caravellas : on en avait sauvé le plus grand nombre, et on m'assura que l'on y était 


\section{AU BRÉSIL.}

parvenu en leur faisant boire abondamment de l'eau-de-vie. Les Indiens ont, avec raison, une peur effroyable de la petite-vérole. On me raconta un trait de cruauté révoltante, qui est bien propre à les maintenir dans leurs appréhensions. Un planteur, voulant se venger des Tapouyas ses voisins, qui le tourmentaient, fit jeter dans les forêts des vêtemens qui avaient été portés par un homme mort de la petite-vérole; plusieurs sauvages furent infectés, et moururent misérablement victimes de cette mesure inhumaine.

Quand l'ouvidor s'est préparé à commencer son voyage au Mucuri, nous nous sommes embarqués pour visiter auparavant Caravellas et le Rio Alcobaça. Notre pirogue, après avoir glissé rapidement entre les rives verdoyantes du Peruipe, nous a conduits à un bras du fleuve qui, s'en séparant à son embouchure, le fait communiquer avec le Caravellas. Des cocotiers élèvent leur cime orgueilleuse près de la villa, et donnent au paysage un caractère d'originalité qui plaît beaucoup. Le lait contenu dans les fruits que l'on porte en Europe, et qui sont déjà vieux, est d'un goût fade et même mauvais : ici on les cueille quand ils ne sont 
pas encore tout-à-fait mûrs; alors l'eau ou le lait a un goût d'amertume douceâtre très-agréable; elle est de plus extrêmement rafraîchissante. On accommode avec ce présent de la nature bienfaisante différens mets de très-bon goût; ainsi on racle la noix et on la fait cuire avec des haricots noirs, ce qui leur communique un goût très-délicat; on en prépare aussi avec du sucre et des épices une très-bonne confiture, qui malhenreusement ne supporte pas le trajet par mer jusqu'en Europe.

Un cocotier peut porter jusqu’à cent fruits, dont la valeur est de vingt à vingt-cinq francs; de sorte qu'une plantation de trois cents à quatre cents de ces arbres produit un revenu considérable. Un cocotier en bon état se vend 4000 reis ( 25 francs). On l'emploie à plusieurs usages. Son bois étant dur et tenace, la tige ne rompt pas aisément dans les coups de vent; elle se ploie en criant fortement. Ses racines courent à fleur de terre en formant un rẻsean ẻpais.

Au sud du Péruipe les cocotiers sont trèsrares, ainsi que je l'ai déjà observé; mais au nord de Viçoza, surtout à Belmonte, à PortoSeguro, à Caravellas, à Ilheos, à Bahia, etc., ils sont extrêmement communs; tout le long de 
la côte orientale on les nomme cocos de Bahia. Cet arbre parait aimer beaucoup l'air de la mer, car il croît le mieux dans les endroits où le sable du rivage est baigné par l'eau salée (1). Un renflement à la partie inférieure de la tige, quand il est jeune, le fait aisément reconnaître. En allant par eau à Caravellas on voit fréquemment de petites forêts de cocotiers, dont l'aspect est singulièrement riant; les habitations champêtres, situées à l'ombre de ces arbres, sont très-pittoresques.

Tout le rivage est couvert de mangliers touffus (conocarpus et avicennia). Leur écorce, utile pour les tanneries, s'envoie à Rio-de-Janeiro. Le propriétaire d'une fabrique decuirs de cettecapitale entretient une quantité d'esclaves à Caravellas, uniquement occupés à recueillir et à faire sécher l'écorce des mangliers. Un gros navire, nommé pour cette raison le casqueiro (le chantier), fait constamment des voyages pour venir chercher ici et transporter à Rio-de-Janciro sa cargaison de tan.

(1) Cette observation est confirmée par le témoignage de M. de Humboldt. Voyage (Relation historique, tom. I, p. 154, in $\left.-4^{0}\right)$. 
On désigne sous le nom de manglier des espèces d'arbres très-différentes. On préfère pour la préparation des cuirs l'écorce du manglier rouge ou mangue vermelha (conocarpus racemosa), qui diffère par sa taille moins haute et par ses feuilles épaisses et ovoïdes du manglier blanc ou mangue branca (avicennia tomentosa ); celui-ci a des fenilles étroites, allongées, un fruit oviforme, un peu cotonneux, de la grosseur d'une petite prune; il est plus svelte, et s'élève plus que l'autre.

Dans la soirée notre navigation fut trèsagréable; nous passions d'un canal dans un autre, car entre Viçoza et Caravellas le terrain est coupé d'une quantité de criques, formées par des îles couvertes de mangliers. Nous entendions sortir de ces bois les cris d'une multitude de perroquets; c'étaient tous des curicas(1). Des hérons se tenaient immobiles sur les singulières racines des mangliers, qui partent d'assez haut le long du tronc, se recourbent pour descendre dans l'eau et s'y enfoncer en terre, et

(1) (Psittacus Ochrocephalus, L. ou Amazonicus Latham ). Voyez Histoire naturelle des Perroquets, par Le Vaillant, pl. 110. 


\section{AU BRÉSIL。}

forment ainsi des arcades qui suivent diverses directions. Une petite espèce d'huîtres s'attache en grande quantité à l'écorce de cet arbre, et l'aratì, ou crabe bariolé, y vit aussi en troupes nombreuses (1),

Un grain violent, accompagné de pluie, nous surprit en cet endroit, et dura jusqu'à notre arrivée à Caravellas; où nous entrâmes dans l'obscurité. Nous prîmes notre logement à la Casa da Camara, demeure de l'ouvidor. Caravellas est le lieu le plus important du Comarca de Porto-Seguro. Ses rues sont bien alignées et se coupent à angles droits; il y en a cinq ou six principales; aucune n'est pavée; l'herbe les couvre. La grande église est sur une place près de la Casa da Camara; les maisons sont propres, la phipart n'ont qu'un étage. Cette ville fait un commerce considérable avec les productions de son territoire, entre autres la farinha, un peu de coton, etc. On exporte quelquefois dans une année 54,500 alqueirès de farinha, qui, au prix moyen de cinq pataques ou de 11 francs l'alqueiré, donne une somme de 599,500 francs.

(1) Macgraf fait mention de ce crabe, nommé Aratie pas les indigènes, p. 185. 
Ce commerce attire à Caravellas un assez grand nombre de navires de Pernambouc, de Bahia, de Rio-de-Janeiro et d'autres ports de la côte orientale; une quarantaine de petits bâtimens sont quelquefois mouillés devant la ville; enfin le .Casqueiro procure souvent la facilité de pouvoir aller à Rio-de-Janeiro, ou d'y envoyer des lettres. Les navires de Pernarabouc sont ceux qui emportent le plus de farinha, parce que le territoire de cette ville ne produit pas en quanité suffisante cette denrée si nécessaire. Les années de sécheresse y occasionnent quelquefois une disette complète, ainsi que le voyageur Koster l'a observé dans sa relation.

Notre projet étant de revenir en ce lieu après le voyage au Mucuri, où nous comptions passer quelque temps, nous ne sommes restés que trois jours à Caravellas, et nous en sommes partis pour le Rio Alcobaça, qui coule plus au nord à travers les forêts. Sur ses bords se trouve la fazenda de Ponte do Gentio (Pont des Sauvages ), qui appartient au comte de Barca, et que nous désirions examiner. Nous avons d'abord remonté en canot le Caravellas pendant quelques milles, puis nous avons continué le voyage par terre. Le soir nous sommes arrivés 
a la petite fazenda de Pindoba, dont le propriétaire, M. Cardoso, nous a reçus de la manière la plus gracieuse. Les environs sont sauvages et tout remplis de forêts où l'on n'a pas encore pénétré; on n'y rencontre que des maisons ou des plantations isolées. Notre conversation avec M. Cardoso ayant tombé sur le canton qu'il habite et sur les curiosités naturelles, il se fit apporter une pierre que l'on a trouvée à fleur de terre; c'était un morceau de grès grossier, poli et taillé en forme de petite hache. Notre hôte assura que c'était une pierre atmosphérique tombée à terre dans un grand orage; et de même que tous les Portugais présens, il fut très-mécontent de ce que nous la regardions comme un outil fabriqué par les sauvages. Le merveilletix a toujours plus de charme que la vérité pour l'homme ignorant.

En partant de Pindoba nous avons traversé un petit torrent; ensuite, ayant monté des chevaux que nous avaient loués les propriétaires des fazendas voisines, nous sommes entrés dans une vaste solitude, où les forêts, les halliers, les. plaines couvertes de hauts roseaux se succédaient alternativement. Les fazendas isolées ont de grands hangars dans lesquels on prépare en 
quantité la farinha, principale production de ce canton. Ces bâtimens, ouverts de tousles côtés, ne consistent qu'en un toit de roseaux ou de feuilles de palmier, soutenu par de forts piliers, et qui met à l'abri les grandes chaudières en maçonnerie où l'on fait sécher la farinha.

Au nilieu d'une forêt composée de tiges élancées qui s'entre-mêlaient confusément les unes avec les autres, nous fûmes -surpris du chant singulier d'une espèce d'oịseau que nous ne connaissions pas encore. Toute la forêt retentissait de cette voix ; c'était un sifflement trèsfort, composé de cinq à six tons perçans. Ces hôtes bruyans des bois étaient en troupes nombreuses; dès que l'un d'eux se faisait entendre, tous les autres lui répondaient en chœur. Nos chasseurs, excités par la vivacité de leur curiosité, se jetèrent aussitôt dans les halliers ; mais quoiqu'ils fussent en nombre, ils eurent beaucoup de peinè̀ tuer quelques-uns de ces chanteurs. Cet oiseau, qui est du genre des moucherolles ou gobe-mouches (1), est de la taille

1) IMuscicapa vociferans. Longueur, dix pouces; toutes les parties supérieures, d'uu gris cendré, en quelques endroits parsemées de brunâtre ou de jaunâtre; les parties infé- 
d'un merle; sa couleur est d'un gris cendré sale. Les Portugais de la côte orientale lui donnent le nom de sebastiam; dans la province de Minas-Geraës il porte celui de grive des forêts primitives (sabia do mato virgem).

A l'extrémité de la forêt nous sommes arrivés chez la senhora Isabella, propriétaire de grandes plantations de manioc, dame très-bienfaisante et chérie dans tout le canton. Comme elle a la réputation de guérir plusieurs maladies, les malades et les pauvres viennent en foule chez elle; elle les guérit, ou au moins les soulage et leur fournit des vivres. Elle nous reçut avec une extrême bienveillance, et nous fit présent pour notre voyage d'un petit cochon et d'un gros canard, parce qu'elle prétendait que nous manquerions de provisions à Ponte-do-Gentio.

Nous sommes bientôt parvenus sur les bords de l'Alcobaça, qui est très-petit en cet endroit, et nous nous y sommes embarquiés; notre voyage

rieures gris cendré un peu plus pâle; poitrine et dessous du cou très-foncé; sommités des plumes de la partie inférieure un peu jaunâtre en quelques endroits. On a donné à cet oiseau, dans le muséum de Berlin, le nom de muscicapa ampelina. 
a duré deux heures à la fraîcheur de la soirée; nous avons passé en remontant le fleuve devant la fazenda de M. Munis Cardeiro; ensuite nous sommes arrivés à celle du ministre, qui est située sur la rive septentrionale du fleuve, dont l'eau est de couleur sombre; il est très-poissonneux et nourrit beaucoup de jacarés. Ses bords sont entièrement garnis de bois touffus. L'aninga ( arum liniferum, Arruda) crôt dans ses eaux.

Ponte-do-Gentio est une fazenda que léministre a achetée des héritiers du capitam mor Joào da Sylva-Santos, avec la terre qui en dépend. Elle était autrefois dans un état très-florissant. Son ancien propriétaire était un homme entreprenant; il avait montré dans plusieurs excursions contre les sauvages qu'il ne les craignait pas, et sur sa fazenda il vivait toujours en paix avec eux. Le premier il remonta le Rio Belmonte jusqu'à Minas-Novas. Après sa mort la fazenda, faute de soins convenables, tomba en décadence. Au lieu d'entretenir la bonne intelligence avec les sauvages, on les irrita; un nègre tua dans la forêt un indigène de la tribu des Patachos. Ce crime souleva les sauvages. Pour se venger ils attaquèrent les nègres dans une fazenda, et en tuèrent trois à coups de flèche. Alors la con- 
fusion et le désordre augmentèrent sur la fazenda, et sa valeur baissa beaucoup. Le ministre l'acheta pour un prix très-médiocre. Actuellement on cherche à rétablir la paix avec les sauvages, et à remettre la fazenda sur un bon pied. Il s'y trouve quelques familles d'Indiens, six familles d'Ilhorès (natifs des Açores), neuf Chinois, quelques nègres, et un feitor ou économe portugais.

Le gouvernement avait fait venir les Chinois à Rio-de-Janeiro pour y cultiver le thé; ensuite quelques-uns ont été envoyés à Caravellas, et d'autres ici pour travailler comme journaliers; mais ils sont trop paresseux et ne font que des ouvrages extrêmement faciles. Ils demeurent tous ensemble dans une petite maison. Un d'eux s'est fait baptiser et a épousé une jeune Indienne. Ils ont conservé en Amérique les usages de leur pays; ils célèbrent leurs jours de fête, mangent de préférence toutes sortes d'oiseaux, et ne sont pas, dit-on, scrupuleux dans le choix de leurs alimens. Tout est en bon ordre et très-propre dans leurs cabanes de roseaux. Leurs lits par exemple sont garnis de jolis rideaux blancs, drapés avec élégance et relevés sur les côtés avec des crochets de bronze d'un 
travail délicat. Ces lits si bien arrangés forment un singulier contraste avec la chétive cabane de roseaux dans laquelle ils sont placés. Du reste ces Chinois dorment sur une natte fine, et posent leur tête sur un petit coussin rond. Nous leur vîmes manger le riz absolument à la manière de leur pays, avec deux petites brochettes de bois. Ils recevaient nos visites avec beaucoup de plaisir; ils nous parlaient en mauvais portugais de leur patrie chérie, et nous racontaient qu'elle valait bien mieux que le Brésil. lls nous ouvrirent aussi leurs coffres, dans lesquels il y avait de la porcelaine médiocre et une grande quantité d'éventails qu'ils avaient apportés pour vendre.

Les bâtimens de la fazenda et la fabrique de farinha sont situés dans une petite vallée près de la rivière, entre deux éminences; si l'on gravit la plus orientale, sur laquelle est le $\mathrm{Po-}$ voaçao, on aperçoit tout le pays d'alentour qui est couvert à perte de vue de forêts sans aucune interruption. Ce n'cst que sur la rive droite du fleuve que l'on découvre quelques endroits où les hommes se sont établis.

Nous avons parcouru les forêts voisines avec nos ghasseurs et quelques mamelus paresseux, 
et nous avons tué un grand nombre d'animaux; entre autres le paresseux commun ou aï ( $\mathrm{bra}$ dypus tridactylus, L.) : jusqu'alors nous n'avions trouvé que le paresseux à collier noir (bradypus torquatus, Illiger).

Nous faillimes en ce lieu à avoir le malheur de perdre M. Freyreiss : il était parti seul le xnatin avec son fusil pour aller à la chasse; à midi nous ne le vîmes pas revenir, quoique ce fìt l'heure à laquelle il avait coutume de rentrer. La soirée arriva; l'obscurité croissait de plus en plus; nous l'attendions toujours vainement; notre inquiétude augmentait à chaque minute. Je fis tirer des coups de fusil à des intervalles trèsrapprochés pour lui servir de signal : enfin nous entendîmes dans le lointain un coup de fusil très-faible. Aussitôt des Indiens, pourvus de torches ou plutôt de morceaux de bois enflammés, partirent avec ordre de pénétrer vers l'endroit d'où le bruit était parti. Ils rencontrèrent heureusement $M$. Freyreiss, et revinrent avec lui à minuit : il était épuisé de fatigue. Voici se qu'il nous raconta:

«Ayant suivi pendant long-temps, nous ditil, un sentier peu praticable qui cessa tout à coup, je m'enfoncai toujours plus avant dans I. 
la forêt : quand je voulus revenir sur mes pas, je ne retrouvai plus le chemin; je passai la journée entière à le chercher; je marquais les arbres devant lesquels je passais pour reconnaitre les endroits que j'aurais traversés : mais toutes mes teutatives pour m'orienter furent inutiles; je finis par grimper sur une montagne, espérant que de ce point, ayant la vue plus libre, je pourrais apercevoir quelque objet qui me guiderait pour sortir d'embarras : je me flattais vainement; je rencontrai partout des bois qui se succédaient sans interruption. Un ruisseau, sur les bords duquel j'arrivai, me fit naître l'idée d'y entrer et de suivre son cours à gué, parce que je supposais qu'il me conduirait jusqu'aux bords de l'Alcobaça, et que je pourrais ainsi atteindre la fazenda : cette espérance fut encore déçue; le ruisseau aboutit bientôt à un large marais, dont les eaux, en diminuant de profondeur, n'avaient pas d'issue. Ma position devenait extrêmement inquiétante; affaibli par le manque de nourriture, échauffé par une marche pénible, mouillé par l'eau du ruisseau, je tombai d'épui-' sement. L'obscurité survint; alors je rassemblai le peu qui me restait de force, et je fis une petite cabane de feuilles de palmier. Les mous- 
tiques me tourmentaient d'une manière affreuse; mais ce n'était pas la plus grande de mes peines; je craignais avec raison l'attaque des sauvages et des bêtes féroces; et mes inquiétudes étaient d'autant plus fondées que je manquais des instrumens nécessaires pour faire du feu, afin de tenir les animaux écartés. Je me résignai donc à ma triste position, résolu d'attendre patiemment le retour du jour; cependant il ne pouvait pas me faire entrevoir une perspective bien consolante, puisqu'un heureux hasard seul était capable de me faire retrouver mon chemin, et que jétais si mal pourvu de poudre et de plomb, qu'il me serait impossible de soutenir long-temps mon existence par la chasse. Dans cette situation affreuse, que l'on se figure, s'il est possible, la joie que je ressentis lorsque j'entendis les coups de fusil tirés à Ponte-doGentio! Ranimé par l'espérance, je me levai et je répondis à ce signal par deux coups de fusil très-forts : je me rapprochai du cốté d'où le bruit était venu, et bientôt je rencontrai les Indiens qui me cherchaient. )

Heureusement pour M. Freyreiss que l'atscntion avec laquelle nous écoutions pendant le silence de la nuit nous permit d'entendre les 
coups de fusil qu'il tira; s'il eût été un peu plus éloigné, ou derrière une hauteur, il lui eût été aussi impossible d'entendre nos coups de fusil qu'à nous d'entendre les siens; nous eussions manqué de moyens de le retrouver, et son sort dans cette solitude eût été extrêmement misérable, car il comptait, an retour du jour, marcher pour revenir à la fazenda, d'un côté opposé à celui vers lequel il aurait dû se diriger. Cet exemple peut servir à prouver combien il faut être prudent quand on veut chasser seul dans ces vastes solitudes sans les connaître, ou sans posséder la sagacité des Indiens pour s'y retrouver. Le feitor de Ponte-do-Gentio, homme bien au fait de la chasse dans ces cantons, avait une fois perdu son chemin : il avait erré dans la forêt pendant sept jours; mais, étant suffisamment muni de poudre, de plomb et d'instrumens pour faire du feu, il avait pu pourvoir à ses besoins les plus pressans, et était enfin heureusement arrivé à une plantation sur les bords de l'Alcobaç. Deux Indiens, que l'ouvidor avait envoyés pour suivre ses traces et le ramener, entrèrent dans la plantation peu de temps après lui. On est dans l'erreur quand on s'imagine que dans ces solitudes 
l'on doit trouver partout de quoi se nourrir. Malgré la quantité d'animaux sauvages qui vivent dans ces bois, il se passe souvent plusieurs jours sans que l'on aperçoive une créature vivante; d'aillenrs une observation déjà faite, et qui se confirme ici, prouve que les animanx sauvages sont toujours plus nombreux dans le voisinage des habitations humaines que dans l'intérieur des grandes forêts.

Nos collections avaient été accrues de quelques morceaux intéressans; mais nos insectes, surtout les papillons, avaient été singulièrement endommagés par les petites fourmis rouges; nous parvînmes à les sauver en les saupoudrant de tabac en poudre.

Le 25 janvier nous avons quitté Ponte-doGentio, et nous sommes revenus chez la senhora Isabella; on était occupé à préparer la farinha. Un toucan (1) apprivoisé attira notre attention; ses gestes comiques, qui le paraissaient encore davantage par la singularité de sa figure et la grosseur disproportionnée de son bec, nous divertirent beaucoup. Il avalait avec une avidité excessive tout ce qu'il rencontrait,

(1) Ramphastos dicolorus, $\boldsymbol{L}$. 
même la viande. On nous l'offrit, mais, cet oiseau ne pouvant supporter notre climat, nous refusâmes le présent.

On récolte dans cet endroit beaucoup de miel, que fournissent des abeilles jaunes, dépourvues d'aiguillons : pour se le procurer on suspend sous les toits des tronçons de branches d'arbre creusé, dont on bouche l'extrémité avec de l'argile, et on laisse au milieu un petit trou rond. Ce miel est très-aromatique, mais il n'a pas autant de douceur que celui d'Europe. On prépare ici une boisson agréable et rafraîchissante en mêlant ensemble du miel et de l'eau.

Le lendemain 26 nous sommes retournés à Pindoba, et le soir nous sommes rentrés à Caravellas. En deux jours nous y avons terminé nos affaires, et nous nous sommes embarqués pour regagner Viçoza. Un beau clair de lune favorisait notre navigation; des milliers d'insectes luisans, tels que des lampyres, des taupins, et peut-être d'autres encore, volaient autour des buissons qui hordaient le rivage. Nous avons retrouvé dans la Casa da Camara les Boutocoudys de la suite de l'ouvidor. Cependant la compagnie de ces sauvages nous 


\section{AU BRÉSIL.}

incommoda moins que les hurlemens continuels d'un chien, qui avait été mordu par un serpent venimeux. On lui donna du suc du CardoSanto (argemone mexicana) (1), plante épineuse très-commune dans ces contrées; mais le pauvre animal mourut. On regarde à tort la quantité des serpens venimeux du Brésil comme plus considérable qu'elle ne l'est réellement; les habitans du pays eux-mêmes prétendent que la plupart de ces reptiles sont dangereux; ils ne savent le contraire que d'un petit nombre, et nommément de la grande espèce de Boa. Au reste, quelques serpens sont très à craindre, par exemple la vipère verte et le jararacca, tous deux du genre trigonocephalus; mais les plus redoutable: sont le serpent à sonnettes (crotalus horridus), et le curucucu (lachesis mutus, Daudin; ou crotalus mutus, $L$. ) : ce dernier, notamment celui qui a sept à huit pieds de longueur, se trouve dans tout le Brésil. Le serpent à sonnettes, nommé cobra cascavello par les Por-

(1) C'est sans doute cette plante dont Azara fait mention quand il parle de la guérison de la fièrre. (Voyages, etc., tom. I, p. 132.) 
tugais, ne se trouve que dans les contrées hautes et sèches; par exemple il est assez commun à Minas-Geraës et dans l'intérieur de la capitainerie de Bahia.

Après notre retour de Viçoza au Mucuri, nous n'avons pas fait un long séjour dans la villa qui porte le nom de ce fleuve, parce que l'ouvidor était déjà à l'endroit où l'on s'occupait d'établir la nouvelle fazenda de Morro d'Arara. M. Freyreiss avait résolu d'aller rejoindre notre troupe à Espirito-Santo; quant à moi, je préférai de remonter le Mucuri en pirogue, jusqu'aux travaux que l'on entreprenait, et d'y séjourner quelques mois dans les forêts. Cependânt, après aroir fait chacun nos préparatifs, nous avons encore passé deux jours ensemble à Mucuri, et nous avons profité de ce temps pour parcourir les environs. Nous avons visité entre autres les travaux de la route nouvelle que le capitam Bento Lourenzo avait commencée avec ses Mineïros, et qui était déjà pousséeèà trois lieues. Elle part des maisons mêmes de Port-Allègre, et coupe des prairies marécageuses et des savanes, dans lesquelles on avait construit des ponts avec des fascines; au-delà on avait déjà entamé une ouverture 
dans les halliers et dans l'épaisseur de la forêt.' $\mathrm{Au}$ reste ce n'était qu'un sentier, et la route n'avait pas une grande largeur. Des troncs d'arbres prodigieux étaient étendus çà et là; on avait mesuré les distances au cordeau, et marqué, par des entailles, le nombre des legoas sur la partie antérieure d'arbres, qu'on avait unie après en avoir enlevé l'écorce. Nous avons encore rencontré, en divers endroits de la forêt, les cabanes où la troupe des Mineïros avait passé la nuit.

Près de la dernière plantation du Mucuri, qui appartient à M. Joào Antonio, la route des Mineïros s'approchait des rives du fleuve et des maisons que l'on y a bâties. Nous y sommes allés en compagnie de M. le curéVigaro Miendès et de l'escrivam de Mucuri, et nous avons trouvé le capitam Bento Lourenzo; il nous mena sur la hauteur où est située sa maison, et fit avec ses compagnons une décharge d'armes à feu en notre honneur; c'est l'usage des troupes armées ou des soldats dans les solitudes de l'intérieur du Brésil, surtout dans les postes militaires, quand des étrangers leur rendent visite; et à cette occasion on charge fortement les armes. Après aroir 
passé quelques heures fort agréablement avec le capitam et avec M. Joào Antonió, qui tous deux nous comblèrent de politesses, nous avons repris par le fleuve le chemin de la Villa.

Le 3 février nous partîmes chacun pour notre destination : M. Freyreiss se fit transporter de l'autre côté du Mucuri pour retourner à Espiritu-Santo, et je remontai le fleuve avec deux pirogues. Nous fîmes une salve de nos armes pour nous dire adieu quand nous étions déjà loin l'un de l'autre, et nous ne tardâmes pas à nous perdre de vue.

L'emplacement choisi pour la fazenda et la scierie du comte de Barca est située à peu près à une journée et demie de route de l'embouchure du Mucuri; on l'a nommé Morro d'Arara (Mont des A raras), à cause de la grande quantité de cette espèce de perroquets (psittacus macao, $L$. .) que l'on y trouve. Je partis pour ce lieu en compagnie du capitam Simplicio da Silveïra, escrivam de Belmonte, qui avait été principalement employé quand on avait voulu conclure à Belmonte une convention avec les Boutocoudys. Il avait avec lui un jeune Indien 


\section{AU BRÉSIL.}

Meniàn (1), et tous deux parlaient la langue de ces sauvages.

Les rives du Mucuri, bordées partout de forêts, offrent par les nombreuses sinuosités de ce fleuve, qui est en général étroit, une grande diversité de points de vue pittoresques. Il fallut pousser péniblement notre pirogue en avant contre le courant du fleuve, qui était alors haut et rapide, travail d'autant plus fatiguant, que le soleil, à son plus haut point d'élévation, dardait d'aplomb ses rayons brûlans sur notre tête, et échauffait à un tel degré le bois de la pirogue, que l'on pouvait à peine le toucher.

Le martin-pêcheur vert à ventre roux (alcedo bicolor, $\boldsymbol{L}$.), et la belle hirondelle vert blanchâtre (hirundo leucoptera), étaient très-communs le long de cette partie du fleuve. Le dernier de ces oiseaux se repose sur des branches basses, ou sur des arbres morts qui flottent, ou bien vole à la surface des eaux. Sur terre, on ne le rencontre que dans leur voisinage.

(1) Les Menians qui habitent à Belmonte sont un reste d'Indiens Camacans dégénérés. Plus tard il en sera question d'une manière plus détaillée. 
Nous vîmes des quantités de chauve-souris grises (1), posées sur les arbres penchés aúdessus des eaux, et sur les rochers, où elles passent la journée à l'abri de la chaleur. On les distingue à leur nez saillant. Nous abattîmes de dessus un arbre du rivage le beau pigeon qui, sur une partie de la côte orientale, porte le nom de pomba trocaës, et à Bahia celui de pomba verdadeüra; c'est la columba speciosa des naturalistes (2).

L'après-midi nous avons passé devant la plantation de M. Joào Antonio, où, quelques jours auparavant, le capitam Bento Lourenzo nous avait salué d'une salve de mousqueterie. Déjà il avait, avec son monde, pénétré plus avant dans les forêts. Quand l'obscurité commença, nous descendîmes à terre au milieu des bois, et nous allumâmes du feu. La nuit fut belle et

(1) Vespertilio naso, espèce nouvelle, remarquable par sou nez très-allongé, presque comme une trompe; il s'avance d'une ligne au-dessus de la mâchoire supérieure; oreilles extérieures petites et très-pointues; poils du dessus du corps jaunâtre foncé gris brun; le dessous du corps gris jaunâtre plus pâle.

(2) Histoire naturelle des pigeons et des gallinacées, par Temminck, tom. I, pag. 206. 
chaude, mais, comme dans tous les climats brûlans, excessivement humide. Le cabouré, le cholarua, le bacurau (caprimulgus) et le capueira (perdix guianensis), firent entendre leur voix seulement au commencement de la nuit, et animèrent ainsi cette vaste solitude qui inspirait une certaine horreur. Le cabouré surtout s'approcha beancoup de nous; sa voix grêle retentissait de dessus l'arbre le plus voisin du feu, que cet oiseau semblait regarder par curiosité. Les Indiens qui conduisaient notre pirogue se couchèrent à demi nus, sans couverture et sans abri; quelques-uns, à une certaine distance du feu, sur la terre humide, et s'endormirent tranquillement; nous au contraire, qui n'étions pas endurcis à la fatigue, nous nous étendîmes sous de grosses couvertures de laine, sur un lit formé de branches et de feuilles de cocotiers.

Le lendemain matin, pendant que l'on préparait le déjeûner, une volée d'araras vint se poser près de nous en pous sant de grands cris. Mariano, un de nos Indiens, se leva aussitôt, prit son fusil, se glissa derrière les oiseaux, et ajusta si bien son coup qu'un instant après il revint tout joyeux, nous apportant le premier 
de ces beaux perroquets que nous eussions - réussi à nous procurer depuis que nous étions en voyage.

A près le dîner nous nous sommes rembarqués, et nous avons navigué jusqu'au soir, que nous sommes descendus sur un banc de sable, où nous avons allumé du feu. Pendant que nous étions occupés à préparer notre arara pour le joindre à notre collection, nous avons aperçu une grande pirogue remplie de monde qui nous appelait ; c'était M. Charles Frazer, anglais, pro. priétaire d'un établissement à Comechatiba sur la côte, à peu de distance de Porto-Seguro: il avait formé un projet de voyage semblable au mien, et arrivait avec sa suite pour l'exécuter. Nous avons passé tous ensemble la nuit dans cet endroit, et nous en sommes partis le lendemain.

Vers midi nous sommes arrivés à un canal ombragé, large d'une douzaine de pas, et situé à la rive septentrionale du Mucuri. Quelques jours auparavant l'ouvidor l'avait fait débarrasser des broussailles qui l'obstruaient; c'est un passage, formé par la nature, pour la communication du fleuve avec le lac d'Arara, qui est assez grand et environné de toutes parts de 


\section{AU BRÉSIL.}

montagnes boisées. L'ouvidor avait commencé à fonder, à un quart de lieue plus haut sur les bords du lac, la fazenda du ministre à Morro d'Arara; on avait déjà abattu du bois et construit quelques cabanes. L'ouvidor nous reçut très-poliment; je fis sur-le-champ mes préparatifs pour passer une couple de mois dans cette solitude écartée.

FIN DU TOME PREMIER. 




(6) 6 -

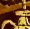

